\title{
CIVILISATIONS
}

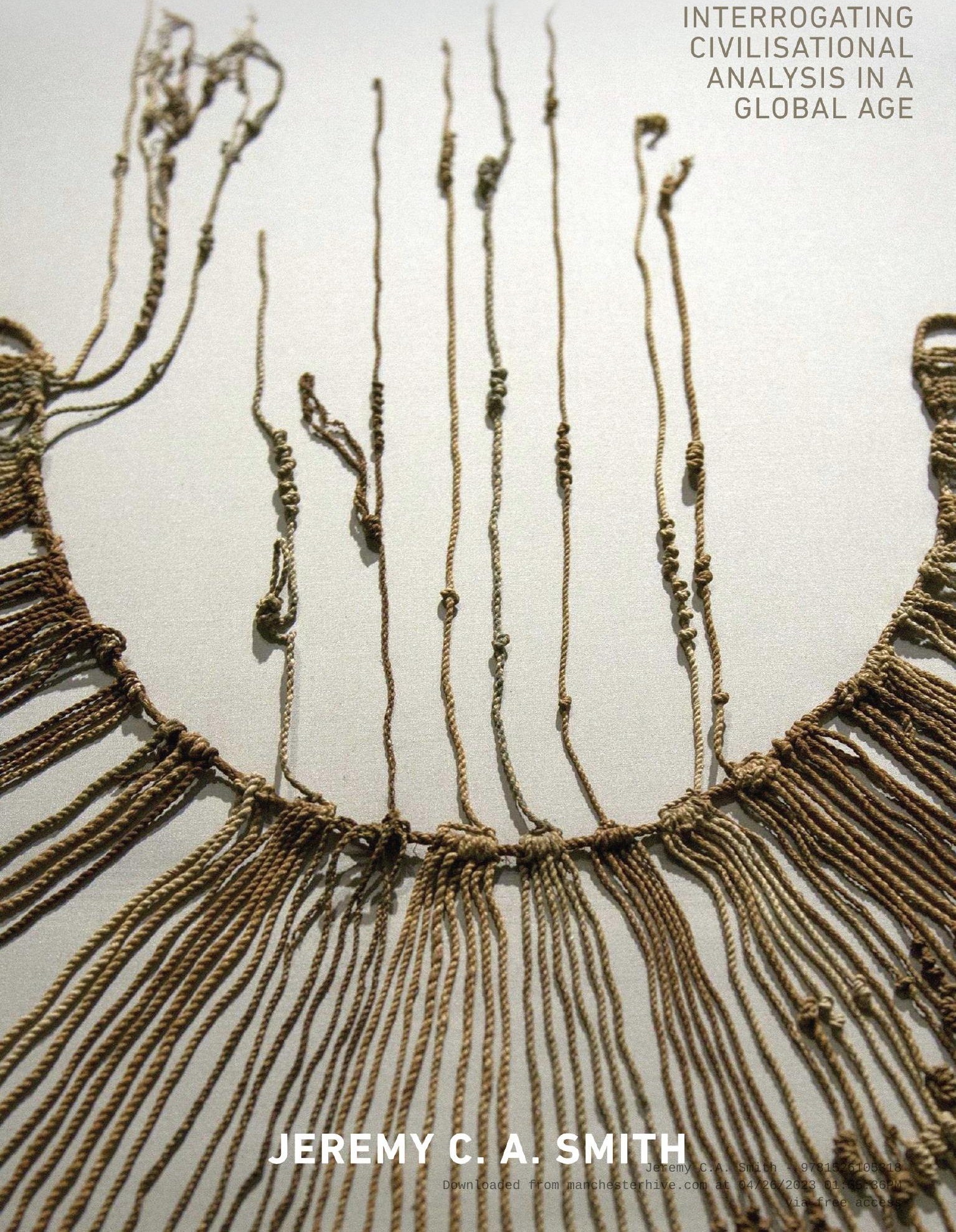


Jeremy C.A. Smith - 9781526105318 Downloaded from manchesterhive.com at 04/26/2023 01:55:36PM via free access 


\section{Debating civilisations}

\section{MANCHESTER 1824}

Manchester University Press 
Jeremy C.A. Smith - 9781526105318 Downloaded from manchesterhive.com at 04/26/2023 01:55:36PM via free access 


\section{Debating civilisations}

Interrogating civilisational analysis in a global age

JEREMY C. A. SMITH

Manchester University Press 
Copyright (C) Jeremy C. A. Smith 2017

The right of Jeremy C. A. Smith to be identified as the author of this work has been asserted by him in accordance with the Copyright, Designs and Patents Act 1988.

Published by Manchester University Press

Altrincham Street, Manchester M1 7JA

www.manchesteruniversitypress.co.uk

British Library Cataloguing-in-Publication Data

A catalogue record for this book is available from the British Library

Library of Congress Cataloging-in-Publication Data applied for

ISBN 9781526105288 hardback

ISBN 9781526105295 paperback

First published 2017

The publisher has no responsibility for the persistence or accuracy of URLs for any external or third-party internet websites referred to in this book, and does not guarantee that any content on such websites is, or will remain, accurate or appropriate.

Typeset by Out of House Publishing 


\section{Contents}

Acknowledgements vi vi

Part I: Theoretical engagements in civilisational analysis 1

1 Civilisations debated: uses and critiques of 'civilisation' 3

2 Currents and perspectives in contemporary civilisational analysis 25

3 Counterpoints, critiques, dialogues 53

4 Inter-civilisational engagement: imaginaries, power,

Part II: Studies in inter-civilisational engagement 111

5 Saltwater horizons: seas, oceans and civilisations 113

6 Pacific imaginaries: ontologies of connection, reconstruction
of memory

7 Engagement in the cross-currents of history: perspectives on civilisation in Latin America 151

8 Japan in engagement and the discourses of civilisation 169

9 Conclusion 185

References 193

Index 204 


\section{Acknowledgements}

This book about the core of studies of civilisations in history and sociology has been written from the edges of two continents: the eastern edge of Australia and the western edge of North America. Both edges are along terrestrial borders of the Pacific Ocean. I feel myself influenced by the ecologies of these places with their ocean prospects and coastal horizons. Those ecologies, those horizons help with thinking about civilisations, societies, inter-connections and flows. More than places, however, it is people - several people - who have contributed to the thinking that sits behind the main arguments made in the chapters that follow. Some have provided direct support as interlocutors around major theoretical, political and historical questions; others have read drafts and provided feedback; and yet others have contributed indirectly in different conversations over several years or by providing me with their work.

Amongst them I acknowledge Craig Browne, Dietrich Jung, Alice Mills, José Mauricio Domingues, Janice Newton, Johann Arnason, Said Arjomand, Jane Mummery, Wolfgang Knöbl, Charles Crothers, David Waldron, Jamie Doughney, Adam Yaghi, Teruhito Sako and Karl Smith. I am especially grateful to John Rundell and Strobe Driver for their valuable feedback on various chapters. Long discussions with John have been irreplaceable experiences of intellectual friendship. I give particular thanks to Suzi Adams for many years of valuable conversations and for her intellectual and general friendship. In addition to Suzi, I would like to acknowledge shared discussions with my other colleagues from our journal Social Imaginaries: Paul Blokker, Natalie Doyle and John Krummel. I want to extend my thanks to all the editorial and production staff at Manchester University Press. Thanks to Robin Cohen is called for, given his patient encouragement at the outset of this project (including when he was on holiday!). My thanks for a second time (and the second monograph) go to Cathie Pilbeam for her copy-editing expertise and to Fiona Bryant and Gavin Myers for their wonderful and timely administrative help.

In addition to people, the project has received generous support from Federation University Australia, where I teach and research. I would like to thank, in particular, John McDonald for his enthusiastic support. A significant portion 
of the research for the book took place as part of the Visiting Fellowship at the Centre for Studies in Religion and Society at the University of Victoria in British Columbia. I am especially grateful to the Centre's Director, Paul Bramadat, for his warm and collegial support during my fellowship.

I would also like to thank my partner Bronwyn Jennings for her unwavering patience and support and to our daughters Sari and Mietta for putting up with a ridiculously busy father.

An earlier version of the final section of Chapter 3 appeared as: 'Grounds for Engagement: Dissonances and Overlaps at the Intersection of Contemporary Civilizations Analysis and Postcolonial Sociology', Current Sociology, 63, 4 (2015), 566-85. 
Jeremy C.A. Smith - 9781526105318 Downloaded from manchesterhive.com at 04/26/2023 01:55:36PM via free access 


\section{Part I}

Theoretical engagements

in civilisational analysis 
Jeremy C.A. Smith - 9781526105318 Downloaded from manchesterhive.com at 04/26/2023 01:55:36PM via free access 


\section{1 \\ Civilisations debated: uses and critiques of 'civilisation'}

It is unfeasible for human beings to dwell like animals in solitude and it is a corollary of their nature to at all times seek collectivity in dwelling and abode. Philosophers enthused by this sociality, have defined this circumstance by asserting 'humans are naturally predisposed to sociality', and in their terminology, civilisation (Madaniyyah) consists in the sociality of mankind [sic] on the realm of earth.

(Ibn Khaldun, cited in Sentürk and Nizamuddin, 2009: 67)

Let us bear in mind that our population is neither European nor North American, but are closer to a blend of Africa and America than they are to Europe, for even Spain herself is not strictly European due to its African blood, institutions and character. It is impossible to pinpoint exactly which human family we belong to. Most of the indigenous peoples have been annihilated, the European has mixed with the American and with the African, and the African has mixed with the Indian and the European. We are all children of the same mother but our fathers are strangers and differ in origin, blood, figure and form from each other.

(Simon Bolivar, cited in Bolivar, 2009: 87)

Sailing is a noble thing ... it joins together men [sic] from different lands, and makes every inhospitable island a part of the mainland, it brings fresh knowledge to those who sail, it refines manners, it brings concord and civilisation to men [sic], it consolidates their nature by bringing together all that is most human in them.

(George Pachymeres, cited in Paine, 2013: 599)

Khaldun, Bolivar and Pachymeres point to specific notions of civilisation. They stress, respectively, the human creation of social cooperation, the mix of humanity and the crucibles of connection. Each casts one particular insight into conditions of human existence as an anthropological universal, which each believes is the essence of social life. Each feature, in fact, can be found 
in abundance in a host of societies. In a modest way, each illuminates a small corner of a sociological axiom about humanity's past: human connection and engagement across different social formations and civilisations (including in conflict) are extensive, while the occurrence of isolated societies is less common than is often believed. In a contemporary world context of tensions and conflicts (whether of global inequalities, poverty and increasing ecological calamities, or around violence, war and terrorism), an argument that there is a profusion of webs of social cooperation evident in past societies need not be an indulgence in the innocent pastime of historical curiosity. Instead, it can be a potent argument about a diverse range of social formations and what their connections and conflicts suggest about how to confront the problems that contemporary societies face. In place of perspectives positing a clash of civilisations, such an understanding of the past can better serve the purpose of understanding and responding to the problems of the twenty-first century. Moreover, how the critical social sciences can help to elucidate and explore those problems can be extrapolated if a clear perspective on historical connectivity is adopted.

Within the Western human sciences, debate about questions of connectivity has often taken national societies, rather than civilisations or empires, as the principal unit of research and the main form of human sociality. There is nonetheless also a significant vein of scholarship on civilisations as collectives coursing through the early phases of modern archaeology, anthropology, history, philosophy and sociology. Beginning with Emile Durkheim, Marcel Mauss, Max Weber, Oswald Spengler, Pitirim Sorokin, Karl Jaspers, Eric Voegelin and Arnold Toynbee, comparative sociologists, philosophers and world historians have produced theories and inquiries taking civilisations as the main unit of analysis. The advantage of focusing on civilisations is that the scope of analysis expands to formations that are larger and older than nation states and empires while at the same time incorporating them. Strong claims have been made that this corrects the socio-centrism and presentism characteristic of conventional sociology. At the same time, modern scholars of civilisations inherited a legacy of nineteenth-century Eurocentric thought and have only reinterpreted it to a certain degree and in certain ways. They trialled theories that could be no more than incomplete and were based on assumptions open to critique, while the comparative studies that they produced were always open to revision on the basis of new evidence and altered perspectives. The comparative analysis of civilisations would always be a debating point.

'Civilisational analysis' is a late-twentieth-century appellation for this field. The field is defined by its object, which includes both 'civilisation' taken as a 
singular object and discourse and multiple 'civilisations' taken as a diversity of formations and trajectories. Though it is considered as a single field, civilisational analysis incorporates many traditions and perspectives and is multidisciplinary (Arjomand and Tiryakian, 2004a; Arnason, 2001, 2007; Katzenstein, 2010a). Moreover, it is a retrospective appellation. The phrase appears to be first used in the 1970s by Vytautos Kavolis to refer to a longer tradition (Kavolis, 1995). Many important landmarks in civilisational analysis were published in the 1980s and 1990s by Fernand Braudel (1985, 1993), Benjamin Nelson (2012), William McNeill (1991) and S. N. Eisenstadt and his associates (1986, 1996). But international traction was gained soon after when Edward Tiryakian and Johann Arnason described a whole contemporary field as 'civilisational analysis' in special issues of the journals Thesis Eleven and International Sociology (see Arjomand and Tiryakian, 2004a). Furthermore, the essayists of those issues distinguished contemporary perspectives from the early ones of their forerunners by their critiques of the Eurocentric legacy of social thought and the Eurocentrism of the discourse of civilisations (Hall and Jackson, 2007; Mazlish, 2004). If it seemed that sociology owned the field, then Arnason's résumé of its theoretical and disciplinary diversity (2003), perspectives from political sciences (Hall and Jackson, 2007; Katzenstein, 2010a; Unay and Senel, 2009) and Felipe Fernández-Armesto's world history of civilisations (2001) served as reminders of the breadth of interest across the human sciences.

Debating Civilisations focuses on the scholarship produced in this field since the 1970s. As a second major part of this project, I put forward an alternative version of civilisational analysis that critically evaluates and extends key insights of research in the field. In evaluating the field in the first part of this book, and starting with this opening chapter, I use the phrase 'contemporary civilisational analysis' in order to highlight the context and stated purpose claimed by its proponents. In regard to context, the field is deeply influenced by the end of Cold War rivalry. With respect to purpose, the phrase distinguishes efforts to selfconsciously critique Eurocentric legacies in history and sociology. Civilisational analysis revived through critical reflection on inherited notions of 'civilisation' and 'civilisations'. Considered as 'uses' of civilisation, questions can be asked about the extent to which contemporary civilisational analysis has achieved its aim of critical reconstruction of the legacies of the scholarship of civilisations. In this opening chapter, I examine the genealogy of the uses of civilisation in earlytwentieth-century sources. Early ventures into civilisational analysis by sociologists, historians and anthropologists produced advances on nineteenth-century conceptions, while experimenting with theories of civilisation and civilisations. One of the most important achievements was the pluralisation of the notion of 
civilisation. The end of the genealogy coincides with the outline of the alternative advanced and defended in Debating Civilisations, an outline elaborated at length in Part II.

\section{Uses of 'civilisation'}

The critical renaissance of civilisational analysis occurred in the context of five sets of transformations. First, the Cold War came to an abrupt end, loosening the constraints imposed on the international order by the balance of superpowers. Despite a short phase of American triumphalism, a new multipolar international order was on the cards. 'Civilisation' and 'civilisations' became topical in public discourse, particularly with Samuel Huntington's bellicose vision of clashing civilisations and religions as the main alleged organisational principle of post-Cold War rivalries. Second, in the wake of the attacks on the World Trade Center, the Bush administration and its willing allies invoked a civilisational enterprise reminiscent of colonial-era civilising missions in wars of occupation in Afghanistan and Iraq and in its 'War on Terror'. Third, the growth in complexity of migration strained mono-cultural conceptions of nationality previously prevalent in nation-states (Castles et al., 2014). Policies of multiculturalism that have taken their place presuppose a mixed demography and intermingling religions and civilisations. Furthermore, they are premised on continuing diversification. Multiculturalism is fragile and periodically beset by xenophobic reaction. Plurality is undeniable, however, and it is evident not only within states, but in the international arena. The rise, surge and growth of regionalism is a fourth transformation. The sheer number of supranational blocs, agreements and associations is evidence of a reconfigured multipolar order. The dynamics of regionalism go even further. There are other transnational and non-governmental actors that impel regionalisation in other ways also. Finally, revealing a fifth context, the threat of climate change to human survival is frequently couched in terms of a 'threat to civilisation', meaning the organised social order in this instance.

In this context, the uses of 'civilisation' and 'civilisations' have been doubly contested. Kapustin poses the period as one in which a 'big' discourse of civilisations is an analytical contrast to a 'small' discourse (2009). The former is composed of long-standing debates about civilisations that have accumulated over the last two centuries in the humanities and social sciences. The 'small' discourse is a more public and ideologically driven one. The 'small discourse' brings about a 'conceptual and normative impoverishment of the idea of "civilisations", and in that state serves a neo-conservative mode of cultural politics (Kapustin, 
2009: 151). On the terrain of public discourse the neo-conservative politics of civilisational clash has been rigorously contested. But within the 'big discourse' the uses of the language of civilisation and civilisations were contested in different ways also by civilisational analysis and post-colonial and other radical critics. The critical response involved reconsideration of religion, tradition, nationalism and modernity (Arjomand, 2014b). African, Indian and Asian perspectives rebuffed Huntington, though they did not get due exposure in the larger public controversy. Thus, despite the breadth of critique of the politics of the 'clash thesis' in the humanities and social sciences, the shrill idiom of the small discourse and its ability to capture the Western media has made it the 'louder' of the two discourses.

Contemporary civilisational analysis did not enter the controversy without conceptual traditions. The conceptual pre-history was a background to uses of civilisation in perspectives and debates argued out in sociology, world history and anthropology. Three conceptual images of civilisations are prominent in the field. First, civilisations are conceived as socio-cultural units, entities or blocs in an 'integrationist' image. In 'processual' explanations civilisations emerge out of long-term uneven historical processes. Finally, in a 'relational' image civilisations are believed to gain definition and institute developmental patterns through inter-societal and inter-cultural encounters. A century of perspectives informs all three images. Both contemporary civilisational analysis and earlytwentieth-century perspectives in turn have a pre-history in the development of a vocabulary of related terms and a discourse around civilisations bound up with experiences of colonialism. Before illustrating the three kinds of uses of 'civilisation' and 'civilisations', I want to trace the history of semantic developments of the notions of 'civilisation' and 'civilisations' coextensive with the expansion of Europe's empires and consubstantial with colonialism. Through this, we can see how the conceptual apparatus was implicated in colonialism and how it was mobilised in critiques of colonialism.

Terminological equivalents for 'civilisation' existed in Chinese and Arabic long before they emerged in European languages (Aktürk, 2009). Notwithstanding this longer history, etymologies of 'civilisation', 'civilised' and 'civility' suggest that the modern terms had origins in eighteenth-century Western Europe (Febvre, 1973). 'Civilisation' and 'culture' were intertwined in their early discursive development in historically complex ways (Rundell and Mennell, 1998: 68 ). The words were carriers for Western notions of tradition and modernity. Culture and civilisation were, moreover, bound together in the genealogical dispute between French and German intellectuals about the character of social institutions and forms of manners, and then in a nineteenth-century Romantic debate about progress and primitivism (Elias, 1978). 
From the outset, the neologism 'civilisation' culturally presupposed 'barbarism' as an opposite. At the height of the Romantic debate about progress and primitivism in the early nineteenth century, 'civilisation' was in common use. In this context the conceptual pairing of civilisation and 'barbarism' was thoroughly conditioned by Europe's historical experiences of the conquest of the Americas, the decline of Islamic civilisation, by colonial encroachment on South-East Asia and growing domination of India and Africa and by intrusion into the Pacific. Throughout the development of the European semantics of civilisation, the range of meanings had accommodated a spectrum of possible connotations, ranging from the most relativist nuance through to schemes of universal societal evolution. In different periods, one current would often dominate. Europe's era of Romanticism was more critical of the idea of civilisation, whereas the progressivist meta-narrative of the second half of the nineteenth century countered Romanticism's relativist critiques with the evolutionism of Lewis Morgan, Herbert Spencer, Friedrich Engels and the early Durkheim (Rundell and Mennell, 1998: 20).

As the dominant narrative in the second half of the nineteenth century, the progressivist narrative imagined a future of secular dynamics of development based on the impulses of civilisation. The standard of civilisation in international law presumed a European monopoly of civilisation in which quasi-juridical criteria were crafted to determine inclusion of the so-called civilised nations (Gong, 1984). As the standard subsided after the First World War, other constructions and appropriations of 'civilisation' emerged. Pro-independence elites in Japan, Turkey, India, China and Indonesia confronted Western ideas, partly from their own civilisational vantage-points and partly through critique of the intrinsic inconsistencies of the discourse of civilisations. Plural uses gained greater leverage in this context as champions of self-rule and independence in Asia advocated for the worth of other civilisations (Duara, 2001). In countries treated as peripheries by the imperial city centres, intellectual and political elites interrogated the ideas of civilisation and turned them into nationalist devices with which to bring colonialism into question (Morris-Suzuki, 1993). The mantle of 'civilisation' became a contest as the discourse of civilisation blended with a rhetoric of 'nation'. Japanese, Indonesian, Vietnamese and Indian intellectuals and nationalists envisaged alternatives to Western colonialism in Asia that acted as models in the phase of rapid decolonisation (Duara, 2004).

These brief comments on the discourse of civilisations emphasise the external environment of European cultures and societies and the imperialising projects that conditioned Western cultural development. The goal of etymologies of 'civilisations' has been the post-Orientalist reconstruction of the discourse of civilisations (Duara, 2001, 2004; Mazlish, 2004). In the wake of this reconstruction, sharpened cultural sensibilities have nurtured a self-correcting impulse in 
contemporary civilisational analysis. Through self-correction, contemporary civilisational analysis has aimed to rethink the relationship of the discourse of civilisation to colonialism through a carefully crafted genealogy of its many conflicting meanings. Critics from post-colonial sociology examining civilisational analysis and the related area of multiple modernities have argued that the field has fallen short of an adequate understanding of colonialism and civilisation due to its abiding Eurocentric assumptions. More specifically, they claim that proponents of contemporary civilisational analysis and multiple modernities have failed to achieve the non-Eurocentric comparative sociology they strive for by presuming the originality of European modernity even as they recognise divergent trajectories and plurality of constellations (Bhambra, 2007: 56-74, 2014: 32-7; Go, 2013; Patel, 2013). The significance of the critique lies in the reminder of the centrality of colonialism in the constitution of forms of modernity and the importance of an encompassing historical sensibility in the exercise of historical comparative sociological analysis.

The arguments in post-colonial sociology are addressed here in Chapter 3. For the moment, I note that as compelling as some of the post-colonial sociologies are, they do little to discern divergent approaches, including efforts to reconstruct the genealogy of the discourse of civilisation. The general benefit of the latter lies in making the risks associated with this contested concept explicit. 'Civilisation' is a word with stubborn historical associations with colonialism and a risky analytic for the social sciences. However, as it has been a normative concept, 'civilisation' is also elastic and ambiguous. It can be equally the vehicle of critique as well as advocacy, and indeed it has been. More reflective versions of civilisational analysis address established uses of the concept through recovery and further development of a greater plurality of meanings (Aktürk, 2009). The uses of the idioms and discourses themselves are also a component of modern empires and the historical experiences of colonialism and have been the subject of critique in civilisational analysis.

In the first half of the twentieth century, nationalist critiques of imperial sovereignty not only began to undermine colonialism, they also forced a concept of civilisations in the plural to the forefront of the discourse of civilisations. Within sociology and world history, civilisations were in the main cast as endogenously created entities. The focus on entities brings out disagreement over the defining attributes of larger formations. The problem with such a world view surfaces when some societies and cultures are recognised as 'civilisation' on the basis of a debated set of attributes and others are not. When all attributes are put together, the list can look long. It can add up to a 'checklist', such as that which Fernández-Armesto - writing at the turn of the millennium - urges us to avoid: cities, law, private property, enduring arts, tombs, palaces, temples, 
decipherable languages, sacred texts, literature, library, academies, clothes, trade, production, systems of extensive transportation and communication, cartography, armies, institutions of imperial government, class domination and stratification. As Fernández-Armesto observes, when progress is indexed against markers of civilisation like these, the analysis becomes dangerously flawed and implicitly evolutionist (2001: 17-25, 28-30). In this context, the three images of civilisation and civilisations began to coalesce in the early twentieth century.

\section{Integration, process and interaction}

There are examples of this first image of civilisations in the works of Oswald Spengler and Arnold Toynbee and, indeed, in some of the studies produced by Max Weber. To a degree, the point applies also to Durkheim and Marcel Mauss, though their formulations skirt the boundaries between integrationist and relational images.

Spengler and Toynbee each map a full-blown version of this approach in their own way. They were unique figures in history at that time. No others were attempting to build up a global picture of civilisations on the same scale. Though their writings reached large audiences and had a demonstrable public impact, they were on the fringes of history departments, which were busy with the fortification of national histories. Spengler and Toynbee took aim at macro-historical contexts by indexing the amorphous attributes that seemed to revolve around notions of civilisation. Spengler's trajectory was set in the conflagration of the First World War, and it did not escape the zeitgeist of dejection that descended upon Western societies at the loss of aspiration to a standard of civilisation. According to Spengler, civilisation is the decadence of culture in the mature phase of its life cycle. In the 'organic succession' phase, culture is succeeded by civilisation when it ossifies (Spengler, 1966). His biotic metaphor of civilisations sees a post-historical condition as the end point in the life cycle of a culture where it 'suddenly hardens, it mortifies, its blood congeals, its force breaks down, and it becomes Civilisation, the thing which we feel and understand' (1966: 310). Spengler's congealed and stable units - his count is eight - are an abandonment of his otherwise firm grasp of the past as moving history. The schema of cultures flourishing, solidifying as civilisations and entering a phase of slow, but inexorable, atrophy runs up against any appreciation of contingency. Civilisations count when they attain timeless cohesion and you can 'feel and understand' their unity.

Like Spengler, Toynbee had a significant impact on scholarly thinking about civilisation as a material objectification of a spiritual core. His view of instituted religion was more sanguine than Spengler's, and he was more alert to the detection 
of crossroads of civilisations. Nonetheless, his enterprise lay in the cataloguing of lasting civilisations. His encyclopaedic catalogue of twenty-one civilisations - or thirty-one on a later count (Toynbee, 1972: 11) - is a product of the great interest he showed in the unities of civilisations as well as contacts between them. He remained true to the proposition that there are unities in world history, and that to discern these one must spurn the fragmenting nationalism of historical specialisms and national histories. While his encompassing frame did help in pinpointing inter-cultural encounters, communication and fusions, his holism risks elaboration of a human history of closed monads (Arnason, 2003: 63).

Early sociological ventures into theorising civilisations were more exploratory and open to further amplification by successive generations. Durkheim and Mauss worked at the interstices of concepts of civilisations as, first, spatial wholes and, second, as constituted in interaction. The imprecise, compact and ambiguous nature of their perspective puts them on the cusp of the two approaches I have posited here. Their early sketches of the characteristics of civilisations coincided with Durkheim's survey of ethnographies of non-stratified cultures in The Elementary Forms of the Religious Life. They brought recognition of the complexity of so-called primitive cosmologies (Durkheim and Mauss, 1971). Together they linked societies and tribal formations to larger and more durable civilisations as kindred groups of societies (Durkheim and Mauss, 1971). Not all civilisations reflect the same capacity to generate cohesion; the 'unequal coefficient' of the internationalisation of societal logics meant that 'civilisations' would be uneven in their global impact. As a framework, this could be interpreted as a conceptual core amenable to contrasting conclusions. On one hand, the framework buttresses the images of civilisations as cohesive and self-contained forms. On the other, it could be pressed into the service of historical sociologies of intra-civilisational and inter-civilisational encounters and indeed there is a relational accent in their essays. On balance, the relational image looks like it wins out. This vein of theory is openly pluralistic and anthropological and at odds with the proto-functionalist typology of segmentary societies of Durkheim's earlier work. Durkheim and Mauss give recognition to the complexity of indigenous cognitive systems and cosmologies that anthropology had brought to light. Moreover, when considered alongside The Elementary Forms of the Religious Life, a version of Durkheim's collective representations is evident.

The anthropological members of the French Durkheimian School gained the most from the multi-civilisational turn. Durkheim and Mauss bestowed legitimacy on the study of stateless social formations qua civilisations for other anthropologists and sociologists including Claude Lévi-Strauss, Louis Dumount, Marshall Sahlins, Marcel Granet and, later, Pierre Clastres and Robert Redfield (Arjomand, 2014b: 24-8). While French anthropology 
provided a clear direction, the trajectory in Germany for civilisational thinking was less definitive. Developments in early German social theory focused on comparison of formations and raised questions of comparative methodology (Tiryakian, 2014: 93-4). Weber defined comparative analysis as comparison of ensembles of material and ideal elements. Weber uses the term 'civilisation' rarely. However, his work encompasses many collective formations, revealing that he accepted the pluralistic notion of civilisations. Notwithstanding that, he set out in the core of his comparative historical sociology to measure other civilisations against the comprehensive process of Western rationalisation (Wittrock, 2014). The defining question of his comparative historical sociology is the problem of theodicy. For Weber, the world religions produce different rationalities in response to the incongruence of worldly and sacred realms. As a result, different economic ethics emerged to guide variants of economic practice. The core of his sociology of religion can be contrasted with his own sociology of cities that, arguably, produced a second image of civilisational patterns. Weber's The City can be read as a separate line of thinking, which stresses urban imaginaries as conduits of alternative civilisational and democratic-revolutionary potential (see Rundell, 2014). The City is an open book in the sense that it lends itself to multiple versions of modernity, including one of a long civilising process. Weber is not seeking to construct a typology of cities, preferring to more actively explore the contingency of urban formations. Cities create particular civilisational thresholds, he finds, but this varies according to the institution of urban imaginaries and the pattern of positive and negative consequences. The alternative reading emphasises radical contingency in the conception of the history of cities.

This remains a minor current of Weber's thought. Our attention is focused on his core comparative historical sociology. He turned the German social sciences towards civilisations, but with dubious results. Despite extensive exploration of Eastern civilisations, there are problems with his most-developed accounts. The first is the glaring absence of empires in his sociology of Asian civilisations. The limits to his comparative historical methodology are most apparent in the comparison of China and India with the West. Though he did not have reliable and valid data available to him for his comparative historical sociology of China, it is the narrow conceptual presuppositions informing his method that stand out (Weber, 1951). China's attributes are each held up as deficits of Occidental rationalism in law, economy, religious heterodoxy and ethics. Above all, the Chinese cultural pattern is seen as cognitively deficient compared with the baseline of the West that Weber used. His comparative analysis of India is more substantial and has more sustainable conclusions (Weber, 1958). However, like his comparative historical sociology of China, it is premised on the search for the balance of elements of the 
capitalist spirit privileged in the developmental paths of Western countries that may be sourced in religious traditions and which can explain the absence of capitalism. He seems unable to avoid the view that Asian religions are contemplative, while Western capitalist ethics are an exceptional example of the emissary type that favours world transformation. The larger issue at stake is his lack of recognition of the historicity of non-Western civilisations that backgrounds his privileging of the West (Adams and Arnason, 2016: 187-8). In summary, Weber's sociology of religion and comparative methodology privileges the test of aspects of the European constellation in comparative analysis, even if his framework does not preclude exploration of particular cases of inter-civilisational junctures.

The early perspectives of Durkheim, Mauss, Spengler, Toynbee and Weber tend, on the whole, to a nascent integrationist image, though Durkheim, Mauss and Weber remain open to alternative interpretations. The problem lies in the lack of attention to the cross-flows of forces, ideas, influences, customs and people in which civilisations are constituted and indefinitely alter. In the wake of their lives and work, the problem continued to foster a tendency to reduce complex formations - with sophisticated cosmologies and modes and systems of decision-making and conflict resolution, patterns of trade and exchange, and remarkable understandings of the biosphere - to typical objects and practices for the purpose of defining which societies are 'in' and which are 'out' when it comes to stratifying hierarchies of progress. Civilisational analysis between the 1930s and the 1970s did not examine stateless and non-nucleated societies very often. In developing an alternative to the integrationist image, proponents of processual sociologies and approaches endeavour to evade reductionist consequences of this kind. How successful have they been?

Process-based approaches take the persistent ambiguities that haunt conceptions of civilisations as a point of departure. Analyses of civilisational processes are well known in comparative sociology. But they have also gained prominence in political science and international relations. A notable exponent of the processual image from sociology is Norbert Elias. The dissemination of his ideas is a contemporary development and therefore subject-matter for the next chapter. One point to note is that his historical sociology presents as a general theory when comparative analyses reveal general variation in civilising processes (Arjomand, 2014b). If this is true, how might other processfocused perspectives handle comparative methodological issues? International relations perspectives show more awareness of inter-regional and global connections, as one might expect them to (Unay and Senel, 2009). In order to make 'civilisations' analytically useful in studies of world politics, Hall and Jackson propose to shift the axis of definition. They argue that civilisations are not essences, but processes (2007). Many critics of crude essentialism, 
they observe, end up with softer varieties of reification. 'Considering a civilisation to be composed of a coherent ensemble of values, or a characteristic set of dispositions is no less essentialist than Huntington's approach' (Hall and Jackson, 2007: 2). They distinguish a 'fourth generation' of scholars from the three generations Arjomand and Tiryakian profile in their summary of the field (Arjomand and Tiryakian, 2004a). Hall and Jackson make the distinction on the basis of the fourth generation's ability to transcend essentialism. Whether there is sufficient intellectual cohesion to talk of a fourth generation is a problem that can be put to one side in order to see that there are examples of emergent scholarship focusing on processes and relations. With insights from international relations theory and comparative historical sociology, selfstyled constructivists examine the shift in boundaries of civilisations caused by transformations in the relations of power (Hall and Jackson, 2007: 6). There is, in other words, fluidity in the historical and ongoing production of civilisations. Civilisational identities in world politics may be relatively stable, but the undercurrents of process supporting them flow quite freely. Hall and Jackson suggest six theses as an agenda for researching civilisational processes (2007: 7-8). Civilisations are: 'weakly bounded', 'contradictory not coherent', 'loosely integrated', 'heterarchical, not centralised', 'contested, not consensual' and 'states of flux'.

As a prelude to larger analyses, Hall and Jackson's theses are sound lines of inquiry. However, the resulting research into each does not live up to expectations. Perspectives gathered together in collaboration under this banner therefore seem unified less by these specific agenda and more by their general stance of post-essentialism. Thus the exact ideational and material processes producing civilisation and civilisations are not plotted in such a way that gives the reader confidence that the problem of essentialism is indeed being transcended. In the drive to depart decisively from essentialist models of civilisation, post-essentialist strategies may overlook processes of essentialisation in which ideal interests mutate into material forces. Peter Katzenstein makes a valuable observation when he describes the pliability of civilisations as pluralist complexes:

They are both internally highly differentiated and culturally loosely integrated. Because they are differentiated, civilizations transplant selectively, not wholesale. Because they are culturally loosely integrated, they generate debate and contestations. And, as social constructions of primordiality, civilizations can become political reifications especially when encountering other civilizations. Civilizations constitute a world that is neither a Hobbesian anarchy nor a Habermasian public sphere, neither empire nor 
cosmopolis ... Instead, they are weakly institutionalized social orders reflected in and shaped by a variety of practices and processes. (Katzenstein, 2010b: 5-6, emphasis added)

In his version of a processual perspective, Katzenstein merges Eisenstadt's grasp of civilisation as institutionalised orders with Elias's strong sense of historical movement, process and development. Katzenstein's blend of international relations and comparative historical sociology embraces processes of orientation to place, time and collective identity. Furthermore, his blend pinpoints anthropological constructions of relationships to the world and to divinity. Processes and practices through which these orientations coalesce and change occur in trans-civilisational and inter-civilisational encounters as well as pluralist intra-civilisational contestation and debate (2010b: 32-6). He illustrates this by remarking on the concentration of essentialist convictions in the encounters of Europe's empires that, in late modernisation, erupted into catastrophic and genocidal wars. Katzenstein and his associates are closely in touch with the processual vein of thinking, but also with the scholarship of encounters and contexts (2010a), that is the relational approach. This collaboration is the nearest thing to a fusion of all three approaches. It is the third approach that is the most suggestive of directions for the version of civilisational analysis that I am advocating and the most open to further innovation.

Commenting on Toynbee and Spengler's histories of civilisations, Bruce Mazlish points out that few today follow such uses. Instead, scholars are more 'interested in cross-border and trans-civilisational encounters. In fact, some scholars now prefer to think of such interactions as constituent of civilisation, not peripheral and accidental to them' (2004: xii). Scholars of intercivilisational encounters epitomise the trend Mazlish throws into relief. The formulation arose out of the work of Benjamin Nelson in the 1960s and 1970s on the emergence of Western 'structures of consciousness'. The path it took to reach its upgraded state in Johann Arnason's civilisational analysis was substantial. Two representative quotations serve to recapitulate Arnason's position and the moves beyond Nelson. Arnason is interested in high-impact interactions between civilisations. His attention is particularly drawn to the 'openness to encounters' as a vital part of civilisational patterns. There is no simple definition of this notion and a lengthy quotation is needed to convey the enlargement of his analytic:

This approach is radically opposed to the models which posit closure as the primary or predominant state of civilisations. Visions of closure and efforts to achieve it are not uncommon, but they are best understood against the background of intrinsic and fundamental exposure to other forms of sociocultural life. By the same token, 
however, the comparative analysis of civilisations has to deal with different expressions and levels of this underlying openness. Nelson's interpretations of the structures of consciousness and their involvement in intercivilisational encounters suggest ways of theorising the general connection as well as its variations. But before taking that line of argument further, we must broaden the analytical perspective. Our discussion of civilisational patterns has emphasised the need for a multi-dimensional model, giving more weight to institutional structures and dynamics than Nelson did, and this view must now be extended to the field of intercivilisational relations. If civilisations are to be analysed as interconnected constellations of meaning, power and wealth, the same applies to the processes that unfold across civilisational boundaries. (Arnason, 2003: 288)

Arnason's multidimensional approach to the creation of civilisations introduces to the field the least reductive theoretical and comparative framework. Indeed, it is non-reductive and thus the analysis can find wider applications than Nelson's original concept. With this analysis, Arnason intends to research historical encounters in context in order to reconstruct civilisational dynamics. The emphasis would be one-sided in his view if the obverse notion of intracivilisational encounters were not taken into account:

I would speak of intra-civilisational schisms when the shared cultural premises of a civilisational complex are interpreted in radically divergent ways that lead to - or at least point to - conflicts on the level of institutions and power structures and when the dimensions of dissent and struggle are such that they give rise to alternative civilisational patterns. (Arnason, 2006: 50)

This is the most constructive example on offer in the field because it properly expands the scope of interactions and conflicts. Moreover, Arnason calls attention to institutional dynamics of economic and political power alongside cultural and ideological crystallisations without getting tangled up in quasi-evolutionary assumptions. If the aim, however, is a comparative framework for understanding the mutual formation of large complexes, then analysis of only the most decisive examples of interaction will not suffice. A fuller picture of the relational patterns of civilisations must take account of the density of interactions and connections as well as landmark encounters.

Even with this qualification, it is not hard to appreciate that Arnason's synthesis of inter-and intra-civilisational encounters puts his work at the forefront. His position is more extensively and critically treated in the next chapter. For the moment, it will suffice to note that his theoretical and empirical projects help to clarify the range of inter-civilisational encounters and the quality and degrees of aperture and closure that exist within civilisational constellations. It is therefore 
a basis for theoretical innovation, provided there is departure around a few gaps. For example, there is little on colonial modernities and what are often known as 'new world' settler-colonial societies in the Americas and the Pacific. Moreover, Arnason's conception of civilisations still precludes indigenous cultures qua civilisational forms. Both of these problematic aspects are raised in the development of a version of civilisational analysis focused on imaginaries, on power and on deep and dense inter-civilisational engagement.

The outline below of a conception of social imaginaries and power relate the problematic aspects to inter-civilisational engagement. Cornelius Castoriadis's theory of the social imaginary (1987 [1975]) and his specific notion of power helps to stress how imaginaries create engagement, conflicts and dissonance between civilisations. There is potential in his theory for development of a reconceptualisation of civilisations.

\section{Civilisations, imaginaries and inter-civilisational engagement}

Castoriadis's notion of the imaginary institution of society can be located in a larger field of social imaginaries (Adams et al., 2015). Though civilisations did not figure amongst his many interests, his concern with the ontology of creation produced a social theory with vital resonances with contemporary civilisational analysis. He asks fundamental questions about the human creation of an 'indefinite' number of societies that should be of interest to civilisational sociologists. The notion of the imaginary that he founded was briefly adopted by Eisenstadt as the imaginaire of civilisations qua cultural ontologies (Eisenstadt, 2004). In this phase, civilisations for Eisenstadt denoted formations that furnish themselves with worlds of meaning through which social and political orders are structured. Arnason more actively engages with Castoriadis's thought. He critically recomposes Castoriadis's theory of the imaginary as part of a larger reconstruction of civilisational analysis undertaken to underline dimensions of meaning and power. As well as resonating more generally with conceptions of the ontological nature of civilisations, Castoriadis's theory of the imaginary directly helps elucidate the nature of human collectives, the institution of otherness and the boundaries of exclusion and inclusion. In his larger work The Imaginary Institution of Society, he theorises the manner in which collectivities in their wholeness construct distinct social and historical modes of life that are meaningful to their subjects. What matters, what counts, what is in and what is out are a series of choices in collective self-representation. 'Who are we as a collectivity? What are we for one another? Where and in what are we?' (1987 [1975]: 146-7) are questions of collective identity that go to the problem of distinction and alterity. These are 
questions for collectivities that may be tribes, cities, societies, empires or, for that matter, civilisations.

Two criticisms are relevant in considering the relationship of Castoriadis's notion of imaginary to civilisational analysis. First, in implying that the object of analysis is national societies, theories of social imaginaries unnecessarily risk socio-centric assumptions (Adams et al., 2015). In spite of Castoriadis's unequivocal position that an indefinite variety of collective life is always possible, society remains the main institutional creation of the imaginary for him. An exact range of multiple imaginaries - capitalist, imperial, even civilisational are needed as a starting point. Second, Castoriadis's formulations suppress the phenomenological side of the world as the greater meta-context of all life. If the world is understood as the backdrop to the creation of societies, states, civilisations and empires, then the variety of connections between collective formations can be brought into the frame of analysis. Collective identities and forms of meaning are generated relationally in the interaction of different kinds of formation. In the past, socio-centric explanations of culture common to functionalist theories in sociology and anthropology have suppressed the field of meaning and the range of exogenous impulses on social formations. The constitution of collective identities is confined to internally composed territories when, in fact, collectivities are, as Arnason puts it in his interpretation of Castoriadis's theory, 'relational in a twofold sense ... inseparable from specific ways of locating society in the world, and [dependent] on demarcation from other collectivities' (2003: 60).

To take this further beyond socio-centric assumptions, Castoriadis's notion of the social-historical must be taken into account (1987 [1975]: 170-202). Castoriadis sees history as inseparable from the collective forms instituted by the imaginary (1987 [1975]: 150). Collectivities are engulfed in historical significance. Bringing this point into the civilisational framework, we can conclude that all societies, empires and civilisations produce a self-perception of history and how continuous and discontinuous connections to the past are. Because all societies, empires and civilisations are also always bearers of historical meaning in the broadest and deepest sense, the key to understanding lies in elucidating their social-historical conditions. Since all forms of social organisation create institutions of life, economy and polity and images of the world and the modes of knowledge through collective imaginaries, all societies 'have' history. Therefore, following Castoriadis's line of thinking, all human groupings are bearers of historicity - as an abiding sense of continuity or discontinuity - even those supposedly 'without history'. This vision is compatible with an encompassing comprehension of civilisations beyond the regular roll-call of state-based formations. It alludes to other collectivities - ethnic, indigenous, 
archaic formations with proto-state and stateless structures, religious communities, trans-national language communities and so forth. This breadth of the collectivities of human existence is the reason I use the term 'imaginaries' only from this point.

The sum of collectives bearing different historicities are also given to a variety of relations with other collectives. Collective formations acquire and modify identity, historicity and meaning through interaction in the world. In Castoriadis's terms, collectives are circumscribed by a categorisation of difference, or rather an unpredictable othering (1987 [1975]: 150). As collectives, civilisations develop inclinations and aversions to varying degrees to encounters and engagement. Furthermore, dispositions to encounter are generally adjustable. Civilisations in mutual engagement are more affected by the presence of strangers and encounters with other modes of economic organisation, abstractions of knowledge and belief and models of polity. Below I define connectedness of this kind as inter-civilisational engagement. I elaborate on the definition in Chapter 4 and give illustrations of diverging civilisational combinations of inclinations and aversions - the forms of othering - in Part II. Before proceeding to that definition, the relationship of power to imaginaries must be considered.

Just as all human formations are engulfed in historical meaning and institute myriad varieties of relations, they are also embedded in different kinds of power. Castoriadis distinguishes three kinds (1991). First is 'radical ground power', which can be termed an implicit background power. Ground power is not situated in any visible institution alone. It is trans-institutional, the "power of outis, of Nobody' (1991: 150). Ground power permits states and other transterritorial organisations to advance to places where their concrete institutions are not physically present. In the creation of ground power, symbols stand in for enforcement and can do so beyond the effective reach of coercive and legal institutions. Castoriadis argues that ground power is the power that gives power in the second sense, as the 'explicit power' of state and other institutions. As Castoriadis's notion of power is relational, explicit power refers to the conservation of order in the face of social and class conflict and the mutation of order as the result of conflict. Explicit power addresses itself to the imagination of the legitimacy of order as well as a monopoly of arms, taxation, law-making and administration. It denotes a general capacity to formulate 'sanctionable injunctions' (1991: 151). This is not to be confused with states, which are secondary institutions differentiated from the anonymous collective (which might in turn be imagined as a sovereignty in sacred kingship or an imagined popular will). Explicit power makes possible the separation of the institutional apparatus of states and in turn constrains popular participation in the political operations of those institutions. It also blunts the interrogation of existing conditions and, in 
some instances, generates outright exclusion. The asymmetry of the extreme arrangements of the latter ends up as a third kind of power: 'domination'. Castoriadis distinguishes domination as a sub-species of explicit power evident in circumstances of the greatest asymmetry. The imaginaries that create collectivities also generate power and its instantiations. At the same time, imaginaries are irreducible, which includes being irreducible to imagined power and its institutional configurations.

With these points on power in mind, it is time to define inter-civilisational engagement. In defining this via the theory of the imaginary, it is no longer necessary to accept a conception of civilisations as only separated entities or solely as historical processes. Instead, it is contended that the imaginary institution of civilisations occurs in and through their interaction with each other, that is, through movement. Imaginaries structure both the inclinations and limits to engagement and encounters. In other words, they mark the settings of closure and porosity and relational orientations. Through recurring relationships, civilisations become engaged and in that engagement they are meaningful and powerful (in the sense of co-instituting power). Engagement is defined as the regularisation and routinisation of contact and encounter, the myriad, mostly undocumented, untraceable, routine contacts and connections, carried out by anonymous actors, as well as those that stand out as full-scale encounters. Engagement is deeper than encounters due to its regularity and greater continuity. My definition is reiterated and then unpacked in Chapter 4, where the relationships of imaginaries and power are elucidated across four specific dimensions of inter-civilisational engagement. The four dimensions are migration, economic relations, cultural exchange and creation and reconstruction of models of civilisation. They are treated as analytics in Chapter 4 and then throughout Part II.

Prior to that extensive discussion, I profile the intellectual terrain of contemporary civilisational analysis and its key thinkers in Chapter 2. As well as outlining the perspectives of contemporary civilisational analysis, Debating Civilisations looks at critical counterpoints. I relate civilisational analysis to its critics by foreshadowing some lines with dialogue with the counterparadigms of globalisation analysis, Marxism and post-colonial sociology. Through examination of paradigms that are positioned as alternatives, or are explicitly critical of contemporary civilisational analysis, the most salient criticisms are related to the modified version advocated here. Some short comments on how this takes place, and why, are necessary to show how the version of contemporary civilisational analysis that I elucidate in Chapter 4 is arrived at. 


\section{Critical perspectives on civilisational analysis}

When post-colonial sociological responses are compared with perspectives at the interstices of Marxism and civilisational analysis and then globalisation theory and civilisational analysis, other problematics come to the fore. Perspectives elaborated in globalisation analysis, Marxism and post-colonial sociology reveal 'power' to be a still-troubling problematic for civilisational analysis, which is one other reason for prefixing Castoriadis's notion of power in the passage above. In comparing contemporary civilisational analysis with the competing paradigms of globalisation theory, Marxism and post-colonial sociology, valid theoretical criticisms and substantiated correctives can be found. For instance, post-colonial sociologists underline historical contexts of colonialism and power in the development of Western ideologies of civilisation. Post-colonial sociologists are also sharply critical of the multiple modernities hypothesis. More precisely, they critique the manner in which modern social formations appear sequestered when viewed through the prism of multiple modernities. Their suggested alternative is the methodology of connected histories as a different basis on which to interpret the global hierarchies of power constructed in historical and present formations. As a second example, globalisation theorists have a pre-existing genre of the civilisation of modernity. However, the field is haunted by the kind of presentism that civilisational analysis is critical of. Even so, there are important interlocutors who speak to civilisational analysis from paradigms of globalisation theory and who highlight important forms of power and domination operating on a global plane. They reflect longer and more complex histories of globalisation and tend towards multidimensional analyses of historical civilisations and contemporary modernities. Because those addressing the problematics of civilisations and globalisation demarcate higher levels of connectedness in earlier phases of global history, they are able to produce insights useful for a conception of civilisational engagement. The third counterpoint, Marxism, is at odds with civilisational analysis over a rupture in global history: the advent of modern capitalism. Capitalism is a marginal problematic in civilisational analysis. One way to correct the neglect is through a conception of the imaginary of capitalism. A longer history of capitalism's emergence can be reconstructed through a theory of the imaginary. Though this is a larger task in itself, there are interpretations in Marxism that furnish insights into the imaginary of capitalism. Elements of Marx (in one interpretation) and Antonio Gramsci and the neo-Gramscian civilisational analysis of Robert W. Cox fit a theory of the imaginary of capitalism. Marx's imaginary of capital and money theorised in The Grundrisse and elsewhere is one element prescient to early modern forms of dispossession and accumulation. Gramsci's 
elucidation of the cultural dimensions and geographical inequalities of capitalism are threads of a larger picture of variation of capitalism. The two elements are integrated in Cox's political economy of civilisational variety. Matching Cox's analysis with arguments around the varieties of capitalism, it becomes possible to find common ground between Marxism and civilisational analysis, where otherwise there is critical dissonance. An important point to reinforce is that civilisations diversify capitalism. The differences between the three paradigms and civilisational analysis are quite striking. Yet, as argued in the third chapter, there are criticisms to take on board around the shortfalls and limitations in contemporary civilisational analysis as well as several points of common ground.

\section{Structure of the book}

The opening chapter is concerned with contexts of contemporary civilisational analysis. During the course of Chapter 2, context gives way to content. Part I covers theoretical engagements with the problematics of civilisational analysis. Some are within the field, others are outside and represent alternative paradigms. By weaving through a critical survey of the field and elucidating relations with critical paradigmatic alternatives, I highlight gaps that, in turn, can be partly tackled in a model of inter-civilisational engagement. Part II continues that theme with substantive studies of inter-civilisational engagement. Readers interested exclusively in civilisational analysis as a field may elect to focus on the main part of Part I. Should readers wish to be acquainted with my model immediately, skip through to Chapter 4 and then either proceed with Part II or track back to Chapters 2 and 3. The text is amenable to different but equally valid reading strategies.

Chapter 2 launches Part I with a description of how contemporary civilisational analysis is related to the theories of modernisation from which it emerged. This is followed by a straightforward outline and assessment of the main perspectives in the field. Readers not familiar with Elias, Eisenstadt and Arnason can become acquainted with their perspectives, as well as encountering critical comparison and evaluation. This approach lays the groundwork for comparison with competing paradigms in Chapter 3. The method of comparison involves productive use of dissensus between paradigms to identify spaces for potential agonistic debate around common problematics and methodologies. Chapter 4 outlines inter-civilisational engagement as my innovation and basis for an alternative account. In this opening chapter, I have submitted the contention that civilisations are created through openness to engagement and encounters. The contention is further developed in Chapter 4 
across dimensions of migration, economic movements and connections, cultural engagement and the political reconstruction of civilisational models. Historical engagement entails dis-engagement also. The non-borrowings, dissonances and conflicts of civilisations are noted alongside cases of fragmentation and the collapse of large empires.

The outline of inter-civilisational engagement in Chapter 4 is broad in scope. I pepper the argument with examples to illustrate key points. One aim of Debating Civilisations is to sketch an extension of the comparative analysis of civilisations into its empirical gaps, which takes place in Chapters 5, 6, 7 and 8. A vital gap in contemporary civilisational analysis is the question of how civilisations are shaped by relationships to oceans and seas. With the rise of new perspectives and debates in oceanography and history - particularly maritime history - it is a good time to begin to address this lacuna. Chapter 5 examines inter-civilisational engagement in oceanic and thalassic civilisations. Since the Pacific as a civilisation of the ocean is almost entirely untouched in civilisational analysis, it is analysed in Chapter 6 as a specific substantive case study. Characterising the Pacific, with Epeli Hau' ofa (2008), as Oceanian civilisation, I argue on the basis of critical scholarship for a wider perception of indigenous civilisations and the range of historical experiences of dispossession, survival and revival. Case studies of modern cultural and political engagement and conflicts in the inter-civilisational region of Latin America underscore the context and legacies of colonialism. One of the cases is indigenous revival in the late twentieth century. Chapter 8 looks at the very different region of East Asia. Specifically, the chapter explores Japan's deeper connections with China and the West and how these have influenced cultural and political thought. The Conclusion is a précis of the overall argument with highlights of what is absent from civilisational analysis at large. At the very end I ask questions about the vocation of civilisational analysis in contemporary contexts of creation and transformation, which includes critical global problems of the human condition. I conclude that a scholarship of engagement can aid the critical purpose of elucidating transformations that stimulate lasting improvements to the human condition.

That is a glimpse into what Debating Civilisations attempts to articulate. There are several things the work does not do. No attempt is made to comprehensively represent the whole field of civilisational analysis. The critical paradigms engaged for counterpoints and intersections are not fully represented either. They are instead canvassed for what I believe to be the best points for constructive dialogue between different paradigmatic positions. Nor do I, as a sociologist and not a historian, attempt a global history of civilisations on the scale of Toynbee, Braudel or Fernández-Armesto, who perform majestic feats within their realm of expertise. What I leave out may 
make the argument vulnerable to criticism. However, I hope that the reader appreciates the inter-disciplinary spirit of bringing research in world history (and occasionally international relations) to problems from social theory and historical and comparative sociology. I favour an agenda of research into more interactive constellations that serve to underline how deep the level of connectedness is. The spirit of inter-disciplinary research is a sine qua non of any agenda of this sort. Historical and empirical inquiry has been pushing in this direction amongst numerous scholars who participate in multidisciplinary and inter-disciplinary research around civilisations. By outlining and problematising contemporary civilisational analysis, Debating Civilisations pushes the directions the field is tending towards beyond their current limits. 


\section{2}

\section{Currents and perspectives in contemporary civilisational analysis}

The previous chapter explores the context in which civilisational analysis revived in the humanities and social sciences. The key contention is that contemporary historians and comparative sociologists have posited integrationist, processual and relational images of civilisations. The three images apply to a more diverse range of viewpoints and perspectives than prevailed in earlier studies of civilisations in anthropology, archaeology, history and sociology. In this chapter, those images are profiled and interrogated. As a whole, the chapter aims to articulate the insights and limitations of each image by setting out how each shapes approaches to civilisations. Along the way, I pose questions about how open each particular image is to analysis of the creation of interactivity. The images are represented, respectively, by the work of Eisenstadt, Elias and Arnason. By exploring how each problematises, historicises and compares civilisations, the achievements of the contemporary scholarship of civilisations can be critically assessed. Once the current limits of the field are established and the critical counterpoints of competing paradigms assessed - the task of Chapter 3 - it then becomes possible to explore in greater depth an innovative way of framing the study of civilisations as inter-civilisational engagement, specifically migration, economic relations, cultural exchange and the re-creation of models of civilisation.

Given that post-war contexts laid the groundwork for the manner in which contemporary civilisational analysis would be shaped as a paradigm, more explanation on this period is required prior to examination of the three images. Before the twilight of the Cold War created conditions for the resurgence of civilisational analysis and the proliferation of perspectives, the marginalisation of inter-disciplinary and multidisciplinary studies of civilisations by the modernisation paradigm favoured the integrationist image and a more homogeneous field. Modernisation studies and area studies seized the spaces of Western history, sociology and politics that might have otherwise been occupied by civilisational 
analysis. Modernisation studies served Cold War objectives in the political climate of superpower rivalry, when the multidisciplinary and inter-disciplinary research agenda on civilisations could not (Cox, 2002: 139). In addition, civilisational analysis was at odds on key points with the socio-centric and methodologically nationalist mainstream, which in the post-war period was preoccupied with national histories and national societies. In highlighting the different developmental paths of many civilisations, a minority current of sociologists, historians and archaeologists resisted the trends in modernisation and area studies towards a dominant narrative of societal evolution. They did so from the margins of their disciplines. However, civilisational analysis - such as it was in the 1960s and 1970s - mirrored modernisation and area studies in other minor ways. The prevailing focus of the modernisation paradigm on society as a relatively discrete unit of research had an equivalent in civilisational studies. That equivalent lay in the conceptual cast of civilisations as discrete and internally transformative socio-cultural entities, rather than an interactive model of overlaps and interconnections of civilisations.

Modernisation theory reached its apogee in the context of the Cold War and the end of Europe's empires; that is, when the declining hegemony of the Western European powers became so clearly observable that it could no longer be denied. Decolonisation had two consequences in this respect. First, the rise of new nation-states resulted in a Third World contrasted with the wealthy and mostly Western First World. Second, new migratory movements emerged as a consequence of colonialism and were continued as repercussions of neo-colonial influence and interference in the affairs of new post-colonial states. For Britain, France, the Netherlands and then Portugal, new migrants from the former colonies gave their economies new sources of manual labour (Castles et al., 2014: 108-11). Together, both consequences served to undermine mainstream accounts of society and culture that neglected the diversity of civilisations, cultures and economies that defined the lives of a majority of humanity.

The Cold War also shaped modernisation theory's fortunes and fates. As the United States assumed leadership of the West, the burden of social scientific knowledge of new Third World societies was claimed for American modernisation analysis and made a policy priority of a succession of US governments from Truman through to Johnson. Large research grants from public funding bodies and private philanthropic foundations buttressed the development of modernisation studies led by Talcott Parsons, Edward Shils, Daniel Lerner and others. Under the influence of Parsons' sociological programme of study of evolutionary universals, modernisation theory developed a typology of modernity and tradition. Though it dichotomised many diverse societies, the typology also presupposed developmental potential for all societies whereby they would 
emulate a single model of modernity. The rapid shift from a world of empires to an international arena of nation-states put questions of convergence, reform and development on the agenda. Meanwhile it forced the Western social sciences to empirically confront the fullness of collective experiences previously subsumed by colonialism. Under these circumstances, attempts from within the modernisation paradigm to reconcile palpable divergence in developmental paths and diversity of societal forms with a meta-narrative of convergence made the paradigm unviable and unjustifiable (Wagner, 2014). Moreover, the modernisation paradigm found itself incapable of responding to new critiques by theorists in world systems analysis and dependency theory who posited enduring and new forms of domination. The critique of modernisation as a category demonstrated how inadequate the paradigm was for the functions it was called into being for.

The rise and decline of modernisation theory dominated the social sciences to such an extent that space for alternative paradigms was cramped. One way to think about the fortunes of civilisational analysis in these decades is in terms of 'generations', as Tiryakian (2004) and Arjomand (2014b) do. Comparative sociology and civilisational analysis can be divided into three generations of scholars. The first features in the opening chapter. The second generation conducted scholarship in the downturn of modernisation theory. Melko and Scott (1987) show how civilisational analysts of this generation sustained analytical schemes developed by Rushton Coulborn and Carroll Quigley after the Second World War. What did the schemes look like? Quigley's was typical. For Quigley, civilisations congeal around dynamics of expansion and accumulation (1979). The requisites of civilisation are order and law, long-distance trade, growth of cities, presence of a middle class, and literacy (1979: 266). In sequences of ascendancy, crisis and expansion, civilisations undertake either '(1) reform, (2) circumvention, or (3) reaction' via cultural and technological adaptation (1979: 144). The fates of civilisations are determined in such responses. Quigley's concept of seven successive stages of development attempts to reconcile history and evolution. When civilisations decline, resources for expansion come from succeeding peripheries. In this manner, the evolution of many civilisations tracks previous patterns: Greece emerged from the edges of Minoan civilisation, Islamic civilisation arose on the eastern periphery of classical civilisation, and so forth.

Classificatory models like Quigley's circulated within the International Society for the Comparative Study of Civilisations, founded in 1961 by Benjamin Nelson, Othmar Anderle and Vytautas Kavolis (Melko and Scott, 1987: 1-3; Robertson, 1992: 3). The Society sported high-profile intellectual leaders. Pitirim Sorokin was its first president. When the Society relocated to the United States in 1970, Benjamin Nelson took over the role. Other eminent scholars associated with the Society include Parsons, Toynbee, Immanuel Wallerstein, Kroeber, Andre 
Gunder Frank and Marshall Sahlins. High-profile figures did not result in greater impact in the early years of the Society, despite the energetic efforts of its founding generation. However, according to available accounts, the Society has been a lively debating society. Its members have concerned themselves with methodological and epistemological controversies, analysis of components of civilisations and acting as a clearing house of definitions and perspectives. In the course of the Society's life, many scholars continued in the integrationist vein of the histories of the interwar years. With the passage of time, varying aspects of the vitality of civilisations have become more prominently represented, and the field has become more inclusive of different indices.

Such was the second generation. For the third generation, Arjomand nominates Marshall Hodgson, Nelson, Eisenstadt, Donald Levine, Edward Tiryakian, Eliezar Ben-Rafael, Arnason, Bjorn Wittrock, Luis Roniger, Bernhard Giesen, Sheldon Pollock and Georg Stauth (Arjomand, 2014b). Eisenstadt, Levine and Tiryakian stand out as reconstructed modernisation sociologists who lived through its peak era and who have subsequently adopted post-functionalist positions. Also, the critical dialogue they engaged in with modernisation studies conditioned their subsequent trajectory. If international relations scholars were added, Peter Katzenstein would be in the lead, with Brett Bowden, Martin Hall, Patrick Jackson, Robert W. Cox, Sadik Unay, Muzzafer Senel and Pavlos Hatzopoulos following. Others could make the list, including the proponents of the call for a Dialogue of Civilisations, such as Fred Dallmayr, Michalis Michael and Fabio Petito.

The group identified by Arjomand are defined by their problematisation of early-twentieth-century perspectives on civilisations and a high level of debate about new propositions. International exchange around different theories, applications of methodology and epistemology and substantive findings have driven contact and dialogue. Eisenstadt's coordination of a large multidisciplinary network in coherent research around Axial civilisations, multiple modernities, Islam, collective identities and the public sphere put him at the epicentre at different times. The same is true of Tiryakian and Arnason at different points. Collaboration and debate have been watchwords in international relations also. A common scholarly public engaged through conferences, publications and personal communication has added to a larger 'conversation' around contemporary civilisational analysis. Researchers who foreground early modernities cooperated in a similar manner. That particular research path seems to have petered out after 2005, however, with a lack of consensus about 'when' early modernities coalesced. The field came to be dominated by problematics of multiple modernities and process-based comparative analyses. The perspectives of Eisenstadt and Elias are the most representative of, respectively, integrationist and processual 
images of civilisations. The most prominent image in Arnason's work is the relational one, the current closest to the model of analysis expounded in Chapter 4 and Part II of the current work. A critical précis of Eisenstadt's and Elias's chief contributions shows gaps in their models of civilisational sociology, as well as, in Arnason's case, directions for conceptual reconstruction.

\section{Eisenstadt's comparative civilisational analysis}

Eisenstadt's leadership in the revival of the overall field makes him a seminal figure. In the 1990s, he spearheaded major research enterprises defining the agenda for contemporary civilisational analysis. Along with Tiryakian, Eisenstadt steadily changed his substantive focus to civilisations as part of 'a long march of reckoning with modernisation theory' (Salvatore, 2006: 279). In this shift, his comparative sociology entailed critical continuity of an integrationist image of civilisations. As a result of that process, Eisenstadt and Tiryakian came to emphasise social dynamics and the study of empires, modernities and civilisations in place of 'society' as the unit of analysis (Eisenstadt, 2000a; 13-17; Tiryakian, 2004). How does Eisenstadt define civilisation? In one place he describes civilisations in the strongest integrationist terms possible, posing them as discrete 'areas and sequences' (2001: 1915) in a conception 'very close to, but distinct from' naming them as 'socio-cultural units' (2001: 1916). In fact, he has other answers to the question also. However, there is one clear statement made in a programmatic essay that seems the most representative. Civilisation is 'the combination of ontological or cosmological visions (visions of trans-mundane and mundane reality) with the definition, construction, and regulation of the major arenas of social life and interaction' (2000b: 2). As a programme of research into cultural ontologies, he organises his comparative sociology around three problematics: Axial civilisations, multiple modernities and the civilisation of modernity (Delanty, 2004: 393). Each is examined sequentially here.

Chronologically, Axial civilisations came into view first. Picking up on insights into the significance of human evolution in this era from Karl Jaspers, Benjamin Schwartz and Eric Voegelin, Eisenstadt extended the problematic of the Axial Age beyond the first millennium BCE (Eisenstadt, 1986). Following Martin Buber's proclivity for multidisciplinary investigations into creativity, he coupled philosophical notions of axiality with Weber's comparative sociology of worldly orientations and came up with 'Axial Age civilisations', in which a creative tension between transcendental and mundane orientations crystallised. Put simply, the first signs of philosophical reflection on the nature of the cosmos, matter and materiality and being, and social, economic and political life emerged across 
Eurasian societies during this time. In different Axial civilisations, cultural ontologies crystallised with new kinds of reflexivity. There was greater scope in these new social orders for interpretation and questioning about the terms of human conduct and the norms of social life. Doctrines and ideologies were consolidated as a result of the epistemological breakthroughs made. In other words, particular transformative ideologies were instituted along with the means of continuity of knowledge, new forms of collective memory and identity. Knowledge could be written down, reproduced, passed on and passed down, its contents critiqued and its categories and second-order questions subjected to debate. In all, knowledge could be consciously transformed.

Eisenstadt renewed interest in questions of the Axial Age. His original contribution was to assemble specialists from history, sociology, classical studies, linguistics, philosophy, religious studies and sociology to develop a collaborative multidisciplinary research programme that could set civilisation as the consummate plane of all social orders (Arnason et al., 2005; Eisenstadt, 1986). For Eisenstadt, the gulf between the ontological conception of higher and lower orders of existence produces the conflicts of social life that become the dynamics of development and the basis for long-term developmental paths. A sharp focus on transcendence and the world religions defines his approach to civilisations in this register of analysis. The Axial paradigm thus, refined, becomes a different lens through which to view and understand problems familiar to neo-Weberian sociologists: structural differentiation; coalescence and agency of intellectual elites; access to and participation in the decision-making of states; religious schism and movements of protest; and social action shaped by the balance of worldly and transcendental religious ethics (Eisenstadt, 2002a: 256-64).

Questions about the historical sociology of Axial civilisations surfaced in the 1990s and prompted ongoing discussion (Arnason, 2015; Arnason et al., 2005; Bellah and Joas, 2012). There is no space here to explore the myriad paths of the subsequent debate. But one criticism can be foreshadowed. At no time has any systematic attempt been made to bring other non-Axial zones into the picture (with the one exception of Japan) to defend the Axial civilisations thesis. If that step were systematically taken, then Eisenstadt's conception of civilisation and its dimensions would be further problematised and questions would emerge about modern empires as states. To take that step would require reformulation of the initial typology of Axial civilisations in order to incorporate major societies for which the crucial developments occur after the Axial Age. But this would raise further doubts about the categories of transcendental and worldly orientation to different civilisations across Eurasia.

The second problematic is his concept of multiple modernities (Eisenstadt, 2000a). Eisenstadt has not been alone in infusing the concept of modernity 
with a consciousness of multiplicity. Gaonkar's alternative modernities (1999), Jan Pieterse's 'new modernities' (2010) and Therborn's four roads to modernity are different projects on the many forms of modernity (Therborn, 2003). One clear benefit that can be claimed for pluralism is that it avoids many of the pitfalls of theories that evoke a one-world scope of analysis, such as world systems theory and cruder specimens of globalisation studies. Immediately, an analytical difficulty emerges (Wittrock, 2000): how many modernities can there be? In response, some critics of the idea of multiple modernities have backed a model of global modernity while recognising real variation (Domingues, 2012). Eisenstadt's perspective is distinguished in this field of unfolding pluralities by the manner in which he delimits the number of modernities by the cultural ontologies of many civilisations. For Eisenstadt, if there is a special source of cultural ontologies, it is the world religions. In other words, his answer to the question of 'how many modernities?' is that the world religions define the number of cultural ontologies, thereby demarcating the multiple modernities.

As multiple modernities are conceived as spatially distinct entities, one would imagine that there would be clear continuities between the research programme around Axial civilisations and the paradigm of multiple modernities. Commenting on the continuities, Knöbl argues that path-dependence is implicit in identification of core premises of modernity with the Axial tensions laid down in antiquity (2006a: 219-20). However, there are two crucial discontinuities between the literature on Axial civilisations and the research into multiple modernities. The discontinuities entail a problematic methodological shift. Revisionist histories of axiality emphasise inter-connectedness, while the paradigm of multiple modernities structures studies of separate constellations (Wagner, 2012: 153-4). The linkages that were formative for civilisations of the Axial Age are diminished in the separation of constellations of modernity. This is a critical point of distinction between integrationist and relational approaches, and also the model advocated in these pages of inter-civilisational engagement. Observing the discontinuity between the Axial civilisations and multiple modernities theses, Wagner urges advocates of multiple modernities to "place less emphasis on the separate and different origins of the cultural programmes, and consequently some diversity between contemporary modernities, and ... focus instead on the long-term interconnections in world history' (2012: 154). Wagner isolates an underlying shift from inter-connection to detachment in the work on civilisations, which is unquestionably an obstruction to clarifying questions, debates and findings.

This is one issue and it is a crucial one for the purposes of the current argument. In an effort to avoid Eurocentrism - a second issue - Eisenstadt specifies heterogeneity, divergence and polycentricity in social formations as the principal objects of analysis (Eisenstadt and Schlucter, 1998). What results is a qualified pluralism 
that struggles with the questions of the origins of modernity. The question of which modernity and which programme emerged first is a vexing one from the outset. In setting bearings for the multiple modernities paradigm, Eisenstadt and Schlucter affirm that the balance of diffusion of the original cultural programme of Europe and indigenous elements of creativity in other modernities is an empirical question. In their words, it is essential to treat the developmental dynamics of each civilisation 'not only in terms of approximation to the West but also in their own terms' (1998: 7) in order to adequately demarcate the multiple modernities. This might open the door to investigating the linkages that blend external and local models of thought, polity, economy and organisation and how forms of power are interspersed throughout different dimensions of instituted social life. Yet, at the same time, Eisenstadt reiterates the argument that Europe is the first modernity with the prototypical cultural programme. An alternative to notions of globalisation and global modernities forms with this qualification, yet it is not one that captures the relational character of the imaginary institution of multiple social formations and civilisational constellations. To be sure, Eisenstadt's framework is premised on acute awareness of pluralities. Rejecting theses on hybridisation, Eisenstadt focuses on 'how different collectivities define themselves in different ways with respect to the common problematic of modernity' (Delanty, 2004: 397). He sees this as a continuous reconstruction of the West's premises in particularly innovative developments. Other modernities have constantly redeveloped the premises of European modernity, starting with the Americas (Eisenstadt, 2002b). But the invisibility of connections between formations of modernity is too prominent to disregard. The partition of the units of analysis in the multiple modernities paradigm is at the root of this. A tension therefore exists between the commitment made to plurality and the a priori premise that the West's cultural programme is pre-eminent. Post-colonial sociologists believe this to be an unacknowledged Eurocentrism that structurally conceals the interconnectedness of social formations (Bhambra, 2007: 56-79; Boatcă and Costa, 2010; Patel, 2013). They pinpoint the isolation of the units of analysis, as others have also. The a priori assumption of geo-cultural unities characteristic of area studies scholarship is a very clear difficulty for theorising multiple modernities. The explicit agenda of multiple modernities has to compete with other models of plurality in modernity. If it is to have force in a crowded field of explanations, it will need to redress the problems raised here. It is hard to see how this could be done without returning to the problematic of connectivity of civilisations and the connectivity of modernities.

This touches on Eisenstadt's third problematic, which he launched later in his career. His notion of the civilisation of modernity flows from his singularisation of the Western European modernity as the original programme (Eisenstadt, 
2002b: 28) and its self-transforming expansion into the Americas, Central and Eastern Europe, and then to the world at large (Eisenstadt, 2004). In his theorisation of the civilisation of modernity, his perspective edges closer to the globalisation paradigm. Through multiple reinterpretations and the development of institutional patterns from those reinterpretations, Western modernity grew to become a world 'civilisation of multiple modernities' (Arjomand and Tiryakian, 2004b: 3). From where Eisenstadt stands, it looks as though the elaboration of the Axial tensions in the modern age is leading to an ecumenical civilisation of modernity in which traditions are mobilised as interpretive resources. The civilisation of modernity's Great Revolutions are the bridges from the axialities previously theorised by Eisenstadt and others to the multiple modernities, which are instituted in the world regions formerly dominated by Axial civilisations. Democratic, radical and totalitarian solutions to core modern problems all have roots in the Axial tensions reinstituted in the Great Revolutions (Eisenstadt, 2004), suggesting path dependence of the kind highlighted by Knöbl. Furthermore, some civilisations - in reaction to the civilisation of modernity - seem to Eisenstadt to be generating new and self-evidently authentic universalisms.

On these points, Eisenstadt's third problematic resembles a response to the globalisation thesis, rather than a dissention from it (Spohn, 2011: 293-7). His conception of the 'civilisation of multiple modernities' turns on a unique dialectic of universal and particular consciousness compatible with more complex renditions of globalisation. Admiring this image of globality, Robertson highlights how Eisenstadt's sociology renders 'the importance of the Axial Age as foundational with respect to ... the multidimensional globalization process' (Robertson, 2011: 308). Consciousness, a set of legacies from the Axial Age, vacillates between globality in different dimensions of social life - 'the world scene' (Robertson, 2011: 309) - and distinctive modern civilisations. The contrast is so great that it did not take much for Katzenstein to relabel the notion as the 'global civilisation containing multiple modernities' (2012b: 226). Compared with Katzenstein's strong conception of interaction between civilisations, Eisenstadt's contemporary civilisational analysis looks to have illuminating moments, but lingering difficulties in explanation.

Katzenstein's assessment of the relevance of the theory of multiple modernities alludes to the third problematic in Eisenstadt's oeuvre. The question of the 'civilisation of modernity' that Eisenstadt poses forces contemporary civilisational analysis to gain some purchase on issues of the present and prospects for the future. On the whole, it appears that comparative sociology has more difficulties grappling with civilisations in the present than perspectives in international relations, which focus on the twenty-first century (Hall and Jackson, 
2007; Katzenstein, 2010a, 2012a; Unay and Senel, 2009). Eisenstadt's specific attempt to reconcile the crystallisation of reflexivity in Axial civilisations with modern consciousness in the civilisation of modernity is the least well-developed and least convincing area of his comparative sociology. Indeed, this line of argument in civilisational analysis equivocates on the relationship of modernity to civilisations. As Arnason points out, Eisenstadt seems particularly undecided between attribution of modernity to adaptation of the Western model of selftransformation and a supra-cultural civilisation of modernity (2003: 173-4). Eisenstadt's explanation of the civilisation of modernity struggles to establish lineages of modern reflexivity going back to Axial articulations of transcendence, so much so that he hypothesises a Second Axial Age to describe modernity. The most that can be achieved is identification of comparable tensions defining the social and cultural premises of varying social orders. The tensions produce openness, antinomies and fragility as democratic visions of modernity compete with totalitarian and Jacobin ones (Eisenstadt, 1999a). Both visions draw on civilisational legacies, as well as the trans-national cultural and political programme of modernity. A global civilisation of modernity is therefore both less and more than the civilisations that precede and coexist with it (Arnason, 2003: 324-5). On one hand, modernity as a supra-civilisational imaginary erodes civilisational legacies under the logics of capitalist globalism and rationalisation. On the other hand, the social and cultural premises of civilisations dynamically effect the very cultural and political programme of modernity. Eisenstadt did not clarify the exact nature of the trans-national civilisation of modernity. Where does this leave the world religions, which are unquestionably modern in his view? What is the relationship to his problematic of multiple modernities? The questions are not adequately resolved in Eisenstadt's later writings. To reformulate them as the productive tensions of modernity leaves only questions for others to take up.

\section{Eisenstadt's comparative civilisational analysis in retrospect}

A conflation of religion and civilisation lingers in Eisenstadt's comparative civilisational analysis. The imprint of Weber's sociology of religion is still visible, even if some of the blockages in the Weberian sociology of religion have been overcome (Katzenstein, 2010b: 15-17; Spohn, 2006: 14-16). The world religions originating in the Axial Age, in Eisenstadt's view, animate civilisations as changing traditions in the modern world (Domingues, 2012: 20-3). By sharpening preliminary insights made by Weber, Eisenstadt sets religion at the heart of the civilisational premises of order. Meaning is then constructed as an overgeneralisation of Axial hypotheses to a variety of developmental patterns (Arnason, 
2003: 236-7). Ultimately this risks the charge of culturalism with which critics pummel civilisational analysis. Moreover, religious movements and theocratic elites are accorded especial agency as a consequence of the defining influence conferred on religious visions. A path-dependent logic of development is implicit in the connections made by Eisenstadt between the constitution of Axial tensions and current-day multiple modernities, yet the contingent processes that facilitated continuity are not adequately established (Knöbl, 2006a).

Eisenstadt's estimation that religion furnishes meaning at the roots of human existence as well as informing civilisational orientation and political action is an influential argument amongst his many interlocutors. However, the anomalies of the Axial Age paradigm are still hard to wish away. The civilisation that most closely integrates religious and civilisational coherence is Islamicate civilisation, which was not included in early debates about axiality. When religious coherence is overstated, other aspects of civilisational development can be overlooked. A few examples help illustrate the point. For instance, the logics of imperial expansion are not adequately related to successful campaigns of proselytism (Spohn, 2010: 59). Nationalism, which should figure as a modern feature of civilisations, stands neglected (Arnason, 2003: 61-2). In Eisenstadt's perspective, for instance, religious traditions constitute modern patterns, rather than resisting them - an important and well-argued insight. However, much the same can be said also for scientific, political and philosophical traditions that are differentiated from religious traditions. For example, the imaginary significations that furnish Western societies with conceptions of materiality as pre-classifications of the biosphere are indispensable to the institution of the sciences. The perception of materiality had origins in scepticism, materialism and idealism in the Mediterranean's antiquity. Another reference point, ancient kingship, embodies a nucleus of sacred and political power in the historical studies of civilisations that inform Eisenstadt's theory. But treating the problem of political power in the modern world is a different matter and one that demands a wider span of imaginary reference points. On the whole, as Arnason has more recently argued, the problematic of power as constitutive of civilisations is neglected in Eisenstadt's explanatory framework (Arnason, 2015).

Related to Eisenstadt's construction of civilisational analysis out of the sociology of religion is an under-estimation of the interaction of civilisations, especially in the constitution of multiple modernities. Significant insights from the published research in early modernities were not fully carried forward into the multiple modernities paradigm. Early modernities outside Europe emerged from processes of instituting inter-connections through which they co-instituted themselves. Articulation of trans-regional and consubstantial connections in this body of research is based on unequivocally post-Orientalist perspectives 
(Katzenstein, 2010a: 16). Moreover, where civilisational analysis continued to work on this problematic - particularly on Eurasia-wide processes (Arnason and Wittrock, 2004) - the balance of connections, divergences and breaks continued to be debated. The opportunity to empirically elaborate relationships between early modern linkages and latter-day figurations is lost in the absence of comparison of modernities across historical time (Wagner, 2012: 64-73, 2014: 294-5).

In this section, I have provided an obligatory summation and evaluation of Eisenstadt's key problematics. He played an indispensable part in reviving and sponsoring civilisational analysis. For this reason alone, his work deserves to be considered and here it is critically discussed as representative of the integrationist image of civilisation. The processual image is a contrast that puts into question important aspects of the projects led by Eisenstadt. Norbert Elias's historical sociology is a way of marking out some contrasts with Eisenstadt's integrationist analysis.

\section{Elias and the civilising process}

The premise of Elias's scholarship of civilisations is that there are civilising processes, rather than civilisation per se. Elias's historical sociology of the civilising process reconstructs the emergence of social constraint towards self-constraint in observable daily habits and behaviour over the course of the long European Middle Ages (Elias, 1978, 1982). Part-trained by Alfred Weber, he uniquely reformulated Max Weber's sociological categories. He then uniquely historicised them. In doing so, he produced a genealogy of the transformation of violence, which addressed the same problem of the brittle threshold of civilisation that Freud did, but which brought in sociological method and historical sensibilities. He applied a theory of 'the civilising process' to the very long temperament of violent and uncensored behaviour. Elias crafted a historical sociology of the advancement of a threshold of shame that paired the uneven civilising of affects with the coalescence of modern power (Rundell and Mennell, 1998: 25-7). For Elias, forms of civility developed in concert with two tendencies. First are the centripetal and centrifugal movements in the figuration of power, or the impulses towards centralisation or devolution of the state and its agents. In other words, the temperament of general behaviour occurs alongside the expansion of taxation, confinement of the legitimate use of violence to military forces and the creation of rationalised administrative organisations. The second tendency is the monetarisation of economic life. In urban bourgeois culture, trade, the division of labour and the use of money, outward expressions of tempered behaviour supplanted the combination of explicit violence with the structuring of economic 
life. Moreover, monetarisation enabled large-scale taxation, a precondition of centralised governance. Each tendency was dependent on the other.

The emphasis on process was not all. He developed a relational notion of power well before Foucault or Bourdieu did (Arnason, 2015). Power is not a quantified capacity waiting to be seized, but rather is intrinsic to the interaction and conflict of groups, classes and elites. State monopolies on legitimate coercion and taxation did not emerge through the accumulation of power, but rather through movements in the balance between groups, classes and elites in the state and in civil society. Though the European civilising process produced, over the long term, a greater degree of societal inter-dependence and a relative internal pacification of violence, Elias is quick to add that this is not the outcome of a linear process but an uneven and fragile one of group, class and elite struggles and conflicting rationalities. Throughout his life, furthermore, he worked on a theory of the 'decivilising process' whereby the collapse or suspension of constraints can be explained. Power fluctuates and is contingent for Elias, much as it is also for Castoriadis.

The unique appeal of his paradigm to current-day sociologists lies in the bond between modes of civility and patterns of state formation and the very longterm processes through which the bond emerged. Known also as figurational sociology, it gives an account of the structuring (or 'figuring') of behaviour and agency by the civilising process. There is one further important and relevant element of Elias's figurational sociology. He tracks the emergence of a European consciousness of civilisation (see also Bowden, 2007). According to his account, Europeans had - in a process of collective amnesia - eliminated all memory of the civilising process by the nineteenth century. In its place sat an ideological notion of civilisation which was the self-consciousness of the West:

It sums up everything in which Western society of the last two or three centuries believes itself superior to earlier societies or 'more primitive' contemporary ones. By this term, Western society seeks to describe what constitutes its special character and what it is proud of: the level of its technology, the nature of its manners, the development of its scientific knowledge or view of the world, and much more. (Elias, 1978: 3-4, emphasis in original)

Notwithstanding this important insight, Elias did not incorporate cultural factors into his explanation of the figuration of social structures or his theorisation of power. As far as the current argument is concerned, there is an even more significant gap. If Elias's figurational sociology of the civilising process does well in scrutinising endogenous and intra-societal dynamics of state formation and the taming of routine violence, it did not probe any dimension of the interaction 
of civilisations. None of the main phenomena he deals with are considered as coextensively instituted through the deep engagement of civilisations. In particular, the expansion of empires and variety of imperial orders finds no place. Yet, colonialism denotes a whole other side to violence and warfare. Europe's modern empires were two-sided states, being colonial and more or less dictatorial abroad and national and amenable to democratic pressures at home. Might not the impulses to restraint at home be counter-balanced by releases of violence in colonial environments? Whatever the answer to that question, outbreaks of imperial violence call for explanation, whether they take the form of repressive violence or inter-state wars. Other perspectives in studies of international relations focus on problems of international conflict and the exercise of kinds of 'soft power' - as, for instance, in the establishment of the international standard of civilisation (Gong, 1984). Gong's analysis would be relevant for an international elaboration of Elias's theory not because states were faithful to the international standard (as they were often not), but because of the normative threshold it set. It is relevant in its positive appropriation by nationalist movements seeking to end colonialism (Duara, 2001). They turned Europe's universal standard of civilisation and its normative tenets against Europe's global empires. Robertson shows that Elias's perspective could be pressed into partnership with Gong's (Robertson, 1992: 116-25). Even so, the absence of the international arena from Elias's analysis is a stark omission and, in this respect, his results are context-bound and thus tacitly Eurocentric (Arjomand, 2014b: 34). Where it traverses any of these topics (e.g. war) it does so in a one-sided fashion without clarifying vital exogenous influences.

None of this is to claim that the theory of the civilising process is closed to revision or internationalisation. Since the theory of the civilising process does not hypothesise civilisational unities in its examination of the impulses and logics of state formation, Elias's notion of power could be corrected and marshalled in a different methodology and with a different analytic. Different results would emerge, without attenuating his useful and original insights. Moreover, it is quite clear that there are other figurations of power with distinct civilising processes. Framed as international studies, comparative analysis can be carried out from within Elias-inspired figurational sociology. Studies of Singapore, Japan and the United States have done just that (on Japan, see Karlin, 2014). The extent to which imperial contexts of power and inter-civilisational interaction could be worked into figurational sociology remains to be seen.

Arnason is open to the examination of civilising processes in international contexts (Arnason, 2004, 2015) and he gives careful consideration to Elias's model and methodology. Arnason's version of civilisational processes brings valuable studies of inter-civilisational encounters to bear on some of the questions 
raised by Elias. A compelling interest in Benjamin Nelson, Marshall Hodgson and Williams McNeill took him towards a relational image of civilisations. As a practitioner of this approach, Arnason is a link between the third generation and the problematics of earlier comparativists, particularly Weber and Durkheim and Mauss. Since readers are less likely to be familiar with his work, the presentation of his ideas is longer. As he exemplifies the relational image by extending the findings of Nelson and Hodgson in particular, his work is an important precedent to the version of civilisational analysis argued for in Chapters 4 and 5 .

\section{Arnason's core questions}

Arnason's civilisational analysis matters for two reasons. To start with, his work matters as a point of orientation and innovation for the notion and historiography of inter-civilisational engagement I articulate and defend in Chapter 4 and Part II. In the remainder of this chapter, I outline Arnason's core questions and mark the shifts that have occurred in his approach. Having charted his oeuvre, I critically canvass perceived gaps in order to push his reconstruction of intercivilisational encounters towards an alternative conception of interactivity and connectedness.

As a second reason, Arnason's work matters in its own right for its relationship to the field. Arnason goes further than any other comparable thinker in reflecting on civilisational theory as a mode of historical and sociological analysis. The discipline of philosophy helps by raising key second-order questions of the field and paving the way for a hermeneutical focus on understanding. Through critique of enduring and unresolved conceptual difficulties and epistemological gaps he arrives at a critical assessment of comparative studies of civilisations and concludes that it is a paradigm-in-the-making capable of revising its theoretical formulations in light of empirical and comparative findings (2007). Arnason's own contribution ranges from creative theoretical fusion and detection of untreated empirical problems to theoretical and historical controversies and dilemmas. In a self-stylisation of his approach, he dubbed his 1990s research on Japan 'postWeberian' (1997a). The phrase appears less often later in his writings, but three premises remain in his meta-theoretical trajectory from that point: multidimensional analysis is the key to understanding 'civilisation' and 'civilisations'; culture and power are inter-related; and civilisations are created through intercivilisational encounters. Across the course of the development of his thinking, he has combined this early trajectory with a historicist position of being strongly 'for history', a contextualist position of being 'for regions', and a permanently provisional attitude towards theoretical, historical and empirical questions. 
Moreover, he develops a methodology best described as post-transcendental phenomenology, centring on a phenomenological concept of 'world' fashioned over the course of an intellectual career (see Adams and Arnason, 2016). With this methodology, he reconstructs Eisenstadt's 'cultural ontologies' via a reinterpretation of Weber as diverse cultural and inter-cultural articulations of the world. In his chief work Civilizations in Dispute, his agenda for ongoing inquiry is organised around the cultural, political and economic constitution of civilisations; in his words, 'meaning', 'power' and 'wealth' (Arnason, 2003). With this interpretivist and historicist agenda, he addresses four fundamental questions. What is civilisation? How are civilisations constituted culturally, politically and economically? In what ways are civilisations related to regions? How do historical contexts shape different civilisations?

The first question is foundational to the others and is the pretext of a turn to a relational image: how should 'civilisation' be conceptualised? The strong culturalist lineage in civilisational analysis should be assiduously avoided in answering the question (Arnason, 2011b: 109). Strong versions of 'identitarian' culturalism found in Spengler and Huntington uncritically reproduce images of closed civilisations. Following Dumont and the phenomenologists Jan Patočka and Maurice Merleau-Ponty, Arnason prefers inquiry based on interpretation and understanding over strong causal models of explanation produced in identitarian versions (2003: 65). Urging problematisation of conceptions that postulate the internal unity of civilisations, Arnason expounds a 'stronger emphasis on and better understanding of differences and differentiation' (2003: 5). It is, for example, noticeable that some civilisations generate more adaptable collective identities, while others are better at singularising internal cultures. Arnason's position lends credence to the conclusion that any hard-set integrationist images will do little to illuminate actual patterns. In fact, thorough and open-minded research on civilisations and their contexts should put into question 'a persistent tendency to take Western patterns and presuppositions for granted, rather than to re-think them in the light of comparative analysis' (1997a: 5).

With two further moves Arnason's position is set at a further distance from the integrationist image. First, borderland zones, moving frontiers and shared regions should be incorporated into a more capacious conception of civilisational dynamics (2007). In turn, this opens the way to an understanding of regionality with wider potential applications. How civilisations 'exist' in spatial terms becomes a problem of how regional frontiers effect collective identities. Moreover, the spatial existence of civilisations is also a problem of how civilisational dynamics influence regional patterns (Arnason, 2003: 31). A more capacious geography of civilisations that accounts for interstitial geographical spaces has the potential to resonate with other perspectives in history and post-colonial 
studies and to discern patterns of interaction and connection. Second, Arnason's notion of civilisational patterns portrays civilisations as more complex and diverse than previously believed (2004). Durkheim and Mauss's characterisation of civilisations as societies with a family resemblance is not sufficiently pluralistic for Arnason's liking (2003: 296-304). Too many world regions are multicivilisational to take Durkheim and Mauss's formulation at face value. With the notion of civilisational patterns, Arnason aims to better understand a host of civilisational components: multiple political centres, the organisation of imperial states and regional spheres of cultural or religious reach.

With these two moves Arnason turns to dimensions of power, meaning and wealth - the second question - in order to chart the encounters of civilisations. Arnason's particular non-functionalist understanding of power de-reifies this core concept. 'Power' is not a 'thing' that varies according to the quantity that a state, ecclesiastical or economic institution holds. For Arnason, power is constituted and mutates according to shifting patterns of culture. To be more precise, patterns of power and patterns of culture interact and define each other in a variety of ways. One civilisational complex will exhibit one particular set of patterns of culture and power. Twentieth-century Russia is an example (Arnason, 1993). Soviet power was influenced by historic interaction with both Central Asian and Western states, and with Western revolutionary traditions. Other constellations are quite different and reflect other sets of relationships of culture and power. As a civilisation, Japan, as a separate instance in a different context altogether, actively 'singularises' its model of power in encounters with a regional Sinic civilisation (Arnason, 1997a). Confronted with variety, the job is to judge on the basis of evidence compiled and scrutinised. According to Arnason, conflict, protest and movements are often found at work in shaping intermingled patterns of power and patterns of culture. A wholesale transfer of a set of patterns of power and patterns of culture is rarer, however (Arnason, 2003: 189). Institutions of power may be mobile, particularly with modern empires that trans-nationalise military force and administrative reach, while constraining the spread of cultural values of the core. In some civilisations, the creation of power occurs through expansion of cultural institutions. For instance, the extension of Islamicate civilisation throughout South-East Asia influenced state formation particularly in sixteenthcentury Indonesia and Malaysia, miles from the armies of the Safavid Empire.

Arnason analytically separates 'meaning' from socio-culture. He posits historically received 'multiple constellations of meaning' (2003: 294) or (following Nelson) 'cues' (2003: 149-57), which contour the cultural ground for interpretation, communicability, conflict, dissonance and reflexivity. 'Culture' fluctuates more than many other civilisational analysts think, according to Arnason. 'Cultural problematics' as horizons of meaning may frame political, economic 
and cultural interpretations, but they are not free-floating (2007). Nor are they entirely unstructured or non-structuring. A civilisation's potential for intercultural experiences and reflexivity is tested by encounters with other bodies of meaning. Two features distinguish his analytics of meaning and socio-culture from Eisenstadt's cultural ontologies. First is the heavy emphasis on the imaginary as a horizon of meaning. Through his theoretical reconstruction Arnason dissociates himself from neo-Weberianism (if not from Weber himself). Second, his post-transcendental phenomenology produces a hermeneutics of culture that minimises the difficulties of cultural determinism (Adams and Arnason, 2016). Cultures appear more dynamic, diverse and contingent, but are still contained by the imaginary.

'Wealth' is constituted on a more homogeneous plane, and thus it tends to exhibit tendencies towards integration more readily. Following the tracks of Braudel's history of capitalism, networks of wealth can be traced to the early modern expansion and intensification of trade. According to Arnason, any perspective on wealth generated from within civilisational analysis should recognise the novel problematisation of economic practices associated with modern capitalism. The processes involved with capitalism's institution were certainly not culture-free (much less meaning-free), even though they were trans-civilisational. In the twentieth century, emerging varieties of wealth are demonstrably more diverse than many political economists have thought. Theories of the "new spirit of capitalism' mark out different varieties that precondition the domestication of capitalism in national and regional contexts (Arnason, 2005).

The intention of Arnason's multidimensional model is to produce a notion of a civilisational complex flexible enough to accommodate diverse institutional environments, cultural frames, geographies and forms of conflict. It leaves room for the legacy of inter-civilisational encounters to enter the picture. However, the composition of power, wealth and meaning in a specific context also structures how interactive a civilisation is in relation to others. This is an important presupposition for historical inquiry and I carry it over into Chapter 4 and Part II, in which inter-civilisational engagement is theorised and specific world regions are explored. More generally, I regard inter-civilisational encounters as an aspect of Arnason's model of civilisational analysis that is amenable to further revision.

Before proceeding to Arnason's historicist and regionalist outlook, some points of further distinction from Eisenstadt's comparative sociology seem apposite. Arnason's reconstruction proceeds by responding to the pressing questions put by Eisenstadt about modernity and civilisations. Differences surface, however. Where Eisenstadt is fixed on reconciliation between the body of research into Axial civilisations and the paradigm of multiple modernities, Arnason is far from confined by that problem. Arnason's option of a 
historicist treatment and critique of the Axial Age debate means that he can handle Axial civilisations as contingent on their historical age and makes no presumptions about the lasting impact of breakthroughs to reflexivity. The rest then becomes an empirical question and can be left to the results of ongoing research. No archetypes prefigure the unfolding of particular modernities in relation to formative civilisational legacies. The ambivalent turn to plural modernities and civilisations inaugurated by Eisenstadt and others in the 1990s is sharper in Arnason's programme because he is not constrained by a typology of macro-sociological formations (Wagner, 2012: 67-8). Moreover, he properly exercises historicist concerns by focusing on successive modernities, alternative modernities and possible series of civilisational developments in one geographical zone, rather than multiple modernities in an integrationist vein. Historical contingency is accorded more respect in his picture of civilisations by his introduction of hermeneutics into civilisational analysis (Adams and Arnason, 2016: 181).

Over time, Arnason's plea for historical perspective has grown, the third of his key questions. The fact that Arnason turns to specialist histories repeatedly to validate his theoretical suppositions shows how strong his quest for historical understanding is. Electing to count as one of a number 'who want to see civilisational analysis develop as a branch of historical sociology' (2014: 180), he is positioned against the uncritical use of typologies to evade careful research. Few generalisations can be made ahead of systematic research, and constant selfreminders of contingency in history are important when it comes to identifying empirical regularities in social formations, states or civilisations (Knöbl, 2011). On this view, the paradigm remains quite incomplete without a properly historical foundation.

On the back of this historical sensibility, Arnason's projects have headed in an increasingly historical direction. The projects can be grouped into three types of historical sociological analysis. The first type comprises investigative prolegomena into South-East Asia (1997b) and Byzantium (2000). The prolegomenon qualities of the two studies could be charged with failing to bridge the gap between theory and empirical application, but then this is only to bear out his point that much careful history is needed to validate civilisational arguments (Spohn, 2011: 29). The second type of project goes further. In edited collections of essays by specialists in Islamicate civilisation, Greece and Rome, Arnason and others prosecute key debates and air fresh arguments about historical and current assessments of the significance of major civilisations (Arnason, 2011a; Arnason and Murphy, 2001; Arnason et al., 2006). Arnason's own full-scale studies are the third type of project. He situates Soviet modernity in relation to different political traditions (1993), and Japan in relation to East Asia (1997a, 2002). 
The monographs on Russian-Soviet and Japanese civilisations are enough to represent the multi-civilisational regions in which Arnason's programme is most extensively operationalised. The Soviet experience brings specific components to the fore: a reworked history of imperial modernisation, engagement with Western dynamics (and to a lesser extent the Central Asian one) and traditions, and the fate of revolutionary Marxism in the context of Russia's long-term trajectory (1993). The Soviet Union inherited a 'composite civilisation' . At different times, the Russian state had experimented with Westernising strategies. The foundation of the Tsarist state was marked by a problematic relationship with autocratic Byzantine and Eastern Orthodox traditions. Its fortunes were shaped by conflicts with other states along the way, especially the Mongol invasion, war with Japan and the First World War. Three regimes were watersheds: Ivan the Terrible, Peter the Great and the Bolsheviks under Lenin. The key to understanding the Soviet state lies in tracing continuities with the Tsarist state and its traditions, in particular the elaboration of the 'Petrine imaginary' based on Peter the Great's modernisation-from-above. The radicalisation of Jacobinism occurred in juxtaposition to Tsarist colonisation of a limited public sphere, but, Arnason argues, it absorbed more of its opposite (1993: 55-69). Stalinist Russia, on this account, completed the fusion of imperial and revolutionary traditions and then fully Russianised the state apparatus.

Two observations situate this study of the early 1990s in a developing lineage. First, Arnason balances his historicist position on the factors of historical background and interpretive agency. Traditions loom particularly large in the Soviet case, but with the qualification that 'if the exploration of this background begins with a brief discussion of the Russian state and its trajectory, there is no suggestion of collapsing all other factors into the long-term dynamic of state formation' (1993: 28). This is an example of Arnason's hermeneutical emphasis on interpretation precluding a slide into linear evolutionist determinism. Second, the meta-theoretical categories of Arnason's programme were not formed at the time. Some important features of his later theoretical scaffolding are plain, however. His cautious reference to the Axial Age theses and the encounters of civilisations foreshadow his later theoretical approach.

Arnason's model of civilisational analysis is more formed in his historical sociology of Japan. Japan is a dual civilisation. On one hand, its ontological orientations are to its own traditions. On the other hand, it responds as a civilisation to exemplary foreign constellations. Its historical experience is punctuated by momentous encounters with China and the West. The capacity of Japanese civilisation to differentiate itself as both a civilisation and a state has defined its trajectory. Japanese experience has also been marked by a propensity to carefully read and respond to the external environment. 
Successive regimes have met external challenges with a range of responses, from strategic withdrawal to intensive relations. In the external environment, the stand-out civilisation is Chinese. Yet claims about the continuities of the Confucian East Asian sphere and Japan's incorporation into it have been overstated (Arnason, 1997a: 377-9). The break with China in the middle of the nineteenth century was a creative crisis activating traditions that checked Confucianism. More originality can be attributed to the post-1868 Meiji period in respect of consolidation of civilisational patterns. Arnason diverges markedly from Eisenstadt on this point (Eisenstadt, 1996). The Meiji break was too pointed to assume the degree of continuity that Eisenstadt does. Japanese modernity is a new chapter, but not one in which previous patterns were dissolved or traditions abandoned altogether. The ability of the regime to commence imperial expansion in the late nineteenth century based on its previous peripheral status in Asia - and to extend this further in the Showa era - was unparalleled, even if the over-extension of its military plans resulted in failure (1997a: 486-91). It signalled the imagination of new civilisational capacities. Arguably, these have been more successfully marshalled by the post-war developmental state that has reinvented capitalism (1997a: 475-502). Japan's capitalism is the problematic least addressed by Arnason beyond his initial insights (Smith, 2014c). More could be done to emphasise the modernity of Japanese capitalism. Yet Arnason does enough to illustrate the creative powers of Japan's capitalist form and how singular the developmental state has been.

Both in-depth monographs turn up distinct civilisational patterns and histories. Arnason reaffirms regional contexts in order to validate the proposition that civilisational patterns are more on the unique side than most analysts admit. He does more than endorse the study of different world regions. He begins the work of incorporating regionality - the fourth key question - as a problem itself into the civilisational paradigm. Arnason starts with existing concepts of regions and regionalism (2003: 314-22). His formula focuses on different relationships that regional identities have with civilisational impulses. Picking out the most pertinent examples of regional civilisations will not do when a better strategy is on offer. That strategy is a delineation of how particular 'civilisations are more regional than others, and some regions are more civilisational than others ... [T] he task of civilisational theory is to account for the spectrum of variations on both sides, rather than to single out the most congruent cases' (2003: 315). Arnason's strategy counters tendencies to reification of regions as stable geographies by casting 'both sides' as dynamic. So, while approximately one hundred regions are coextensive with civilisations, it is the most illuminating mixtures that require analysis, including less likely 
candidates such as South-East Asia (Adams and Arnason, 2016: 170). In contrast, the relationship between civilisation and region in Islamicate civilisation is weaker and has been cause for historians to be more cautious than in the past (Arnason et al., 2006).

Looking at macro-regions might be another mode of assessment of region and civilisation. In a collaborative collection of essays not covered above, Arnason and Wittrock explore the late medieval period across Eurasia (2004). In this collection, comparative sociologists and historians show the exceptional historical sensibilities characteristic of the sociological imagination. Even more noticeably, they exercise regional sensibilities; that is, deep appreciation of regional, interregional and trans-regional contexts. A consensus gels around two conclusions. First, there is enough to justify continued research into congruencies of region and civilisation in Eurasian experiences. Second, global history should include inter-civilisational encounters with Eurasia in its log of central dynamics. This brings in Arnason's leitmotif: inter-civilisational encounters, which is where the historical and regional sensibilities meet.

What distinguishes inter-civilisational encounters from other kinds of linkage? Arnason builds on conceptions of inter-civilisational encounters developed by Nelson, Hodgson and Jaroslav Krejci (Arnason, 2003: 187-94). Fleshing out what he perceives to be the underdeveloped aspects of Nelson's thinking, Arnason elaborates a notion of cultural problematics from Nelson's cues on Europe's encounters, and then suggests that this could have been taken further via comparison with other civilisations (2003: 147-54). The most decisive element is evidence of 'mutually formative relations between civilisational complexes' (2003: 287). Arnason departs from Nelson by asking what makes specific civilisations more open to confrontation with other and different socio-cultural formations. Arnason attributes special importance to encounters in multicivilisational zones. Another point of departure is to bring in economic and political as well as cultural factors (2003: 289-92).

The interaction of civilisations is best viewed through the prism of a 'phenomenology of encounters' (2006: 39), or the hermeneutical transfer, absorption, circulation or exchange of elements. Careful reconstructions of specific cases serve to clarify major contentions. A brief sketch of inter-civilisational encounters for India and Japan reveals Arnason's method. Blockages to the benefits from India's encounter with Ancient Greece came from a lack of reflexivity in both civilisations in respect of each other, but particularly so on the part of Indian civilisation. By way of contrast, India's encounter with the West resulting from British colonialism revealed Indian reflexivity much more so than for the British side (2006: 42-5). A contrast with these two encounters is the depth of the twosided encounter with Islam that occurred in India's early modernity. Comparison 
of the three encounters in India's past shows a 'continuum' of inputs into India's cultural memory (2006).

Arnason's reconstruction of the Japanese context illustrates a different continuum. Japan is 'emergent and relational' and especially given to inter-civilisational encounters (Arnason, 1997a: 80). Throughout its history, Japanese self-belief in a separate civilisation proved important. Encounters with China-centred East Asia seem to contrast with the marked self-seclusion of the Tokugawa era from 1600. Yet the latter phase can also be seen as an orientation to events, or rather a distancing from East Asia as part of restructuring the domestic social order. Japan's cultural orientation occurred at a distance, and in the latter part of the Tokugawa period. A noticeable eighteenth-century intellectual current of Western learning established a foundation of knowledge that was a pretext to the Iwakura Mission, which involved a comprehensive programme of learning about other states and cultures launched during the full-scale encounter with the West across the 1860s and 1870s. Japan's self-shaping continued to be linked to changes in the international arena from this point. The whole civilisation's history is composed of recurrent swings between the regional context and an internal sense of uniqueness.

In Arnason's summation of the histories of India and Japan, inter-civilisational encounters punctuate the past. Arnason argues, contrary to Eisenstadt, that long-term trajectories are uneven and that connections with past civilisations are mainly made through interpretations of cultural, political and economic doctrines, patterns and models. Not in thrall to the problematic of cultural ontologies - but also far from denying their importance - Arnason seeks to uncover the interpretive transformation of civilisational origins. He is especially interested in the transformative moment of inter-civilisational encounters, which always have an interpretive dimension. Even though civilisational histories are generally discontinuous, inter-civilisational encounters are distinguished by their impact and durability.

But this raises questions about the status of inter-civilisational encounters and underlying connections between societies, cultures and states. What precedes encounters, apart from the social imaginary significations that make interaction possible? In a passage that points to the kind of economic ties that constitute inter-civilisational engagement as I outline it in Chapter 4, Arnason points to the nub of the problem: 'it is not enough to point to the omnipresence and variety of economic contacts: only major turning-points with far-reaching consequences on a civilisational scale will fit the term' (2003: 289). The statement is at odds with the notion of inter-civilisational engagement propounded in these pages. But it clarifies a point of disagreement, which revolves around the distinction between the 'omnipresence' of contacts and 'major turning points'. It is methodologically 
difficult to disentangle significant encounters from the forms of engagement with consistent certainty. However, in a later essay (2007), Arnason offers a tentative way forward. He responds to new scholarship on entangled histories and modernities - which pointed to the complexity and depth of connectivity in the modern global order - by asserting that a map of inter-civilisational encounters can help differentiate specific scenarios in the global age. That this is a helpful step is not in doubt, but it does not give recognition to the depths of connections. For the present author, it suggests that connectivities are obligatory subject matter for civilisational analysis.

Arnason's account of the West's prominence in modernity can serve to illustrate my point. To begin with, credit is given to inputs from Islamicate civilisation via inter-civilisational encounters between the two (Arnason, 2006). However, it still does not give enough due to contributions to Europe from other civilisations in terms of the overall range of networks, bonds and links, including the more routine and less visible kinds of inter-civilisational engagement. FernándezArmesto shows the problem in a different complexion when he states:

European culture ... is then seen to have been at least as much the product of influences exerted from east to west as the other way round: the spread of farming and of Indo-European speech; the Greek and Phoenician colonisations; the migrations of Germans and Slavs; the coming of Christianity, that Oriental mystery-religion which Europe had appropriated; the steppeland invasions; the Ottoman pressure; the spread of what used to be called 'international communism,' which has lost its empires but left its mark. And all of these movements have to be seen against the background of the long-constant flow of technology and ideas from farther east: Arab sciences, Indian mathematics and spirituality, and Chinese inventions. The importance of these in the making of Europe is still only beginning to be acknowledged in the West, but the evidence of it is all around us. (Fernández-Armesto, 2001: 311)

Fernández-Armesto makes conspicuous the sense of the volume of inputs over the longue durée in a manner hard to refuse. European exceptionalism dims in the face of the patterns of engagement that are formative of the cultures of northwestern Eurasia. Taking a more international perspective seems more promising. To the long-term impulses of Eastern inputs we can add the historic conjoining of the Western hemisphere and Eurasia through the European conquest of the Americas. The era was a watershed in which early modernities coalesced in approximately the same time frame and joined an inter-regional expansion of connections. Without doubt, that problematic of interaction as part of the constitution of the modern world has been a concern to other historians, ranging widely from Chris Bayly and Kenneth Pomeranz to Enrique Dussel, and from J. G. A. Pocock and Anthony Pagden to world systems analysis, James Blaut, 
Jack Goody and de-colonial historians. Integration of pre-modern global connections remains as yet more the domain of world history and economic history than civilisational analysis (Inglis, 2010), a matter of great challenge to the latter.

How could comparative and historical sociology offer more to a reconstruction of connected early modernities? Arnason's entreaty to civilisational analysis to emphasise agency and the historical and dynamic nature of civilisations itself foregrounds the entanglements of civilisations (Knöbl, 2006a). Nelson and Arnason's relational models could be strengthened by retraining the analytic focus on the depth of entanglement that historical agency carries. If framed as such, the density of connections would, however, undermine the exceptionalism claimed for any civilisation. Salvatore submits a similar argument when he proposes that Arnason's triad of power, meaning and wealth taken to its logical conclusion would be elaborated as trans-civilisational logics (2007). The social philosophies of other civilisational bases that Arnason credits with a part in the crystallisation of the Western tradition contribute more, as far as Salvatore is concerned. Islamicate civilisation - and possibly others as well - are fields 'of ongoing inter-civilisational processes and transcivilisational encounters' with a worldwide impact (2007: 331). Comparative and historical sociology has not realised the vitality of trans-civilisational dynamics, perhaps because 'the spirit of "Western exceptionalism" does not yet appear to be absorbed and neutralized in the comparative perspective of civilisational analysis' (2007: 331). Civilisations are produced by interconnected processes and should feature as such, rather than as fragments of a complex institution of Western modernity. Contemporary civilisational analysis has not yet found the right stress on multivalent integration.

Re-scoped in this way, contemporary civilisational analysis could leave behind integrationist definitions and study neglected societal figurations that have not previously made the grade as 'high civilisations', but which are embedded in inter-civilisational engagement and therefore subject to the processes of trans-civilisational reconstruction. This would pose different questions about power, as well as looking at fresh figurations not normally examined as civilisations. Arnason for one is receptive to suggestions of further revision. In his view, civilisational analysis cannot exhaust understanding (Arnason, 2010) and 'should not be mistaken for an attempt to subsume everything under civilisational categories' (2011b: 117). When couched in these terms, civilisational analysis appears responsive to criticisms from within and from without. There is a small critical reception of Arnason's work. A number of the criticisms highlight areas where civilisational analysis at large has even more gaps. Two areas stand out: the status of new world formations and the underdeveloped field of colonial modernities. 


\section{Critical reception}

A first area that critics focus on relates to those societies and cultures omitted from the scope of analysis. Arnason has yet to incorporate new world and oceanic theatres of civilisations substantively in deliberating on his core questions, or to look at indigenous civilisations in any detail. More generally, contemporary civilisational analysis has not incorporated either in its paradigm (see Rundell, 2004). Given the interest Arnason shows in Durkheim and Mauss with their exploration of Pacific, Aboriginal Australian and pre-Colombian civilisations, one would have thought that this might be a frontier of deeper interest, so this is a little surprising. But there are notable acknowledgements of the gaps and further invitations to fill them. The achievements and limiting boundaries of Eisenstadt's comparative essay on the first American modernities are a starting point (Arnason, 2010: 11-12, 2011b: 117). Noting that Eisenstadt draws into relief the religious premises of Euro-American colonialism, Arnason points out that detailed scholarship challenges the results of his analysis (Blokker and Delanty, 2011: 127-8). Too many complexities are highlighted in the historical and sociological literature on the Americas to leave Eisenstadt's intended research strategy untouched. Marking out the respective positions of Eisenstadt and those who picture multiple American regions with multi-civilisational influences (including the present author), Arnason argues that a more nuanced mode of analysis is needed.

When it comes to indigenous civilisations in the Americas, however, Arnason's own impressions are open to question. Noting that a fuller assessment of the status of indigenous cultures would have to await later consideration, Arnason estimates that only two cultures out of the extended continuum of pre-Colombian societies could qualify as civilisations. There is limited evidence of inter-civilisational encounters between the Incan and Mexica (Aztec) civilisations. True enough, although the detail of connection between the two might increase in the hands of future archaeologists and philologists. Considered from the point of view of inter-civilisational engagement, however, the picture looks more nuanced. Evidence from the growing scholarship of the pre-Colombian Western hemisphere (and after colonial intrusion) points to wider and denser regional networks of movement of people, goods, contacts and ideas; in short, a hemisphere of inter-civilisational engagement in which contacts are thicker than has been previously thought has yet to have an impact on civilisational analysis or theory (Sabloff and Lamberg-Karlovsky, 1975; Trombold, 1991). In part, this has been an empirical matter and in part it is a theoretical and epistemological one. The question of connectedness of pre-Colombian civilisations may now be re-problematised. The rise of indigenous consciousness since the 1970s has led 
to cultural and political association between first peoples up and down the two continents of the Western hemisphere. Between constructions of shared indigenous memory and revival of cultural traditions, living civilisations with living cosmologies have constituted themselves as collective actors. The last word does not lie with neglect, however, but with a reminder about the provisional character of analytic evaluations. When asked about Africa, Arnason replies, 'There is no a priori reason why the paradigm should not be applicable to other parts of the world but each case will raise specific problems' (Blokker and Delanty, 2011: 127). Obviously, this should also be taken as an invitation to further exploration of new world regions, including oceanic ones.

Colonial modernities are a second area of critical response. Arnason's engagement here is pithy in theoretical terms. However, his treatment of historical specifics amounts more to a series of evocative suggestions for specialists than to a sustained attempt at a larger fusion. His theoretical engagement can be summed up briefly. Arnason calls for an altogether different theoretical strategy and methodology to unpick Eurocentrism's traditions. Arguing that the 'metahistorical meaning' of visions of East and West have been amassed through a long but twisting history of image-making, he points to the very incomplete nature of deconstruction of Orientalism. Post-colonial deconstruction is incomplete, but so too are deconstructive projects of civilisational analysis, about which Arnason is plainly more optimistic. Post-colonial critique is far from fully formed, however. Arnason indicts post-colonial thought itself for failure to properly analyse actual colonial modernities (2003: 323-9). Suggestive pointers on North Africa, British India, the Near East and Thailand clarify the extent of the challenge. Though he discusses East Asia, Arnason does not consider published works explicitly thematising East Asian colonial modernities. They nonetheless present some key arguments distinct from Arnason's version of civilisational analysis. East Asian historiography is urged to rethink relationships between problematics of colonialism and modernity (Barlow et al., 1997). Nationalist historiography is particularly unfit for the task of pulling together colonialism, modernity and nationalism to reconsider inter-relationships of the two, as is the existing Subaltern Studies tradition also. Above all, scholars of East Asian colonial modernities emphasise a mode of history not absorbed with national or single societies and able to link the formations in question. The results of the projects on colonial modernities may have been piecemeal, but they potentially supplied momentum for further development. However, interest in colonial modernities as such was, at best, slow at the end of the 1990s. There can be little doubt that colonial modernities would require more attention to progress new insights. But other paradigms of comparative sociology and relational 
history could expand the problematics formulated by research on colonial modernities. Any chance of reconciling Arnason's suggestions with established directions (such as Toni Barlow's) is subject to the general relations between contemporary civilisational and post-colonial analysis. There is not much optimism about this, but in the next chapter proposals for potential meeting points between the two fields are made.

\section{Conclusion}

This chapter critically summarises the positions of three representative figures of contemporary civilisational analysis in order to delineate insights and shortcomings. They each are heirs to different images of civilisations developed in classical sociology and by early world historians. Each reconstructs the work of their predecessors in their own way. There is room still for further interrogation of the precepts of contemporary civilisational analysis. In the versions included in this chapter, modern colonialism is marginal and, at times, empires are absent. Furthermore, the integrationist image in particular emanates an inherited impression of civilisations as relatively stable and separate unities that in itself displaces the wide span of contacts, connections and exchanges between social formations. As far as my version of contemporary civilisational analysis is concerned, this is the significant shortcoming. It draws attention away from flows of migration, economic movements, cultural transmission and adaptation and the redevelopment of models of statehood. There are other gaps. The relationship of civilisations and economies do not receive specific attention either - something of a puzzle given that they concerned Weber, Mauss and Durkheim (Swedberg, 2010). More precisely, capitalism as a modern social formation interacting with civilisations is noticeably lacking. Arnason is an exception in this regard. He has a more developed theorisation of capitalism and civilisation, with basic categories of wealth and money in place. More may yet emerge in his oeuvre by way of a defined direction about this particular problematic. However, capitalism and the international arena are also the subject matter of paradigms that partly rival civilisational analysis, partly share intellectual space with it and are therefore partly responsive to it. Globalisation studies, Marxism and post-colonial perspectives are three paradigmatic alternatives to civilisational analysis. Their interface with debates on civilisations reveals dissonances, but also common spaces in which agonistic engagement around common problematics might be possible. How that could be so is the focus of the next chapter. 


\section{Counterpoints, critiques, dialogues}

A challenge for the field of contemporary civilisational analysis is to rethink heterogeneity, plurality and differentiation in terms of porosity. Interaction between permeable civilisations on different scales and across different dimensions invigorates heterogeneity. If anything, civilisational analysis has yet to benefit from efforts to unearth regular patterns of interaction and gauge the results from long-term rhythms of engagement on the endogenous dynamics of civilisations. The relational model proves to be the most advanced to date in respect of these goals, but it can be pushed further. Before taking steps towards a model of inter-civilisational engagement in Chapter 4 and Part II, I reflect, in this chapter, on competing paradigms. What can they offer in terms of the gaps identified towards the end of the previous chapter, or indeed any others? The three competitors in question are globalisation analysis, Marxism and post-colonial sociology. How they can be situated in relation to contemporary civilisational analysis is the work of this chapter.

The method here is to find productive dissensus between paradigms. A precondition of method is description of the main concept. Paradigms are bodies of thought that are coherent and plausible enough to attract supporters in a general contest of ideas and values. The questions they pose must be sufficiently compelling - and yet also insufficiently resolved - to suggest constructive directions for ongoing research. Moreover, competing paradigms will pose arguments to one another, but also exhibit dissonance. They will 'speak' past each other, as well as to each other. The critiques and counterpoints are treated here from the point of view of paradigmatic dissonance, as well as from the point of view of common spaces between paradigms. In urging an elaboration of common ground between civilisational analysis and international relations, Jackson argues instructively that the lack of agreement paves the way for an agonistic strategy of carving new scholarly terrain out of dissensus. Jackson goes on to argue that by 'working in media res, intervening into an already ongoing set of contentious conversations and exploring a novel combination of commitments', it becomes possible to productively share a dialogue (Jackson, 2010: 179). Applying Jackson's advice on 
the dissensus between civilisational analysis and the three paradigms of globalisation analysis, Marxism and post-colonial sociology, this chapter spells out points of actual or possible dialogue.

In the opening section, critical counterpoints from the globalisation paradigm are foregrounded. It is common for accounts of globalisation to emphasise the novelty of the emergence of the global plane. In civilisational analysis, this is regarded as a species of presentism that ignores longer historical trajectories and complex historical processes. However, there are exceptions. The multidimensional accounts of the emergence of globality by Roland Robertson and Goran Therborn address the criticisms of globalisation analysis. Robertson does so as an interlocutor with civilisational analysis; Therborn's perspective is contrapuntal both exercise a historical sensibility. Common ground exists where the problematics of world region and regionalisation come into focus. By contrast, Marxism is largely silent on the chief problematics that concern civilisational analysis. At the same time, in stressing the rupture of capitalism with past social formations, Marxist critiques highlight a whole area that civilisational analysis has neglected. Three perspectives are compatible with an understanding of capitalism and civilisations as coextensive modern imaginaries: one interpretation of Marx, Antonio Gramsci's Marxism and Robert W. Cox's neo-Gramscian civilisational analysis. The sharpest critiques of civilisational analysis come from post-colonial sociology, which takes aim at the reproduction of essentialism that post-colonial sociologists perceive in comparative studies of civilisations. Furthermore, postcolonial sociologists are explicitly critical of the comparative sociology of multiple modernities on the grounds that it fails to meets its own stated objective of going beyond Eurocentrism. Their critiques home in on how comparative sociologists have retained an unreconstructed notion of modernity incapable of reflecting the breadth of historical experiences of colonialism. Between the two fields there are significant differences over how culture is conceived, what politics should inform analysis and how the character of modernity has been construed. Much of the overt critique comes from post-colonial sociology, but there are rejoinders in civilisational analysis on these points that open up unexplored common ground.

There are key arguments in all three paradigms to take into a conception of inter-civilisational engagement. Robertson and Therborn make the case for longer histories of contemporary configurations or long 'waves' of globalising impulses. Furthermore, civilisations interact with the global plane to constrain processes of homogenisation or de-localisation. The perspectives in Marxism I single out suggest that capitalism's early modernity was more important than has been previously accepted. The coalescence of an imaginary of money and the creation of cultures disposed to accumulation were developments related to 
the growing engagement of civilisations from the sixteenth century onwards as transatlantic colonialism linked the Western hemisphere to civilisations across Eurasia. Extending into later centuries and the outgrowth of Europe's empires, the interaction of civilisations with capitalism produced varieties of capitalist figuration of polity and economy. Finally, post-colonial sociologists argue for the 'connected histories' methodology as a means to overcome the analytical flaws of civilisational analysis and the paradigm of multiple modernities. Connected histories can serve post-colonial critique and the disclosure of historical and current-day hierarchies of power. When partnered with other relational versions of history, the methodology of connected histories can be harnessed to explore the linkages of civilisations also, both in contexts of colonial power and prior to the onset of modern colonial empires. Each of the counterpoints has contributions to make to a reconstructed version of civilisational analysis where problematics can be discerned around which common agonistic debate does, or could, occur.

\section{Globalisation}

The globalisation paradigm has developed coextensively with contemporary civilisational analysis. Though the two paradigms overlap, they also compete with each other as modes of explanation (Inglis, 2010). At first sight, the relationship between the two is a contest between, on one hand, theses on new global forms growing out of higher levels of inter-dependence and, on the other hand, presentation of evidence of countervailing impulses of diversity and re-diversification. Furthermore, globalisation theorists privilege the trans-national mobility of power. When civilisational analysts examine power, they view it as grounded in civilisational contexts where it is shaped by cultural factors. There is also a standoff over questions of continuity and discontinuity (Inglis, 2010: 137-41).

Contemporary civilisational analysis takes its place in a spectrum of responses to globalisation theory. There are a number of criticisms levelled at the globalisation paradigm. The most far-reaching contributions from sociology and anthropology are sharply critical of the worst neo-liberal 'globalony' about the forces of uniformity operating on the world plane. In addition, exponents of the global age thesis stand accused of extending the one-dimensional arguments of modernisation theory by proposing theses of the homogenisation of cultures, economies and governance (for example, see Albrow, 1996). Other criticisms haunt suggestions of over-determining processes of globalisation. Persuasive arguments are backed by evidence that nation-states are not in irreversible decline and continue to vigorously entrench capacities. But perhaps the most serious 
criticism concerns key problematics and the scope of analysis. Many in sociology and amongst social anthropologists caution against the presentism of globalisation theses. Their general views intersect one of the more prominent criticisms of globalisation theory coming from civilisational analysis: that there is a lack of proper perspective on the significance of long historical trajectories (see Tiryakian, 2014). Any serious attempt to extend the historical scope of waves of globalisation ought to begin with the epoch suggested in the early modernities literature. Furthermore, the outgrowth of connections associated with the expansion of modern empires, colonialism and the trans-nationalisation of economic power is a problematic that should be central to understanding early waves of globalisation from the fifteenth century onwards. A global optic of the sixteenth and seventeenth centuries cannot adequately leave out increased density of connections and networks of engagement in several world zones. On the whole, occlusion of early modernity in the globalisation paradigm makes it hard to avoid the conclusion that too much of the argumentation is extrapolated from the sediment of European experience (Connell, 2007).

The best thinkers amongst the scholars of globality seem aware of such problems. While also locating themselves at odds with a number of assumptions of civilisational analysis, Robertson and Therborn develop more complex multidimensional models of globality. To begin with, although Robertson's sociology originated in the Parsonian modernisation paradigm, he developed a multidimensional model of globalisation, partly in dialogue with civilisational analysis in the 1990s. Robertson's thinking formed against the backdrop of Elias's and Gong's notions of the civilising process and over the course of a longer exchange with Vytautos Kavolis (1992: 3). It is in dialogue with Kavolis about universalism and the particularity of civilisational bases that Robertson clarifies the meeting point between globalisation as a process and the civilisational paradigm as an analytic. Robertson's reply to Kavolis is formative for his own concept of international society and therefore globalism. Civilisations have not been erased. Rather, the multiplicity of civilisations is a prelude to globalisation and a consequence of it. His notion of globalisation can be distinguished from more simplistic accounts by the conceptual depth and multidimensional character of its analytic. Globalisation for Robertson is an ideal type of a 'global field' (1992: 25-7). Aside from structural logics of time-space compression, Robertson recognises the crystallisation of 'extensive awareness of the world as a whole' as a long-term outcome of coalescing global culture (1992: 78). The global field includes the world system, national societies, humanity and selves. In construing globalisation through a Parsonian lens Robertson puts culture forward as an abstract order. However, culture encompasses and interacts with economic and political processes rather than existing alongside them. In other words, multidimensional processes are 
presupposed from the outset. Robertson sets the scene by analysing global cultural, religious, cognitive and material dynamics of power at a trans-national and trans-civilisational level well above national societies. Different dimensions of power are not reproduced in a static pattern of inter-dependency, but are highly changeable (Spohn, 2014: 134-5). This conceptual distinction sets Robertson at a distance from his earlier Parsonian sociology.

In examining the interaction of multidimensional processes in economy, culture and politics, Robertson consciously notes the historical dynamics of forces of capitalism and imperialism, which, as he sees it, have been thoroughly researched (1992: 28-9). Robertson's assumption is too hasty. While there have been notable gains in historical scholarship, the theoretical implications are not exhausted. Modern colonialism and capitalism remained under-examined problematics in contemporary civilisational analysis and there is still work to do in theorising power in both domains. In this respect, Robertson's ideal type of the global field has the virtue of a more explicit focus on power and culture. However, his presumption that the historical sociology of capitalism is finished work - or 'well-trodden ground' (1992: 29) - blocked further development.

In respect of culture and power there is a fruitful tension between Robertson's sociology of globalisation and contemporary civilisational analysis. Robertson's vision of the world has phenomenological cadences that open up common ground with civilisational analysis. Civilisations, for Robertson, develop internal images of a world order. Globalisation solicits civilisations 'to be increasingly explicit about what might be called their global callings (their unique geo-cultural or geo-moral contributions to world history)' (1992: 130). The cultivation of civilisational identities by the impulses of globalisation is evident in explicit debates about involvement in the global world. Involvement implies interaction with the world and a relational side to the institution of civilisations. Robertson's main proposition goes in a different direction. Globality, if it is to be meaningful, refers to the outgrowth of worldly consciousness. There is a variety of civilisational responses to the growth of worldly consciousness. In turn, world consciousness sustains the plurality of civilisations. If growth of world consciousness and awareness of 'global involvement' (1992: 132) is one of the strong theses of globalisation, then it must be countered, with Delanty in this instance, that the translation and translatability of whole-world cognitive consciousness is highly complex (Delanty, 2003: 451-2). There is a more forceful diversification of worldly articulations than Robertson allows for. Globality as consciousness looks more like a shifting terrain of different projects of globalisation that continue to imbue places with special meaning. Europe, the United States and Japan are three large projects with which to begin (Inglis, 2010). Robertson is not unaware of this, as evidenced in his elaboration of Japanese globality (Robertson, 
1992: 85-96). But the world appears, in the final instance, a received singular order for him, not one made in coexistence with others as the term 'project' might suggest. The image of the singular world order falls short of the complexities of a longer historical trajectory.

Those complexities are the centrepiece of Goran Therborn's treatment of the problematic of world order. He advances a distinctly historical, multi-variable and pluralist account of globalisation and modernity. This account does not really locate him in the camp of globalisation studies, or that of civilisational analysis, but combines findings of both. The world has been through six waves of globalisation and pathways to modernity that cut across historical civilisations (Therborn, 2011). Two definitions matter in his version of globalisation: civilisation and the idea of 'waves'. To begin with, he defines civilisation as old cultural formations with a very long-term impact on global history. The impact is threefold. First, alongside diffusion of the world religions, cosmologies with a differentiated conception of the sacred spread in the first millennium CE (and not the Axial Age). Second, civilisations institute a canon of works in 'classical' form (for literary civilisations) or mythology (for oral ones). Third, civilisations create sets of social, material and economic practices in shaping environments that produce economic trajectories. Five civilisations laid down the ancient bedrock of the waves of globalisation: the Indic, Sinic, European, West Asian and sub-Saharan. 'Waves' refers to processes of intensification and extension of social processes that have lasting legacies. They can be macro-regional and planetary. But the important point is that waves of globalisation overlap and impact on all dimensions of social, economic, political and cultural life. Over time, and with each wave, more and more of the world is incorporated into common dynamics.

The first wave is synonymous with the Axial Age. In the second wave (15001600), Europe's early modern empires conquered and colonised the Western hemisphere. Indigenous peoples suffered colonial occupation as genocidal conquest and millions of Africans suffered it as the catastrophic slave trade. War and world power were internationalised in the third wave (1750-1815), with Britain emerging as the premier European force at the expense of France. High Imperialism and competition amongst Europe's imperial powers were in the forefront of trends in the fourth wave (1830-1918). Europe overtook Asia as the core macro-region of the world economy for the first time since the height of the Roman Empire. The fourth wave ended with the formation of world organisations like the International Labour Organization and the League of Nations. The fifth wave (1919-89) introduced world politics, the onset of the Cold War and the worldwide revolt against colonialism. Globalisation came into its own in the sixth and final phase from 1990 onwards and entered into popular consciousness. Finance and financialisation emerged as forces of globalisation par excellence. 
Time-space compression altered communication, media, finance, investment, trade and governance, and set the parameters of how the politics of opposition to neo-liberalism and global inequalities would take shape.

The last two waves are the ones normally known as globalisation. More historically minded perspectives begin with the fourth or even third wave. Therborn fixes longer historical phases as reference points and thereby treats older sources of globalisation. He treats force, domination and power as part of the same problematic and process; that is, as a wave of globalisation. These factors are fundamental to globalisation, just as the growth of commerce and migration are. All these dimensions of the waves of globalisation involve interaction between civilisations, sparking a spectrum of conflicts, encounters and connections. In this respect civilisations are seen by Therborn as crucial to globalisation. However, in casting civilisations as the sediments of history and the bedrock of globalisation, Therborn implies a static understanding of 'civilisations'. They appear in his account to lack historical processes of transformation, at least after the first wave. His model allows no place for the present dynamics of civilisations. If there is a part for civilisations in globalisation, then it is as artefacts of global history that counteract homogenisation. The pace of the present is set more by globalism manifested regionally. He sidesteps civilisations as creations in the present, whether as processes (as Elias and other processual theorists would have it), as collective representations (for Durkheim) or as active ontologies (Eisenstadt). Civilisations persist residually as powerful historical presences, but do not contribute to the main energies of the world.

One further sociologist of civilisations and globalisation extends Therborn's approach, but casts civilisations as contemporary forces in global modernity. José Mauricio Domingues brings a multidimensional and nuanced account of global modernity from within contemporary critical theory. He uses the phrase 'civilisational imaginaries of contemporary modernity' to designate the counterweights that occur under the rubric of globality (2012: 98). Global modernity as a civilisation in itself emerged through the entanglement of civilisations. The expansion of global modernity coincided with the outgrowth of Western modernity (2012: 2-4). Civilisational imaginaries generate diverse forces of fragmentation in the form of various solidarities to counter the homogenising impulses of globalisation. In tension with his view that modernity has radiated from the West, Domingues follows Therborn's four paths to modernity to discern four general groupings of solidarities and agencies (2012: 21). Many of the civilisational composites trek the four paths that are changing at a striking pace since they are 'contingent, fragmented, contradictory social formations, yet they may coalesce and produce a partial fit between their dimensions' (Domingues, 2012: 22). Civilisational imaginaries are contradictory patterns, in his account, 
and therefore pace-setters. Yet they are also capable of curbing and altering global dynamics. The kinds of solidarity constructed by social actors in the conditions of global modernity - and that condition those conditions - remain startlingly varied due to the contingency of civilisational imaginaries.

The obvious conclusion from Domingues's sociology of modernity is that globalisation has no pre-ordained outcome. Rather than a shapeless determinism, globality is subject to fluctuations and tensions, as are the countervailing civilisational imaginaries of modernity. His perspective is pliable to the problematic of regionalisation also discussed by Robertson and Therborn. Although regionalisation is claimed for the domain of globalisation studies, contemporary civilisational analysis has also been able to fashion regionalisation as its own subject matter. Do findings in the two fields intersect at all? Spohn observes that contemporary civilisational analysis already incorporates regions in its analyses of cultural and institutional power at a civilisational level between national societies, inter-state relations and the emerging global arena (Spohn, 2014: 135). Arnason backs a flexible and two-sided approach. According to Arnason, historical scholarship calls for an interactive image of relationships between region and civilisation whereby the two transform each other in concrete cases (Arnason, 2003: 314-22). The state of regional studies is such that some political scientists and international relations scholars have started to look to contemporary civilisational analysis to re-problematise world regions and area studies (Katzenstein, 2010a), suggesting that more development through cross-fertilisation of propositions and empirical investigation is possible.

If there are prospects for more productive research, there is little suggestion of a convergence of views on regionalisation involving globalisation and civilisational theorists. Each paradigm handles the problematic differently. Neither is exhaustive. Globalisation theory does more to pinpoint the international mobility of institutions of power. Contemporary civilisational analysis exercises mesosociological analysis more effectively and does more at that level to illuminate constellations. There are three preconditions for further exploration of regionalisation at the interstices of both paradigms. The first is theoretical appreciation for the diversity of zones, practices, processes, actors and traditions in the twentieth century. A higher awareness of the impact of rebellions against colonialism coinciding with the breakdown of Europe's empires from the 1930s onwards is the second. Third is the weight of colonial legacies on civilisations ruled by the West. Critical reflection on contemporary civilisational analysis from the vantage point of globalisation theory stimulates attention to these three shortfalls. The global optic should prompt questions about power in the twentieth-century denouement of the colonial empires and emergence of conditions of post-coloniality. The regional optic broaches other questions about newly stimulated processes 
of pluralisation, traditionalisation and hybridisation. What new, multiple identities have emerged? How do they criss-cross class boundaries and articulate with subaltern positions? If new processes of modernisation are in train, what impact do they have on religion? The questions might be related to how some regions are more marked by the colonial past than others. The three preconditions cannot be taken further here, but could be discussion points for dialogue around regionalisation, power and civilisations.

Speculation on the future of the globalisation paradigm would be hazardous. It is striking that in sociology the main surge of interest in globalisation came in the 1990s. It has often been remarked along the way that popular globalisation discourse seems to have a good deal in common with Marxism - a significant guiding theoretical framework of capitalism for the opposition to neo-liberalism. At first sight, Marxism would appear even more at odds with contemporary civilisational analysis. Civilisational researchers are quick to dismiss the most economistic interpretations of Marxism. Yet some Marxisms resist the undertows of economism and they are relevant to civilisational analysis. If they have achieved a critical position that can have inputs into contemporary civilisational analysis, what might they contribute?

\section{Marxism and civilisational analysis}

The suggestion that Marxist histories or sociologies have a place in contemporary civilisational analysis would find few supporters in any quarter. On the civilisational side, proponents contend that Marx's economic determinism and the modernist doctrines that followed it exclude Marx's system of thought from the field. At the same time, some accept that civilisational analysis has yet to properly incorporate the economic dimension (Swedberg, 2010). Marxist critics of civilisational analysis might well contend that civilisational analysis is a new culturalism in which class conflict and power are framed out. Both sets of conclusions leave the impression that the two paradigms are mutually exclusive.

It is evident that there is no dialogue. One would be possible, however, on the basis of unorthodox interpretations of Marxist political economy that address problematics of capitalism, power and civilisations together. There are traces of interest in civilisational problematics in Marx and Gramsci's work on the symbolic and cultural dimensions of social formations. A more complete political economy of civilisational interaction in Cox's work brings Marx and Gramsci together with others in a cross-fertilisation of Marxism and civilisational analysis. The reinterpretation of Marx here privileges the imaginary of capital and money, as he presents it in The Grundrisse. Marx's 
observations on money and the capitalist imaginary amount to a sketch that is later rethought and elaborated in a sweepingly comprehensive philosophy of money by Georg Simmel (Simmel, 2004). As potent as Simmel's social theory is, the interpretation of Marx is preferred here as it connects with Marx's analysis of the subordination of labour to suggest patterns of the imaginary institution of capitalism, patterns that also involve the interaction of civilisations.

My line of thinking advances through Marx, then Gramsci and finally Cox. Marx linked money to wealth and capital, much as Simmel did later (2004), by disclosing the orders of abstraction it has brought to economic life as a component of modernity. He also drew out the cultural dimension of class struggle as well as identifying the class agency at work. Gramsci's Marxism grounds the abstraction of capitalism in a variety of social regimes that have emerged from the combat around capitalist hegemony. He emphasises the consequences of the cultural and normative dimensions of class struggle more explicitly. Both threads are mostly drawn together in Cox's model of interaction between diverse manifestations of regimes of accumulation and civilisations in the world order. To the model of civilisational analysis under construction here, Cox's interpretation of Marxism contributes an understanding of the capitalist imaginary and its highest orders of abstraction, the institution and mobilisation of power and an understanding that civilisations continue to interact with a global plane to produce variation in world capitalism.

Marx is a starting point. He had little to say about civilisation as such. Yet his deliberation on the imaginary of capitalism is suggestive of related problematics. Before exploring these problematics, Marx's main conception of civilisation as expanding and conquering capitalist modernity must be summarised, as it is the main thrust of his political economy. Capitalism, in this view, adds to the store of humanity's productive capacities while subsuming nature and non-capitalist social relations. The pre-modern relationship between polity and economy in most societies is ruptured by the cataclysmic rise of capitalist modernity. Marx argued that pre-capitalist modes of production instituted societies where state power was allied with long-distance trade in promoting economic relations. In such pre-capitalist modes of production, it was the superstructure that codetermined social relations. At the onset of capitalist modernity, capital emerges in the pre-eminent position and takes charge, as it were, of the state, thus reversing the previous balance of power. Marx forecast that the contradictions of expanding forces of production around Capital and Labour will eventually run up against the limitations of capitalist modernity. After capitalism's progressive phase of conquering nature and overcoming other modes of production and the autonomy of the state, it is plagued by its own contradictions and subject to 
cyclical downturns. Capitalism under these conditions is ready to be superseded by a higher form of society.

In parts of his work, Marx emphasises the phantasms of industrial capitalism. Passages in which the contradictions of the capitalist mode of production are stacked up against the historical character of class struggles and their consequences illuminate other aspects of capitalism. The chapter on money in The Grundrisse and chapters on the working day and the results of the immediate process of production in Capital touch on another model of the constitution of social relations (Rundell, 1987: 146-99). Marx's reconstruction of the subordination of labour to capital - the so-called subsumption model (Rundell, 1987: 17389 ) - enlarges the influence of the symbolic and normative spheres of social life in class relations, in industry and in the process of production. The struggle of classes determines not only wages and conditions but the shape of the production process, control over it and indeed the terms of engagement of industrialists and workers. However, struggle and political conflict are symbolic as well as being agential. Symbols help make sense of agency, which in turn contests the tracks of progress and alters its course, sometimes dramatically. The accumulation of capital is rendered here as a narrative in which symbolically mediated class relations have the power to shape basic institutional patterns. Capitalist industry thereby becomes an objective technological and rationalist civilisation that formally and really confronts labour in industry and endeavours to bring labour under its dominion.

Enlarging the symbolic and normative subordination of labour also puts in doubt basic premises of value and this raises important questions about the abstraction of money. The theory of money sketched in The Grundrisse is used in the current work to bolster the conceptualisation of inter-civilisational engagement in economic relations. At variance with the main perspective in Capital, Marx construes money's symbolic form as 'abstract wealth' in The Grundrisse. Money is not a representative of the forces of production, but a form that actively interposes itself in the transformation of social relations from pre-capitalist to capitalist. Money is a mobile power that passes through the world symbolising utility. In this respect, money has an elemental quality. It travels over cultures and spaces communicating its symbolisation of utility trans-spatially and trans-culturally. In doing so, it acts also as the object of different orientations to accumulation that all emerge from diverse constellations. Money is thus an abstraction to which civilisational contexts throw up different concrete orientations. As an abstraction of general purpose in the early modern outgrowth of capitalism, money was a general object of trade, finance and insurance. It follows that trade deserves a more proper place alongside the organisation of production in the theorisation of the material and symbolic outgrowth of capitalism. Marx's 
theory of money as symbolic abstraction informs the discussion of economic relations in Chapter 4.

Returning to the subsumption model of class representation, note that, as far as Marx is concerned, capitalist subsumption sets off repeated struggles for control over production and work and over regulation of other spheres of modern social life. It is possible to infer from Marx's elaboration of this model an allusion to a larger social regime of the kind that later intrigued Gramsci. Moreover, the subsumption model is given to elucidation of other kinds of power and domination. The form of domination extends to other spheres and relations between national societies and between civilisations. There is also an analogy of the subsumption of labour in the symbolic diminution of nature and the mobilisation of scientific knowledge for that purpose. By subordinating nature, capital adds to the generation of a bourgeois social world and capitalist civilisation. Marx's own words hint at the depth of this transformation. Under 'the great civilising influence of capital ... nature becomes purely an object for humankind, purely a matter of utility' (Marx, 1973: 409-10). In this rendition of the capitalist social formation, the first notion of civilisation noted above returns to the fore. However, Marx's allusions are to the symbolic and possibly imaginary dimensions of civilisation and capitalism, even though he does not pose or expressly theorise them in these terms.

In summary, there are two elements in this unorthodox interpretation of Marx that can figure in another historical narrative of the creation and expansion of capitalism. First is the mobility of money as abstract wealth. Second is the potential of class and social conflict to kindle varieties of social regulation. Both problematics may have been marginal to Marx's political economy and historical writings. They hardly translated into twentieth-century Soviet Marxism. Gramsci, on the other hand, represents a different Marxism and one with echoes in Cox's political economy. Gramsci did not consider civilisation as such, nor was the full range of Marx's critical political economy available to him. However, he is one of Marxism's most focused primary theorists on culture, economy, politics and agency and in that capacity worked up a theory of capitalism's social regimes. In 'Notes on Americanism and Fordism', he construes culture to resemble civilisation (Gramsci, 1971: 277-318). Like Georg Lukacs, he is philosophically located in a tradition of non-positivist and Romantic Marxism that is influenced by Weber (Lowy, 1996: 13-15). Given the echoes of Weber in his outlook, it is not far-fetched to suggest that there is a tacit civilisational dimension to his theory of capitalism and state formation.

Gramsci's prescient notes on Americanism are notable for two features. First, he generates significant insights into the complexity of social formations and how power is instituted in varying combinations of coercion and 
consent. Second, he explores culture and politics as constituents of variations in capitalism and, in doing so, incorporates something like a civilisational dimension; that is, a dimension of social life above culture in which elemental meanings are instituted. In the United States, a cultural and moral order aligned to Protestant capitalist hegemony had been cultivated along with the development of Fordism. Hegemony construed in this way falls somewhere between explicit and tacit power, as Castoriadis conceptualises them. Gramsci asserted that hegemony comprised several components. In the United States, the technical mechanisation of systems of production and reorganisation of the labour process appeared to demand reforms of the subjectivity and habits of life of the working class. Fordism, however, produced different versions of virtue for different classes. Hard work, acquisitiveness, sobriety, family responsibility and consumption were working-class virtues suited to largescale industry. All such virtues were promoted through moral campaigning. Moral reform became a civilising crusade to reconstruct the character of labour itself. In the United States, the promise of unprecedented ownership of leisure goods came with the constraint of new virtues in the regimentation of work. The repertoire of restraints on the 'way of life' was wide enough to include a version of virtue for the bourgeoisie as well. For the capitalists and the professional managerial elite, virtues of self-reliance and ever-energetic application were vocational forces. Patterns of ideology and culture such as these condition the structures of accumulation and regulation.

In encountering mass Americanism, European societies confronted a regime of ethics as well as an expansion of consumption. In Italy, the particular regime of accumulation and rationality associated with Americanism could not be replicated in full at that time, even though elements of Fordism were invading Italian industry in the north. While Gramsci's idea of 'civilisation' trails Marx's first notion of civilisation qua capitalist modernity, Gramsci constructs Fordism's Protestant ethics in a manner reminiscent of Weber. He identifies this as a cultural formation particular to the United States. Instead of a systemic logic that expands teleologically towards total rationalisation, the invasion of liberalism and rationality is seen as unfinished and resisted. Gramsci sheds light on the meso-sociological and micro-sociological forces competing with each other in the real-life worlds of factories, cities, families, unions and parties. The struggle against rationalisation is constant across these spheres.

Gramsci's notes also allude to the world-making, or rather remaking, that comes with Americanism as a result of the conflictual figuration of classes. In the background is modern Italy's relationship to its incomplete renaissance. Italian civilisation confronts Fordism as an entrenched world. In this confrontation, Americanism appeared to Europeans as a civilisational force of rejuvenation. 
There is thus a national struggle over the moral order that is civilisational in its contours as well as a class struggle that is political and economic.

Gramsci's reconstruction of problems of moral order and social existence in 'Americanism and Fordism' paved the way for a series of later neo-Marxist conceptions of capitalism. One neo-Gramscian offshoot turned explicitly to problematics of civilisation. Robert W. Cox has a disciplinary background in international political economy and international relations. He began by taking the implications of Gramsci's perspective on the uneven development of Italy's south beyond its national confines to an international level. For Cox to do this effectively, he harnessed theories of capitalism developed by Fernand Braudel, Karl Polanyi, Pitirim Sorokin, Georges Sorel, Harold Innis and Weber.

A plurality of versions of capitalism is implicit in both Polanyi's theorem of social economy and Gramsci's observations on the cultural composition of the American figuration. Cox's research had already laid down how various social structures of accumulation had formed in the world economy by cutting across different modes of production and class blocs. He later twisted this sense of plurality in a civilisational direction, while retaining this critical emphasis on variations to the historical structures of capitalism - a combination of problematics marginal to civilisational analysis. Cox's collection, The Political Economy of a PluralWorld, more comprehensively melds neo-Gramscian international political economy with civilisational problematics (Cox, 2002). Three of his general problematics are shared with civilisational analysis: civilisation in the singular coupled with a pluralistic notion; the nature of historical change diversified by different temporalities; and the potential of an interactive multi-civilisational order. Each is considered in turn below.

What is civilisation in Cox's estimation? There are some common-sense assumptions of civilisation and civilisations in the post-Cold War era, banal truths if you like (2002: 176-88). Cox casts civilisation in the singular as a background myth, almost as collective 'naturalized' intuition. For Cox, people do not identify with civilisation in their daily lives; it is a powerful common sense that operates at the level of the subconscious. Civilisations in the plural emerge as images built up over time as they are constructed inter-subjectively; 'civilizations exist in the mind' as a type of group animus (2002: 39). Three general orientations of the mind distinguish civilisations from one another: conceptions of time and space; how relations of individual to community are constructed; and cosmologies of the world and universe (2002: 177). Civilisations are distinguishable configurations of these three orientations.

Change is the essence of civilisations, according to Cox. Different temporalities are evidence of different rhythms of historical change. The patterns of diversity Cox finds do not match the image of territorially bound and reified entities 
that are the commonplace of neo-realism. He is led to the axiom that processes of change are the only enduring feature of civilisations. At the level of civilisation, the greatest stimuli to change come from the "carriers of interpenetrating influences' (2002: 145). It is reasonable to conclude that inter-civilisational connection counts the most, in Cox's account, in varying historical change and the settings of temporality.

This strong sense of interaction in the world order of civilisations is not confined to analysis of time and historical change. Plurality and pluralism are political values, as well as analytics. Noting US and Western hegemony in the United Nations and in world-capitalist relations, he poses his own utopia of a truly multi-civilisational international arena in which 'a weak centre in a fragmented whole' maintains a balance between states (2002: 185). Marx's image of struggling forces within societies is wholly projected by Cox into the world order as the analogy of a polycentric coexistence of civilisations without a hegemonic centre. This is the opposite of the 'one-ness' intrinsic to the project of globalisation and Anglo-American philosophies of neo-liberalism. It is premised on a substantial enlargement of mutual understanding through unconditional dialogue in which there is 'no closure, no end of history. No one (individual or civilisation) may legitimately reify the Other; i.e. treat it as an object (as in orientalism)' (2002: 174-5). Who can generate the vision for this? Cox looks to the organic intelligentsia of social movements for potential compacts of human and workers' rights, reduction of warfare and violence, remediation of threats to the biosphere and reversal of social inequalities. This is a worthy vision, though it remains unclear how polycentric norms can be instituted and communicated worldwide in an interactive politics that appears to be Cox's utopia.

Along with moves by Katzenstein and others in international relations to focus on the civilisational level (see also Unay and Senel, 2009), Cox's axiomatic comments are a significant contribution from the political sciences to the paradigm of civilisational analysis. They have not gone unnoticed and not escaped critical reception. The detractors cannot be addressed here, excepting one observation. Cox's advanced theory of international political economy is the most striking attempt to marry civilisational analysis and a version of Marxism, and none of the critics address this aspect of Cox's work.

Cox's vision of a pluri-civilisational normative global order animates the existing multipolar world, which still bears many contours of the modern empires (as he is well aware). To conclude, three comments on the historical emergence of capitalism are called for in light of the three Marxist perspectives examined in this section. First and most obvious is the accumulation and multi-nationalisation of capital. Processes of accumulation occur under different social regimes that more or less temper expansionary tendencies. The outgrowth of the economic 
sphere is a by-product of the intensification of inter-civilisational engagement in early modernity and can only properly be understood as a multidimensional process. Second, the expansion of different kinds of capitalist rationality and forms of trust are significant as cultures of capitalism. Contrary to some enthusiasts for globalisation, the expansionary pattern is not uniform, nor does it lead to uniform results. For example, practices and forms of trust are situational and should be seen as such. Arguably, trust is contingent on civilisational contexts as well. Third, the monetarisation of economic relations vividly transformed material practices and what they mean in everyday life, invoking the imaginary of money that Marx sketched in The Grundrisse. From the point of view of globalisation analysis, the financialisation of commerce, investment and accumulation represents an escalation on the global plane of economic activity. As a result, financialisation has reconstituted money as a new species of imagined wealth. Although much debated, there is a general understanding that the exponential growth of finance capital has instituted a sui generis trans-national economic power. However, from the point of view of civilisational analysis, there is a longer history to these processes that is essential to understanding the dynamic relationship of the capitalist imaginary and its civilisational varieties. These three comments are elaborated in Chapter 4 in analysis of the multidimensional engagement of civilisations.

The historical remaking of the modern world as a global world by colonial empires is tied up in this emergence of the imaginary of capitalism. Relationships of colonialism and capitalism feature in the next chapter. However, there is a third counterpoint to consider. Civilisational analysis has generated quite different perspectives from post-colonial currents on civilisations, capitalism and colonialism. Is there a juncture at which they meet?

\section{Post-colonial currents}

In this section, I compare the forming fields of post-colonial sociology and contemporary civilisational analysis to single out incongruities and demarcate points of potential dialogue. By any assessment, post-colonialism is a complex field. It is too large to survey here. The focus instead is specifically on post-colonial sociology, due to its critical meditations on both post-colonial studies and the paradigm of multiple modernities. The central barrier to finding common ground between post-colonial sociology and civilisational analysis lies with the theoretical and normative dissonances of the two fields and their criticisms of each other. From the vantage point of civilisational analysis, some outcomes over the course of post-colonialism's life 'deserve nothing but rapid dismissal, while others seem open to mutually instructive dialogue' (Arnason, 2003: x). At the same time it 
must be accepted that not all works of civilisational analysis are responsive to the potential of cross-fertilisation with other critiques of Eurocentrism. Some comments on the specific nature of post-colonial sociology are needed to clear the ground for comparison of the two fields. Potential cross-fertilisation is then explored by bringing in perspectives on connected histories.

Post-colonial sociology came from critiques of two areas of scholarship. The first target has been existing post-colonial studies, which has narrowed its power of disclosure to literary and cultural criticism (Bhambra, 2007; Boatcă and Costa, 2010). Second, there is critical alarm about sociology's general detachment from post-colonialism (Connell, 2007; Go, 2013). Apart from these common points of origin, post-colonial sociology is still solidifying. Unlike other versions of the post mode, post-colonial sociologists insist that power and epistemological domination should be central to sociology. In examination of particular histories of imperialism, post-colonial sociology has made power a central problematic in ways that have not proved possible for post-colonial studies in the humanities. But metropolitan social science is also implicated in post-imperial political, economic and structural forms of domination (Connell, 2007). By invoking a macro-sociological level of analysis of global inequalities, post-colonial sociology pinpoints the problematics of power that figure in a challenge to the epistemological foundation of metropolitan sociology. The field also claims considerable critical purchase in critiques of power at the meso-sociological and microsociological levels (Boatcă and Costa, 2010: 20-6). Post-colonial sociology thus fashions itself as a critique of the whole frame of social, economic, epistemological and political relations.

Dissensus between civilisational analysis and post-colonial sociology turns on three key issues: how culture is conceived, what politics should inform analysis, and a dispute over the character of modernity. Post-colonial critique of essentialist conceptions of civilisation pinpoints the neo-Weberian strategy of privileging European cultural dynamics. Civilisational analysis reifies cultural units, according to Boatcă and Costa (2010: 23-6). The cultural programme claimed for Europe in civilisational analysis essentialises culture, rather than making a persuasive argument for European exceptionalism (Bhambra, 2007: 5-8). In doing so, post-colonial sociologists claim, civilisational analysts bracket out power and the social with the consequence that complex landscapes of identity and conflict are homogenised. Stable cultures posited as entities fill the global picture of civilisations in a manner that resembles Huntington's analysis too much to be a viable alternative to it. Instead, post-colonial sociologists advance 'relationalism', defining this alternative as historical sociologies of those relations that manifest essences. Bhambra argues for a framework of 'connected sociologies' as an analysis of modernity as a consubstantial emergence from the relations 
between societies, particularly the hierarchies of imperialism (Bhambra, 2014). Building on connected histories, post-colonial sociology aspires to a relational framework better suited to the goals of a proper global sociology.

Contemporary civilisational analysis is not unresponsive to the critiques. Responses are most evident in process- and interaction-based approaches - the second and third approaches discussed in the second chapter. Hall and Jackson privilege process over essence in a strategic response to concerns over essentialist notions of culture (Hall and Jackson, 2007). Their emphatically 'post-essentialist' perspective is 'a serious effort to suggest and develop modes of civilisational analysis that do not rest on such misleading foundations' (2007: 2). Emphasising themes of power, process and discourse in different ways, Katzenstein's picture of civilisations posits trans-civilisational and inter-civilisational engagements as more likely than unified civilisations with a core essence. Engagements of these kinds are processes of formation and flux of regions. The processes privileged by Katzenstein are thus not essentialist reconstructions. Mention of interaction of civilisations brings Arnason to mind as the chief current-day proponent of 'intercivilisational encounters' that shape civilisations. The significance of his work is discussed in Chapter 2. For present purposes, it is mentioned to point to nonessentialist achievements in contemporary civilisational analysis. The collective research enterprises led by Hall and Jackson, Katzenstein and Arnason are all achievements beyond essentialism and should be acknowledged as such. Postcolonial sociology seems not to have taken them into account.

The second dissonance is orientation to transformative politics. Scholars in contemporary civilisational analysis do not stand out with any specific political position and so it is more accurate to describe the politics of the field as an orientation. Post-colonial sociology, by definition, is at odds with older imperial hierarchies that are reproduced in contemporary social science (Boatcă and Costa, 2010; Connell, 2007). At the same time, older post-colonial perspectives are abandoned because of their accommodation with a 'politics of image' that endorses the ethos of tolerance of existing versions of multiculturalism. In their stead, post-colonial sociology aims for a new social scientific landscape informed properly by the historical knowledge bases of the peripheries and critical disclosure of the relations of domination (Bhambra, 2014). Southern theories and sciences are foremost in this respect for their content, but also for their alternative epistemologies and methodologies (Connell, 2007). Connell does the most to empirically canvass and compare bases of knowledge of peripheries as 'Southern' ideas, beliefs and doctrines. Her quest for a science that reflects southern worlds and assists the development of a global sociology gives her a political mission that resonates with the transformative politics sought by other post-colonial sociologists. For Bhambra, by highlighting 'the importance of the politics of the present 
(and the past) in our interpretations' (2007: 147-8), post-colonial sociology can address many of the gaps in post-colonialism at large, for which the latter has been criticised from other radical perspectives. The inter-connections of the past should be reinterpreted from many standpoints and potentially with new facts in order to effect the provincialisation of Europe (Bhambra, 2007: 153-5). Any critique of the present rests on core values that should also guide interpretation of the past. Shilliam (2015) provides a solid example of practice in connected histories in his survey of decolonial scientific connections between anti-colonial movements linking Africa, New Zealand (Aotearoa), the North Pacific and the United States. The presence, contestation and activity of Maori and Pasifika communities (particularly the youth) in creating solidarities between different postcolonial cultures denies the monopoly of truth claimed by the post-colonial heirs of colonisation.

Sociology has only began to elucidate and give voice to linkages made between indigenous movements such as the Maori and Pasifika ones. Latin American scholar-activists have made more progress in highlighting the weight and political significance of alliance-building across indigenous movements. Latin American decolonial thought and praxis is one position claimed by post-colonial sociology to serve a politics of the present and to claim a point of departure from existing post-colonial critique. The findings of Latin American decolonial scholaractivists have been neglected by established post-colonial studies. Drawing on legacies of dependency theory and liberation theology, Latin American perspectives correct the loss of critical impetus evident in the one-sided cultural criticism of much of post-colonial studies (Moreno et al., 2008). Too many are silent on present-day political, social and economic conditions - a charge laid against both civilisational analysis and post-colonial thought by Marxists (Dirlik, 1997). Decolonial critique, with its deep roots in oppositional movements to which dependency theory and liberation theology are related, is oriented to projects of transformation of the relations of domination. Moreover, decolonial critique is a carrier of the specific historicity arising from a long experience of colonialism. With this strong sense of historicity, Latin American decolonial intellectuals, like post-colonial sociologists, uncouple the notion of coloniality from postmodern relativism in order to keep notions of social power and inequality at the heart of analysis. Coloniality is presented as a historical experience of power, dispossession, slavery and other modes of forced labour, and a long war of indigenous peoples and their civilisation going back to the late fifteenth century. Decolonial scholar-activists keep current-day forms of the global power of capitalism firmly in the frame. This is a strong base from which to explore indigenous civilisations, particularly in the Western hemisphere. Historical connections in the Western hemisphere that have been recently recovered have strong 
similarities to indigenous and black solidarities identified in decolonial scientific practice observed and advocated by Shilliam in the Pacific (2015). Indigenous practice is a counter-science, in Shilliam's account, due to the 'deep relation' it embodies. Shilliam observes that '[d] ecolonial science seeks to repair colonial wounds, binding back together peoples, lands, pasts, ancestors and spirits. Its greatest challenge is to bind back together the manifest and spiritual domains' (2015: 13). Forms of decolonial critique in post-colonial sociology have much to offer, but only early results are available at this point. By contrast, traditions associated with subaltern studies have not paid much attention to indigenous civilisations. Nor has contemporary civilisational analysis.

Civilisational analysis has no equivalent of a politics of present conditions. Instead the common denominator is a normative commitment to the ideals of the democratic imaginary and a critique of the totalitarianisms of the twentieth century (Eisenstadt, 1999a; Wittrock, 2000). How the social order is instituted, how conflict is shaped, how social goods are constructed and sought, and how social relations are mediated depends on deeper cultural premises and the quality of societies produced from them. Investigations into democracy are not confined to constitutions, procedures and laws but also the sources of motivation in politics. Eisenstadt poses this as the 'fragility' and continuity of modern democracy, describing it in terms of the 'central premises' of political life (1999b). Democracy is truly contingent (and hence fragile), even though informed at its roots by the cultural premises set by the political revolutions of modernity. Politics is therefore related to other dynamics of modernity in contemporary civilisational analysis, instead of acting as the pivotal point of epistemological orientation as the 'politics of the present' does for post-colonial sociology.

Eisenstadt's theses around multiple modernities are the final and most controversial area (Boatcă and Costa, 2010; Patel, 2013). Post-colonial sociologists have their own particular criticisms, best represented by Bhambra. The stated originality of Europe's cultural programme reveals a Eurocentric position too prominent for the multiple modernities paradigm to act as a thoroughgoing alternative (Bhambra, 2007: 56-74). The West is 'both the origin of modernity and ... the origin of multiple modernities' (2007: 67). Furthermore, the image of processes of multiplication of the original programme remains diffusionist. Even when finer typologies are introduced, diffusion of Western forms remains the implicit process. Despite disavowals of Orientalism, the multiple modernities paradigm amounts to a European exceptionalism unable to adequately serve pluralistic social science (Bhambra, 2007: 67-71). Bhambra's alternative is an interrogation of the very notion of modernity itself and adoption of 'connected sociologies' as a paradigm of explanation and project of change. In her project, slavery, imperialism and racism are connected to modernity (2014). Parts of 
her critique hit the mark. Even so, other aspects of civilisational analysis are bracketed out from critical assessment altogether, making it a partial critique. Bhambra treats only a fragment of Arnason's civilisational analysis and there is no acknowledgement of his variance from Eisenstadt's theses on Axial civilisations and multiple modernities. There are also other possible directions for multiple modernities that are not considered. For example, theories of power in multiple modernities carry potential for the development of an illuminating political sociology (see Knöbl, 2006a). Neither post-colonial sociology nor contemporary civilisational analysis have yet perceived that potential.

Clarification of positions on the main points of contention is a good way to start clearing the ground for common and mutual understanding on key points. The ground for dialogue can be enlarged via a reconstruction of two further positions: the use of ideal typology and the connected histories genus of global history.

Bhambra critiques ideal typology for its rigid commitment to value-relevant categories (as allegedly universal) irrespective of empirical evidence (Bhambra, 2014: 146-9). The consequence of adoption of multiple modernities as an analytic is to replicate an erroneous methodology, rather than fundamentally revising the hierarchy of knowledge and values informing it. In order to replace ideal typology, she proposes to harness the connected histories methodology pioneered by Sanjay Subrahmanyam (Bhambra, 2007: 153). For Bhambra, this paves the way for a more adequate explanatory framework. Other currents in history stress entanglement of states and civilisations by going back to an era of early modernity. For example, Shalini Randeria analyses 'uneven and entangled modernities' as a compelling reformulation of the multiple modernities paradigm incorporating diverse experiences of colonialism (2002). In the place of societies and civilisations, she emphasises intra-societal modernities in order to explore the variation in social experiences of modernity. Looking to the global plane instead, Conrad and Sachsensmaier distinguish inter-cultural connections and worldwide exchanges as articles of analysis (2007). From their point of view, some historical conjunctures are more vital in the degree of connection achieved. The fin de siècle phase of globalisation commencing in the 1880s is one such conjuncture (2007). Shilliam turns the focus to a more recent phase of building anti-colonial connectivity by looking at the deep relationality built in the 1970s and 1980s between Maori and Pasifika movements in New Zealand (Aotearoa), Black Power movements in the United States, Pan-Africanists and Rastafarians (Shilliam, 2015). Inspired by strong sentiments of solidarity and goals of consciousness-raising in overseas movements, young activists, musicians and artists found motivation to examine their own traditions and revive the modality of connection that existed in their worlds. Support for indigenous 
and black movements at the World Council of Churches in 1968 - though not so widely publicised - along with the reform programme of Vatican II Catholicism made black liberation theology a feasible and appealing way to challenge white (Pakeha) hegemony in New Zealand (Shilliam, 2015: 71-87).

Each of these perspectives on entanglements in global history displaces ideal typology. Shouldn't they get more of a hearing in civilisational analysis? The first integrationist approach seems more blocked from the results of interactive models. Ideal typology brought to much of civilisational analysis an image of civilisations as relatively detached, endogenously generated entities. By analytically isolating components of social formations for the purposes of comparison, this particular approach acts to suppress inter-relationships. In comparative analysis of a neo-Weberian inspiration, components of civilisational constellations are catalogued as types, and thus civilisations and societies appear as detached, bounded and unaffected by exogenous influences and flows. As a result, the full vitality of connections within which civilisations 'exist' and become meaningful has not been as fully recognised. Fitting civilisations to ensembles of types of components - rather than setting them against the historical background of their situated contexts and connections - inhibits a fuller picture of the abundant plurality of the social historical world including forms of domination, exploitation and violence. The emphasis on linkages that is foregrounded in connected and relational histories restores to analysis of civilisations macro-regional and meso-regional contexts and the exogenous influences on civilisations circulating in them.

An instance of the displacement of ideal types is with the presumed unity of Europe itself based on a selection of perspectives. Potential exists for paradigmatic common ground here around which adversarial dialogue could be conducted. Dipesh Chakrabarty's project of provincialisation is a helpful junction as, like post-colonial sociology, it represents greater distance from post-structuralist perspectives. His interpretive strategy undermines the image of Europe as the centre and its history as a generalisable universe (Chakrabarty, 2000). Arnason has an interesting angle on this (2003: 346-50). A realignment of Chakrabarty's project and civilisational analysis could bring strengths from each area to a newly constituted perspective. For Arnason, Chakrabarty's assertion that the figurative unity of the West should be differentiated from historical geographies of power in Europe implies a distinction between Europe's universalised provincial histories and its own outposts. The dismemberment of the figurative image of 'Europe' is a shared interest of post-colonial thought and recent civilisational perspectives alike. He points out that Eastern and Central European histories would look different with a nuanced geography of Europe's centres and peripheries. Research incorporating the multi-civilisational European past would 
respond to Chakrabarty's appeal. Some post-colonial sociologists have notably pursued a similar critical decentring of the presumed European bloc. In all, then, Chakrabarty's provincialising approach can clearly be related to the connected histories of world regions by problematising world regions whose homogeneity is exaggerated.

Subrahmanyam's connected histories could contribute to opening the intersection of the two fields. The approach brings together areas of histories artificially kept apart by the conventions and prejudices of national histories. Post-colonial sociologists have enthusiastically endorsed his methodology, if not always his findings. Comparative and historical sociologists would benefit from returning to his work for more careful consideration. His notion of 'connected histories' and his characterisation of early modernity as a conjuncture of processes embody one periodisation of early modernity running from the fourteenth to the eighteenth centuries (Subrahmanyam, 1997, 2005b). Changed material conditions in the sixteenth century furnished favourable circumstances for enlargement of the geographical reach of world connections (2005b: 107-10). Simultaneously, those conditions supported the emergence of early modernity as a global conjuncture of quite uneven and dissimilar processes - including the conjoining of major trading networks, the European voyages of exploration, conquest and colonisation, and the multivalent activities of Indian traders in the wider Asian sphere. In his prolegomenon, Subrahmanyam picked out five key vectors of integration: increased travel and growing inter-cultural awareness; greater conflict between urban and agrarian cultures and nomadic societies; a distinct outgrowth of world trade; renewed ideologies of a Universal Empire across different polities; and the coalescence in variable guises of nascent processes of individuation (1997: 736-40). Early modernity was a global conjuncture that should be 'delinked' from specifically European paths and re-scoped as a wider unity. Subrahmanyam draws out the networks traversing many regions and sometimes distant trajectories and formations. His argument discerns specific connections between and within empires and states across a Eurasian modernity.

On the surface, there seem to be good reasons for scholars from both fields to be interested in Subrahmanyam's reconstruction of the early modern conjuncture given his analysis of concurrent connected processes. His specific factors are still up for debate, of course. But the methodology should be appealing, and it clearly is for post-colonial sociologists. For Sheldon Pollock, the methodology is provisional, and is treated as such in his wide-ranging histories on Eurasian transformation. His histories illustrate barely examined disparities in early modern inter-regional and trans-regional processes (Pollock, 1998, 2004). Part of the reason for the neglect that he highlights is that the historical evidence pointing to macro-regional spheres is patchy. But the problem is more 
than an epistemological one of finding evidence. The challenge is to transcend the legacy of Orientalism with methodological shifts. In Pollock's eyes, 'connected histories' is a mode-in-the-making, capable of sorely needed scholarly work on neglected regions in neglected phases (Pollock, 1998: 6). His version incorporates the capacity to privilege processes that reach across many societies, notably the vernacularisation of Sanskrit and Latin in the early second millennium. In Pollock's hands, culture shapes the kinds of power that ruling classes develop and exercise. His historical sociology extends Subrahmanyam's scope of connected histories into language, court cultures and power.

While Pollock's research sits in civilisational analysis, Subrahmanyam's histories do not receive the recognition in the field that they should, with a few exceptions. Subrahmanyam is suspicious of the proposition that civilisations are long-term formations, and he responds with emphasis on connected regions and regional contexts. When it comes to comparative sociology's neo-Weberian meta-theoretical framework, Subrahmanyam is clearly distant. He spurns Weber's 'cultural explanation' because of its Eurocentrism and it finds no favour with him due to the privilege it accords to Western Europe (1997: 760). This may be the reason for the limited engagement of Subrahmanyam and contemporary civilisational analysis.

The reception from post-colonial sociologists is warmer. The affinity of the two makes sense at first, as Subrahmanyam's methodology decentres European exceptionalism. Subrahmanyam himself makes no comment on post-colonial sociology that I know of. But he is scathing in his critique of post-colonial currents in general. He spurns post-colonial critique in its entirety, noting the paradox that post-colonialists miss the sixteenth-century juncture in which efforts at writing world history started to emerge because of their preoccupation with the European monopoly of history (Subrahmanyam, 2005a). His hostility explains his neglect of the decolonial tradition in his histories of the Iberian empires. As observed above, Latin American post-colonial thinkers have distinguished themselves by arguing that modernity should be reconceived as a figuration of coloniality derived from the imperial formations considered here by Subrahmanyam. Extraordinarily, Subrahmanyam overlooks the work of decolonial scholars. Of course, it is the ahistorical character of post-structuralist versions of postcolonialism he has in mind.

Other world histories that have affinities with 'connected histories' show that the trend is wider. Relational histories highlighted by Randeria and Conrad, along with global history more generally, seek renewal beyond nationalist historiography. Other arguments for renewal have taken place during the time that Subrahmanyam and Pollock have been active scholars of inter-regional linkages. The problematics of connection and regionalism can be common ground 
between contemporary civilisational analysis and the connected histories advocated by post-colonial sociologists and practised by Subrahmanyam and Pollock and others. Civilisational research into world regions lays claim to a decentring effect as a result of the critique of area studies and re-problematisation of modernity that puts regions into question (Arjomand, 2014a; Katzenstein, 2010a). But there are limits too set by the multiple modernities paradigm, which could unwittingly reproduce aspects of area studies. Regional zones and civilisations might easily be conflated. The counter-argument is that regionalisation and inter-civilisational engagement are associated but variable processes. Two contrasting seventeenth-century examples serve to illustrate the point. East Asia in early modernity had a thick regional nexus engaging Japan with China, which at that time had reached a new low. Japan's response was a deliberate strategy of withdrawal. Regionalism in early modernity was defined in East Asia by this unusual pattern of engagement whereby Japan voluntarily put a distance between itself and China. By contrast, in the colonisation of Meso-American worlds the Central Americas were forcibly incorporated into a newly emergent sphere of trade, slavery and exchange. In the context of a hemisphere of inter-civilisational engagement, the Conquest related Central America to multi-layered regions and sub-regions, intra-hemispheric connections and long chains of inter-continental dependence. In these two examples, one finds very different patterns of regionalism and varying interactive environments. Japan undertook voluntary reconstruction of regionality; Central America was forcibly and violently and violent insertion into the world nexus of empires.

Both examples foreground early modernities. In existing civilisational analysis, connectedness is more adequately thrown into relief in studies of early modernity than it is in studies of later multiple modernities. A focus on early modernity as a period has brought into question accepted wisdoms about the sources of modernity. In Subrahmanyam's words, 'it is certainly important to distinguish between "colonial modernity" and that which existed both before and elsewhere, but we cannot simply assume from this that what was there before was not itself a form of modernity' (2005a: 3-4). He suggests that turning the lens of connections on longer histories of contemporary constellations can be helpful in disclosing non-Western modernities, as well as better understanding the colonial empires and the colonialities that they engendered.

\section{Conclusion}

With some interpretive licence, I have explored three paradigms in this chapter, looking for prospective relationships with the field of contemporary civilisational 
analysis. The intersections that come into view are of different kinds, and they have different prospects for progress. Civilisational analysis is close to perspectives on globalisation and regionalisation. The most illuminating of perspectives in globalisation theory examine longer historical trajectories, much as scholars of civilisations do. The claim of an intersection is more challenging to sustain with Marxism. However, the argumentation here serves to underline traces of Marx's insight into the symbolic and imaginary dimensions of capitalism. To this we can add Gramsci's elaboration of normative spheres of social life associated with different figurations of capitalism. We then have some basis for theorising how civilisations interact with global capitalist impulses to produce varying social regimes. Cox's model of international relations results from a wide-ranging synthesis of civilisational theory and neo-Gramscian Marxism. This is not the only one possible of course, but it is suggestive of much that is left out of other versions of contemporary analysis of civilisations. For Cox, civilisations are interactive and it is in a wide range of interactions that the boundaries are reset. Change comes about through a combination of endogenous contradictions and through encounters with other civilisations. Cox's accent is unmistakably on the multiplicity of civilisations formed in unintended interaction. Likewise, the capitalist imaginary produces varieties of capitalism through interaction with the multiplicity of civilisations. On the basis of Cox's theory, a key claim can be made around inter-civilisational engagement: early modernities are more important in the long formation of capitalism, particularly in respect of the cultures and juridical instruments of trust and the coalescence of the imaginary of money. This claim is explored further in the next chapter.

In the last section, the developing critique of post-colonial sociologists highlights questionable theoretical premises and methodological choices in the multiple modernities scholarship. They contend that connected histories and other versions of relational history are better equipped to provide understanding of the hierarchies of power in imperialism and in successive post-colonial formations. Empires are a formidable feature of the history of state power in modernity, and yet are only accounted for in recent decades and even then incompletely so. Post-colonial sociology invokes the centrality of empires, slavery and modern colonialism in the formation of the world system. A space can be elucidated in which the two paradigms claiming the mantle of anti-Eurocentrism could cross. For the version of civilisational analysis advocated here, I take away the potential of methodologies of relational history to also suggest connections between civilisations. Against the backdrop of other versions outlined in previous chapters and the critical counterpoints of this chapter, the next step is to elucidate the nature of inter-civilisational engagement in detail. 
4

\section{Inter-civilisational}

\section{engagement: imaginaries, power, connected worlds}

Chapter 4 of Debating Civilisations outlines the conceptual framework of intercivilisational engagement, thus establishing the groundwork for the deeper studies of Part II. The stress in Part II is on a new approach that critically harnesses the best research in civilisational analysis, history and sociology that focuses on interaction between civilisations. The new approach joins existing civilisational analysis with an appreciation of the imaginary creation of forms of interaction and a survey of critical paradigmatic alternatives. Some comments on the interaction and paradigmatic alternatives preface a fuller introduction of my principal concept.

To begin with, I emphasise the ties instituted by existing and coalescing imaginaries between different societies. Imagined connections and obstructions produce a remarkable diversity of linkages instantiated by exchange, adaptation and reform. Civilisations are made meaningful and therefore 'real' by the commerce of ideas, goods, aesthetics, political and legal models, sciences and techniques and by the movement of people. Mobile people, knowledge and practices shape interaction and transmission - in other words, how porous the boundaries and divisions are. Responsiveness to ideas, beliefs, methods and styles emanating from different traditions is a gauge of those traditions' porosity. 'Civilisations' understood in this way are given meaning in contexts of interaction, connection and exchange, which often involve power.

The counterpoints foregrounded in Chapter 3 matter hermeneutically to the current argument as paradigmatic alternatives to learn from. What do those counterpoints have to say? From the point of view of connected histories and post-colonial sociology, the links between societies are greatly neglected in dominant nationalist traditions of history writing and sociological research. In that line of argumentation, we can also see that globalisation theory is also vulnerable due to the absence of connections prior to 
the nineteenth century that appear in its purview. Because of the presentism of the short histories of globalisation, global connectivity itself is not given visibility over the long term - though there are interesting exceptions at the margins of that paradigm that stress long historical processes. Marxist explanations of economic relations focus on the exponential accumulation of economic power in various ways, but are less well equipped when it comes to civilisations as large-scale complexes. Again, as we have seen there are interesting exceptions at its perimeters where there are openings to other enriching perspectives. Manifold links between societies of a longer pedigree are accentuated in global history and in the relational histories featured in the previous chapter. All of these paradigmatic points of view illuminate important insights. However, they fall short on critical questions that can be posed within civilisational analysis. None look deeply at the interstices or the connections between civilisations as such.

The aim in this chapter and the next is to address this gap by assembling a framework for comparative and historical research into deep relations between civilisations. In extending the interactionist current of contemporary civilisational analysis, I elucidate four dimensions of inter-civilisational engagement: migration, deep engagement in economic relations, cultural exchange and creation, and political reconstruction of civilisational models. The four dimensions are not exhaustively treated and are analytics for further substantive research, starting with the exploration in chapters in the subsequent part. This chapter features several examples that illustrate aspects of the argument. Most of them are remote from the twenty-first century and are chosen to illuminate what has generally been neglected: the very early development of large-scale connections in human history. The aim of the examples selected is to clarify the framework rather than to validate it as such. Subsequent chapters in Part II, on the other hand, aim for greater depth by exploring the modern case studies of the Pacific, Latin America and Japan.

\section{Dimensions of inter-civilisational engagement}

As argued thus far, historians and sociologists have explored a host of civilisations sitting between the opposing poles of definitive closure and porosity. The historical record throws up quite distinct cases of trans-cultural and transactional closure. Given the diversity, a robust conception of civilisational diversity must incorporate less-inclusive formations that have existed. At one end of the continuum, histories and sociologies that trace inter-civilisational encounters pinpoint pivotal episodes of contact, communication and exchange. They have also 
noted unusual cases of non-encounters, in a manner of speaking, where there is no contact or where civilisations are demarcated by detachment.

Notwithstanding important cases of closure, the transactions between civilisations are, on the whole, deeper than many of the major accounts in comparative sociology and world history have suggested. It is contended here that civilisations are made meaningful at points of intersection. Processes of creation of structures, beliefs, modes of learning, identities and forms of belonging gain impetus in the rhythms and tempos of interaction instituted by imaginaries. This is not to suggest that primarily endogenous modalities of life have no influence, but rather that those modalities are animated by cross-fertilisation and communication, however unequal, power-laden and conflictual that may be. Moreover, inter-civilisational contacts are not just 'cultural' in the thinner sense that Alfred Kroeber intended when he asserted that high levels of dispersed human contact characterised much of pre-industrial history (Kroeber, 1948). The significations of civilisations also lubricated the economic, political and demographic contacts and associations of the pre-industrial cultures that Kroeber explored. The most visible of the many routine connections and those that have lasting impacts are outright encounters (in the sense described by Nelson and Arnason). It is as a result of recurring relationships that encounters are possible and gain their importance in constituting civilisational dynamics. In the opening chapter, inter-civilisational engagement is defined as the regularisation of contact and encounter. To be sure, intense periods of deep inter-civilisational engagement should be scrutinised as ground-breaking inter-civilisational encounters in order to discern wider ramifications. However, inter-civilisational engagement is often more generalised and pervasive. It has a heavier gravity in the structures of daily existence. Regularised contacts and connections over long historical periods are of a different order to encounters. Where encounters are treated analytically as episodic and time-bound forms of interaction, inter-civilisational engagement can be applied as a problematic of the connectedness of world regions, societies and cultures over a longer duration. Of course, there are differing degrees of inter-civilisational engagement, just as encounters differ widely in the significance that the literature attributes to them. Be that as it may, there are precious few societies and civilisations that have been isolated from inter-cultural contact altogether or that have completely closed and fixed symbolic borders for lasting periods of time.

Engagement occurs and unfolds as a process in four discernible dimensions:

1. Migration leading to, in some instances, the creation of inter-cultural spaces. Conquest, warfare and occupation are particular spurs to migratory movements, flight, exile and enslavement. 
2. Deep engagement in economic relations through commerce, the practices of trust-building, the growth of networks and, in the last five hundred years, the imaginary institution of forms of capitalism.

3. Cultural exchange and creation through practices of borrowing, blending, translation, imposition and fusion in science, the arts, architecture, religion and language.

4. Exchange may involve the political reconstruction of civilisational models.

States have some involvement across the board. Also, all dimensions are contexts of explicit power, though no dimension is over-determined in its entirety by the modes and dynamics of power. There is momentous evidence establishing engagement across all four dimensions in human history and plenty to suggest that more could be unearthed with further investigation, and indeed will be. Comparative sociology and world history has focused primarily on land-based civilisations. The civilisational perspectives on oceanic and seafaring empires featured in the next chapter show a different complexion of inter-civilisational engagement and thus they are considered also as zones of engagement.

\section{Colonists, pilgrims, missionaries, slaves, workers: migrants as bearers of engagement}

It is a tenet of migration studies that all societies put out migrants (Manning, 2013). Under the influence of nationalist historiography historians have, until recently, consistently under-estimated the weight of migration in global history. By employing a civilisational perspective, some balance on historical trends can be pursued. A point to begin with is that nomadic movements and the invasions of marginalised peoples have been formative influences in the origins of civilisational bases. They were not related to trade or proto-state formation, but were sui generis one-way movements (Therborn, 2011: 35). Initial waves of exit from Africa formally ended with the invention of agriculture and animal husbandry and early manifestations of conflict. Since both manners of food production enabled human settlement, the seven (or nine, in some accounts) parallel inventions of agriculture laid the ground for the first civilisational bases between 11,000 and 4,000 years ago (McNeill and McNeill, 2003: 25-51).

Nomadic passages continued and indeed have been an abiding feature of global history. Since the formative phase of human expansion, nomads have also re-stimulated civilisational bases at different points (Cox, 2002: 144). Sea-bound movements were crucial (Gillis, 2013: 22-4). Voyaging brought distant ancestors of Australian Aboriginal civilisation through South-East Asia to the southern 
continent. In the last primary migration, Lapita peoples consolidated the western Pacific and then spread to Fiji and Samoa before completing colonisation of the ocean basin by reaching the Polynesian islands and Easter Island (Rapa Nui). Four theories of the peopling of the Americas are still debated, but the Bering Strait land bridge is still considered the most likely route (Paine, 2013: 22-5). Further migrations around Ando-America and Meso-America stimulated processes of primary state formation and civilisational crystallisation. When states disintegrated (the Mayan being a prime example) further waves of migrants entered the major centres, often resulting in the foundation of new states. In sub-Saharan Africa early expansion of Bantu-speaking peoples into southern Africa is a different example of nomadic migration.

Ancient migrations were expansionary. Early Egyptian hegemony set a maritime trajectory for the Mediterranean. In the Bronze Age, colonising impulses were a particular feature of sea-going peoples in the eastern Mediterranean, especially the Phoenicians and the early Greeks. Phoenician expansion occurred through creation of trade cities without the protection of an empire. The Greeks were more land-bound and bent on replicating cultural worlds through the establishment of colonies. They were roundly oriented to localised and autonomous coastal markets rather than a quasi-imperial thalassocracy of controlled trade like the Phoenicians. The Romans more fully subsumed colonisation under the logic of warrior conquest. In turn, the long warrior and maritime empire of the Romans suffered invasions from Huns, Vandals and Goths. The Han Empire also bore incursions into northern China. Invasions weakened the dynasty, which, in turn, became vulnerable to internal rebellion. Dynastic decline resulted and the greater empire disintegrated into rival regions. On the other hand, the Turkic steppe nomads who plagued the northern Chinese were also integrated into the caravan trade, making them distinct as a peripatetic people.

Nearly a thousand years later, the SeljukTurks penetrated Islamic lands prompting cultural renewal amongst urban elites (McNeill and McNeill, 2003: 130-3). An unintended effect of their presence was to reconfigure the composition of Sunni and Shia forces. They gave effect to a cultural transformation through the shock of frontal conflict. Later weakened by the Crusades, an arm of the Seljuk Turks remained in Anatolia and became 'Turkish' through long-term occupation (Manning, 2013: 97-8). The nomadic empires emanating from Central Asia had a deep effect on South Asia, arguably demarcating new political regions and precipitating the formation of the Delhi Sultanate (Pollock, 2004: 268-9). Finally, the occupation of New Zealand and other islands in the Pacific by Polynesian voyagers pushed peoples at the edge of the eastern perimeter of the Asian littoral into extraordinary efforts of colonisation. 
The above paragraphs suggest that the tempo of post-nomadic migration was highest in the second millennium. Taking the second millennium as a discrete time-bound problematic, Hoerder identifies five sub-periods (2002: 2-8). In the first, spanning the twelfth to the fifteenth centuries, Mongol unification of Central Asia shaped trade and demographic movements, giving way, at the end of this phase, to a new post-feudal unity in Europe. The long disruptions to continental migration subsided in the fifteenth century. For the second period (ending in the eighteenth century), Hoerder privileges 'an intercivilisational comparative approach' to examine increased rates of migration (2002: 3). Whether compelled by adversity at home, sent by state or religious authorities or forced through slavery, people moved from Europe and West Africa to the Americas, from East Africa to South-East Asia and from western India to China. Missionaries, pilgrims, labourers, peasants, officials, merchants, artisans and soldiers who moved to new lands confronted the economic and cultural universes of distant and sometimes unfamiliar civilisations. Labour migration included slaves forced into the flow of emigrants departing Africa, Europe and India. For them, the confrontation with the economic and cultural universes of other civilisations was bewildering, particularly if they had been transported by sea. Should they survive the torments of an ocean crossing, then the trial of adjusting to new climates, regimes of labour and violent social and racial hierarchies faced them next, an inter-civilisational experience distinct from that of free labourers.

In the third period, a more familiar story of industrialisation, urbanisation and the expansion of capitalism unfolded. Unprecedented waves of migration to and within the Atlantic world patterned the institution of American societies. Colonialism structured migration in Asia even more than in the second period. Tens of millions of indentured contract labourers moved. Some returned to their countries of origin; many joined new communities that became entrenched over time. Chinese and Indian traders were prominent in dealings with the new colonisers and lived in enclave communities of their own, whether within Asia and the Pacific or in southern or eastern Africa. Distinctly new migratory routes across the Pacific mostly ended at American destinations. The sheer numbers migrating were significantly higher. In the first half of the twentieth century Hoerder's fourth period - the acceleration of Asian migration was one driving trend. In contrast, migration to the Americas closed down abruptly in the 1920s. Stalinist Russia's main passages were internal via forced relocation to the barbaric Siberian gulag. Post-war refugees fleeing war and totalitarianism coincided with migrants from newly decolonised states. In India's case, decolonisation was spectacularly cataclysmic in its early months, producing unprecedented transfers of Muslim, Sikh and Hindu refugees. In the fifth period, post-colonial emigration to the metropoles of the former empires turned monochrome white societies 
into multi-ethnic ones. Return migration brought former imperial servants back. For example, the aftermath of the Algerian War brought imperial cadre back to France as the starting point of France's most spectacular wave of postcolonial migration. Canada and the United States scrapped race-based restrictions on immigration to receive migrants from Asian and Pacific states and the Caribbean and Latin America. Labour and refugee migrations make up much of the rest of Hoerder's picture as it emerged before the end of the millennium.

If modern colonialism propelled experiences of migration, so also did pilgrimage. The first-millennium expansion of the world religions laid down many of the paths of pilgrimage (Therborn, 2011: 37-42). The practice of leaving a home community in response to a spiritual calling, with the expectation of returning, travelling often great distances and then completing the circuit with a return journey, thrust countless numbers of the faithful through different lands. Infrastructural support, waystations, accommodation and signposts sprang up over time on the most frequently used roads. As well as sacred acts, economic transactions occurred en route. The monotheistic religions regulated the pilgrim's obligations. The Hajj is the most encompassing and oldest of such movements. Since the late eighth century the Hajj has pulled pilgrims in vast numbers from Central Asia, North Africa, India and later South-East Asia. As the Hajj was on the long-distance trunk road between China and West Asia, it attracted traders on an annual basis. Islam was not alone in requiring pilgrimages. Before the Jewish Diaspora Judaism had included a duty to visits Jerusalem annually. Catholicism promoted pilgrimage successfully up to the fourteenth century, after which it declined in the face of Protestant denunciation of the practice. Major journeys were a lifetime inter-cultural event. Only one of three major destinations for pious peregrinators involved inter-civilisational experiences on a significant scale: travel to the Holy Land. The numbers travelling in a year counted in the hundreds and not the thousands that made pilgrimages within the European continent. The impact that pilgrims returning to Europe had was disproportionate to their numbers. Along with relics from the Holy Land, they returned with expensive and unusual goods sourced from the caravan trades. It is anachronistic to characterise this as medieval tourism. At the same time, sociologically speaking, pilgrimage involved so much more than fulfilment of spiritual commitment. Pilgrimage made energetic crossroads just as trade did.

Missionary ventures are a comparable kind of migration. Buddhism, Hinduism and Islam spread through South-East Asia through the collective labours of traders and migrants. Early Iberian missionaries to the Americas were the first to use emigration as a specialist vocation. The Jesuits launched worldwide missions in the sixteenth century. In the course of their vocation they amassed a significant archival store. Their encyclopaedic documentation of data about other 
civilisations amounted to an inter-cultural record. Likewise, later British missionaries to the South Pacific also produced ethnographic records of customary practices. Missionary enterprises found in inter-civilisational spaces have often been established via a whole transfer of agents and beliefs. Missionaries are symbolically associated with conquest. But missions can also act as agencies of intercivilisational engagement where their impact 'is not that of the direct shock of conquest but the slow accumulation of pressure upon an established order' (Cox, 2002: 144).

Iberian missions arose with the colonisation of the Americas. By the time of Columbus's intrusion into the Caribbean several empires throughout the world had occupied neighbouring territories and countries beyond them: for example, the conquest of Ando- and Meso-America by the Inca and Mexica (Aztec), the colonisation of north-western Africa by the empire of Songhai and the penetration of the Balkans by the Ottoman Empire, of southern India by the Vijayanaga Empire, of Indonesia by Majapahit and of Central Asia for a time by the Timurid Empire. The conquest of the Americas stands out for the violence wrought by colonial migration, as well as for the societies that it produced. Spain, Portugal, France and Britain allied their colonial bases in Africa with their American empires to fashion a tri-continental slave trade on a vast scale. Slavery was a legally codified form of migration, but its juridical form simply marked its barbaric practices rather than preventing them.

The exceptional asymmetry of transatlantic colonialism should not divert attention from the effects of migration on migrants. Large-scale migrations were highly transformative processes of inter-civilisational engagement. For expansionary civilisations, mostly European from the eighteenth century on, colonialism augmented trans-national cultural spheres (Anglosphere, Lusosphere and so forth). In conditions of political and economic domination, the emigration of Europeans escalated, assisted by improvements in transport and communications technologies and pushed by poverty and poor prospects in Europe. In the later nineteenth century, steamships cut travel times for people and their belongings. The telegraph brought synchronicity to communication. Whether as part of the nineteenth-century flood of colonists to the American New World, or to join émigré communities in British, Dutch and French colonies elsewhere, migration held out the hope of better life chances and inter-class mobility.

In no way is this exclusively a European experience, though much of modern migration is traced to Europe's empires. The peak decades of the nineteenth century may have seen tens of millions of Europeans migrate, but the numbers moving across the Indian Ocean and much of Asia tally with the higher number of eighty million (Manning, 2013: 1). Much of the movement was related to growing Western colonialism. Chinese, Indian, African, Pacific 
Islander and Japanese migrants coursed along new routes to South-East Asia, Australasia and across the Pacific Ocean to the Americas, often as indentured labourers, but some travelling as de facto slaves seized in so-called blackbirding operations (Matsuda, 2012: 219-25). Some two million Chinese left their homeland (nearly half of them headed for the goldfields of California and Ballarat in south-eastern Australia). Chinese migration slowed dramatically after that with the decline in gold mining and the constriction of demand for indentured Chinese labour. Indian migration continued unabated, however. Somewhere between thirty and forty million Indians were recruited to other parts of the British Empire between 1830 and the First World War (Castles et al., 2014: 88-9). The decline of Indian industry in the face of favoured British imports created adverse conditions that pushed labourers overseas. Japanese labourers exported, in effect, to Hawaii, Peru and Brazil formed hybrid communities. Longer-term minority communities thus developed and, in some instances (like Fiji), were deployed for divisive purposes to stoke racial resentment. Significant improvements in transport and communications technologies supported voluntary migrations within and out of Africa, Asia and Latin America (Castles et al., 2014: 5). Even amongst the voluntary migrations, not all migrations were equally voluntary as inequalities and discrimination often forced people to migrate (Castles et al., 2014: 85). Liberal models of migration are in this respect an ill-fit for empirical patterns of modern labour migration. Even when migrants moved under compulsion, the collective experience of migration resulted in engagements of peoples of different cultural backgrounds from places with different histories.

Within some imperial communities migration was supported in the context of multinational empires. The cosmopolitan animus of civilisations opened passageways for subjects to move around (Aktürk, 2009). The Ottoman Empire promoted multinational migration within a framework of codified coexistence. Administrators within the de-ethnicised bureaucracy were significant beneficiaries. However, the picture is not all benignly cosmopolitan. One instrument available to Ottoman officialdom was the surgen, a tool of forced migration of ethnic Turks designed to support colonisation (Hoerder, 2002: 111). Later the British Commonwealth, as the empire's heir, offered a global sphere of travel and migration for its subjects. Flows of people, ideas and artefacts in and out of the centres of multinational states could have a cosmopolitanising effect on the heartlands of such empires. All these migrations ran along the channels created by colonialism. Migration on the eve of the First World War - arguably the end of the apex of imperialism - is estimated to constitute 1.5-2.0 per cent of the world's population (Therborn, 2011: 111); those rates are not far short of current-day trends. It stood in stark contrast to the restrictive and discriminatory population and 
migration policies of the interwar period enacted by the same countries that, prior to the First World War, had produced the highest rates of immigration.

Though modern global migration is hardly neglected in the social sciences, it would be remiss not to note regional and post-colonial trends. Multidirectional and multidimensional migration is evident across many regions. Many countries seen as 'origin' countries are in fact also 'receiving' countries that host their own immigrant communities (Castles et al., 2014: 55-82). Diaspora, once a pattern of diffusion attributed to the Jewish experience, has been redefined to encompass the dispersal of many other peoples with strong cultural links to 'home' (Cohen, 2008). Southern migration to the North is a distinctive trend underpinned by the global restructuring of production and heightened insecurity. Refugees fleeing war, persecution or environmental loss are part of this. The greater number are the millions of guest workers drawn to the hotspots of global economic activity, those in the international trade in coerced and bonded labour and mobile professional and entrepreneurial elites. Needless to say, the experiences across that range could not be more divergent. A number of the patterns of migration into Western Europe follow the entanglements of empire created by European colonialism and continued in neo-colonial relations with independent states that were formerly colonies. The sheer cultural diversity resulting from the legacies of colonialism, foreign policy pursuits of the former imperial states and the fallout of post-communism is a reminder of the variety of modes of living constructed across the spectrum of societies.

\section{Economies as relational: long-distance trade}

Like migration, economic relations are about movement. Inter-civilisational engagement constitutes economies as relational in the uneven and unequal spread of trade and money and in commercial networks based on practices of trust-building. Dense country-wide and intra-regional economic exchanges have been threads of sustained contact, communication and travel between communities to varying degrees throughout much of the history of state-based and proto-state societies. However, it is in zones of high-volume trade incorporating meeting points on long-distance routes that we find economic crucibles of intercivilisational engagement.

In examining the patterns of pre-modern trade, economic historians often remark on the paucity of documentary evidence. Archaeology fills in gaps with other kinds of records, especially with trade over long distances. Archaeological finds suggest that exchanges over great distances have been taking place for at least forty thousand years (Goldin et al., 2011: 16). Ancient civilisations 
developed economic relations with one another. By necessity long-distance trade meant passing through different cultural universes while negotiating with agents and officials along the way. In itself, this did not create contact points between civilisations. However, long-distance trade deserves far greater prominence in connecting states, cities and civilisations in very ancient nexus of Mesopotamian and Indus Valley civilisations. Moreover, trade flowed far more easily and was consolidated in lasting webs of connections where empires could, under the right conditions, push back the frontiers of other states. The Greeks (under Alexander), the Romans and the Han Dynasty provided protection for more widespread trade. Cultures spread with all three empires; the Greeks laid down cities, the Romans expanded citizenship and law and the Chinese generalised language, science and the arts. Most certainly, short-distance travel has been the experience of many, while long-distance merchant migrations may have been the privilege of few. But the massing of inter-civilisational engagement through trade is more evident at the crossroads of long-distance routes and the consequences were momentous. Many routes and zones have left archaeological traces yielding evidence of inter-civilisational engagement around economic relations.

Five zones of long-distance trade illustrate uneven and unequal growth in contact and connections. Two are trans-Asian, one pushes into southern Asia, the fourth is a northern nexus and the last is the worldwide commerce of modern colonialism.

The first is the Monsoon trade. The Indian Ocean has the oldest track record of continuous human engagement of any major ocean. Over the last four millennia, the coexistence of many civilisations in this ocean environment has been shaped by seasonal cycles. The trade spiked as Islam spread from the end of the eight century (Chaudhuri, 1985; Paine, 2013: 262-90). Monsoonal conditions dictated the timetables of merchant shipping from East Africa through the ports of the Arabian Sea, the Red Sea, the Bay of Bengal and the Java and South China Seas and then through to Japan and Korea. Experienced mariners knew how to navigate the oceanic ecosystem by predicting airstreams, tides and currents and knowing the right land sightings to seek out for navigational bearings. Regularity made transport reliable and predictable. Cargo and ships passed through transfer ports, travelling from one end to the other, even when their mariners did not. Ships could island-hop their way across the seas of the Monsoon trade. The winds would take mariners to intermediate destinations where they could pass their cargo on to associates and then complete the round-trip. The journeys were lengthy and took them through myriad cultural milieus. Commercial emporia emerged out of the punctuated patterns of trade in cities and intermediate ports along the chain of distribution. To differing degrees, cities such as Aden, Melaka, Muscat, Hormuz, Goa, Canton, Aceh and Surat were inter-cultural locations for 
encounters with diversity. They were full of go-betweens, negotiators and agents for multiple interests. India's coastal centres on the eastern Coromandel Coast and over in Gujarat also turned out maritime communities of a like nature.

As well as India and China, Islamicate civilisation was also favoured by this climate system and the segmented patterns of travel that it threw up. In fact, if there has been a force that enjoyed a premier position at any time in the Monsoon trade, it would be Islam. The consolidation of the Abbasid Caliphate gave commercial impetus and state protection to Muslim and Jewish merchants looking to the Indian Ocean trade. Development of rich coastal and oceanic markets compensated for downturns in the caravan trade. Islam's exceptional influence reached a high-water mark before the thirteenth century, but it did not survive external challenges and internal divisions (Curtin, 1984: 119-29). The longterm effects of the Crusades discouraged the ecumenical long-distance trade. Fractures within the dynastic figuration of the Caliphate weakened its position in ocean-going trade. With the Mongol conquest of Baghdad and the shift of the Caliphate to Cairo, the emporia trade opened up to others. The primary beneficiaries were Indian interests, particularly Gujarati traders. Chinese merchants were not far behind (Paine, 2013: 346-9). Commercial ventures from Canton under the protection of seven naval squadrons launched in the first third of the fifteenth century pushed Chinese frontiers to India and then on to Zanzibar.

Venturing into the Indian Ocean paid off for China. Other states recognised the Celestial throne and sent ambassadors. China's accumulation of worldly knowledge was permanently enhanced. The initiative to withdraw from the naval strategy came from an anti-mercantilist imperial court eager to regain control over its eastern ports and indeed over the state. The court bureaucracy may have been inimical to seafaring and to commerce, but coastal China remained porous enough and its lively eastern and southern seaports continued to ply a vibrant trade. Marginalised within the neo-Confucian universe, merchants in Fukien were able to augment overseas communities in a kind of 'undercover colonialism' (Fernández-Armesto, 2001: 345). They would be China's continuous seaward outlets. Despite Fukien's lively port and the volume of trade that flowed through it, the involvement of the Chinese Empire in oceanic ventures was over and it was left to traders to go it alone. The imperial state differentiated itself from maritime commerce. Chinese hegemony in the Indian Ocean was not possible, nor could other powers completely dominate the trade. Commerce in fact flourished with many powers, entrepôt cities, ordinary ports and merchant networks participating and none monopolising the balance of power before the nineteenth century (Hoerder, 2002: 164-86).

The importance of the Indian Ocean is debated, but a general consensus exists that, at the very least, it was the major world theatre of trade until the late 
eighteenth century (Pomeranz and Topik, 1999). Even though Islamic trade had greater competition from the thirteenth century on, the three so-called gunpowder empires of the seventeenth and eighteenth centuries benefited from falling production costs and expansion in production and elite consumption (Bayly, 2012: 17). Improved liquidity and shipping, particularly at the height of the Moghul Empire, aided seaborne trade. At that time, the tempos of the crowded basin began to alter with the intrusion of European states and mercantile interests.

Passage by land was less secure, though it was rarely closed off. The second illustration of long-distance trade is the so-called Silk Road. The well-known trunk route was in fact a trans-regional series of passageways running south into India as well as west to Central Asia, the Sahara and North Africa. Chinese goods were transmitted by portage through Eurasia as early as the first and second centuries BCE. Travellers, mariners and merchants on return journeys brought back knowledge of the worlds they had traversed, so starting a prominent and long civilisational learning process for China. China's reach was such that it became aware of expanding Roman hegemony at the western end of Eurasia, on the other side of the Armenian segment of the Silk Road. At one point, Roman merchant enterprise reached as far as the Ganges trade. Chinese merchants got to eastern India. The produce brought from the opposite ends of Eurasia went further than its carriers, however, providing a 'calling card' for both civilisations. Their comprehension of the known earthly world was tested and expanded as a result of economic relations. Long-distance trade left its mark on the internal development of both China and Rome, not least because it returned to Chinese and Roman centres an imagination of the totality of the known Eurasian land mass (Paine, 2013: 79-81). Mutual awareness may not have resulted in lasting direct ties between Rome and China. But on a regional scale various passages of the Central Asian trunk route were livelier because of long-distance trade runs.

The highways that criss-crossed Eurasia underwent a revival in the early second millennium (Hoerder, 2002: 2-3, 30-1). The east-west trade that moved more extensively along the joints of overlapping contiguous cultural zones from Song China to Islamic East Africa and sub-Saharan Africa also shows greater density of connectivity. Trade moved in many directions as north-south routes were augmented. Maritime trade was enhanced by the efforts of the Song Dynasty to consolidate a system of canal and river portage in support of its overseas commerce (Paine, 2013: 291-315). After a phase of conquest by the Mongol armies, the consolidation of a pax Mongolica provided cover for an increase in long-distance trade and distribution of a range of new goods and inventions, languages, fashion, food, maps and religion. Economic or cultural goods could not unify a trans-continental world. But it was part of a coalescence of Eurasia-wide 
connections, particularly as long as Mongolian protection prevailed. Within the larger configuration, there were significant disparities of power between the seats of government in northern China and the zones of Inner Asia and the disparities spilled over into commerce. Furthermore, Mongol interests fashioned which goods, religious beliefs and ideas, plants and science circulated, particularly through its network of courts. But once the chains of exchange were secured, the traffic in goods at least was more uninhibited. Knowledge of trading conditions also grew under these circumstances. Merchants - along with scholars, post-masters and clerks - published compendia of countries, roads and cultures reflecting their manifold experiences of trekking trade routes. In all, the early second millennium was a phase in which processes of learning improved on the highways that criss-crossed Eurasia.

The degree to which Eurasia can be analysed as a macro-region prior to the fifteenth century remains a debating point (Arnason and Wittrock, 2004; McNeill and McNeill, 2003: 119-21). The questions in dispute suggest that inter-civilisational engagement was greater, but was also uneven and produced an unequal and diverse macro-region. As trade increased, so also did the inequality between regions. North-south trade began to supplement cross-Eurasian routes, the third illustration here. China and India oriented to South-East Asia with even greater vigour. China's consolidation in the thirteenth century of an economic sphere gave it an advantageous tributary trade. During its historic phase of maritime expansion, Chinese commerce encompassed the South China Sea, reached Manila and connected Indochina with Java. The position of the Chinese in Melaka was also favourable given the city's position on the cusp of north and south trade winds (Braudel, 1985: 524-9). Being able to manufacture paper currency on a significant scale helped. It also helped that Chinese merchants were well-protected militarily. Independent of the state, however, they fashioned a large and entrenched overseas diaspora in South-East Asia. China's was not the only trade to shift direction. Indian traders too sought to augment strategic placement in the spice trade. Under the Delhi Sultanate, Gujaratis and Bengalis purposefully made further in-roads on the congested commerce of Asian ports. By the seventeenth century, it was evident that the caravan trade had begun to switch its axis. Possible decline in trans-Asian trade was mitigated by the intensification of multi-directional and intra-regional trades in Central Asia and the Indian sub-continent. Russian producers and merchants were incorporated into augmented north-south flows into central and southern Asia across the seventeenth and eighteenth centuries, much to the advantage of Central Asia and China.

Some trades that also enhanced inter-civilisational engagement did not span one axis or other of the larger Eurasian land mass. A north-west sphere 
of exchange between Byzantine, Arab and Swedish Viking traders emerged in the ninth and tenth centuries - the fourth illustration of long-distance trade. Viking trade enlarged a zone networking Scandinavia, the Baltics, Belarus and Ukraine with the Black and Caspian Seas via the Don, Dnieper and Volga Rivers (Paine, 2013: 244-6). The foundation of Rus cemented Viking colonisation. The occasional Viking war with Byzantium did not prevent the construction of commercial networks. By tapping Arab and Byzantine trade Swedish Vikings were able to draw goods and wealth through eastern Europe's riverine channels and into circulation in a far-flung chain of exchange leading north and west. Thus the eastern and northern states of Europe were linked with Rus and even further east. On several occasions in the late ninth and early tenth centuries, they raided ports on the Caspian Sea to reach Iran in extensive efforts to emulate their gains with Byzantium. Wealth ran, for a time, but the gains were less permanent. One important effect was to create channels of trade into eastern and northern Europe and through the trans-peninsular riverine network for rare goods from Central and East Asia. Today, popular culture may remember Vikings as a force of raiders. But they also stimulated the circuits of exchange across Europe even before they were 'Europeanised' in the thirteenth century.

The fifth and final illustration is the transfer of plant, food and animal species across modern empires and civilisations. The traffic in species started with force and conquest and then fell to commerce (Pomeranz and Topik, 1999: 81-115). Empires were the conduits of the circulation of species. The Americas have the most exceptional history of species transplantation, so much so that it has been characterised as an 'ecological exchange'. A good deal of this did not begin with commerce but scientific and cultural appropriation. New World artefacts were gathered by Europeans for display. Representations crafted for artistic and scientific purposes brought images of strange marvels to Europe. Actual artefacts were also collected and then housed and reassembled in museums, gardens and libraries. Exhibited for display purposes, they gave the appearance that the phenomenal diversity of the New World could be grasped and indeed possessed as though it were a commodity to own. When it came to plants, the volume of specimens imported and introduced grew, with vast collections accumulating in England's Royal Society and the Paris Academy of Sciences.

Commerce was never too far away from this traffic in cultural curios and scientific specimens. Foodstuffs soon followed. Maize, tomatoes, potatoes, papaya, custard apples, pineapples, tobacco and cacao and other varieties of beans circulated from the Americas via Europe to Asia and Africa. The linkages of longdistance trade between the Indian and Atlantic Ocean zones took consumables back in the other direction. Exotic stimulants such as tea (originating in China) and coffee (from Yemen) were initially banned by European governments and 
then permitted for exploitation in plantation economies developed under the auspices of colonial authorities. Some got back as far as the Americas at the western end of the ecological exchange, where yams, sugar and wheat were also cultivated. Notably coffee and sugar were the boom products of slave-based production in the Caribbean and Central and South America. Europe's trading firms reaped monopoly profits for themselves and tax revenues for governments. At the height of British and French colonialism the transfer of species became more strategic. For example, in the nineteenth century, the British were able to transplant rubber and tea on a large scale from original sources in Brazil and China to Malaysia and the Indian sub-continent. Major relocations of species across the French and British empires had significant socio-economic and environmental effects, and they were lasting ones.

\section{Economies as relational: money, trust, networks, varieties of capitalism}

Contractual and monetary instruments were not a single-civilisation monopoly of Renaissance Europe. Trust-based, long-distance credit had existed in antiquity. Moreover, finance was already part of Chinese networks well before Italian banking inter-linked economic movements. Chinese finance lubricated longdistance trade across Islamicate civilisation by the time Italian bankers were beginning to aggregate money-lending practices for European economies. The more recent and influential zone of trust, Islamicate civilisation, provided 'protected' status for non-Islamic communities in spaces of coexistence. Islamic cities magnetically drew a miscellany of pilgrims, intellectuals, traders, farmers and artisans to a multi-lingual world where Central Asian languages, Iranian, Turkish and Urdu were spoken (Braudel, 1993; 64-8; see also Arjomand, 2004). Of course, Muslim traders had much in common with one other. Arabic was a lingua franca. Merchants and travellers shared an intensity of faith and thus performed the same rituals and precepts of piety. Wherever they went, they could expect to live under Islamic law and taxation. Yet urban communities were also more generally inter-cultural and receptive of a profusion of languages. Cities of the eleventh and twelfth centuries under Islamic protection also had substantial export trades involving urban communities of foreigners. Italian merchants were one such community. Their long-term observation of Islamic practices, combined with engagement in caravan and seaborne trades, contributed to the Italian aggregation of commercial instruments.

Instruments developed coextensively in Islamic and Byzantine law provided frameworks for contracts and insurance before the outgrowth of Italian banking 
brought security to the Mediterranean economies (Paine, 2013: 223-8) and indeed in the emporia trade of Asia (Chaudhuri, 1985: 210). The commenda was a major instrument of contractual obligation. The body of laws that included the commenda enshrined principles of inter-faith partnership, as well as bilateral agreement. For the Armenian network of communities, the commenda was an especially important commercial bond (Aslanian, 2011). Moreover, the body of instruments that includes the commenda inscribed in juridical form the conditions in which the risks of long-distance ventures could be shared. In this climate of engagement, Italian finance synthesised a range of instruments. Bank notes, bills of exchange, promissory notes, cheques, insurance contracts, scriptural notes and letters of credit affirmed and certified fulfilment of commitment. Measures such as these, taken to secure credit and realise value in circulation, added to the long-distance chains of exchange.

The proximity of different systems of finance and risk-sharing operating in the Mediterranean and Indian Ocean meant that monetary forms and insurance could be developed consubstantially through mutual learning. Increased confidence and the objectification of trust enhanced cross-civilisational networks. The expansion of mediated economic relations symbolised by money, value and wealth brought greater connection. By the seventeenth century, the world economy that centred on terrestrial Eurasia, South-East Asia and the Indian Ocean had begun to feel the effects of the influx of specie from the Atlantic world zone. The rise in quantities of silver resulting from mass mining in Spanish-America's encomienda economy increased purchasing power in East Asia, the Middle East and India (Chaudhuri, 1985: 17; Pomeranz and Topik, 1999: 179-80). Since specie began to flow persistently eastwards through the capillaries of large regional economies in more definitive forms, greater liquidity applied in long-distance relations. Far from common in everyday economic matters, money increasingly mediated long-distance trade. The velocity of exchange increased in many world economies over the long term, notwithstanding short-term secular downturns. The more liquid commerce was, the greater was the impulse for further monetarisation. States were crucial guarantors of the value of currency. Some were better at it than others. Islamic states had a strong tradition of legal tender (Chaudhuri, 1985: 215). By contrast, South-East Asian regimes took few initiatives in minting regnal coins. Overall, the pattern of state guarantees emerged unevenly.

American specie filled the gaps in credit by becoming the material manifestation of money. In explaining the symbolisation of wealth that money brings, Marx distinguishes the material manifestation of money from value itself (Marx, 1973: 145-6). He may have gone too far in attributing the emergence of 'world coin' to 'the circulation of American silver from West to East', but the long-term 
outcome is clear enough (1973: 227, emphasis in original). Later, gold as a metal acquired the quality of a 'world coin' while at the same time materially enhancing the imaginary of money.

Joint-stock and multinational companies have given corporate form to long-distance economic relationships since the sixteenth century. Before then, merchants plied their trade through family and associate networks, by means of business alliances sealed through marriage, and via overseas co-religionist or compatriot merchant communities. Family networks hosted travelling kinfolk while en route to their final destinations. Merchant families pioneered key migratory routes (Manning, 2013: 119). I have suggested above that instruments of objectification of trust have lubricated commerce relations over much of the millennium. Where legal regulation failed - and it frequently would - the informal solidarities of merchants have often succeeded. As co-religionists share established moral precepts, as fellow nationals are known and share language and memory, and as family members are kin - all are more easily integrated into extended coalitions. Known agents in mercantile communities are also important lubricants in chains of exchange. Communicating information and business intelligence helped to maintain the integrity of existing relationships. Merchants vouchsafed the reputation of agents, negotiators and administrators. They communicated the conditions in which the network operated and spread news on the trustworthiness of a spectrum of agents far afield. By dint of their acts, corresponding traders created an ethic of responsibility as very few agents could afford to gain a reputation as untrustworthy or deviant (Aslanian, 2011: 86-119, 177-81). There is no reason why such webs of trade should not be considered capable of the complex multi-functional aspects of business, such as handling and warehousing freight, negotiating with local agents and municipal officials and with mariners.

Robust historical networks such as these are defined by Philip Curtin as 'trade diasporas' (Curtin, 1984; see also Pomeranz and Topik, 1999). Curtin perceives a general pattern. Breaking off purposefully to settle in another city as strangers, traders learned languages, customs and techniques of local trading that they could utilise in negotiations between the host and original communities. Furthermore, almost everywhere communities were created in separate spaces, according to Curtin. Aslanian's deep research into the Armenian merchants in New Julfa casts doubt on Curtin's typology. In a persuasive case, he utilises extensive archival records to develop an economic sociology of trust, identity and community organisation (Aslanian, 2011). The Armenian merchants of New Julfa serve as a good illustration of cross-civilisational organisation that facilitated inter-civilisational engagement in economic relations. They were a network with extensive reach in trans-Eurasian trade. Aslanian finds little relevance in the 
trade diaspora paradigm for the picture of the Armenian trade communities that he constructs. In order to answer questions about the mode of organisation and trust that this stateless network instituted, he turns to theories of social capital. Four factors underpinned trust: the insularity of the network; the web of information, espionage and news that traders maintained; the coercive grip on family members when merchants were abroad; and courts and tribunals that could curb malfeasance. Comparison with Sephardic Jewish and Multani merchants shows that trade networks spanned a spectrum of polycentric to monocentric organisation and insularity. The Armenian network was tightly insular, while the Sephardic one recruited outsiders and incorporated cross-cultural commerce more readily. Aslanian's research provides insight into the breadth of merchant networks tied up in early modern long-distance trade, a breadth too great for the category of 'trade diaspora' to bear.

The worldwide Armenian web was uniquely inter-civilisational. Its political links accommodating relationships with states is a notable feature, particularly the Ottoman state and the Safavid Empire. As carriers of the overland trade Armenians stretched further, migrating into southern and north-western Europe. The network traded across Eurasia with all the European powers. Indeed Armenian communities had a presence in all the major early modern empires (Hoerder, 2002: 175-7). The trans-imperial Armenian nexus included China, Russia and the gunpowder empires (Aslanian, 2011). Their far-flung reach from Manila to London meant that the network was a bearer of inter-civilisational experience insofar as it was a singular force. Armenians cemented ties across a large macro-region without recourse to significant state power of their own. Beyond the spheres of influence in their range, they were talented in other diplomatic negotiations that enhanced their wider reputation as brokers.

The variation of outstanding historical communities is the most salient point of Aslanian's inquiry. Fukienese, Genoese, Gujarati traders (with their genial Jain traditions), Jewish, Arabian, Portuguese, Parsee, Dutch, Indonesian and Sudanese merchant communities are better defined as organisational webs more or less involved in inter-civilisational trade. Wherever merchants settled as strangers, they encountered different grades of compromise and accommodation. Hospitality towards visitors and new arrivals in a city, at a crossroads or in a village was a test of worldly orientation. Crossroad cities where cultural and economic traffic routinely passed through stand out as examples of both intercivilisational engagement and cosmopolitan spheres of contact. A whole spectrum of sociabilities, ranging from the most welcoming to the ambivalent to the hostile and barely tolerant, influenced conditions of life. Distance from communities of strangers always continued, but in the most porous of commercial cities there were also public spaces of coexistence where differences were not crushed 
or suspended but subject to inter-cultural possibilities (Murphy, 2001: 13-14). Such spaces open up cosmopolitan encounters of the most routine and immeasurable kind that accumulate as patterns of cities and societies. Long-term habitation of places fostered sociabilities in which there is distance and distinction, but also inter-cultural exchange. Conversely, deep suspicion towards strangers or tight restrictions on their participation in the city or even xenophobic expulsion can be various grades of obstruction.

In two long passages on economic relations, I argue that the transformation of patterns of long-distance trade, the growth of money, the codification of trust and the expansion of imagined connections provided complex and early spurs to the imaginary institution of capitalism. As a general view, there is widespread recognition that the great transformation of modern capitalism emerged from political and inter-imperial rivalry as well as from economic movements. But modern capitalism is distinctive in other ways also. The counterpoints to civilisational analysis raised in Chapter 3 call for further remarks on capitalism in light of the examination carried out here of inter-civilisational engagement in economic relations.

Long-distance commerce may well represent latent capitalist forms of economic organisation and orientation, as Weber and Braudel contend. But capitalism is a modern imaginary relating to political, imperial and cultural patterns of the last five hundred years. One perspective suggesting varieties of capitalism is discussed in Chapter 2 (Arnason, 2005). Arnason's injunction that intercivilisational problematics connect with the origins of capitalism is an important point about the salience of long-distance trade (Arnason, 2003: 296). Marxist perspectives are even more emphatic that modern capitalism represents a significant rupture with prior formations integrating trade amongst other things. The mainstream of Marxist political economy attributes the energisation of accumulation to transformed social relations. The specific Marxist perspectives discussed in Chapter 3, on the other hand, concern themselves with the pluralities of capitalism and the varying cultural, legal and political orientations to accumulation and regulation (Cox, 2002). In this view, varieties of capitalism have resulted from two related processes. In the first process, the confrontation between tendencies of capitalist expansion and the interaction of civilisations generates variants of accumulation. Second, the capitalist quest for resources, markets, money, growth and profit confronts resistance stemming from other dimensions of modernity.

The two processes operating in concert give rise to different relationships between states and forms of economic power. For example, the chartered trading firms of Europe's modern empires are instances of the interpenetration 
of capital, colonialism and state, though they never collapse into one another. A greater differentiation can be made in later variants of capitalism. Though he rarely expresses them as variants, Cox distinguishes three dimensions of power in modernity in a manner quite consistent with the distinction of diverse figurations of capitalism. His three dimensions are: the economic realm of capital, welfare, labour, production and consumption; the political realm of states, trans-national non-state actors and social movements; and the ontological realm of civilisations where large-scale varieties of capitalism are shaped. In a Polanyi-inspired statement, he argues that civilisations 'confront the economic imperatives of capitalism and move social economies in different directions' (Cox, 2002: 167). Cox's account logically paves the way for an analytic that reveals a number of combinations of business and labour, work ethics and capacity to appropriate cultural critique. Actually-existent combinations and forms of accumulation produce more diversity than can be properly accounted for in the typologies of institutionalist explanations in the 'varieties of capitalism' literature in political economy.

A contemporary example is the surge in Asia's modernities at the end of the twentieth century. Pieterse has an astute understanding of modern Asia's entanglements that throws into relief cultural and economic dimensions of inter-civilisational engagement (Pieterse, 2010, 2012). Asia's pre-nineteenthcentury lead over the West has been revived and mobilised as a cultural force in 'new modernities'. The new modernities have surged on the basis of a careful renovation of 'traditional life worlds' at a time when Western modernity is subsiding (Pieterse, 2010: 95). Asia's modernities with reflexively constructed traditions mesh well with other economic cultures. They have interacted with traditional Anglo-American philosophies of capitalism, creating new politicaleconomic and cultural fusions in the process. Strategic economic invention and the creation of new styles of consumer taste and cultural representations emerge from the consequent fusions as patterns of renewal and outgrowth. What Pieterse also shows is how civilisational heritages and different regimes of accumulation can be inventively harnessed to engage the capitalist imaginary and produce a proliferation of connections (see also Arnason, 2005; Katzenstein, 2010a).

Here is a contemporary case of inter-civilisational communication. In the twenty-first century, new models of development made possible by the eruption of fresh inter-cultural interpretations deepen the economic engagement of different world zones with variable civilisational legacies. Far from declining with globalisation, civilisations provide important reference points for major nonWestern projects of globalisation; in particular, China and Japan as competing epicentres (see Arnason, 2002; Robertson, 1992: 85-96). In the different modes 
of late Asian capitalisms, we find fusions in culture and political economy epitomising inter-civilisational engagement.

Braudel as a historian of modern capitalism who is outside all of the frameworks discussed above had something in common with them. He pointedly cautioned against positing capitalism as a single system unresponsive to cultural patterns and social orders. He thought that cultural mixes were the most plentiful in early modernity where trade flowed. What I have discerned in the economic histories surveyed here is that many of the routine contacts and connections in economic relations were also inter-cultural exchanges. Perhaps the traffic in cultural goods was never far away from the trade in commodities?

\section{Cultural traffic in the centres and at the crossroads of knowledge}

There are occasions and phases when inter-civilisational engagement is economic, cultural and peripatetic all at once. Travellers and migrants are recipients of culture, as well as its bearers; they borrow as well as carry. The innumerable acts of bearing and borrowing have nurtured creation in religion, science, language, myth, philosophy, architecture and the arts. Cultures change through practices of borrowing and blending, creolisation, combination and synthesis, translation, absorption, detached or embedded learning, mediated contact and representation. The practices are processes. Where practices of learning and reinvention attract intellectual, religious and aesthetic practitioners of different civilisational traditions, it becomes possible to speak of inter-civilisational engagement of cultural and symbolic form and content.

Because Randall Collins's helpful theory of relational processes of cultural exchange is important to the elaboration of this dimension of inter-civilisational engagement in these pages, it is treated at greater length. Collins defines civilisations as magnetic 'zones of prestige' that draw people to their outwardly radiating brilliance (2004). Thick connections are made in the major centres of science, philosophy, theology and art. The principal ideas, practices and styles of creative centres make their way through networks to other world zones. In his historical sociology of philosophy, Collins finds that the centres of philosophical thought strengthen themselves through large networks that reach out to wider circles to become generally known (Collins, 2000). The most radiant of such centres become admired even in other civilisations. The processes by which philosophical traditions are created pertain also to other domains of cultural activity, 
according to Collins, for example architecture and music. Philosophical schools working at new epistemological and ontological abstractions have advanced cultural, moral and scientific inquiry. By dint of possessing such prestige, academies and universities are able to attract proponents of inventions, axioms, faiths, moral precepts, techniques and styles.

The bearers of abstractions and particular cultural products enter prestigious centres which encourage diversity, rivalry and coalitions. Through argument and experimentation, they consolidate extensive chains of diverse people in the orbit of centres of cultural brilliance. By privileging and protecting agonistic principles of intellectual collaboration, host academies, universities, monasteries and cities encourage 'rival positions, variations in stance' in opposition to one another (Collins, 2004: 133). Creativity ensues from intellectual strife and debate. Creative centres then tend to export teachers and evangelists of different cultural currents to the margins of civilisational zones. The intellectual currents formed in the most animated centres radiate outwards beyond the formal boundaries of states and empires and in doing so become civilisational.

These are the most general of factors discerned from an immense variety. There is a larger conclusion to infer from the register of diversity Collins establishes: there is no singular meta-historical patterning of the relationship of political, economic and cultural factors. The variety of figurations of political and economic power and cultural crystallisation comes to light in Collins's sizeable survey. The main generalisation he makes is that multi-centred civilisational zones are eminent. Japan's polycentrism is a strong example, particularly around the historic Kansai region. Islamic schools in Basra, Baghdad, Cairo, Damascus and Cordoba were rich crossroads of philosophical, artistic and religious translation, experimentation and thought. It is not because they were blessed by geography. Rather, they generated cultures of fusion that absorbed and transformed 'the rich traditions of art and learning conserved in the Greek, Roman and Persian worlds [that] fell into Muslim hands, enriching the legacy transmitted from Arabia' (Fernández-Armesto, 2001: 331). Neo-Confucian schools of philosophy in East Asia generated cultures of deliberation that were variously interactive. Europe's so-called scientific revolution embroiled multiple centres in debate and a contest for intellectual autonomy with the Papacy. Europe's philosophical schools could be single-centred also - the Vienna Circle and Paris's 1950s existentialists communicated outwards through channels of prestige. One example shows a variation of patterns quite starkly. The history of first-millennium Buddhism illustrates the potential disentanglement of cultural hypertrophy from political hegemony. Chinese and Japanese travellers were drawn to India to acquire the teachings of Buddhism. Missionaries emanating outwards spread Buddhism to East and South-East Asia. However, the extension of the structures of monastic 
life to Japan, Tibet, Sri Lanka and China did not bring a transfer of political and economic institutions. Cultural goods and religious practices progressed via this centuries-long movement; political and economic institutions did not.

In summary, civilisation, according to Collins, is a process of interaction. Cultural development at the crossroads of civilisations is too prominent to ignore. But there are conspicuous omissions from his scholarship. Plainly omitted are those civilisational interactions not involving 'high civilisations'. Another limitation is symptomatic of much of civilisational analysis. Collins preoccupies himself with land-based empires and landlocked cities that draw different peoples and high volumes of traffic in culture, theology, science and philosophy. Lincoln Paine argues to the contrary that seas and oceans are highways of cultural transmission more so than terrestrial paths, at least prior to the nineteenth century (Paine, 2013). Oceanic civilisations can also be cultural conjunctures, even though they don't depend on the same topography and materiality as mainland zones of prestige. Their land-based sites are obvious enough. However, the paths of their cultural 'radiance' around coasts and rivers and across seas and oceans endow them with a different outlook. Their responsiveness to other civilisational influences is informed by shoreline and saltwater horizons. A framework for addressing this lacuna is the purpose of the next chapter.

Reciprocal engagement of the kind that Collins elucidates is reminiscent of the 'continual mutual borrowing' that Braudel sees as an inescapable feature of civilisations (1993: 8). Braudel perceives the interactive composition of lasting 'cultural assets' and material infrastructure. World historians have enumerated the historical loans, as it were, of distant civilisations to Europe before it established great inequalities of global power in the nineteenth century (see Bayly, 2012; Hodgson, 1993). Yet those historical borrowings intermingled with other processes of mutual borrowing taking place in the multi-civilisational zones of Europe centred on the Mediterranean world and creations that were exported with Europe's empires. For example, early Renaissance universities were centres of cosmopolitan knowledge-sharing, especially given that a significant minority of the academy and the students were foreigners (Hoerder, 2002: 118-19). Universities as multinational communities have been a force for universalist cultures. Epistemologically, they have been conduits of borrowing and sharing of knowledge and cultural goods. They have been part of a larger pattern of crossregional borrowing that has been combined with Europe's inter-continental appropriations and impositions.

The most complex of reciprocal engagement is evident in linguistic and symbolic abstractions that moderate communication. Languages travel, including mathematical ones. Alternatively, as is often enough the case, they are part of a conquest and then impose themselves. The Arabic transmission of mathematical 
devices (especially algebra and trigonometry), the diffusion/emanation of symbols from India and alphabetical script from the Levant are historical illustrations of the processes of transfer of cognition and communication. More deeply engaged societies can also undergo semantic and grammatical intermixing, crosslanguage fertilisation and appropriation, creative adaptation of words and concepts, and phonological transfer. It is rare for invasion and migration to not have an impact in spreading languages. The Arab tribes of the Fatimid and Abbasid Caliphates commemorated in Ibn Khaldun's historical accounts are one example. A large example is the impact of Europe's modern colonial empires. Portugal, Spain, France, Britain and the Netherlands imposed languages as a lingua franca for elites that could become a demotic idiom (as French did in nor th-west Africa). Where wholesale adoption of a language did not occur, terms could still spread through different languages, with the coloniser's tongue also quietly adopting new words (as English did in the long occupation of India). Linguistic blends were more particular. Creole syntheses in the Americas were consequences of protracted inter-civilisational contact in the context of imperial dominion and slavery. Swahili originated in the vibrant thalassic environment of coastal trades between Mogadishu and the Comoros. Later it expanded into the interior.

The argument made here has focused on efflorescent intersections that are often bilateral spaces between civilisations, so to speak. According to Salvatore, a macro-sociological scope can bring trans-civilisational processes that are based on multi-civilisational inputs into the picture (Salvatore, 2007). In transcivilisational processes, cultural techniques, concepts and abstractions circulate more densely by means of mutual sharing, teaching, transfer and translation. Salvatore highlights those patterns in the historical context of Islamicate civilisation. What happens if we take the unit of research as 'multi-civilisational regions'? The examples of trans-oceanic empires that exerted extensive imperial hegemony and a cultural sphere demonstrates trans-civilisational processes. Discussion of these formations takes place below following examination of the fourth dimension of inter-civilisational engagement.

\section{Models of polity and politics in inter-civilisational engagement}

Transfer, communication and political reconstruction of civilisational models constitute a fourth dimension of engagement. Civilisations are frequently associated with empires (Aktürk, 2009: 59-61). When it comes to transmission of civilisational models, the association is situational. In the epoch of modern colonialism, this dimension of engagement almost invariably involves imperial hierarchies of relations between states and broad-ranging constructions of power 
(Katzenstein, 2010b). Moreover, the articulation of engagement is often from central to peripheral elites. Empires exercise particularly hierarchical techniques of political communication and exchange with other states and with elites within their own territories. I start this passage with comments on modern empires.

Steady entanglement of the Western hemisphere with the Indian Ocean basin over the course of the sixteenth and seventeenth centuries expanded the spaces of European empires and the range of encounters that they had. Furthermore, overseas enterprises had a profound impact on state formation and relations between European states. Diplomacy, treaties, alliances and the enlargement of spheres of influence conspicuously formalised the coexistence of modern states. In Europe, nation-states enshrined active mutual recognition in the Treaty of Westphalia. The Westphalian nation-states were empires, as well as nation-states, and they recognised each other as such. Mutual recognition did not negate the competition of empires. Modern inter-imperial rivalries produced particularly power-saturated and asymmetrical episodes of inter-civilisational engagement. The fierce rivalry of empires has been a feature of modernity that could be more fully unpacked.

Historical examples show significant variation in political and legal reconstruction. Civilisations emerging in contexts of a dominant power have often been squeezed into typologies of 'primary' and 'derivative' civilisational and state formation. They can be reinterpreted without the constraints of categories of primacy and derivation. To do so requires harnessing case-specific histories of particular civilisations and how they radically reconstruct models of polity and law in distinctive regional processes. Three can be briefly recounted here. The first, China, shows how close empires and political models of civilisation could be. The second, the first-millennium Sanskrit order of India and South-East Asia, illustrates partial differentiation of the agency of empires from the model of civilisation. The third, Iberian colonialism, exemplifies a simultaneous creation and extension of a model of trans-civilisational rule.

China is a very particular instance of civilisational emulation where models of polity were more or less borrowed without compulsion. Korea, Vietnam and Japan adopted the centralist organisation and culture of Chinese bureaucracy. Confucian knowledge and learning became models of government and law during the Tang Dynasty for Vietnam, Japan and Korea. Scholars who have compared the three trajectories of state formation modelled on the Chinese example find that the innovative modification of borrowed institutions quickly follows their adoption (Arnason, 2003: 295). Talk of Sinicisation during this historical phase over-simplifies the picture of uneven, partial and transformative processes. Even so, the long and original engagement with China furnished Japan and Korea with a paradigm of intellectual, religious, linguistic and artistic involvement. Both 
countries carried the historical memory of engagement with another civilisational force. In both sets of emulation, the relationship of components of Chinese state culture was radically redefined and relativised through comparison with existing indigenous culture and political traditions.

Chinese civilisation itself has a history of collecting, learning and adapting. Trans-Eurasian links were important to China in creating civilisational learning processes. Dense engagement in the main dynastic phases where China grew and connected entailed a political 'flow of information back to China: the compilation of a remarkable archive of knowledge of the world, unmatched in any other civilisation' (Fernández-Armesto, 2001: 223). 'Unmatched' is a strong word, but do not let it divert attention from the historicity that emerges from accumulation of such a store of civilisational heritage. Civilisational heritage and interaction become an orientation when knowledge is accumulated thus over a long historical trajectory. In this regard, China can be taken as an example of a civilisation with an imaginary of greater porosity than older Eurocentric perspectives on it would suggest. It is a civilisation that 'takes in' as well as it emanates and imposes.

A second illustration of the political expansion of a civilisational model through transfer and translation over a large macro-region is the millenniumlong Sanskrit order described by Pollock (1998, 2004; see also Arnason, 1997b). His periodisation is based on civilisation-making that occurred through a body of cosmopolitan aesthetic practices. Eurasian patterns include inter-regional outgrowth of cultural-institutional figurations. Through the use of Sanskrit in inscriptions, courts mobilised literary and cultural form as a power to cosmopolitanise a civilisational model over a number of political centres:

What is created in the period that covers roughly the millennium between 200 or 300 and 1300 (when Angkor is abandoned) is a globalized cultural formation ... characterized by a largely homogenous political language of poetry in Sanskrit along with a range of comparable cultural-political practices (temple-building, city planning even geographical nomenclature) throughout it. (Pollock, 1998: 12)

Sanskrit spread rapidly from North India across the sub-continent and to South-East Asia as a cultural idiom of courtly power and model of behaviour. It was a civilisational high culture that widely transmitted implicit power. No empire, army regiments or religion acted as a vehicle of Sanskrit when it expanded into South-East Asia. There was a linguistic-cultural power that 'gave voice to imperial politics not as an actual material force but as an aesthetic practice, and it was especially this poetry of politics that gave presence to the Sanskrit 
cosmopolis' (Pollock, 1998: 15). Reflecting a pluralist imaginary, the aesthetic practices in question culturally represented a universe of plurality of gods, kings and heroes. Sanskrit's spread occurred through maintaining a certain distance from other local idioms, avoiding confrontation with them and establishing conditions of easy coexistence. The impact on other languages was significant, whereas Sanskrit itself was unaffected. The energy of such processes involves an interplay of cosmopolitan and demotic cultural forms across a multi-state macro-region.

As Pollock reveals, larger commonwealths forged out of inter-civilisational interaction are not always centralist (Pollock, 1998). Regionalising impulses dogged the Sanskrit order. Trans-regionalisation of cultural practices in SouthEast Asia ended when regional court states turned to demotic languages (Pollock, 2004: 258-9). Pollock's hypothesis of the 'vernacular turn' at the start of the eleventh century articulates a new phase in which local languages supplanted Sanskrit. Vernacularisation coincided with the differentiation of a literary mode of cultural production in which the authorisation of the 'right to write' distinguishes the author-intellectual from other cultural producers (Pollock, 1998: 8). The choice of intellectuals to use one language and not another was a choice of communication; 'they chose to write in a language that does not travel - and that they know does not travel - as easily as the well-travelled language of the cosmopolitan order'. Processes of re-localisation of language, cultural forms and power were animated by the use of authorised idioms in high literature at the local level and at the expense of cosmopolitan language. Facilitated by the implicit power of aesthetic practices, other institutions of state were created at the regional level. By the end of the fourteenth century, regionalisation fragmented the field of high culture producing a localised political order. Thus ended the Sanskrit millennium and its cosmopolitan culture hospitable to interaction.

My third example involves an important phase of entanglement of the two Iberian monarchies. In unifying the crowns of Portugal and Spain, the Habsburgs created a 'world-encircling empire' for a time (Subrahmanyam, 2007). Portuguese maritime and political influence in Asia and Africa partnered with Spanish possessions in the Americas, the Philippines and Europe to form a short-lived but extensively global Iberian force. However, the interchange of institutional and conceptual components between Portuguese and Spanish models of polity had two lasting effects. First, both Iberian partners took from the common fund of experiences during the sixty years of union. All the reforms to administration that they enacted responded to a rationalising impulse. Since they possessed territories across the world, it was not hard for them to take an Apollonian perception of the extent of Iberian reach, a global Ibero-sphere as it were. Changes like these reverberated in their imperial imaginaries. 
Second, they pioneered a mode of imperial world view for Europe's empires that echoed in the cultural Gallo-sphere of the second French Empire and the Anglosphere of the British Commonwealth at its height. Previous areas of distinction between Portugal and Spain were blurred during the course of the union. They transferred skills in political diplomacy and the government of religious orders across the two monarchies. Both were shaped by shared imperial experiences and engagement with other civilisations. The urge to territorialise possessions in the manner of large colonies or the Spanish encomienda had not been especially familiar to the Portuguese. It was so after a 'terrestrial turn' after 1570 (Subrahmanyam, 2007: 1372). The Spanish desire for long-distance trade in Asia was prolonged by the deep dalliance with Portugal. Furthermore, the active coordination of colonisation in the Western hemisphere was linked to operations in Africa and the closely connected regions of Asia through an international fiscal system run by both states. Reasonably uniform fiscal practices emerged to buttress administration and trade in American domains and through allied Asian colonies. The union ended with a difficult disentanglement of conjoint imperial institutions and merging outlooks. As conventional historiography would have it, both were destined for decadence. When recounted as a phase of political modelling and expansion the trajectories look decidedly more complex, contingent and based on shared engagements.

The fourth dimension of inter-civilisational engagement is particularly context-dependent and no single pattern dominates. For instance, culture can travel without political institutions pursuing, as Buddhism did originally in its emanation from India. On the other hand, we have the prominent experience of modern colonialism, where systems of administrative practice are often replicated or transferred in part from the larger imperial order, but the institutions and values of democracy are not. The subjugated stand formally as common subjects of an imperial order, but do not have the opportunity to participate in a common culture of equals. In recognising that this is a formative experience of modernity, a nuanced overview must also incorporate other variants. Examination of the broad variation in the confrontation of non-Western worlds with Western colonialism occurs in coming chapters, where cultural and political exchange and resistance are explored.

As noted above, the long discussion of dimensions of inter-civilisational engagement would be incomplete without qualifying the overall argument with remarks on countervailing limitations and opposites. As Marcel Mauss observed, civilisations are known by their 'non-borrowings' as well as by their combinations. In other words, acts and episodes of aversion and conflict are counterweights to 
engagement. There are noteworthy historical encounters between civilisations that have generated enmity, dissonance and conflict. The impact of acts and episodes of struggle against connection is per se self-defining.

In contexts of modern colonialism, non-borrowings can sit alongside conflictridden relationships of power and inter-imperial rivalry. For example, intercivilisational dissonance was a characteristic of Britain's conflict with China during the so-called Opium Wars. China and Britain's mutual refusal of each other in the context of superior British naval power and greater imperial ambition fuelled the conflict. British demands for economic access made sense within the universe of British imperial ambition that worked from an anglicised map of Asia. At the time, opium was the most profitable export staple of the East India Company's Asian trade. In turn, opium facilitated the highly profitable trade in tea for the British domestic market. Of course, the trade was skewed to British interests. Both sides interpreted circumstances according to conflicting values. What mattered to Britain was wildly at odds with what was valued by China's imperial court. China's refusal to accede issued from a world view at complete variance with Britain's, as well as from a desire in Peking to stem the depletion of silver that enabled China to trade. Subsequently, the conflict with Britain shaped the intense resistance to the emergence of Christianity and the later crackdown on the Taiping Rebellion. China's military defeat did not result in 'free trade', but the transformation of trade practices and patterns in China to the benefit of British interests, especially with the acquisition of Hong Kong as a spoil of war. Other Western powers crowded into eastern China and Canton demanding similar access. A dissonance of world views had led China and Britain to conflicting purposes and stimulated the move to war with an outcome that completely improved Britain's strategic position in Asia against its French, Dutch, Spanish and Portuguese rivals. For China, the setback was devastating and it heralded the beginning of large-scale emigration of Chinese labourers to countries in the Asia-Pacific region.

If dissonance produces cultural resistance, distance from alien traditions can be benign in other scenarios. The maintenance of geo-spatial distance between civilisations leans on differentiation as an inter-cultural condition. Enervation in successful states can produce retirement from the deep engagement that propelled their success originally. Distance between civilisations may emerge in conditions of international and regional transformation as well as from those of stable dominance. Such conditions have a differentiating quality; that is, civilisations and states radically 'other' each other. Japan's withdrawal from regional events in the early period of Tokugawa rule and Korea's Koryō dynasty's retraction from Sung China in the twelfth and thirteenth centuries are examples of considered self-distinction from the dominant state. In the case of Japan, historians have 
situated the regime's retirement within a modernisation meta-narrative as a turn to autarky. It is more adequately understood as a strategic response to changing circumstances initiating a political and cultural dynamic of its own, a phase of 'world watching' (Robertson, 1992: 85). Its adventures with detachment were self-shaping from a vantage-point of safe separation. Blockages to engagement such as this are also a kind of engagement, inasmuch as they can be cultureforming against a distanced outside model. In other words, refusal to interact may still be remote engagement with the alterity of other cultures.

But symbolic differentiation can result in refusal and repulsion as well as benign detachment. Repulsion can postpone engagement indefinitely and this is most evident in cases where minorities are persecuted, removed and made refugees or where violent acts of dispossession occur. The forced conversion and steady expulsion of Jews and Muslims from the Iberian Peninsula between the twelfth and fifteenth centuries brought an end to inter-cultural conviviencia. During the same period Jews were forced out of England and Central Europe in a process that similarly recomposed a population and expunged a climate of coexistence. Brutal modern episodes of expulsion that abruptly bring an end to coexistence have a genocidal streak to their logic. The forced removal of five First Nations by the United States in 1830 from their ancestral lands, Japan's massacres in Nanking in 1937 and the scorched-earth purge of peasants that ensued and the blood-letting and expulsion of Palestinians (al-Nakbah in the Palestinian collective memory) that precipitated the formation of modern Israel are a sample. Whether slower expulsion or sudden relocation or massacre, the refusal to accommodate ethnic and racial others redefines dispositions to the histories and ontologies of other civilisations.

Civilisational fragmentation and collapse is much celebrated in Gibbon-esque histories. Some cases involved the use of strategic ambiguity in refusing alliances and negotiating other options. Byzantine civilisation in the Late Middle Ages faced a choice between tactical reconciliation with the Papacy and the risk of losing Constantinople to the Turkish Empire (Braudel, 1993: 2930). Relations between Latin and Byzantine Christendom overshadowed by mutual suspicion plagued the dilemmas facing Constantinople. Major initiatives to reform state structures and fiscal practices failed along with efforts to prosper on the back of economic growth, which left the empire vulnerable and internally fragmented. Refusal of Latin Christendom's gestures of reconciliation precipitated the Venetian-led invasion of 1204 and the dissolution of the Byzantine Empire for several decades. The ornamental heritage of Byzantine civilisation was violently desecrated. When the empire was formally reinstituted, one last cultural flourish took place in the diminished city of Constantinople. Caught between the Latins to their west and the ascendant 
Ottomans to the east, the inhabitants of the city were isolated. The end came finally more than two centuries later. When Rome's conditions for reuniting the two churches were refused, the way was paved for the decisive Ottoman siege in 1453 . The civilisational legacy was dispersed following the collapse of the state and capture of control of the eastern Mediterranean by the rising Ottoman Empire.

\section{Conclusion}

In the course of this chapter, the ties instituted by human imaginaries are plotted analytically across four dimensions of inter-civilisational engagement. The examples given should serve to clarify variations. They also accentuate the importance of connections prior to the centuries often associated with the so-called global age. I see this as a corrective to the picture of high connectivity in modernity portrayed in many studies of globalisation. In conducting this survey, I have been broad. I continue to be so in the next chapter, which launches Part II. The world's waterways, coasts and seas, so much of the biosphere we inhabit, are neglected realms of civilisation-making and interaction. I aim to correct that in the next two chapters. 


\section{Part II}

Studies in inter-civilisational engagement 
Jeremy C.A. Smith - 9781526105318 Downloaded from manchesterhive.com at 04/26/2023 01:55:36PM via free access 
Saltwater horizons: seas, oceans and civilisations

In this chapter, I aim to interrogate the relationship between oceans, seas and civilisations. A beginning can be made with the peculiarity of ocean environments the vital forces of seas and currents. According to geographer Phillip Sternberg, oceans are spaces of 'fluid mobility and ... tactile materiality ... continually being reconstituted by a variety of elements: the non-human and the human, the biological and the geophysical, the historic and the contemporary' (Sternberg, 2013: 157). When it comes to theorising oceanic spaces, the object should be 'the actual work of construction (labor, exertions of social power, reproduction of institutions etc.) that transpires to make a space what it is' (2013: 158). The 'actual work' includes connections across oceans, and within them also. A maritime-centred perspective on the past can help reach my aim by revealing how problems of accessing and travelling on navigable waterways, seas, coasts and oceans have ingrained themselves into the patterns of civilisation-making and interaction (Paine, 2013). At the same time, a maritime history of the world can add to an elucidation of the dynamic inter-relation of civilisations with the assemblage of oceanic forces.

There are four aspects to this inter-relation discussed in this chapter and then in Chapter 6 . The four aspects criss-cross the four dimensions of inter-civilisational engagement. First is the orientation of civilisations to seas and oceans. Many societies exhibit a cultural and perhaps civilisational reluctance to embrace seagoing, while others are less hesitant. Creative orientations to seafaring can be seen in the acquisition of navigational and cartographical knowledge and techniques, constant processes of learning about aquatic travel, the formation of maritime communities and religious axioms about sailing. Second, oceans - like societies that are land-bound - are zones of conquest. As we shall see, oceanic civilisations and states over the last five hundred years have an impetus to connect and conquer other societies. How oceans are incorporated into the cosmologies of civilisations is a third aspect. For islander civilisations dependent on 
the sea, aquatic worlds often circumscribe myth, spirituality and art. Finally, the extensive mobility available to societies disposed to seafaring widens their range of exposure to different temporalities. Seafaring societies meet both the temporalities of islander societies inhabiting seas and oceans and those of other constellations of marine and naval forces. In world history, seas, coasts and oceans are ecologies of engagement as surely as terrestrial environments are.

Civilisations take to the water, as it were, travelling with merchants, fishers, migrants, sailors and administrators. How they do so in the Atlantic, the Indian and the Pacific Oceans is well researched in studies of those zones. Heightened interest in studying oceans as human domains has grown in the humanities and social sciences (see Bentley et al., 2007; Gillis, 2004, 2013). In contrast, histories of inter-oceanic connections are rare (Paine, 2013). There has been no sustained attempt to integrate oceanic studies into civilisational analysis, nor any attempt to revise either in dialogue with the other. A few points emerge here as responses to the lack of contact between these respective fields of scholarship. To begin with, I propose that connections across seas span a range of remarkable diversity, just as links across lands do. A typology of those connections can discern features of oceanic, portal or thalassic, and islander-based civilisations in their orientation (Mazlish, 2004: 21-41; Murphy, 2001; Paine, 2013) - an orientation that is as decidedly civilisational in character as any of the land-based empires. Yet, the orientations of oceanic, portal and islander civilisations have not received the attention that they should in civilisational analysis. Moreover, the disciplines of world history and sociology have favoured contained national societies and landbased civilisations qua civilisation. But even when oceanic, portal and islanderbased civilisations are treated, it is less for their imaginaries and proclivity for engagement and more for their part in the histories of other larger and 'greater' states, empires and civilisations. In response, I contend that maritime civilisations reach out to saltwater horizons and are animated by oceanic imaginaries. They develop marine, naval and imperial institutions with potential for longrange travel voyages and large-scale conquests. Maritime civilisations purchase on a liquid surface and navigate fluid currents and complex underwater fluxes. Above the undercurrents, open skies are ever-present and ever-retreating horizons. They relinquish the coasts with enough confidence to cross seas and oceans relying on marine knowledge, maps and journals, and the aptitude and technology for taking readings of sun and sky. Physical mobility helps foster the figurative imagination of mobility.

When coupled with the nascent institutions of imperial power, oceanic imaginaries produced maritime empires with goals for conquest via water rather than over land. Europe's Atlantic seaboard states constructed imperial states of this kind. Collectively, they subjected oceanic space to a higher order of naval and 
juridical power, with far-reaching consequences. Oceans and seas have been defined as zones of colonialism, especially over the course of the last five centuries (Bentley et al., 2007; Klein and MacKenthun, 2004). A goal of Europe's empire-building has been control and politicisation of the seas - an end in itself sought by early colonisers as new intruders into old worlds (Mancke, 1999). As an end, control obliged imperial states to create legal and diplomatic instruments for the negotiation of warfare and conflict in extraterritorial space. States extended their authority in oceanic zones as implicit power through instruments of law and diplomacy and via norms of conflict management. Many seas had been contested for centuries: the Mediterranean, the Red Sea, the Arabian Sea and the Gulf of Aden, the South China Sea and the Bay of Bengal. But subjection of maritime endeavour to a normative, juridical and diplomatic framework was a new feature of emerging patterns of conquest and imperialist expansion.

Cartographical representation of oceanic space, along with naming seas, was the companion of this transformation. Modern cartography plotted the steady extension of the frontier of the imagined globe. Coextensive with the delineation of continents, European cartography instilled an abstract divisibility to the oceans, seas and islands. Abstraction in cartography needs common standards. Imperial institutions thereby adopted standard semiotics of space in cartographic representations. For Spain, the Casa de Contratacion; for France, the Academie Royal des Sciences; and for Portugal, Padron Real - all harmonised European conceptions of the world in common semiotics of proportionate spaces, including oceans and seas. Cartography has been inseparable from modern power, even while it extended human imagination. In all of the above ways, oceanic imaginaries have been sources of creation.

\section{Oceanic civilisations and empires}

There were conspicuous ocean-going states and civilisations prior to the fifteenthcentury breakout of Europeans from their continental worlds. FernándezArmesto cites the Phoenicians, the Vikings and the empires of Asia as examples of such civilisations (Fernández-Armesto, 2001: 320-2). Nevertheless, at the demimillennium a consolidation of oceanic links began. The empires and imaginaries of transatlantic colonialism conjoined the two zones of the Indian and Atlantic Oceans, slowly at first and then more definitely. To properly appreciate this, the scholarship of modernity must forgo the landlocked self-understanding of the Western tradition and take to the water, so to speak. Europe's empires of the seas created global visions by signifying claims over oceanic space in order to extend their imperium. Having re-signified the world's ocean spaces and incarnating 
their signification in the art of cartography, the agents of imperial states were able to imagine continents as continents, islands as islands and oceans as oceans, and give names to all of them. Manifold connections between two world zones grew with the intensification of imperial and civilisational rivalries. Colonisation of the Pacific Ocean followed, slowly, beginning in the late eighteenth century.

Perspectives and problematics brought up in Chapters 2 and 3 are relevant to the modernity of colonialism, as it might be considered within civilisational analysis. A focus on inter-oceanic links could lead to a scaled-up version of connected histories reconceptualised as connected oceanic regions. Early modernities can be reframed as processes of inter-civilisational engagement spanning Eurasia and the connections of the greater transatlantic and Pacific. In highlighting those possible reframings and the growing density of connections, I am reiterating three key arguments put forward in earlier work around the thesis that the distinctive trajectory of Europe relates to early 'Atlantic modernity' and extending that argument to the world's multi-civilisational regions (Smith, 2006). What distinguishes my elucidation of Atlantic modernity from the regular story of the rise of the West is a focus on the following dynamics:

1. The outgrowth of Europe's Atlantic empires that integrated Africa, the Western hemisphere and the rest of the world.

2. The imagination of civilisation that coalesced in the imaginary signs of colonialism.

3. Early forms of capitalism instituted through new regimes of accumulation, slavery, development of practices of capitalist rationality and the expansion of trans-continental markets.

The tri-continental Atlantic zone was joined with other global networks discernible in the build-up of early modernities. Atlantic societies were joined with historic Eurasia - part of which was incorporated into the Indian Ocean zone - through extensive imperial connections between multiple centres. The wind patterns of the Atlantic favoured a conjunction of the two oceans. Ships drawn to the Roaring Forties and across the South Atlantic would eventually pass the southern tip of Africa and find a route to the Indian Ocean. The conjunction linked the Eurasian land mass to a hemisphere not occupied by the Western Atlantic powers. Through inter-civilisational engagement across the Atlantic, Indian and Pacific Oceans, a number of the early modernities discussed in contemporary civilisational analysis manifested themselves coextensively in greater world contexts.

Each oceanic zone has distinctive histories. Much of the recent scholarship of Atlantic history has established how the Atlantic seaboard states had no 
competitors in oceanic space in the Western hemisphere. The situation diverged completely from the seas ringing the Indian Ocean and the states that patrolled them. In their land invasion of the Americas, by contrast, they confronted Amerindian peoples and civilisations. In time, they competed with each other in the Atlantic Ocean and around the Caribbean. Legal philosophies armed imperial states with novel world visions of oceanic sovereignty, such as Hugo Grotius's Mare Liberum and the principles of suzerainty underpinning the Treaty of Tordesillas. With respect to Africa, Asia and the Middle East, European colonialism remained mainly commercial until the nineteenth century. Importantly, Europe's empires asserted the right to sovereignty in the Indian Ocean, principally against their European rivals. The claims could not be effective immediately but they were a measure of imperial ambition and imperialising logic. Britain, France, Portugal, the Netherlands and Spain expanded and then internationalised different versions of imperial power and their corpus of laws for the high seas. Born in the north-western periphery of Eurasia, the oceanic empires extended inter-European rivalry into the Indian Ocean, where they were marginal to a congested zone of trade criss-crossed by regional circuits of transport of goods, people and information (Fernández-Armesto, 2000). Moreover, throughout the Indian basin a complex patchwork of sovereignties presented the interloping powers with a more strategically challenging scenario than in the Atlantic. Prior to the nineteenth century, the transformative effects of the linkage between the Indian and Atlantic Oceans were mostly felt in the Atlantic.

Before the entry of the Portuguese, Spanish, Dutch and English forces, the Indian Ocean was a crowded and heterogeneous world of its own (Chaudhuri, 1985). Attracted to the spice trade and the potential for strategic advantages over each other, Portugal, the Netherlands, Britain and Spain were drawn deeper into the Indian Ocean. Initially, they were unimportant outsiders arriving in zones of complex and dense rivalries (Matsuda, 2012: 74-87). Portugal was only able to navigate its entry into the Indian Ocean because it could exploit the intercivilisational transfer of navigational technologies from Asian and Arab sources. The option of quickly establishing colonial monopoly, in the manner of the EuroAmerican empires, was simply not available to them in theWestern Indian Ocean. Instead, the Portuguese had to adapt to existing patterns of trade (Hodgson, 1974: 19-22; Matsuda, 2012: 49-63; Russell-Wood, 1998). The distinctly Catholic traders met Muslims, Jains, Hindus and Jews in settlements that acted as contact zones between merchant forces. In extending their imperial sphere from the Atlantic to the Indian Ocean, Portuguese sailors, traders, officials and soldiers were engaging in a globalising encounter. While en route around Africa they engaged in the habitual rituals of possession on the West African coastline, using methods learnt from Islamic forces in the long Reconquista of the Iberian 
Peninsula (Smith, 2006: 91-2). The rituals stopped after crossings of the Cape of Good Hope. As they entered the Indian Ocean as a 'Western' force, they had to do so on Eastern terms. In following an entrepôt pattern of empire-building, they used a combination of naval and military coercion and negotiation to acquire ports at Mombasa, Mozambique, Goa, Melaka, Macao and Nagasaki. Through their company, the Estado da India Oriental, they established a vehicle of colonial power that could maintain routes of communication, transfer and long-distance movement. Portugal was peripheral to the emporia trade for a very long time and could not have things its own way in many places. Conversely, Portugal's Asian trade was far from peripheral to Atlantic Europe. They collaborated for a time with the Spanish, who held Manila, and expanded their conjoint institutional and economic development (Subrahmanyam, 2007). Yet, it is hard to see how Portugal could have gained hegemony in the Indian Ocean even during the union with Spain, if that was ever their objective. Nevertheless, their commercial involvement conspicuously introduced naval power and large-scale trading companies into Asian and African trade patterns. These factors were indicative of a different kind of imperial state formation from that of the Americas that were more suited to the crowded world region of the Indian Ocean.

For years to come, this would remain colonial intrusion rather than conquest. The Dutch and then the English soon followed. Both were equipped differently from the Portuguese seaborne empire. The modern Dutch state was collectively formed with a delta prospect through which northern Europe's largest rivers spilled out to the sea. It met its challenges by building a worldwide oceanic empire. With experience in piracy and warfare, the progenitors of the United Provinces' imperial vocation were corporatist governors at home and expansionists abroad. At home they instituted a self-balancing confederal polity of estates and riverside cities. They complemented state institutions with a family enterprise-based variety of capitalist economy. As an oceanic empire, it was similar to the Portuguese in that its agents sought forts, naval bases and factories at first and established colonies later. Yet, the protestant Dutch built a distinct Asian empire by, first, seeking to supplant rivals in Asia and, second, by creating corporatist-commercial power and harnessing that power on a qualitatively larger scale. In the form of the Dutch East Indies Company (VOC), the Dutch state created a vehicle for economic monopoly and political and military bureaucracy. While the VOC was in the ascendency, Dutch imperialism progressed and its naval and marine power expanded. For a century-and-a-half, the spice monopoly fetched high profits. When the VOC declared bankruptcy in 1799, formal colonial rule of Dutch Asian possessions became a matter of government administration. Expansion halted. England, initially a minor naval power, also produced an oceanic state from the most extreme margin of the Eurasian land 
mass. When the British government separated the functions of the British navy from commercial interests, it removed fiscal and organisational responsibility from commercial operations, enhancing the profitability of the latter and the viability of the former. Even with modifications to the state, however, Britain's imperial strategies still had to adjust to regional circumstances in Asia and the ongoing competition in the Indian Ocean basin.

What was true for the British applied to their European competitors also: they had to adjust to economies in which they were marginal and they had to negotiate with local authorities. Cooperation with other foreign merchants and urban and regional officials was obligatory in Indonesia, where Chinese suppliers and middle-merchants outnumbered the Dutch for a very long time. Connecting Asian port trade to a longer chain of transport, warehousing and final sale was an enterprise across different cultural zones all requiring cross-cultural negotiations. Furthermore, all this occurred in an era when the Asian-borne trade was still greater than that of the Europeans and when Asian production was still far greater. The Acehnese Sultanate, China and the Ottomans all tried to check the Portuguese advances, but then abandoned the strategy (Mancke, 1999: 229). The Dutch were more of a powerhouse. They outmuscled and outmanoeuvred the strained Portuguese Empire. Strategically and commercially, Portuguese interests were not as significant as the colonial companies of the English and the Dutch would become.

With all the European rivals in the field - including the Spanish in the Philippines - intrusion turned to conquest (Arnason, 1997b: 114). The Dutch (VOC) and English East India Companies advanced centralised bureaucracies as a new vehicle for colonial intrusion. The Dutch VOC succeeded as a well-backed government monopoly with colonial, mercantile and naval responsibilities. With the demise of the VOC, colonial rule devolved to public administration. But Dutch interests generally were on the defensive by the early nineteenth century. The effects of the Anglo-Dutch Wars over the course of the eighteenth century had tempered the will of both sides to war with each other. By this time, exclusion of British commerce from the sea lanes of Asia and from the Pacific had already come to an end, finished off when the British terminated the Spanish monopoly over the Pacific as a direct consequence of the Seven Years War.

At the dawn of the era of Grotius's doctrine of open passage on the high seas, the English were well placed to exploit long-distance trade as a specialism. In the early decades, officials of the English East India Company adopted the strategy of negotiating commercial privileges rather than using force as the first resort in the manner of the Portuguese. In many ways they carried the authority of the empire in their person. As 'agents of empire' they personified an implicit imperium. Thomas Raffles exemplified the embodiment 
of personal and imperial authority in his deal-making strategy in Singapore (Matsuda, 2012: 197-9). The embodiment of authority was generalised in the English East India Company, but British offices were also part-rationalised. In a strategy intended to minimise venality, the restructuring of the Company's staffing produced the model of the Civil Service. As British interests extended their territorial hold, the English East India Company increasingly assumed state functions by resourcing troop regiments with its own soldiers and by developing a system of revenue extraction. With a larger apparatus British imperial authorities were more imposing. By 1830 the transformation to a colonial administration was complete. As they acquired colonial territories in Asia, the British were able to strengthen the web of networks made in the process of linking three oceanic spheres, thereby projecting British imperial power further. In the early eighteenth century the British looked the strongest of the European empires in Asia, though the position was not assured. The shift in strategic weight in Asia from Indonesia to India probably helped them achieve a precarious but discernible advantage at that time (Braudel, 1985: 530-3).

The Dutch and the British stimulated naval development through theVOC and the English East India Company. This was no linear development; along with the French, both lost ground to Asian traders in the early eighteenth century, even with British consolidation in India. The international balance shifted decisively in the nineteenth century. Dutch power advanced in Java (though it was checked in South-East Asia overall), French colonialism spread to and in Indochina and Egypt, and British influence expanded further in India, China and Singapore to a point of effective imperial hegemony (Pomeranz and Topik, 1999: 66-76). The porosity of ports and cities throughout the Indian Ocean and its bordering seas, coasts and archipelagos now assisted. So also did the maturing naval power of the oceanic empires.

In one generation, the impact of Western colonialism was felt in the territories of Asian and Islamic states. The British turned ascendancy in India into the Raj; French incursion shocked Egypt, as French conquests did in Indochina; and the Dutch reorganised Indonesia (Hodgson, 1993: 206). Over the course of the conversion of footholds into colonial territories, Europe's oceanic empires had forged new constellations of power from the connections of the Western hemisphere with the central world economies, state systems and multi-civilisational zones of Asia, Africa and the Indian Ocean. They were fully fledged world empires in the sense that they projected ambitions for pre-eminence in the imperial worlds that they organised. They are categorically distinct from the portal and thalassic civilisations and states that we turn to next. 


\section{Porosity of ports: civilisations of the seas}

Oceanic civilisations and the states and empires that they instituted had a largescale reach. Portal civilisations were more modest and had a thalassic imaginary, a seaward horizon if you will. Though their 'headquarters' was a port city, portal civilisations were more than states with working harbours and open sea-fronts. Their imaginaries oriented to the ebbs and flows of the sea and surrounding islands. Port cities fostered in the mind movements of ebb and flow between the human artifice of the port structures and the natural flow of tides (Murphy, 2001). Places where nature and construction contrast - and also conjoin along fluid boundaries - are ecologies that nurture a marine imagination. Ports help imagine a habitus of flows:

A further part of this pleasure is due to the artifice of port life that is built on the back and forth motion of the waters' edge. At the point of seaborne arrival and departure, nature and artifice blend into a seamless whole. The solidity of the wharf and the fluidity of the channel meet in suspended equilibrium. The pylon of the wharf, upon which the sea washes itself, beating and rocking with the motion of eternal return, is pure human contrivance, driven into bedrock, forming a tectonic joint with nature. The ebb and flow of the marine domain sets the tone for the artifices of the port (its shipcraft, wharves, buildings, urban plan, architecture, social structure and politics) and this nature-become-artifice ultimately replays itself in the higher artifice of abstract human thought. (Murphy, 2001: 11)

Where continuous trade, counter-balancing structures of power and artful politics are signified in the imaginaries of portal states, we can characterise such states as thalassic civilisations. They produce receptive impulses. The make-up of society and material culture in such places structures hospitable environments for strangers and communities of foreigners. Like oceanic states, they embrace mobility and support the mobility of arriving mariners, newcomers, goods, ideas, techniques, philosophies and styles. The materiality, architecture and logics of port cities nurture particular kinds of imagination, and consequently portal societies are welcoming of science and philosophy as well as trade. As conjunctures, they provide the preconditions of creativity. They propagate works of knowledge. They are publishing centres throughout a sphere of influence.

But portal civilisations also relate to other civilisations in particularly open ways. Their orientation is more to negotiated coexistence elsewhere, rather than to total conquest. They 'put out' communities of foreigners to other cities and societies on the terms that others negotiate with them. When their agents 'make landfall' elsewhere they act to negotiate with established social orders. 
Ancient Greek cities and the sea-based Phoenicians exemplified this pattern (see Fernández-Armesto, 2001: 349-65). Port cities established by both colonising powers are trading ports again today, for example Tyre, Piraeus and Cadiz. There are other examples of thalassic civilisations: Renaissance Venice, the Hanseatic League cities, early modern Konigsburg, Muscat and Makran under the modern Omani Empire and the Ryukyu Kingdom. Venice and the Omani Empire illustrate the varying contexts in which portal civilisations can acquire trans-civilisational reach.

\section{Venice}

The Venetian archipelago as a settled habitat is a 'rational impossibility' (Fernández-Armesto, 2001: 294). Swampy marshland makes for a bad location. Yet, over a thousand years, it remained astonishingly independent. As an artefact resisting constant ecological assault, Venice contrasts ornamental grandeur with the city's marshy foundation. Ecology was not destiny. With forts, bridges, squares, wells and ultimately with canals, the lagoon's inhabitants made a city and then gambled on building a seaborne power, a wager that worked. This is a robust example of a thalassic civilisation and empire. In the process of state formation, the political bloc could subordinate, or pattern, economics in decisive phases. Following Weber's uncharacteristic sociology of the city, Rundell argues that an urban imaginary produced an oligarchic city republic (Rundell, 2014: 241-8). The guild patriciate obtained a monopoly position by the end of the twelfth century, leaving the office of the Doge ineffectual. Its thalassic empire added an imperial domain to its sphere of explicit power and an imperial dimension to its fiercely competitive political centre. Though ruthless and corruptible, the guild oligarchy was the crux of a tyrannical concentration of power in the polity. Externally, the oligarchic state attained imperial extension of a very particular and modest kind. With little domestic territory, portal Venice became a consummate seaborne power that, at its height, commanded a network-like empire with an extremely effective and mobile navy (Paine, 2013: 317-21, 429-30). The mercenaries, agents, contacts and intermediaries of the Venetian Republic extended throughout the eastern Mediterranean. Venice was an eastward-oriented conduit of civilisations, so much so that traces of Byzantine and Islamic traditions endure in its art, architecture and urban design. Venetian rulers, merchants, officials and artisans could deal with Islamic, Jewish and Byzantine counterparts without the strictures of orthodox Catholic scruples (and without the support of Rome where necessary). Crucially, the character of the middle imperial power lay in extension more than domination. Toynbee's image of Venice may 
be a misleading and over-simplistic one of ephemerality and decadence, but his assertion that Venice 'succeeded ... because she avoided the strain which imperialism tends to impose upon communities that indulge in it' is credible (1972: 174). Through trading posts, Venice dominated lucrative trade routes from North Africa to Crete and Cyprus, to the Levant and the Black Sea, and then way back to the Mediterranean's west. Venice had grown on the back of its internal struggles and it eased and curbed access to citizenship according to an internal balance of forces and imperatives for expansion. In the east, its commercial partners were frequently its political rivals. Byzantium - for some time its main challenger - fell when Constantinople was captured at the start of the thirteenth century by the Venetian-funded forces of the Fourth Crusade following a particularly unstable period. The Fourth Crusade was a watershed in the rising republic's history. Strategically, Venice gained the eastern Mediterranean as a sphere of influence, while financially the victory delivered a vast windfall in plunder. At that time, the Republic was a preeminent power in the region.

At its peak, what gave Venice an edge over its rivals was its position as the clearing house of Eastern trade with the West. Like other city-states of sixteenthcentury Europe, it was given to creative adaptation of instruments and strategies of commerce encountered in the distant travels of its merchants. The empire's long-distance trade in commodities, art, produce and materials embroiled it in substantial economic transactions with Arab and Byzantine merchants and later with the Ottomans, all of which acted to aggrandise the financial knowhow of Venice's bankers, the technological and organisational resources of the merchant marine and the base of wealth held by the Venetian patriciate itself. Braudel puts the success of Venetian civilisation down to financial power and its augmentation of the state and its agencies (Braudel, 1985: 116-36). In this combination, Venice found a kind of capitalism that its navy, boosted by its mercantile and cultural power, could defend until the Spanish unlocked the Atlantic world for Europeans. Venice's seaborne trade still increased in absolute volume after that event. But in comparison to other states, its fortunes had taken a turn for the worse. In the second half of the fifteenth century, the Ottoman Empire had emerged as a new regional rival. Under Mehmid I and Bayezid II, the Ottomans had successfully converted their state into a seaborne power. The Venetian navy that had provided an effective convoy system of protection for seaborne commerce was in ruins and unable to resist the new competitor. By the time the Ottoman Empire had routed the Venetian navy in the 1499-1503 war, the balance in the eastern Mediterranean had shifted entirely (Fernández-Armesto, 2000: 297). The city republic turned in the sixteenth century to territorial state-building and agricultural production to compensate. Fitting agriculture into a political economy of 
commercial porosity and cultural creation helped Venice survive until the era of powerful national states. Defeat at the hands of Napoleon in 1797 brought the Republic to an end.

Many historians consider the end of independent Venice as a tragedy. Toynbee does not join the chorus of tragic meta-narrative, but the end is decisive as far as he is concerned. He writes that 'on the whole and in the end, Venice failed to make any fresh creative contribution to the life of the society in which she managed to survive; and this Venetian failure can be explained by the fact that Venice, too, did succumb, in her own way, to the nemesis of creativity' (1972: 176). On the contrary, Venice as a portal city continued to welcome and promote cultural creativity. The physical inheritance was not the only legacy of thalassic success. City-making had been based on high investment in the objects of civic pride. The resulting landmarks of public magnificence affected confidence and world-making. Venice had an urban, artistic and imperial imaginary that incubated creativity. In city design, architecture and art, the city incarnated mercantile power. Those entering and leaving always had the republic's power impressed upon them in the surviving heritage of the empire's wealth. The watery entrance impressed with utilitarian and symbolic qualities. Its architecture and urban design combined different genres. The combinations are creative. The Grand Canal is Venetian Gothic; the Rialto Bridge classical. Rival classicisms vied for patrician favour and ebbed and flowed with the city's fluctuating politics. An infusion of Baroque forms and motifs in the late imperial period completed the mix. The result is creative arrangements on public buildings and private residences of facades, reliefs, stylistic columns, crenellations, porticoes, ornate decorations and statues. The construction of piazzas, arcades, palazzi and churches continued the theme of combination.

The traditions are living ones. Venice remains a site for architectural and artistic innovation that accentuates portal features and affects (Murphy, 2001: 2732). In the nineteenth century, British Romanticism discovered Venice for the rest of Europe. The splendour of the city on the lagoon became the subject of art, writing and poetry as well as a haunt of artists, writers and poets. Byron, Turner, Dickens and John Ruskin popularised Venice, but left out the living city of the day. What they did, however, drew people to the living city. When the railway came, the significance of the watery entrance diminished. Its introduction was an instalment in a long story of struggle between so-called modernisers and preservationists over the portal character of the city. Industry and flooding became threats to the city, but they are not the only ones. Long after the empire has passed, the experience of Renaissance magnificence remains a drawcard for tourists, though the watery entrance is very limited for twenty-first-century jetsetters. The number of visitors has grown to levels seen by many as unsustainable. 
Yet, the local population is in steep decline. If the trends continue, will the place remain meaningfully connected? Will its portal character survive? But these are questions that will have to be left unanswered here.

\section{Oman}

Oman's thalassic civilisation mobilised traditions of engagement during a highly interactive phase in the nineteenth century (Nicolini, 2004). The Omani Empire built an orientation to cross-flows and influences on the foundation of a long history of confrontation with other civilisational forms (Rundell, 2015). At the same time, Omani input into inter-civilisational trade built up commercial traffic under its own auspices between the Middle East, Asia and East Africa. Even though the imperial state depended on terrestrial forces and its lands, Oman was a seaward civilisation oriented to oceanic horizons (Fernández-Armesto, 2001: 328-30). Omani shipping heading down East Africa's coast and to India was favoured by the cyclical winds of the monsoon. Oman attached well-networked coastal communities to robust trades of the interior, including the slave trade. Within this network, Kilwa and Zanzibar acted as nodes of exchange between Africa's interior trades and outside destinations in Oman and Gujarat. Omani agents injected a range of raw resources into international trade such as copra, rare timbers, animal hides, horns and shells. The Omani Empire even helped in the creation of Swahili civilisation through their subjection of the Swahili to the powers of the Indian Ocean trade (Nicolini, 2004: 57-66). The engagement of other civilisational forces in East Africa was part of this civilisational process also. Older traditions of intra-African trade and trade between the interior and thalassocracies on East Africa's coasts all the way down to Madagascar are underestimated in the historiography (Paine, 2013: 268-72). Undoubtedly, as Nicolini has argued, they contextualised Swahili integration into Omani commerce. Conjoined circuits of Saharan trade, created by the empires of the Niger Delta and Ethiopia in earlier centuries, formed the backdrop of zones of contact, communication and exchange with Islamic and Christian civilisations. The importance of historical trades for commerce and state formation in the West Indian Ocean has also been underestimated. As elsewhere, cross-cultural knowledge and capabilities were needed to navigate and organise economic relations. In the era of Omani domination of the cities of East Africa, Afro-Arab and Swahili brokers were all involved in allying markets in the interior with wider maritime movements within the greater Omani sphere of influence.

The modern Omani Empire was thus able to exploit the seasons of the monsoon to link Makran, Muscat and Zanzibar with Asia in an extensive civilisational nexus. In doing so, Oman triangulated three very different mercantile 
worlds: Persia and Arabia, thalassocratic East Africa and the interior and Gwadir (later in Pakistan) and Asian ports. Moreover, Oman's own interior lands were a different economic world, more remote from the trading impulses of the coastal nodes. The tribal interior, nonetheless, was not unaffected by the seaward orientation. On the contrary, land-based Omani society had a tradition of negotiating distant relationships with the outside Arab world. Externally, royal authorities had to engage increasingly intrusive European powers. The ascendant Omani state had seen off Portuguese occupation in the 1650s (Paine, 2013: 454). In subsequent decades, competition with Turkish, Persian and Western interests grew. But Oman was up to it and indeed thrived in the new regional environment. The rise of the House of $\mathrm{Al} \mathrm{Bu} \mathrm{Sa'id} \mathrm{in} \mathrm{the} \mathrm{mid} \mathrm{eighteenth} \mathrm{century} \mathrm{began} \mathrm{a} \mathrm{two-}$ and-a-half-century period of uninterrupted dynastic rule. In the late eighteenth century, the Sa'id separated secular and theocratic powers, thereby putting the state on a stronger commercial, naval and diplomatic footing. Playing France off against Britain, Oman was able to settle an unthreatening treaty with the British. Steering a fine strategic line between French and British interests in East Africa, the Omani prince-merchant Sa'id bin Sultan Al Bu Sa'idi (1807-56) was able to sustain an increasingly independent sphere of Omani power and influence in the Indian Ocean. Oman could establish trade relations with the United States, France and Portugal while remaining faithful to the treaty with Britain. Sa'id bin Sultan moved his capital to Zanzibar and from there opened up the extensive and lucrative clove trade. Exposure to European imperial rivalries afforded Omani elites the opportunity to regard Portuguese, then British and French models of imperial statecraft and diplomacy. Through a long learning process they created a sui generis statehood, carefully and strategically crafting an imperial polity that incorporated such disparate elements as the mercantile and slaving elites in Zanzibar and a praetorian military force in Muscat. The empire in Arabia and East Africa had a confederal rather than centralist form. As a result, the Omani Empire was well equipped to challenge the European powers in the West Indian Ocean (Mancke, 1999: 230; Paine, 2013: 454).

The Omani relationship with the British bears this point out. British agents were increasingly prominent in the Arabian Gulf and were able to funnel intelligence on Oman back to London. Knowing the empire well, the British were on a solid footing to negotiate with the Omani sovereign. Britain's growing support for the abolition of slavery in international trade put it at odds with the slaving Omani Empire. While high officials of the British Empire walked a difficult diplomatic tightrope in negotiations with other powers about abolishing slaving, they were seeking an alliance with Oman that resulted in the compromise of the Moresby Treaty. The Omanis for their part artfully used their own position and the dilemmas of the British to their best advantage by using British 
collusion to outmanoeuvre French influence (Rundell, 2015). Oman emerged with decisive control over East African commerce, at the expense of its local rivals. For a time in the nineteenth century, the Omani Empire held a strong position, where others had already succumbed to the force of British colonialism. Economic decline, internal division and a stronger maritime and naval presence of Western forces undermined that position and precipitated a long period of retraction from international prominence. But no more can be said about that here.

\section{Islander civilisations}

Oman's zenith passed with the break-up of the empire into Muscat-centred and Zanzibar-centred states. Island bases in the Arabian-Persian Gulf and East Africa had a dual place in the thalassic Omani Empire as, first, intermediary ports and, second, as part of the segmented nexus of polities under Omani auspices. Islands were the distribution points of many portal civilisations. While islands were crucial in the creation of oceanic and portal civilisations, it is also worth thinking about them as separate entities.

Some can be regarded as islander civilisations. This requires awareness of their historical, collective and indigenous memories. The struggle for memory strikes up against the social problems of the present for many contemporary states. In the twenty-first century, few islands achieve the heights of Hong Kong and Singapore. Many find themselves trapped in dependence and inequality. Yet, this has not always been the fate of such islands (Fernández-Armesto, 2000: 2756). Many have a past in which they played a more pronounced part in intercivilisational networks, even though conditions of human habitation were often precarious. Poverty and inequality within, compounded by inequality in the world economy, makes it hard to visualise a proud past before dependence that some islands had. Places such as Kilwa, the Comoros, Sicily, Madagascar, the Caribbean and Melanesia were nodes of trade, spiritual exchange and intercultural communication. Military occupation and colonisation were not outside their experiences either. Interlopers left layers in the historical accretion of island societies, if they governed long enough. As an example, the Maldives make up an unusual historical assemblage. They appear thrown like a net across the oldest courses of commerce. Stretching from the south of India to reach out towards the middle of the ocean, the islands catch the passing traffic, including a share of the spice trade. Religious artefacts attest to the influx of Buddhism and later Islam to join the indigenous religion in monument-building on the islands. Whatever remains they have left behind have had to defy sporadic bursts 
of iconoclasm. Its strategic value was such that the whole string of islands was captured in the early eleventh century by the Cholas in a move that sealed their advantage in South-East Asia. It is hard to draw generalisations when faced with the variety of societies, such as in the above list. Where are islands in the histories and sociologies of civilisations?

Braudel, Paine and Fernández-Armesto stand out as generalist historians of civilisations and island societies. What shines through Braudel's comprehension of the Mediterranean for the reader is the feel of the islands and littorals and the coasts, currents and breezes (Braudel, 2001). The integrated world that his history recreates presents islands as nodes of interaction between many civilisations that inhabit the Mediterranean basin. Braudel's later reflections (2001) suggest a more nuanced picture with only a formative unity - an image not reflected in his earlier history or by those following his thalassology (Arnason, 2003: 321-2). His geography-heavy thalassology is not beyond critical debate. None of the reception seems to hone in on his privileging of islands in the Mediterranean. Many similar points are also made by comparativists and historians of the Indian, Atlantic and Pacific Oceans. Braudel's focused treatment of the Mediterranean's archaic and ancient islands emphasises networks of communication, trade, exchange and migration (2001). Stepping outside the Mediterranean, there is less history of islands to stir the interest (see, for example, Braudel, 1993). Braudel left a substantial legacy, however, in the study of connectivity across seas, one that spread throughout the historiography of other oceans (Bayly, 2012: 5). Paine goes further than Braudel to argue for a global maritime history that rethinks the space of human agency and asks us to imagine the high seas as the arena in which it occurs. For instance, he paints a picture of Oceania as a world of islands connected in 'the oldest, most sustained, and perhaps most enigmatic effort of maritime exploration and migration in the history of the world' (Paine, 2013: 13). Transmigration across large bodies of water between islands was a pre-archaic world breakthrough that occurred first in the western Pacific. Paine advocates a completely different maritime view of evolutionary complexes of the environment, technology and society. In his view, islands are points of human connection that punctuate inter-linked oceans. A regional case in point is the archipelago formation of Indonesia and the Malaysian Peninsula. The islands and the Peninsula land mass separate the South China Sea (itself split from the Pacific by the Philippines) and the Indian Ocean. The region is porous, shaped by a pockmarking island topography, which enables connection but inhibits unity (Paine, 2013: 169-70; see also Arnason, 1997b). The entire zone has been a vibrant nautical crossroads of trade, politics and spirituality; islands catching the passing traffic in culture, goods and models of organisation (Paine, 2013: 27883). Paine's thalassology sits well alongside Fernández-Armesto's environmental 
world history. Fernández-Armesto exercises vigilance around the circumferences of islands as well as the joins of land and sea. Shores and oceans are magnified in the worlds of island inhabitants. Islands are only 'small' when their civilisation fosters an insular relationship to the surrounding sea (Fernández-Armesto, 2000: 277). He sees the project of civilisation as thin in many island environments and yet its agents often prove remarkably resourceful. Venice is the magnificent exemplar in his classification of small islands civilisations. I have defined its significance differently. Moreover, where Fernández-Armesto regards Pacific island civilisation as an 'exception' (2000: 289), I regard it as the exception to elevate, as I argue below and in the next chapter. Nonetheless, I still find it easy to admire Fernández-Armesto's sensuous grasp of diverse island environments.

Overall, there are no equivalents amongst founding perspectives to the astute appreciation of islands we find in Braudel, Paine and Fernández-Armesto. Mauss deserves more than an honourable mention as one exception. His inclusion of the civilisational complexes of multi-island Melanesia and Polynesia sets their gifting practices in comparative perspective with pre-Brahmanic India and north-west America (Mauss, 1969). Often Mauss's analysis of islands presents an intra-societal picture. However, larger-scale interaction also appears in his short comparative anthropology. As a key instance of this, inter-island rituals model potentially larger encounters on a civilisational scale. Mauss's limited comments on the trade of islands give clues to how his style of comparison of material and moral life could be reorganised to illustrate patterns of exchange across greater distances and involving encounters of more clearly differentiated cultures.

The historical question of islander civilisations continues unresolved and, with one exception, I do not have the room, or the scholarly expertise, to pursue it in the manner it deserves. If we think of civilisations and regions as closely aligned, however, some candidates for further investigation are thrown into relief. The Maldives, the Torres Strait, the Caribbean and the ComorosMadagascar could register in a research programme of this sort. Undoubtedly, there would be more. The paucity of analysis of islands as civilisations may well relate to their general fate in the global age. When the imperial expansion of European states was at its height and the conflicts it engendered were the greatest, islands were incredibly important strategically, economically and culturally. Their decline since has been precipitous. The nature of the demise of most islands is not only economic, strategic and political. As Gillis writes, it is also a product of lost memory: 'We have lost sight of this [the pre-eminence of islands] because in the Western historiographical canon laid down in the nineteenth century, history is presented as if it begins and ends at the edges of continents, and dwells almost exclusively on their interiors' (Gillis, 2004: 85). In the nineteenth century, large-state nationalism also 
devalued island societies (Gillis, 2004: 114-16). Anthropology called attention to island societies, but the anthropological imagination was dependent in complex ways - on colonialism and its devolution, and the early division of the twentieth-century social sciences. In the course of the twentieth century, actually existing island societies were marginalised by globalising logics. Perhaps it is no surprise that a paradigm of comparative analysis such as civilisational analysis, in which large multi-societal complexes are the object of inquiry, should neglect islands. However, if inter-civilisational engagement is the analytic put to work in comparative analysis, then the dense regions of connections of island societies can be brought into the picture.

There is another reason to elevate the significance of islands and islander civilisations. Islands as environments compel reflections on civilisational pasts. At the dawn of the twenty-first century, island environments themselves looked gravely threatened by acute climate change. Vanuatu, the islands of the Republic of Kiribati, Tuvalu (at less than five metres above sea level) and Fiji are critically exposed in the Anthropocene. If islands are needed for a future agenda of civilisational analysis, it is partly because they reanimate the question of a common fate for humanity. Human connections with and across seas, coasts and oceans anthropologically have defined humanity and shaped civilisations (Gillis, 2013). If we accept this, then it follows that one way of thinking about the ecological commons is to picture the 'Earth island' (Gillis, 2004: 167-8); that is, to invoke an island horizon in contemplating possible futures and acting on them. Given that, climate change appears, rightly, as the issue of our times. An islander perspective has more to offer for contemporary civilisational analysis in this area. A view from an island puts ecology into perspective and land and sea-mass into proportion. Oceanographer Sylvia Earle writes in Time magazine, 'Rain forests and other terrestrial systems are important too, of course, but without the living ocean there would be no life on land. Most of Earth's living space, the biosphere, is ocean - about 97\%. And not so coincidentally 97\% of Earth's water is Ocean' (cited in Hau'ofa, 2008: 52). Rising sea levels are not the only issue. Acidification of the ocean, precipitous decline in key species in the food chain and erosion of essential reef environments also present major threats to wider bionetworks. As issues, they should not be limited to thalassology, the earth sciences, marine biology and oceanography. They are questions of life itself for many islanders. Oceans should be included in civilisational analysis more methodically. They can be part of a research programme as byways of engagement and as environments of the institution of civilisations. This would bring ecology onto the agenda more substantially and include it with particular islander standpoints. 


\section{Conclusion}

A promising research agenda on oceans and imaginaries cannot be pursued here except in regard to one notable civilisation: the Pacific Ocean civilisation of Polynesian, Micronesian and Melanesian societies. In the next chapter, I present an extended case for inclusion of the Pacific. In Chapters 4 and 5, I have concentrated on presenting inter-civilisational engagement with a breadth of scope. The coming chapters of Part II concentrate on providing depth by examining modern examples in greater detail and with more focus: the Pacific, Latin America and Japan. By exploring the lineage of ideas around culture, politics, economy and civilisation in these three distinct contexts, I track inter-civilisational engagement in greater depth in specific environments and contexts. 


\section{6 \\ Pacific imaginaries: ontologies of connection, reconstruction of memory}

It is remarkable that the Pacific is almost entirely absent from contemporary civilisational analysis, especially given its evident importance to anthropology, to archaeology and to Durkheim and Mauss - two formative thinkers in the paradigm. But new world contexts more generally are still marginal to civilisational analysis. The lacuna relates to the strengths and limitations of the three images of civilisations discussed in Chapters 2 and 3. American and Pacific new worlds were mostly separated in history from Eurasia - the main nucleus of creation in perspectives of civilisational analysis - until the sixteenth century. Moreover, successor civilisations were more dispersed in Oceania and the Americas, and inter-civilisational encounters were uncommon and more restricted.

The fates of new and old world societies look different when viewed through the prism of capacity for inter-civilisational engagement. Examining four major themes, I approach the Pacific as both a new world and an old world. First, the Pacific is made by a long history of migration. Through voyaging and migration, islander societies expanded, creating and sustaining zones of engagement for millennia before Europeans came. Travel stimulated an imaginary of exchange, the second theme. Exchange cannot be understood with a utilitarian mindset; it is rather an expression of relationship, association and alliance - engagement broadly speaking. The third theme is the new world context. European colonialism conjoined the Pacific to other civilisations in more extensive engagement. This was a violent and disordering historical experience for the Pacific. But, as argued in Chapter 4, experiences of colonial intrusion, dispossession, subjection and dis-embedding can be considered forms of engagement. It was also the case that forms of engagement in general were far from alien to islander societies. As an old world, Pacific civilisation was already relational and had a paradigm of engagement in the relations of exchange that islander societies practised and the cosmologies that endowed meaning to their connectivity. When European colonisation incorporated Oceanian societies into larger trans-national networks of 
capitalism, established cultural habits of exchange could find a place in the trading circuits set up by the colonial empires. Finally, the reconstruction of memory in the Pacific's ocean civilisation revives the values of the past in a project of renewed connection. The chapter ends with a section on Australia's ambivalent cultures which have emerged from the British-Australian project of colonizing the lands and worlds of old world indigenous civilisations. Australia, in particular, is in the Pacific, but also out of place in the Pacific.

The Pacific's absence from contemporary civilisational analysis continues in a scenario in which critical scholarship on the Pacific has grown. Through exchanges between historians, artists, novelists, sociologists, activists and archaeologists from the region and counterparts from elsewhere (known as 'outlanders'), debates about post-colonial conditions have produced new insights, helped to foster cultural memory and islander identities and languages, generated different methods and shaped new practices (Borofsky, 2000). Furthermore, the expansion of knowledge and the range of cultural exchanges has fostered an awareness of the status of the Pacific as a civilisation in its own right. Islander-intellectuals in the arts, politics and sciences, such as Albert Wendt, Vaine Rasmussen and Vilisoni Hereniko, have steadily cultivated exchanges with professional historians who have privileged indigenous historiographies in new epistemologies of the Pacific - Donald Denoon, Kerry Howe and Marshall Sahlins, to mention the main figures. Against the backdrop of cultural and political dialogue, anthropologist, activist and artist Epeli Hau'ofa proposed the encompassing name of 'Oceania' for the Pacific on the basis of cosmologies that share common themes (Hau'ofa, 2008; Waddell et al., 1993). Continuing Wendt's use of 'Oceania', Hau' ofa's purpose was to replace a connotation of detachment of insignificant lands with one of engagement and exchange. Before turning to the four themes of the chapter, I want to examine the terms on which it can be claimed that Oceania is a civilisation as a way of supporting Hau' ofa's project and turning to the question of inter-civilisational engagement.

From a civilisational angle, Oceania is a larger world with reviving social and cultural resources despite the extraordinary disordering produced by colonialism. Where does it start and where does it end? For this question, no answer seems adequate. Geography has no single answer, but it does identify a number of distinguishing features. The Pacific has big horizons. Though there are many islands, there are also long distances. Its vastness puts everything else in perspective. The Pacific's surface area is larger than the planet's combined land surface. If space alone is taken as the criterion, most of the Pacific's islands seem tiny in this vast ocean. As the world's largest ocean basin, the Pacific is geologically and environmentally integrated by surprisingly few sets of seismic patterns and deep water flows. Geological integration aside, it is problematic to attribute unities to 
Pacific worlds. The Pacific includes minuscule and disappearing atolls, but also the huge island continent of Australia and the large islands of New Zealand and Papua New Guinea.

Generalisation would therefore seem hazardous, but that is exactly what European explorers did when they labelled diverse islander societies as Micronesia, Melanesia and Polynesia. 'The Pacific' itself is a European construction of the very oceanic imagination discussed in the previous chapter as a counterpart to continental imagination. At the same time, a critical sensibility helps when navigating current-day uses of inherited geographical traditions. An interesting historical example is Matt Matsuda's incorporation of archipelagic Indonesia, the Philippines and the Malay Peninsula into his geography of a greater Pacific world (2012). In his analysis, South-East Asia was part of the nexus of engagement from the demi-millennium that interconnected other worlds with the Pacific basin. The geography of Oceania, in this alternative view, is inhabited by diverse peoples with lengthy shared and conjoined histories. There is no definitive nucleus; instead there are many cultural centres of an older polycentric civilisation. The shared and conjoined histories are discontinuous, however, and one of the main forces of discontinuity is capitalist modernity. Two centuries of integration into emergent capitalism, which has been consubstantial with subsuming colonialism, has transformed the meaning of the Pacific's geography. Arif Dirlik is right to highlight the discourse of the 'Rim' (1997: 129-45). But the discourse is neither all-powerful, nor pervasive. The Pacific's past is polycentric and its forms of memory embrace connected centres, a continuous mythology (both temporally and spatially), particular historicities and an unusual mode of inter-cultural engagement. For critical generalisation to be possible, an appreciation of this mode of engagement and its dimensions is obligatory.

\section{An ancient world of migration}

A next step in charting engagement is to summarise the migratory origins and patterns of the Pacific constellation. The Pacific had migratory routes favoured by intertidal systems that created a rim of sorts (Gillis, 2013: 33). Ancient patterns of Austronesian migration from New Guinea through to Tonga and Samoa, and then Hawaii in the north and New Zealand in the south, laid down maritime routes. Early experimental travels gained momentum somewhere around 1500 BCE, when Lapita peoples took a qualitative leap into the unknown by spreading through what is known today as Micronesia. They reached Fiji and then - as canny emigrants - spread further afield. In doing so, ancient navigators expertly 
and methodically expanded in the last wholesale human migration (FernándezArmesto, 2001: 281-9; Paine, 2013: 13-22; Scarr, 2001: 21-8).

Migration entailed interaction with seas and the ocean that became a model for interaction between peoples. It is indicative of a first Pacific imaginary. Connections to the sea are etched in the body of inter-cultural relations of exchange and in Polynesian cultural memory. Polynesian and Micronesian mariners were expert navigators and inferential learners. They could empirically assess wind and direction by literally 'feeling' the swells of the ocean. Taking their bearings from the sun and stars, they calculated positions on reed maps to slowly cover the remote Pacific. Familiarity with regularly travelled seas, reefs and island coasts gave mariners knowledge of ocean movements and the cycles of aquatic life.

The long-term pattern is not straightforwardly continuous, however. Periods of broken occupation of particular islands ended with fresh arrivals. Islander memory and myth records waves of migration such as these. There is evidence also in the archaeological record. Moreover, stratified chiefdoms created in a process of state formation were significant factors in the twelfth- to thirteenthcentury shift in migratory patterns. Territorial polities cropped up in the eleventh and twelfth centuries in Vanuatu, New Caledonia, Fiji, Hawaii and Tonga. Stratified state organisations and practices emanated to smaller Polynesian islands with new migrants in a pattern of engagement in which patterns of polity-making were modelled for multiple island societies.

After millennia of expansion, Oceanian peoples had reached the edges of the ocean basin. New Zealand (Aotearoa), the hardest destination due to its unfavourable winds and a less hospitable climate, was reached at end of this period. Occupation of Aotearoa was a thirteenth-century watershed for connectedness in Oceania. The furthest reaches of the ocean were also occupied. Mariners were able to get to know it well enough to reach its eastern perimeter and settle on Hawaii and Easter Island/Rapa Nui. Both of these were, on the best assessments possible, mostly one-way migrations. At a considerable distance from their original sources, Hawaii and Rapa Nui were remote from the chains of engagement and the circuits of long-distance voyaging. Connections with the South American coast seem possible, but the evidence of links is, at best, inconclusive. By the time the first European explorers appeared, Hawaii and Rapa Nui were part of a far-flung network of knowledge centred on the learning houses of Raiatea in the Leeward Islands (Matsuda, 2012:132). Both sets of islands hatched outpost societies generally regarded as separate civilisations. Archaeologists, historians and to a degree anthropologists have marvelled at the achievements of the Rapa Nui and the Hawaiians and with ample reason. The extent of migration is evidence of the power of mobility in Oceanian civilisation. 


\section{Exchange as a paradigm of engagement}

From the outset, travel by water was an indispensable part of relations between island cultures. The maritime talents of Polynesian and Micronesian mariners maintained contact between islands and within separate societies. With common Austronesian linguistic roots, communication between and amongst Polynesians and Micronesians generally presented few barriers. Regular and organised visits between islands supported exchanges, as well as communication. Exchange and ritual events, such as the Kula, were simultaneously economic, spiritual, strategic and societal. As represented in Malinowski's ethnography and Mauss's reviews in The Gift, the Kula and like rituals incarnated exchange and alliancemaking (Mauss, 1969; see also Rundell and Mennell, 1998: 20-1; Sahlins, 1989). Through enactment and re-enactment of relationships islanders were able to reaffirm the links that integrated them. Indeed, the rituals bonded archipelagos and were important enough in some places to be enshrined in sacred platforms and statues. In turn, interaction on a larger scale between discrete cultures was defined by their reciprocal connections. The benefit of Malinowski's and Mauss's anthropologies of exchange is that they privilege the symbolic co-institution of social relations. Malinowski's ethnography examined islander reciprocity in isolation from other exchange circuits. Since Mauss explores the manifold nature of exchange by comparing different networks and their interactions, thereby casting reciprocity into a comparative frame, his model warrants further remarks.

Mauss's anthropology shows that exchange mediates non-commodified relations in intra-civilisational relations. His ethnographies of gifting boost understanding of the importance of exchange and the complexity of cosmologically constituted notions of obligation. The Gift (1969) reviews ethnographies of potlatch, Kula and other forms of reciprocity with a focus on the power of exchange in evoking obligation and sociability and in organising the consociation of different islands. While his comparison of such complexes in Melanesia and Polynesia - and with pre-Brahmanic India and north-west America as well - presents an internal picture, larger-scale interaction also appears. Pacific societies are characterised by a paradigm of organisation of material and moral life that empowered trade and exchange across greater distances and involving encounters of more clearly differentiated cultures. Though connections with societies around the edges of the Pacific were sporadic prior to the nineteenth century, Oceanians had a paradigm of connectivity that could be scaled up to larger encounters and longer journeys. In Mauss's discussion of inter-island rituals, elements of inter-societal relations are pieced together (Mauss, 1969: 24-8). Social relations created through an accretion of acts of reciprocity and exchange can be understood as an implicit model of civilisation-building. Islander societies were 
allied in a larger consociation. In depicting the societies of the Pacific in this way, Mauss construes them as civilisations with rich cosmologies and capacity for reciprocal social relations.

The model of social relations that Mauss elucidated was at odds with prevailing conceptions of civilisation associated with colonialism. Though materially 'poor' to European eyes, Pacific social formations were constituted by fertile cosmologies that structured intricate bonds of obligation. The social relations of Pacific societies were enlarged in complex processes of entwinement of local economic practices of reciprocity with other civilisational varieties of capitalism connected with colonialism. The latter entailed logics of expropriation and imaginaries of exchange.

Expropriation of land and resources is well documented (Scarr, 2001) and a few points will suffice to summarise the principal patterns. Major exports of copra, guano, phosphate, sugar and coffee were at the heart of the plantation economy run by Western, Australian and New Zealand companies. Towards the end of the twentieth century, mining and logging reached unsustainable levels on many islands, especially Fiji, Bougainville and the Solomon Islands. Any survey of the past of Oceania would be incomplete without recognition of the very dark history of 'blackbirding'. Islanders were seized or defrauded and taken with impunity into forced labour, a ruinous fate for islander social organisation and heritage. Depopulation took its toll on islands suffering this fate.

While the extractive logic of capitalism is inseparable from the historical inter-connection of Pacific and Eurasian worlds, the focus here is on exchange, for it is in exchange that we find a resilience of Oceanian civilisation. How historic patterns of exchange were interspersed with the capitalist imaginary of the colonial powers is not a straightforward problem. In Hawaii and throughout Polynesia, island societies negotiated the goods, networks and hierarchies of Western intruders (Sahlins, 1989). The governing chiefdoms absorbed new commodities and adapted them to existing patterns of reciprocity. By doing so, they stimulated new developmental spurts. The inter-cultural character of economic engagement continued to involve exchanges in values and obligations, as well as exchange of goods and services. There can be no naysaying the argument that, with time and the growing colonial presence of British, French, German, Dutch and then US and Australian powers, imaginaries of reciprocal exchange were subsumed under patterns of worldwide capitalist trade. Subsumption meant long chains of connection (Scarr, 2001: 104-6). The flow of information and goods washed over long distances through mediating ports. Well integrated into the circuits of world trade, 'Rim' societies of the Americas, Asia and Australia acted as points of accumulation and transfer of valuable cargo. Still there are limits to integration. The limited extent to which developmental patterns have taken over 
the ways of islander life is attested to by the ongoing advice of economists at the end of the twentieth century that Pacific islanders need to embrace the capitalist spirit more (see Dirlik 1997: 129-33). If that is so, then it should be little surprise that processes of insertion of the "social centrality of the ancient practice of reciprocity - the core of all oceanic cultures' into capitalism's economic orders has been complex, incomplete and always producing a surplus of meaning in exchanges (Hau'ofa, 2008: 36). To have some grasp of those processes requires the context of colonial experiences.

\section{Contested dominion: colonialism, discontinuous cultures and the quest for sovereignty}

The confrontation of European and Pacific imaginaries that came with colonialism brought contrasting civilisations into contact, conflict and dissonance of understanding. Colonialism began when the Spanish, in an extension of their pursuit of paths to and through Asia, dealt a further blow to the Ptolemaic imagination by stumbling on the South Seas (Scarr, 2001: 13-14). The early centuries of exploration and trade were then dominated by Spain's America-Manila trade, which took traders around a circum-Pacific circuit. Over two centuries, the trade became a multicultural enterprise integrating many sites and labourers in different aspects of the production, storage and transport of wealth (Matsuda, 2012: 115-23). But there was a distinct shift. Around the time that the 'Spanish Lake' ceased to be the trading domain of Spanish galleons, European colonialism altered sharply, and with it the consciousness of civilisation. The civilisational consciousness created by Europeans in the takeover of the Americas was extended and altered in the eighteenth century with the colonisation of Pacific societies. With an existing body of signs of civilisation carried over from colonial experience in the Western hemisphere, Europeans did not recognise the complexity of Pacific societies (Mazlish, 2004: 28-48). A patchwork of continuities and discontinuities resulted from the consequent violent cultural disordering of societies, traditions and peoples (Armitage and Bashford, 2014), a definite though incomplete process concentrated in what can be characterised as the long twentieth century of dealings between the imperial and hegemonic powers and the island societies of Oceania (Howe et al., 1994).

Above all, the significance of patterns and impulses of migration that were remarked on by the ethnographically curious did not sink into European consciousness. In the early encounters of the sixteenth to eighteenth centuries, European explorers were in awe of the culture of unmatched navigational skill and migrating practices of Pacific island societies (Paine, 2013: 14). Such 
admiration suited the hermeneutical animus of the age in which knowledge of the 'other' necessarily entailed striving to understand language, belief and custom (Mazlish, 2004: 34-5). Europe's explorers were charged to learn about the natural and cultural histories of the South Seas. There can be little question that island worlds began to impact on science, cartography, ethnology and art. The men who compiled drawings and ethnographic and botanic reports for Paris and London - Jean-François de Galaup, Louis Antoine de Bougainville, James Cook, Joseph Banks, George Vancouver and their entourage - also tapped into existing travel circuits by picking up Polynesian interpreters and navigators, utilising their expertise and transporting them far (Matsuda, 2012: 134-9). Through scientific and maritime reports, through maps, through artistic representation and by contributing to migration, explorers began to produce unusual constructions of otherness. It is difficult to distinguish amongst these with precision to what extent exploration and science were motivated by naive, genuine ethnological curiosity and to what extent this was civilising scrutiny. Furthermore, curiosity separates into art and science, which, though aligned, do not disappear into one another (Beilharz, 1997: 74-5). However, the grades of civilising scrutiny also depended on who was looking and whether their sponsorship was of an artistic, scientific, missionary, literary or philosophical nature.

Patterns of colonial design, inter-imperial competition and 'noble savage' representation took the place of inter-cultural curiosity. For the second newworld zone, Western colonialism was going to be a multinational affair that included Russians and Germans as late imperialists, as well as the United States in its colonial experiments. The British and French entered as the most expansive and experienced imperial powers. Imperial integration of the Pacific and linkages with other world regions only began in the late eighteenth century, even though voyages of exploration had begun 250 years earlier. By this stage, Europe's empires had formed modern visions of civilisation that framed myths of noble savagery. Two overarching myths of savagery operated in the primitivist imagination. Pacific lands presented to Western civilisation, first, as settled, serene and bountiful insights into a pre-civilisational stage of evolution. Second, they were construed as lands available to churches as missions, to the natural sciences and anthropology as laboratories of world history, to imperial governments as colonies and to business interests as sources of wealth.

Christian missionary work had complex engagements and a complex impact. Protestant missions sprang from Britain, Australia, New Zealand and the United States. On a contrary downward trajectory, Catholic fidelity faded as Spanish influence waned and French authorities and landowners increasingly resorted to tyrannical responses to local opposition. Missionaries and merchants departing from the shores of the British colonies in Australia and New Zealand were the first 
to reach into Polynesia. Reports on the Pacific energised missionary zeal in Britain (Matsuda, 2012: 145). Informed by the objectives of Enlightenment and civilisation, different British missions found success and disappointment in native reinterpretation of doctrines of faith. Christian beliefs were adapted and truncated in order to fit the cultural preconceptions of islanders. Few introduced doctrines survived in an unaltered state. As Matsuda writes, 'Not schooled in the fine points of European theology and history, the teachers transmitted their own cultural heritages, metaphors, and stories in words and analogies that interwove foreign messages and island beliefs' (2012: 152). The doctrinal outcomes were syncretic due to the resilience of islanders' cultural universes. But it was not just a matter of mixed beliefs. The Bible gave access to written literacy in the Romance languages. As missionaries worked with the Bible, they found themselves using new terms in pidgin and thereby making subtle modifications to doctrinal beliefs. The mode of missionary work was also mixed, generally in combination with trade, but often also with the introduction of formal education and medicine. American missions to Hawaii in the nineteenth century exemplified the partnership of economic and theological exchange. They also had the benefit of learning from the carefully recorded observations of British explorers. Like the anthropologists who came later, missionaries often allied with colonial authorities, while on some occasions conflicting with them. Like later anthropologists, their observations add to an important ethnological record of life, albeit a problematic one.

Cultural anthropologists entered the field against the backdrop of imperial occupation. It is hard to imagine their enterprise without the mixture of collusion and conflict with colonial administrators that resulted from the imperial context. Overall, they fostered an imagination of islands as societies only lightly touched by modernity (Gillis, 2004: 116-18). None operated in a positivist paradigm-free utopia of transparent data (Scarr, 2001: 204-7). Collecting artefacts and reassembling them out of ecological context for museums and galleries, they also recorded ethnographies of custom and culture, which were important accounts of social organisation and a mode of civilisation. They added to the storehouse of data accumulated by Europeans about islands and islanders since the eighteenth century. Often ambivalent in relation to colonial power, anthropologists could contribute to debates on diversity and race as much as early ethnographic reports of the late eighteenth century influenced Enlightenment discourses on civilisation. Moreover, the most revealing ethnographies - Mauss's, Malinowski's, Franz Boas's, Margaret Mead's - had the virtue of disclosing phenomena unfamiliar to Western minds, however framed by primitivism those disclosures may have been. Hermeneutically, the effect of anthropology was to amend the conception of race and civilisation in social science and to expand the modes of understanding of Oceania. 
Patterns of French colonialism were prominent in Polynesia. British interest enticed French reconnaissance and then strategic colonisation. Tahiti and surrounding islands, the Marquesas and New Caledonia fell under French rule, while the New Hebrides found itself poised in a de facto power-sharing arrangement between the British and the French. If government was a shared burden in the New Hebrides, heavy French investment ensured that its interests dominated the colonial economy (Scarr, 2001: 201). Metaphors and mirages of Polynesia stoked Gallic Romanticism, even while they condensed the cultural and linguistic diversity of the region. French administration brought regimentation to cultural identity, but also a trans-territorial economic sphere that fostered a nexus of exchange. Nuclear testing is seen by many in the region as the incarnation of colonial power and a techno-cultural manifestation of France's imperial imaginary. The human and environmental impact is incompletely documented. Nonetheless, the existing evidence is as alarming as colonialist denial has been obdurate. Support for a nuclear-free Pacific has also run deep and wide. Antinuclear groups had good links with the anti-war movements of Australia and New Zealand in the 1980s when the latter were very large. Though widespread across Oceania, the sentiment leans on specific historical experiences of, on one hand, American-dominated Micronesia and, on the other, French-colonial Polynesia. In the latter, it was a struggle around sovereign control of Polynesian affairs and it was not the only front on which independence has been sought. Nineteenth-century revolts against French rule were heroic episodes for nationalist movements in Tahiti and New Caledonia in the 1970s and 1980s. The past was summoned into the present when historic heroes were named and symbolised in anti-colonial movements. In New Caledonia, where French settlercolonisers were a majority, committed Melanesian (or Kanak) resistance was the most sustained, but waned in the 1990s. The past meant something different for the Francophone majority. France has persisted doggedly with colonial rule, unable, it seems, to relinquish its past status as a world empire (Scarr, 2001: 265).

The Caroline, Mariana and Marshall Islands and Guam - the area of Micronesia - had a shared historical experience of intensive inter-imperial rivalry. Spanish rule gave way, between 1886 and the end of the Pacific War, to German domination and then Japanese expansionism and emigration, ending in outright military takeover. American military occupation of Guam portended overall political domination of Micronesia mitigated by patterns of conflict and campaigns for autonomy and independence. Over several decades after the Second World War, the United States exercised strategic control of the entire zone by combining aid and militarisation in the administration of trusteeships. For the United States, the strategic value of the region has been paramount. Washington has insisted on retaining its military presence to ensure linkages in 
its global network of bases. Continuing nuclear submarine visits have enlarged the magnitude of command that the United States has globally and regionally. Successive American administrations have invested in the objective of regional stability. Local patterns co-determine the balance of autonomy also.

Facing different, but definite, combinations of consent and coercion, the trust territories have shown a varied appetite for independence. The United States has also varied its strategies of accommodation of traditional structures and practices - for example, by being more obliging in Samoa than in Guam. The American presence was a singular influence on subsequent trajectories of development. Using federal aid, education and welfare programmes as incentives, the US government resituated the Mariana Islands in its sphere of influence. In 1979, the Northern Mariana Islands and the Federated States of Micronesia and Marshall Islands went their separate ways, when the former voted for assimilation into the United States, while the latter two opted for partial independence (full independence coming in 1991). The split is significant, but both new states remain in the US sphere of influence - willingly so, it appears. Meanwhile, defiance of US policy has had an anti-nuclear inflection in Palau in the western Carolines. More generally, US governmental arrangements in themselves have demonstrated the tension of a democratic state at home maintaining hegemony abroad by combining degrees of free expression of political will with the absence of citizenship. At its apex, American control encompassed the Philippines, American Samoa, Guam, Hawaii and the Mariana and Marshall Islands. In the 1950s, nuclear testing in the Marshall Islands must have been the worst expression of the logic of neo-colonial domination. In the twenty-first century, Marshall Islanders live with its radioactive after-effects. In the years in between, resisting movements for independence, the United States has managed to hold on to all territories in its regional sphere of influence, except for the Philippines and parts of Micronesia. Hawaii warrants separate mention. It is closest to the United States institutionally and in popular culture, though the final say over its laws and administration rests with Washington. Demographically, its population reflects the flows of Oceania, with Hawaiians and descendants of Chinese and Japanese immigrations together constituting a majority. Japanese investment, aid and tourism have influenced economic relations since the 1970s; so also have Chinese interests since the turn of the century. East Asian influence in the North Pacific is a reminder of the multi-civilisational context of Oceania.

By contrast, other Western powers have left the field. Decolonisation proceeded in two major phases. First, New Zealand and Australia in the 1960s retreated from trusteeships in, respectively, Western Samoa and the Cook Islands and Nauru and, a little later, Papua New Guinea. Most of the initiatives of the second phase (the 1970s) were led by the British. Fiji gained its 
independence; Kiribati and the Solomon Islands entered the regional stage as independent states. The end of joint British-French rule of the New Hebrides was in sight by the mid-1970s and pressure from the Pacific's most powerful nationalist movement forced the issue. Led by Walter Lini, the independence movement declared the sovereignty of Vanuatu in 1980 and immediately faced armed insurrection fomented by retreating French interests. The rearguard action was short-lived. Vanuatu has since looked like one of the most independent states in the region. One cannot help thinking that the fact that neither the French nor the British could individually dominate the New Hebrides - and that they, in a way, counter-balanced each other - is part of the reason why there was space for a robust force for independence to emerge.

Oceania after colonialism faces unsustainable developmental logics, the legacy of nuclear testing and militarism, highly strategised foreign policy regimes and past and current projects in mining, logging and fishing that wreck terrestrial and marine environments. In spite of this, the paradisiacal South Sea Islands are still a figure of tourist discourses and popular cultures that faintly echo earlier Romantic depictions of islander cultures. Needless to say, tourist soft-sells are at odds with the actual fate of many Pacific societies (Howe et al., 1994; Waddell et al., 1993). This is hardly unusual, except that twentieth-century tourism is uniquely more important for the Pacific than anywhere else (Matsuda, 2012: 350-1). Is it possible to imagine other patterns of development? It is time to look at different memories of its pasts and how they are marshalled in contemporary projects of renewal.

\section{Revival and memory}

Looked at on a larger scale and from the perspective of revisionist historiography, the Pacific world looks like a region teeming with life rather than a sparse place of remote islands (Armitage and Bashford, 2014). Oceania is populated, not empty, and has watery highways known in cultural memory, not unchartered seas of a last frontier. The Pacific's creative cosmologies telescope a past of high interaction into the present. It is important to foreground myths, the patterns of engagement, reciprocity and creation to compensate for the inherited cartographies of 'emptiness' bequeathed by colonialism and reproduced in currentday discourses of the Pacific Rim. A paradigm of inter-civilisational engagement is evident in these patterns, even though connections with civilisations outside Oceania may have only fully come in the eighteenth century. There are resources for renewal in the cosmologies of connection and engagement. 
Myth is particularly important. Oceania's cosmology is a storehouse of collective memory, condensing in its creation stories deeper relations with seas and islands and between peoples (Hau'ofa, 2008). Stories and myths incarnate Oceanian historicity - the sense of how weighty the past is. Islander historicity might have much to offer revisionist historiography (Borofsky, 2000), but my interest is in memory's broader relationship with the Oceanian imaginary. How does the imaginary sustain travel, relationships and memory? There are several imaginary significations with which islanders populated and made the Pacific world. The myths of Pacific civilisation are infused with images of land, ocean, horizon and sky. The point of the horizon conjoins the cosmos and the extended seas, reminding the denizens of ocean societies of both cosmological meaning and the material environment of the ocean. The combination of opposites - cosmic and mundane, vast and small, aquatic and atmospheric - is an outstanding feature of an oceanic world made out of migration and interaction between islands. The power of the imaginary is evident in the craft of travel, which are always similes of social relations as well as the means of transport. The horizon contextualises the mythological heritage of the Pacific.

Oceania's myths make up cultural memory across four themes (Mills, 2005: 374-81). First, the divergences in Polynesian, Melanesian and Micronesian oral tradition are variations on common elements. General threads can be discerned in otherwise diverse stories without denying the differences in their structure and content. One thread is that myth mediates the worlds of gods and of humans. Islands themselves could be gods. Gods merge into demi-gods to form hero figures. Hero narratives and romances have generic plotlines that speak of everything from episodes of cosmic creation to the mundane struggle for resources. Common symbols are littered throughout different sets of myth: volcanoes, fire, plants, sharks, fish and sea-monsters, heroic creatures and canoes are found in all the oral traditions.

Second, Oceanic myths narrate the cataclysmic origins of the world. Stories of the origins and emanation of peoples feature a motif of fishing redolent of buoyant ecologies. There is nearly always an archetypal creator. Other features of the landscape, sky and ocean were used to signify different classes, skills and creativity. The chiefly aristocracy appears as the powerful sun, while the popular classes are depicted as the underworld. Particular features of land and sea are used to denote specialist artisans, voyagers and pilots. Metaphors of the topography of islander societies have come down to contemporaries via prior reconstructions of memory.

Third, myths communicate conflict and consociation in the cosmos and in society, echoing the combination of opposites noted above. They symbolise original cosmic, social, class and cultural cleavages in stories of formative struggles. 
Conversely, the structure and content of myths also represent the ties of different groups, for example in inter-dynastic connections between the aristocracies of distinct archipelago cultures. We can add that inherited mythology also speaks of an imaginary sustaining, first, travel and relationships between peoples and, second, open relationships with the past and with ancestors (see Shilliam, 2015).

Finally, art is an especial condensation of the cosmological elements. Depictions of the wars of the gods in heaven and in the underworld parallel the symbolically constituted inter-dependence of cultures and the conflicts within societies. Art preserves ancestral traditions of seafaring and fishing and harvesting resources. Where Western civilisation assimilated the myth of the landlocked Garden of Eden from Hebrew origins, Oceania's myths situate humanity's gardens on the shoreline, in the shallows and the reefs, and out in the aquatic depths (Gillis, 2013: 8-9). They are motifs of Oceanian art as an especial mode of cultural endeavour. Contemporary film and documentary makers, dancers, actors, poets and writers also engage cosmological traditions. Elements of myth with common archetypes are present in their performance and representation.

History as a domain does something similar. Some Oceanic histories posit a nexus between the Pacific's cosmologies and the engagement of islander societies (Hau'ofa, 2008; Matsuda, 2012; Scarr, 2001). Relational histories of Oceania, such as Matsuda's and Shilliam's, highlight post-colonial features as well as trying to reconstruct evidence of the inter-cultural character of islander life before the late eighteenth century. Many aspects of the post-colonial era also speak to engagement and not detachment. The Pacific is connected economically, by its navigable seas, and through shared resources in education, the arts and culture. Additionally, connections are stressed when regional unity is found around the common problems of nuclear testing, expanding regionalism, militarism, security and climate change. Understanding the connected present through the lens of engaged pasts calls for conceptualising the whole world region as a civilisation. In Hau'ofa's eyes, the objective is to put Oceania's histories at the service of islander traditions, rather than accepting the historical narratives bequeathed by Western states (2008: 60-79). At stake here, as Dirlik writes in respect of the Tongan intellectual's significance, is 'the historicity of the indigenous peoples themselves and, therefore, their contemporaneity' (Dirlik, 1997: 140). The past is not fully recoverable, but islander values are and they can be pressed into the service of contemporary movements for sovereignty, viable development and cultural renewal (Dirlik, 1997: 141). Remaking Pacific memories reconfigures power as much as any constitutional assertion of sovereignty. Refusing the historiographical closure left to the Pacific by colonialism, Hau' ofa sees for the peoples of the sea of islands relationships that are large, extensive and cosmological. The present needs to be linked to this past: 
if we look at the myths, legends, and oral traditions, indeed the cosmologies of the peoples of Oceania, it becomes evident that they did not conceive of their world in such microscopic proportions. Their universe comprised not only land surfaces but their surrounding ocean as far as they could traverse and exploit it and the underworld with its fire-controlling and earth-shaking denizens, and the heavens above with their hierarchies of powerful gods and named stars and constellations that people could count on to guide their ways across the seas. Their world was anything but tiny. They thought big and recounted their deeds in epic proportions ... Islanders today still relish exaggerating things out of all proportion. Smallness is a state of mind. (Hau' ofa, 2008: 31)

Organic ecological and genealogical histories can best fathom Oceanian pasts and temporalities, fusing their horizons with those of the present. History-telling as a genre of Oceania is calibrated by genealogies of ancestors (Jolly, 2007). Modern representations of harvesting the ocean and travelling over the seas involve reminders of the ancestors. For instance, Maori encounters animate the ancestors by invoking them in the inter-cultural modality of meetings between peoples of ostensibly different cultures. The Maori who meet do 'not treat these visitors as aliens or "others" but as peoples who already share a relation that must be creatively retrieved because it is not just individuals who are meeting but their ancestors too' (Shilliam, 2015: 2). When cross-colonial connections are made by contemporary indigenous movements in the Pacific, the ancestors are invoked in many ways that ontologically enliven the common elements of Oceanic cosmology. As a mode of historical memory, indigenous cosmologies and myths in the Pacific are mobilised in the cause of political restitution and cultural recovery.

Political economy is another sphere of the restitution of Oceania. The picture is not as bright here, however. A regionally integrated economy binding Papua New Guinea to Sydney and Auckland to the Cook Islands to Samoa and on to San Francisco involves a great inequality between the wealthy centres on the edges and the islands in the ocean. There is also significant intermixture taking place and the lines of inequality are not simply between places, but starkly within them. But another side to the regional political economy is less often acknowledged. Hau' ofa highlights it. In the 1990s, he repudiated the fatalism of postcolonial dependency and the elites that are resigned to it (Hau'ofa, 2008: 30). In his project of New Oceania, the emphasis falls on the unbounded character of contemporary Oceania (Waddell et al., 1993). Hau' ofa speaks of economic selfreliance, mutual ownership of land, movement and connectivity as a millenniaold identity. In displacing the deficit image of the Pacific, Hau' ofa inserts a vision of a densely connected and crowded world, an 'enlarged world' of engagement (Jolly, 2007: 529-30). Moreover, it is a world on the move, so to speak. The 
values, practices and relationality of Oceania are extended to Australia, New Zealand and California by diasporic migration, greater travel and communication, acquisition of property and jobs and a popularisation of the visual arts, film, literature and music (Castles et al., 2014: 166-8). At the end of the twentieth century, Oceania had the greatest percentage of international immigrants of any world region (Castles et al., 2014: 1). Short-term circular visits are a hidden part of migratory movements and may be as significant as tourism (Hau'ofa, 2008: 17). While the lion's share of those are travelling to New Zealand and Australia, migration moves in all directions and not only to the wealthy centres on the edges. Moreover, large Polynesian regional networks are sustained by the circulation of goods and monies between island homes and emigrants living in the United States' west coast states, New Zealand and Australia's eastern seaboard. Not only is money remitted - which, if alone, might be a sign of dependency - but a vast array of objects, technology materials and symbolic foodstuffs flow back and forth in consignments. The informal trade circuit is reminiscent of the 'old' Pacific more than new developmental strategies (Scarr, 2001: 271). The general pattern recreates elements of the reciprocity of economic and cultural engagement of Oceanian civilisation.

Identity is also a matter of memory. What to call Oceania in the wake of decolonisation is a living issue. The change of designation of the South Pacific Forum to the Pacific Islands Forum reflects the shift in the whole frame of geopolitics since the late 1980s. Despite its raison d'être of open regionalism, the Asia-Pacific Economic Cooperation forum (APEC) is a creature of the Pacific Rim states, and not its oceanic sovereignties. It is not just about bloc-making or broad alliances; this is a problem of epistemological and conceptual understanding of the civilisational character of Oceania, its imaginary and its engagement with other world regions, including its neighbouring ones. But, in turn, this raises the question of who should be included in conceptions and discussions of Oceania. I end the chapter with the proposition that Australia is 'in' and 'out'.

\section{In and out of place: Australia in Oceania}

Amongst the islander cultures of Oceania that feature such practices, Australia is a peculiar case that calls for more comment. I can see three reasons to treat Australia as a distinct world. The historical conquest of Aboriginal and Torres Strait Islander civilisation has given new world Australia a sharp and contrasting other. No treaty on which a contest of sovereignty could take place was ever settled. For a long time, Aboriginal civilisation was utterly suppressed in the historical memory as a result of the multifaceted war upon it. To be sure, the position 
of the two civilisations inhabiting the southern continent has been quite remarkable. Moreover, limited immigration from the Pacific until the 1980s constrained sentiments of belonging to Oceania in this context, unlike New Zealand. Second, the British colonised the continent in its phase of exploration, as part of the movement into the Pacific. Britain had models of colonialism to work with, but all derived from contexts outside Oceania. The new colonies were a laboratory for experiments in institutional formation and Victorian-era order. Rapid and designed urbanisation was the creative mark of the British colonies on the mainland continent. The legacy for the Anglosphere was an image of a dream-land - a frontier of capitalist development, but also an escape from capitalist modernity (Dirlik, 1997: 130). Finally, Australia assumed a neo-colonial role in the region with Federation and increased independence from Britain. The region's largest state continued in that vein in alliance with the United States from the 1950s onwards. As a middle-power in world terms, Australian governments enjoyed an excess of influence.

That is a brief summary, which calls for more elaboration. The lure of the Antipodes had a different purpose than the Romanticism associated in the European vision with the South Sea Islands. Many of the latter were 'discovered' on the way to find the dreamt-of Great South Land. None being found, Terra Australis became a substitute. It would be British, but other than Britain; Oceanian, but a huge continent, not an island; connected through its north, but populated in a different and much older migration than the voyaging patterns that created Polynesia. Before Britain established a beachhead in Botany Bay, an immensely diverse Aboriginal civilisation had flourished, enriched by relations into the north. The 'empty' state of the uninhabited lands was a condition that haunted antipodean sensibilities in colonised Australia, in part due to the undeclared war on the peoples, signs, semiotics and Dreamtime cosmology of Australian Aboriginal civilisation. Civilisation-making in Euro-Australia has occurred as a strange condition of uncertain and ambivalent belonging (Beilharz, 1997). In Australia, modernity is in part a problem of how to combine a denied Aboriginal old world with a new world that has no antiquity, no Middle Ages and no revolutionary foundation. Contrasting the deepest temporality imaginable in the Dreamtime - with its stories of Creation from land and sea - is a EuroAustralian historical memory of a short two centuries. Of course, what Australia had as a background were two foundational British myths (Rundell, 2004). The initial myth was that Australia was terra nullius - an understanding that was derived from field reports from Cook's exploration. The signs of civilisation familiar to the British in Asia and the Pacific could not be found in Australia and the potential for comprehending the complex Aboriginal civilisation was outside of Britain's imperial imaginary. As it became the official doctrine of British 
colonialism in Australia, terra nullius directly informed colonial rule and later the creation of a federated polity. More importantly the doctrine of terra nullius was inscribed deeply into Australia's cultural life. When combined with the second foundational myth - that the southern continent would host a 'new' white society based on an imported British constitutional tradition - the basis for racism was set.

Traditions formed in colonial and then federated Australia entailed the subjugation of indigenous memory. Deep ambivalence epitomises cultural perceptions in Australia, partly as a result of the occlusion of Australia's colonial conquest. The two myths have slowly come unstuck as Aboriginal social movements asserted the living presence of an indigenous civilisation and as Australia's population diversified. With the adoption of multiculturalism, the persisting foundation of Australian racism was put into question and contested. However, Euro-Australia still has a damaged historical memory with gaps that, at most, have been irresolutely filled. Moreover, heroic nationalism pervades commemoration of major wars as the mainstream of collective identity, while darker pasts have to be persistently reasserted.

As part of the long process of problematising but not dissembling myths, Australia's post-war turn from British allegiance in foreign policy to alliance with the United States has shaped its place in the western Pacific. Relations with island states are imbued with an imaginary of state and capitalist power. Australia assumed a role of regional power acting in close proximity to US interests. In the wake of decolonisation, Australian policy cast the Pacific as a zone of few economic prospects, heightened political instability and impending environmental decline. Australia's development, aid and foreign policies are guided by fears of the Pacific's absolute marginalisation from globalising processes (Jolly, 2007: 526-9). The developmental model advocated by a succession of national governments and foreign policy experts contains several components of the Australian figuration. Pacific states 'need to open their economies; effect structural change and good governance; abolish customary land tenure and inappropriate, undemocratic traditions; and connect with the dynamism of Asia' (Jolly, 2007: 527). The entire vision of the Pacific in the middle-power strategy centres on Australia leading Pacific states to a viable developmental path. As Jolly observes, Canberra's national policies in trade, security, foreign affairs, immigration and aid have Australia 'both as model and saviour of the Pacific, its future and its prophet', with aid programmes to replace the ceased welfare programmes offered to communities affected by nuclear testing. The inconsistencies in policy directions are amplified in Australia's demonstrably cruel practice of shipping asylum-seekers to offshore detention centres in Nauru and in Papua New Guinea, while expressing 
support for aid and development strategies in the region. Australian governments project ambivalence about their role, reflecting a more general ambivalence of place.

\section{Conclusion}

If the first new world of the Americas still wants for attention from civilisational analysis, then second new-world societies are overlooked almost entirely. In this chapter, I argue that Oceanian civilisation exhibits patterns of deep engagement and connection. The willingness to travel and the proficiency to migrate over vast distances are emblematic of Oceania, as well as constitutive of its island societies. The byways of travel also served for contact and communication, exchange and alliance between islands and up and down archipelagos. Richly diverse, yet with shared components, cosmologies of Oceania conjoin peoples with the ocean environment and with each other. Islander societies have practised inter-cultural engagement with remarkable adaptability to new circumstances. Into these Oceanian worlds colonial powers intruded, stimulating inter-civilisational engagement, including with its most ruinous consequences. Though damaged, Pacific cultures have invoked their own counter-imaginary in closer proximity to past islander experiences. Collective memory - whether continuous or reconstructed - provides resources for coping with critical issues. The cultural fund of memory can also help with thinking differently about climate change and other environmental problems facing the region. Latin America is on the eastern edge of this context also. As another new world, for Europeans, it is the next substantive case examined, as we start to modestly address evident gaps in contemporary civilisational analysis. 


\section{7}

\section{Engagement in the cross-currents of history: perspectives on civilisation in Latin America}

In this chapter, I explore Latin American experiences that shed light on the engagement of civilisations. Most of the theoretical engagements canvassed in Part I either sequester Latin American experiences or do not do them justice. In the past, Latin America has been judged poorly when questions of its civilisational character have been asked. Scholars in modernisation studies and area studies influenced by Louis Hartz's The Founding of New Societies saw the sub-continent as an offshoot of Western modernity. Hartz and modernisation scholars in sociology and political science left an intellectual impression of 'two Americas': a pace-setting northern civilisation and a deficient southern variant. After his break with functionalist sociology, Eisenstadt sought to rectify the impressions left by modernisation analysis in an important essay on the Americas as multiple modernities and a zone of civilisations (2002b). Arguing for the distinctive trajectories of all the Americas, he demarcated a proper civilisational status for Latin American modernity. While this essay was a landmark corrective, it did not go far enough in elucidating, first, the degree of engagement of multiple civilisations in Latin America and, second, the deep indigenous and African influences in the social constitution of Latin American societies. Beyond Eisenstadt's essay, there has been only a couple of major works contributing to debates in contemporary civilisational analysis around the Americas (Katzenstein, 2012b; Smith, 2006). More generally, remarks made at the end of Chapter 3 on the absence of research on Africa, new world societies and indigenous civilisations sum up the landscape of contemporary civilisational analysis at the time of writing. Where civilisational analysis has stretched its latitude to examine African, new world and indigenous civilisations, only limited progress has been made. This chapter begins to address these lacunae with modest moves to apply the model of inter-civilisational engagement outlined in Chapters 4 and 5 to modern 
perspectives in culture and the arts, politics, theology and political economy produced in Latin America.

My purpose in this chapter is to set down a basis for understanding Latin America as a historical zone of engagement of many civilisations. In order to validate the southern continent as a distinct world region of inter-civilisational engagement, I address problems of identity and social movements in dimensions of cultural exchange and the reconstruction of civilisational models. First, I set the scene by examining 'Americanism' as a republican response to the fashionable preference for positivism in the nineteenth century. A counter-imagination contextualises Americanism and is common to modernist traditions and subsequent traditions of radical critique and activism. Second, I delineate modernist movements in philosophy, literature and poetry and the arts that made such modernist traditions. They flourished in the first part of the twentieth century. However, after the Second World War, modernism found radical expression in Latin American Marxism, political economy, liberation theology and indigenous social movements. Overall, I contend that modern Latin America has emerged from the cross-currents, conflicts and dissonances of civilisations. Furthermore, I argue that problems of authenticity and of historical continuity and discontinuity have been central to cultural and political thought of movement engaging international currents.

\section{Latin America in the cross-currents of history}

Cultural and political engagement began in earnest for independent Latin American societies in the 1880s. Perspectives in culture and politics in postcolonial Latin America speak to an 'Americanism' expressed in the phrase nuestra América, first popularised by Cuban nationalist José Martí. In reaction to the prevailing positivist philosophies of science, race and government of the later nineteenth-century, twentieth-century thinkers developed independent viewpoints that presented Latin America with a positive complexion. A succession of modernists asserted a different perception of Latin America's place in global history. In different spheres and in different lexicons they re-articulated the Americanism Martí had in the 1880s and 1890s. The Latin America they envisaged entailed a counter-imagination of the 'North' as South America's other. What Martí expressed in history, others would continue shortly after in the modernist arts, literature, poetry, music and philosophy. A second wave of radical modernism emerged in Marxist politics, political economy, liberation theology and indigenous movements. 
Modernism arose at the turn of the twentieth century as a movement of artists, philosophers, writers, poets, musicians and activists (Schelling, 2000). In a short time, they remedied the positivist cultures that had denigrated Latin America and venerated European doctrines of science, race and statecraft. A coalescing climate of incredulity towards evolutionist doctrines nourished modernist expression. As Miller contends, modernism's affirmation of the past brought together the twentieth-century intelligentsia as a Latin American movement (2008). By embracing history, they repudiated the Jacobin practice of erasing the past. In place of Europe's specific experiences of modernity as conditions of rupture, Latin America's modernists gave expression to distinct perceptions of time and history. The arts and philosophies of modernism were fostered in multiple dialogues with foreign currents in philosophy, literature, politics and art and with Latin America's own multi-civilisational past. Modernists made careful study of foreign trends. However, they also routinely tempered engagement of international currents with the struggle to find a place for them in cultural life. Writers, poets, philosophers and activists often turned to traditions they saw as their own when looking to place themselves in the world. They were at their most creative when unapologetically synthesising southern experiences with international genres, schools and styles.

With newfound energy and insights, modernist intellectuals selectively assimilated Western and Northern ideas, including those of other ambivalent modernists (Schelling, 2000). Their horizons also included reconstructed memories of pasts marginalised by the long Conquest. In the hands of creative modernists, Latin American cultural identity incorporated the deep past far more than their ideological forebears. Creativity involved syntheses of contraries, of painful and violent pasts with hopeful aspirations of the present. Critical modernists emphasised a number of binaries that were unified in tension with each other. Historical specificity and universality were opposites. So also were aesthetic affect and rationalist form, city and 'country' (in fact highlands, forests, pampas, lakes), deep histories and myth as well as short Euro-American histories, and the magical encounters coexistent in the arts with epistemological realism. The generic pattern of combination of opposites-in-tension is contingent on multicivilisational inputs. The form of modernist creativity drew on the heritage and physical worlds of the Americas, yet it was also self-consciously shaped with Western and Northern influences.

Latin America's modernists produced syntheses through dialogue with foreign and local currents of social and philosophical thought. They were thus embedded in inter-civilisational engagement. As explored in Chapter 4, Collins's historical sociology of cultural traffic identifies networks formed by cultural flows in and 
out of major intellectual centres (Collins, 2000, 2004). He seems unaware of Latin American networks, but his sociology of the milieu of creativity can still be usefully applied. In this regard, Latin America's cities should be counted as centres. Favourable socio-economic conditions and expansion of urban cultures created ideal public spaces for urban modernism (Miller, 2008: 30-6). Cities were expanding, especially where high-volume immigration was involved. Vibrant markets and industries gave the impression of economic dynamism. Education and political systems incorporated the middle classes and touched the working classes for the first time. By the turn of the century, parks, plazas, museums, cafes and galleries had sprung up in central urban spaces. Five cities stand out as seedbeds of modernism: Buenos Aires, Montevideo, Havana, Sao Paolo and Mexico City. As a term, moderno circulated readily in the idiom of growing city cultures (Miller 2008: 5-6). The modernist intelligentsia were situated in an urbane public sphere where cross-currents of culture, philosophy and politics flowed abundantly.

\section{El moderno: an intelligentsia for renewal}

Latin America's modernism mostly pre-dated the SecondWorldWar. Reflecting on Latin American interpretations of fin de siècle European modernism, José Enrique Rodó, Alfonso Reyes, the Mexican muralists and José Mariátegui in turn brought into question background notions of 'civilisation'. After the Second World War, Gabriel Garcia Marquez, Octavio Paz and Carlos Fuentes joined Jorge Borges in renewing modernist themes in Latin American literature, essays and poetry. The next two sections take up each cultural figure and their engagements in turn.

Rodó was a transitional figure who creatively adapted outside influences to Latin American identity. First published in 1900, Rodó's influential Ariel popularised self-confidence in Latin America and was an inspiration for many modernist works that followed. Ariel in fact inaugurated a transition to mild ambivalence (Miller, 2008: 23-30, 39-66). In a Romantic vein, Rodó's chief character - a surrogate for Prospero from The Tempest - praises the youthfulness of Greece, all the while affirming both a defence of the democratic polity of the United States and the spiritual potential of Latin America. The greatest states accumulate the 'imprint' of prior civilisations and create from them the 'spiritual environs' of holistic cultures (Rodó, 1988: 91-2). Rodó sensationally urges Latin America's youth to perfect the 'spiritual environs' of Latin America's materially robust cities in a unity of spirit and material culture (1988: 93-5). Rodó pleads, through the voice of Prospero, for Americans to pursue a project, or 'future', of civilisational richness. Yet the balance of argument in Ariel is about a poise of the material and ideal and the many civilisational sources of complex modern societies, 
including Latin American ones. Although Ariel can be read as a cautionary tale about hubris, it can also be read in the spirit of Martís vision as a tract on a future that draws on North and Latin American civilisational influences. Invoking Ancient metaphors, Rodó's tract reads:

More than once it has been observed that the great epochs of history, the most luminous and fertile periods in the evolution of humankind, are almost always the result of contemporaneous but conflicting forces that through the stimulus of concerted opposition preserve our interest in life, a fascination that would pale in the placidity of absolute conformity. So it was that the most genial and civilizing of cultures turned upon an axis supported by the poles of Athens and Sparta. America must continue to maintain the dualism of its original composition, which re-creates in history the classic myth of the two eagles released simultaneously from the two poles in order that each should reach the limits of its domain at the same moment. (Rodó, 1988: 73)

This passage reverberates with Americanism. Mexican Alfonso Reyes is next. He is remembered as a cosmopolitan whose Americanism never left him (Franco and Sánchez Prado, 2004). He was greatly impressed by Rodó's Ariel, which he helped to circulate in Mexico. Perhaps inspired by Rodó he venerated Greece, but his version of Greece was tempered by a national and regional ethos. Hellenism once 'Mexicanised' could be sustained through a broad appeal. Greece, thus construed, belonged to an imagined Latin America as well it did to Europe.

Reyes's philosophy was cautious about the absolutism of either Reason or Spirit (Miller, 2008: 109-42). In Latin America, the absolutism of unrestrained Reason would result in a universalism that would be unviable in the tumultuous environment of African, creole, Hispanic and indigenous influences (Reyes, 1950). European philosophies of history were not sufficiently relevant to Mexico. Distant from the heartlands of philosophy, Reyes underlined the particularities of Latin American history and its historical mindset. He spent a life building a philosophical system on selections from European sources that accommodated the particularities of Latin American history (Franco and Sánchez Prado, 2004). He did not wantonly abandon the achievements of European philosophy, but cast them in southern hues. His philosophy of history prejudiced neither Hegel nor Nietzsche. History did not have a direction, but neither did it lack meaning. Above all, Latin America was a significant part of history: 'We are not a curiosity for aficionados, but an integral and necessary part of universal thought' (cited in Miller, 2008: 125). Americanism when viewed from Mexican fringes, as it was by Reyes, was a different sort of peripheral universalism, at once threatened by its position south of the United States, yet vitally enriched by many traditions. The neglect of Latin America's multi-civilisational history was not only the sin of Europeans. 
The post-revolutionary technocratic state in Mexico was fanatically positivist. Its investment in positivism left the state unreceptive to the many civilisational identities and influences that formed Mexico. His preference was cultural engagement.

Reyes responded to the aftermath of the 1910 revolution with caution, asserting culture over violence and peaceful progress of all over cataclysmic rupture. Others of a later period had a different relationship to the heritage of the Mexican Revolution altogether. The Muralist Movement seized the opportunity to alter the direction and content of the arts. Simple imitation of traditional European art was out and fusion of American and Western influences was in. What the muralists prescribed was the form and the imagery of Mexican identity as a blend of civilisational inputs. The indigenous past was redeemed and validated. Not only were mestiza elites depicted, so also were peasant masses. Diego Rivera was a singular figure in the genre, and the most interesting from the point of view of the influences on Mexican art. For Rivera, American classicism held broad appeal because it incorporated indigenous aesthetics at a deep level. Classicism tapped a desire for authenticity through depiction of indigenous motifs and themes. It was a gateway to new expressive styles and a new popular culture. This is not simply a Romantic reflex, but a way of forging a national tradition with an international reputation. In Rivera's innovative art, the syncretism of styles and meanings, on one hand, posits authenticity at the heart of his aesthetics while, on the other hand, expressing political commitment to a new popular cultural genre. Rivera adapted indigenous iconographies for a revolutionary culture capacious enough to attract Marxists and patriots alike. Beyond Rivera, the muralist movement constituted itself as a milieu in its own right through its prodigious work. It was a milieu deeply influenced by its exposure to international critics. In this they were far from passive in portraying a breadth of historical experiences. In its most vivacious and adventurous period in the 1920s and 1930s, the Muralist Movement variously captured revolutionary optimism, humanism and suffering. Just as José Martí and José Enrique Rodó demanded a place for America in schemes of world history, the muralists implored the world of the arts to find a place for an original Mexican culture. Along with other modernist artists they made significant contributions to the cross-currents of Latin American culture.

Cross-currents also washed through José Mariátegui's Marxism. His outlook was characteristically American and resulted from a creative fusion of Western Marxism and indigenous traditions (Schutte, 1993: 18-71). Not only was Marxism localised in an inter-civilisational environment, the ontological hostility it harboured at the height of Stalinism to indigenous traditions and to Christianity was discarded. Mariátegui's Peruvian Marxism attracted revolutionaries deterred by the hostility shown by pro-Soviet Marxism to Christianity and seeking escape from the suffocating orthodoxy of Stalinism. His philosophy 
earned him a reprimand from official communist parties (Schutte, 1993: 547). For the other side - dissenting left-wing Christians - his critique of the 'slave morality' of the Church establishment was a lightning rod. Marxism was vitally Americanised during the 1920s and 1930s through Mariátegui's initiatives. Renewal of a Latin American genus of Marxism would remain sporadic until the early 1960s. It is little wonder that the generation radicalised during that tumultuous decade was drawn to his version of Latin American thought (Miller, 2008: 143-86). The American and multi-civilisational consciousness that Mariátegui promoted furthered a Latin American Romanticism, a passionate 'reenchantment of the world' (Lowy and Duggan, 1998: 82).

The appeal of Mariátegui's politics and philosophy to later radicals came from his blend of elements as well as his ability to speak to the problem of re-enchantment. His thought comprised a heterodox combination of Freud, Nietzsche, Gramsci and Georges Sorel. The result was a far-reaching critique of Western rationalism. The manner in which he distinguished modernity and capitalism, history and authenticity and organised religion and revolutionary spiritual transformation showed an understanding of the multidimensionality of modern social formations that nineteenth-century positivism had been incapable of (Mariátegui, 2007). Moreover, his critical advocacy of a unity of revolutionary passion, reason, spirituality and modern culture revealed the rudiments of a sophisticated combination of Romantic and Enlightenment traditions (Lowy, 1996: 17-18; Lowy and Duggan, 1998). Despite the antinomies internal to his conception of culture, his version of mestizaje thought and practice reached beyond the polarities of Latin American culture in the nineteenth century.

Above all, though he remained connected to universal Marxism, his thought discerned in Latin American culture living traditions to be honoured and advanced. Mariátegui's Marxism connected the 'Indian problem' to the project of socialism (Mariátegui, 2007). Consequently, he viewed the Conquest as a violent rupture of pre-Colombian civilisations, and not a civilisational advance, as Soviet Marxism would have it (Schutte, 1993: 29). In many ways, he went further by founding an original Marxism with the highest level of recognition of indigeneity of any political ideology.

\section{Post-war modernism: literature, political economy and beyond}

As Lowy and Duggan argue (1998), Mariátegui is a landmark figure in Marxist engagement with Latin American Romanticism. The thread of Romanticism runs through Latin American modernism as a whole. Writers and philosophers strived 
for a place in Universal History for Latin America on grounds that are typically Romantic. The theme of authenticity denied to Latin America by the long shadow of colonialism is a frequent one of popular literature. As a result of the Conquest, Latin American cultures are marked by a peripheral mood of abandonment. Estranged from autochthonous roots - and at the same time also from the promises of modernity - Latin America is 'not quite anywhere, its search for identity necessarily following a labyrinthine path' (Schelling, 2000: 9). How did post-war modernists confront the condition of searching for a place in the world?

The image of labyrinthine quest is made explicit in the influential works of renowned authors Jorge Borges, Gabriel Garcia Marquez, Carlos Fuentes and Octavio Paz. It is the civilisational motif for Latin America. For Borges, Latin America's conditions produce an imagination of urban labyrinths. The labyrinths he depicts in his short stories are paths on an endless quest for knowledge paths that lead only to further marvels, rather than an Archimedean point. He invokes an infinite and unknowable universe, which is not only out in the heavenly cosmos, but inside the mind. Human thought has its own labyrinths that continuously unfold layers of meaning in a quest similar to the exploration of the physical world by the natural sciences. He thought the labyrinths had a universal appeal. Borges's thematisation of quests through the labyrinth in Latin American culture is a characteristic shared with the other post-war modernists. For the other three - Paz, Fuentes and Marquez - the feeling that Latin America was unable to achieve modernity and was searching for a place in world history was expressed as a state of solitude in the labyrinth. Though addressing Mexican culture, Paz's world view has ramifications for the entire sub-continent and is paradigmatic of the labyrinthine quest. According to Paz, citizenship has constructed the Mexican as an abstraction in denial of colonialism, the Conquest and current-day Indian identities. The denial is deepened by the mythologisation of the Mexican state. Mythic continuity is monumentalised in the National Museum of Anthropology and History and in Mexico's official history. The real 'other' Mexico struggles to erupt into public space, Paz concluded decades before the advent of Zapatismo. When it does so, the past erupts into the present. The image of a deeply authentic Latin America searching for a way out of its solitude is shared with compatriot Carlos Fuentes, though Fuentes's rendition is more exasperated. Fuentes argues that no genuine Latin American modernity has been realised, even if the resources for modernising currently exist. Even democracy has brought antinomies and crises such as drugs and entrenched gang violence. On his counsel, the most promising strategy for renewal in Latin America is the return to Hispanic roots. Where Paz and Fuentes come together - along with Gabriel Garcia Marquez - is the point of solitude. Solitude is rendered as Romantic doubt about modernity's intrinsic value, as 
well as the feeling of abandonment outside of modernity. In fact, doubt and ambivalence are the great expression of Latin America's Romantic modernism. From the periphery, solitude in fact is reconstructed as a motif of modernity anchored in a particular time and place. The reconstruction of the motif of solitude is a paradox. Romantic doubt is a perception of solitude as an experience of modernity. Romanticism was itself nourished by inter-civilisational engagement. Western influences are ever-present but indigenous and African cultures are affirmed as Latin American.

Both early and late modernists built bridges with the radical movements of their own times. The later authors of solitude spoke to the social movements and were in different degrees related to them (Borges being an exception). They spoke to another current of modern inter-civilisational engagement - the traditions of radical critique from the 1960s to the opening of the twenty-first century. It seems plausible to argue with Miller that 'the themes of secular spirituality, participatory solidarity, integration of the past with the present, and hospitality' were a common denominator of myriad Americanist discourses (2008: 19). Beginning with dependency theory and Latin American critiques of the 1960s, a major counterpoint emerged to contest the presumptions made about Western civilisation as the telos of secular modernisation. Modernisation analysis framed US policy advice to governments and shaped US foreign policy in the region up until the mid-1960s. Its axiom was that a break with traditional forms would produce institutional development leading to an enlargement of prosperity. Prosperity, once secured, would immunise Latin America against communism. Rostow's theory of 'take-off' was an influential instance of this line of reasoning. As a Northern theory, it was an external model fashioned in the United States.

In contrast, dependency theory had far greater traction and indeed was rooted in sub-continental thought. It styled itself as a radical response to the failures of modernisation. The other main perspectives contesting modernisation doctrines came from Marxist political economy and Latin American structuralism authored by Raul Prebisch and the Economic Commission for Latin America (ECLA or CEPAL). Latin American dependency theory built on both while diverging from each. From Marxism, dependencistas took a radical critique of imperialist domination and further radicalised it. Though dependency theory has an unclear lineage in Marxism, its proponents could claim an intellectual ancestry in Trotsky's pioneering notion of uneven and combined development. The Cuban Revolution gave a general boost to powerful existing traditions of the sub-continental Left. Latin American Marxism could trace a lineage back to an inter-cultural fusion of indigenous, Hispano-American and Western influences. The neo-Marxist credentials of dependency theory are not in doubt, though it has attracted critiques from Marxists also. As one type of analysis of imperialism, 
this school of thought pictures dependency as rooted in large-scale extraction of surplus value from the Third World, Latin America being the consummate case. From structuralism, it took the problematic of dependency as a starting point, while demurring on the gradualism of the ECLA's policy prescriptions. Despite the differences between theories of dependency theory and the political economy of Prebisch and the ECLA, they each framed Latin America in the same terms. Both camps equally typecast the two Americas in juxtaposition: imperialist Anglophone capitalism in the north at variance with dependent development in the south. There were other Latin American sources of inspiration also, including liberation theology and Cuban Marxism.

Critiques of modernisation analysis constitute a kind of Southern Theory (Connell, 2007: 140-55). Critics have been more penetrating than their northern counterparts. They had a critical heritage of social, cultural and political thought, which had accumulated in Latin America over the course of the twentieth century. Added to that was an established conceptual base. Fernando Cardoso, Andre Gunder Frank, Paul Baran and Samir Amin all retained the key concepts of the ECLA's research - especially core and periphery - even though they were critical of Prebisch's more favourable theses about foreign technology and investment. Cardoso in particular can be credited with reinventing dependency theory with a less schematic conception of the international division of labour. He claimed that internal class relations could shape relations with multinational capital. Likewise, distinct internal processes of state development could have an impact on how industrialisation of important sectors took place. In other words, specific figurations of state, economy and civil society mattered in determining the patterns of dependent development. Cardoso stood out with such ideas.

Accounts of the fate of dependency theory are widely available and it remains a reference point for radical approaches in political economy, sociology and political science. Moreover, dependency theory continues to reverberate amongst successive left-wing movements in Latin America. Its own origins coincided with the movement for a theology of liberation and both arose consubstantially with New Left Marxism. The focus falls here on liberation theology, as it is highly influenced by the cultural cross-currents symptomatic of inter-civilisational engagement.

\section{Liberation theology: a movement at the crossroads of ontologies}

Liberation theology was preceded by Paolo Freire's pedagogy and his notions of liberation, consciousness-raising and praxis (Schutte, 1993: 142-9). Selfconsciously sociological and philosophical, liberation theology gained definition 
in Latin American responses to the reform of Catholicism by Vatican II and the 1968 Latin American Episcopal Conference at Medellin Conference. Liberation theology found a collective voice in Latin America, even though liberation theologians were never more than a minority at the episcopal level (Lowy, 1996; Segundo, 1976). Numerical weight may have been unattainable, but the moral authority garnered from the popular base communities was enough to give liberationism international influence beyond sheer numbers in the Church.

In Latin America, liberation theology performed a vital task of memorymaking through conscientisation. Apart from providing cultural and political expression of the suffering of the lived present, liberationists have borne witness to class and civilisational memories. By creating the spaces for making memory and then reinterpreting memory in relation to scripture, liberation theology was able to introduce dialogical construction of cultural memory and traditions. Comparable developments occurred in the Pacific in black liberation theology movements (Shilliam, 2015). In Latin America, the spaces for memory-making look particularly pertinent to the interface of indigenous- and Euro-America where modernity is an experience of violent social imaginaries. Where the phenomenological condition of solitude might be a kind of cultural endowment of the Conquest, religion via liberation theology could hermeneutically construct another collective memory, connecting the living in protest at the violent and disordered past. In this respect, liberation theology should be seen as a modernist movement relating past and present (Lowy, 1996).

Liberationists expanded the repertoire of Christianity by stimulating questions of ethics in base Christian communities. Constant reinterpretation of scripture against the backdrop of present-day conditions put the economic and political order of the earthly world into question. Liberationists describe a three-step hermeneutical methodology that casts doubt on Western ontologies. The three steps are (a) involvement in the communities in which Christians serve, (b) theological reflection on the lived experiences of communities, and (c) programmes of action around deep-rooted inequalities (Gutierrez, 1973). Together the three steps ground salvation in the present and in living communities. Liberationist ethics surmise in Christ's teachings an obligation to save both body and soul. The separation of the two sides of being is a recurring theme in the Western tradition. It is a landmark of the Greeks, a landmark of Augustinian theology and a landmark of Cartesian dualism. Liberationist Christology discards the separation of body and soul in favour of a radical reinterpretation of the metaphysics of Christian purpose, turning the axis of Christianity to a profoundly this-worldly orientation. The history of salvation in the Kingdom-to-come is worked out in the present, not an ever-receding future, and therefore salvation must be bodily and it must redress deprivation. In this way, liberation theology tackles orthodox 
Christianity's dualistic moral ontology of body and soul and the dualism ofWestern eschatological history. While parallel ontologies are articulated in other forms of radical Christianity (Rowland, 1988), the density of this ontological rupturing of Western metaphysics in Latin America is greater than elsewhere due to the articulation of liberation theology with other modernist and radical perspectives.

In pursuing the regeneration of community through hermeneutics, liberationist practices have produced a 'contextual theology' (Rowland, 1988: 126). The violence of the past is a hermeneutical challenge for this contextual theology. Enrique Dussel's hermeneutics seems the most comprehensive and most philosophical synthesis of Latin American and European traditions of thought (1996). Going beyond Paul Ricoeur to ask whether "the dominated can "interpret" the "text" produced and interpreted "in-the-world" of the dominator' (1996: 86), he gives a qualified answer in the affirmative. Dussel's hermeneutics of alterity displace the legacy of mestizo identity perceived by Leopoldo Zea and other proponents of Latin American philosophy. Indigeneity can exist properly in his framework. Thus, however difficult reading the 'dominator's text' is, there are reasons to think that hermeneutics practised in indigenous base communities have helped recollect collective suffering in indigenous communal life and traditions, rather than presume the dissolution of culture and identity. The practices and experiences of indigenous communities have been voiced in the hermeneutical praxis of base communities.

More than just an innovative set of practices, hermeneutics brought a mode of learning to liberation theology. As a matter of principle, all had to learn in base communities and learning entailed a generalisation of communal life. In this respect, base communities resemble Weber's conception of soteriological community (Lowy, 1996: 32-4, 49-50). Hermeneutic circles formed spaces for the making and remaking of memory under, at times, the most difficult conditions. The grass-roots work of base communities was a cultural engagement of reform Catholicism and indigenous communities, which were repositories of cosmovision. Engagement gave validity to indigenous knowledge and created spaces for all-round learning. In those spaces, liberationists could learn in inter-cultural encounters.

As Latin American philosophy was in the background of liberation theology, the problematic of 'liberation' soon came to be a bridge between theology and philosophy (Schutte, 1993). When combined with what liberationists learnt from base communities, the notion shifted onto ontological grounds. What liberation came to signify reflected inter-civilisational engagement. Summarising liberationist Christianity, Gustavo Gutierrez defines it by radicalising Western dualism. He asserts that, for liberation theology, the temporal and mundane planes of reality fuse in eschatological salvation (Gutierrez, 1973: 69-72; Lowy, 
1996: 45-6). The dualistic moral ontology of mind and body cannot be sustained when conditions of deprivation demand a world-transforming theology. For Gutierrez, 'liberation' is therefore a project of transformation couched in terms of 'the turn to the poor' and to active pursuit of social justice. In Gutierrez's ethics, the ontological shift animating the theological turn to the poor delivers a new conception of being human. Moreover, he envisages a new orientation condensed from the historical experiences of inter-civilisational engagement with non-dualistic ontologies, particularly the inputs of cosmovision. The emancipatory politics that flowed from non-dualistic ontologies shifted the responsibility for finding redemption from heaven to earth. With an earthly purpose, theology could connect with nascent indigenous causes, new social movements and radical critiques picking up on the cross-currents of international thinking.

Seen in the longer history of Latin American social and philosophical movements, liberation theology dovetailed with prior currents and concurrent ones. The CEPALismo of Prebisch's political economy, the anti-imperialist protest of the 1960s and 1970s, Latin American Marxism and dependency theory were especially important influences. Connection with social movements that emerged in the 1960s did not abate and gave concomitant currents of thought outlets for deliberation. Practitioners of liberation theology participated and contributed to those outlets with thought-provoking and this-worldly ideas about faith, hermeneutics and praxis.

Connection with other currents of thought enriched liberation theology, which in turn left a legacy for subsequent critiques on the 'social question'. An original vein of critique emerged that emboldened the defence of the political and economic independence of Latin America. The theme continues the critique of neo-colonialism that commenced in dependency theory. Appreciation of the experiences of the South echoed the tradition of Mariátegui's Indo-American socialism, the modernist arts, culture and literature and in sub-continental versions of Marxism. Over a century, traditions such as these issued from historical conditions in which multiple civilisations were violently hurled together and compelled to intermingle. The formations, social imaginaries and civilisational backgrounds of Spanish, Portuguese, Amerindian and African civilisations collided with each other to produce new worlds including syncretic versions of Christianity. Liberation theology was challenged and enriched by this received world. Gutierrez saw as much when he stated that "The discovery of the "other", the exploited one, led ... to reflect[ion] on the demands of faith in an altogether different way from the approach taken by those on the side of the dominators' (cited in Rowland, 1988: 127). The ontological reconstruction undertaken in liberation theology was a partner to the revival of indigenous cosmological horizons from the 1980 s on. 


\section{Engagements with cosmovision, from liberation theology to 'post-neoliberalism'}

In the revival of Amerindian ontology, the strongest movements have been in Ando-America. The civilisational presence propelled by indigenous movements into the public sphere has enlivened inter-civilisational engagement in cultural, social, political and economic life. Furthermore, denser public presence compels states to take seriously recognition of claims for different mixes of self-determination. A full presentation on the impact of the resurgence of indigenous America is not possible here. Elsewhere, I outline a prolegomenon on Amerindian ontology based on textual analysis of published communiqués of indigenous-led summits, confederations, alliances and organisations in Latin America (Smith, 2014a). All that can be recounted here are signs of engagement with ongoing liberation theology and the rise of the twenty-first-century radical Left.

The most forceful claim is around an alternative model of sovereignty. The Westphalian system of sovereign nation-states is no longer relevant to Latin America. In its place, indigenous movements have, since the 1990s, pressed claims for a 'pluri-national' form of human collectivity and coexistence. This inventive notion goes beyond assimilationist regimes of 'inter-culturality' where the protection of cultures takes place in separate and restricted isomorphic territories. There is a challenge to existing states to rethink mono-ethnic sovereignty, which has been met with constitutional reform and deeper commitments by governments in Bolivia, Ecuador and Venezuela. Indigenous movements have influenced the constitutional process through advocacy of an alternative relationship with nature and activism around defence of their lands. The demands from indigenous peoples for environmental protection and far-reaching response to global warming are more forceful due to the centrality of land, rivers, forests and mountains to their economic and ontological security. Land is the wellspring of cultural life and civilisational identity in indigenous world views. Consequently, a different ontology is expressed in indigenous movements opposed to the extraction model of the capitalist economy.

Does liberation theology connect with Amerindian 'cosmovision'? A full profile is beyond the current text, but there are two prominent pieces of evidence of connection since the 1980s. The first is the Colombian Quincentenary of 1992. Originally, it was touted as a seminal event for the Western hemisphere to commemorate the 'Discovery' of America. The prospect of widespread and possibly large-scale protests generated debate over the significance of the history of the Conquest. At stake was the ownership of American history. For indigenous 
peoples, it was unambiguously interpreted as a celebration of civilisational conquest. The episode may be remembered as a watershed in historical interpretation where revisionist narratives were asserted and gained purchase in the public sphere. But in addition to the memory of the Quincentenary for some indigenous peoples the event posed the question of conditions of potential coexistence or of a civilisational settlement. What could a possible post-Conquest settlement be like? Internationally renowned Guatemalan activist Rigaberta Menchu conveyed this sentiment in words that prefigured conceptions of 'living well' (buen vivir): 'By seeking true democracy, true development and making sure that we at least begin to coexist, we can start to create conditions that will allow a genuine encounter of two worlds, of two civilisations in the future' (cited in Wright, 1992: 273). The response to the proposed celebrations was formation of new alliances based on regional confederations across the Americas to protest the Colombian celebrations. To some extent they sought out links with each other as well as other movements. The problem for the Church of 1992 was posed by Padre José Comblin, a veteran liberationist, in the late 1980 s as follows:

Native Americans and Blacks are still in a state of exclusion from society and from culture, both of which originated in the Church ... [R]econciliation demands restitution: the construction of a civilisation in which all are able to develop their potentialities. But there is not only oppression of the Native Americans and the Blacks, there is also a rejected poor and Mestizo population which continues to be marginalized in the present ... Reconciliation in Latin America presumes a total inversion of the whole civilisational and cultural process. (Comblin, 2006: 169)

Unmistakably, reconciliation is configured here as an ethical responsibility in the multi-civilisational context of the Americas. The idea of a 'total inversion' implies that 'justice' in whatever form might be more important than reconciliation.

The second piece of evidence is more contemporary and relates to the lasting diffusion of liberation theology. While liberation had a definable clerical, pedagogical and activist intelligentsia, Lowy makes the argument that dissemination of its ideas and modes of activism left a lasting impression on social thought, political practices and, most directly, major indigenous organisations (Lowy, 2014). He recounts key organisations as heirs of earlier liberationist activism: the Confederación de Nacionalidades Indígenas Del Ecuador (CONIAE), the Movement of Landless Peasants (MST) and the Unitary Peasant Confederation in Guatemala. In Brazil, base communities and the Indigenous Pastoral Ministry have built alliances with indigenous peoples struggling to defend their lands against the attrition resulting from mining and logging. Similar alliance-making has taken 
place across Peru, Bolivia and Ecuador, including co-organising with indigenous spokespeople in international fora.

The most conspicuous meeting point of the confluence of past indigenous and liberationist movements is in the so-called post-neoliberal governments formed at different times in Venezuela, Bolivia, Nicaragua, Argentina, Brazil, Cuba, Paraguay and Ecuador. The clumsy neologism of 'post-neoliberalism' generalises across quite diverse regimes. Governments exercising customary social democratic strategies of development have weaker relationships to indigenous movements and reformist theology. Radical governments aligned to Hugo Chavez's project of twenty-first-century socialism in Ecuador and Bolivia happen to have the largest social movements that vacillate between support for governments and opposition to their actions. The new radical Left captured Latin American governments in the first decade of the twenty-first century for movements and parties amenable to indigenous world views and to the influences of liberationist Christianity. Changing the rules was a priority. In every instance, constitutional reform reinforced connections with indigenous movements, though relationships between Left governments and social movements are complex and revealing of the complexities of holding government for the Latin American Left. Furthermore, constitutional reform is far from the be-all and end-all of political initiatives responding to dialogues with indigenous nations and movements. Strategies of reform aimed at a pluri-cultural and pluri-national polity are variously enacted in all states outside of the southern cone countries.

Bolivia stands out in this regard on two counts. First, the restructuring of the political order undertaken by the governments of Evo Morales went the furthest in accommodating an indigenous cosmovision. In contributing much to the project of founding pluri-national polities and the communal principles of buen vivir, Morales's Movement Towards Socialism (MAS) gave the greatest effect to a decolonial praxis. Second, in championing a realignment of humanity and Nature, Morales utilised indigenous ontologies to reimagine Nature as Mother Earth - a sovereign entity with rights, as well as the source of life, land and meaning. Morales was at the centre of the World Conference on Climate Change and the Rights of Mother Earth held at Cochabamba in April 2010. The intrinsic rights believed by the conference to inhere in the being of the biosphere are a reflection of the connection of the Morales administration to Amerindian ontologies. The will exists there and amongst other governments in this sphere to move beyond the extractivist patterns of production prevailing in AndoAmerica. However, diversifying development - while meeting commitments made to social justice - is a complex challenge for post-Westphalian statecraft. Governments aligned to the project of twenty-first-century socialism are still the best equipped to amplify indigenous ontologies and the influences of liberation 
theology. They have had a pluralising effect on the political and cultural landscape, begun a project to transform statehood, promoted multipolar regional blocs and alliances and brought to the fore the most crucial environmental issues.

Liberation theology has also been an influence with movements elsewhere. First, in Brazil, where base communities have continued, liberation theology has plainly been influential in the formation of the Workers Party and its subsequent electoral successes. Perhaps it was even influential in the demarcation of factional space within the party and the movements it interfaces with. Second, African histories return in dialogues between liberation theology and contemporary movements around hybrid identities in Brazil, Cuba, Ecuador and Venezuela. Movements for hybrid identities make claims for recognition and rights, particularly Afro-Venezuelan and Afro-Brazilian movements. They assert presence as well as reminding all of the violent institution of transatlantic slavery. Third, the Chiapas diocese under Bishop Samuel Ruiz had a distinct liberationist direction in the lead-up to the Zapatista rebellion. Ruiz urged close links with groups in Brazil, Chile, Colombia, Ecuador and Peru, unquestionably putting broader solidarities on the agenda for the Chiapas communities. How substantial the consequences of liberation theology are after more than five decades must be considered provisional. Be that as it may, there are signs of some continuity of radical traditions through all this, especially in the movements and parties promoting the project of twenty-first-century socialism, though their fate is also undecided at the time of writing.

\section{Conclusion}

Latin American interpretations of cultural and political engagement began in earnest in the early twentieth century. In the wake of José Marti's declaration of 'Our America', many modernist writers, artists, philosophies and revolutionaries fashioned affirmative Latin American identities. In visual works, critical philosophy, literature and politics doctrines, they condensed the form, styles and content of many civilisational influences, including the mobilisation of indigenous and African identities. Mindful of subaltern civilisational influences, as well as foreign ones, figures of the intelligentsia reflected historical experiences of the crucible of inter-civilisational engagement in the Americas. As the first currents of modernism declined, a post-war wave of more radical ones emerged. From the 1960s onwards dependency theory and New Left movements coincided with the development of liberation theology at a local level in base communities. Direct links in this lineage vary over time and many movements suffered under dictatorships and repression. The history of inter-civilisational engagement in 
the context of conquest informs all the traditions of Latin American thought explored here. Latin American cultures after positivism no longer saw themselves in the image of Europe. The traditions that succeeded Europeanising positivist currents of the nineteenth century progressively defined a more radical sense of Latin American-ness.

This chapter interprets this phase of inter-civilisational engagement that produced non-Western perspectives on the relationships of civilisations and the syncretic creations emerging from them. By recognising and dramatising Latin American traditions, the analysis in this chapter brings insights into cultural and political engagement in new world environments. If conceptions of civilisation found expression as non-Western visions of civilisation in Latin America at the turn of the twentieth century, what other civilisational conceptions might be possible? Japan is the final case study we examine to look for other patterns of inter-civilisational engagement. 


\section{8 \\ Japan in engagement and the discourses of civilisation}

If civilisational analysis is lacking with respect to Latin America, it has been far from inattentive when it comes to Japan. In previous chapters, Japan serves as an illustration of theoretical engagements with civilisational analysis, as well as illustrating different points of my own argument. The frequent choice of Japan is no coincidence: it has been a focal point of investigation for comparativists in the humanities, the social sciences and political economy with an interest in civilisations. When it comes to the specific field of contemporary civilisational analysis, Arnason, Robert Bellah and Eisenstadt have produced in-depth monographs and numerous essays on Japanese civilisation (Arnason, 1997a, 2002; Bellah, 2003; Eisenstadt, 1996, 2002a). A few others could be mentioned as interlocutors between Japanese Studies as a field and civilisational analysis: Praesenjit Duara (as we shall see), Roland Robertson, Yoshio Sugimoto and Tadao Umesao.

This chapter begins with a brief assessment of the results of the three historical sociologies crafted in the tradition of civilisational analysis. I then move to explore a key phase of Japanese civilisation's interactions. My strategy involves pushing the notions of inter-civilisational interactions and encounters at work in Arnason, Bellah and Eisenstadt further by examining how deeper connections have influenced the coalescence of modern cultural and political thought. The phase I examine begins in the early Meiji period (1868-1912) and ends in the 1920s. Echoing Duara's analysis of East Asia, I submit that a 'discourse of civilisations' formed in Japan through intensive experience of engagement with the West and other countries. Japan's multiple engagements occurred in specific contexts of cultural transactions across what were defined - though ultimately contingent - civilisational boundaries. My focus is on contested conceptions of 'civilisation' thrown up by inter-civilisational engagement in East Asia. 


\section{Japan in focus}

To varying degrees, the three major perspectives on Japan in contemporary civilisational analysis stress the long-term impulses of development. With the following points I will attempt to summarise what Arnason, Bellah and Eisenstadt are agreed on. Japan's civilisational animus formed in the course of historical experiences in East Asia. A critical juncture was reached in the seventh century, when the Taika Reforms were adopted. Reform of the structures of state, the conduct of government and the figuration of court and provincial powers consolidated Japan's imperial sovereignty over two centuries. The collective experience of adoption and reconstruction of outside models was the common element of all the reforms introduced from China. A generic pattern emerged in this long learning experience whereby the originally emulated elements of Confucian state culture were transformed into Japanese cultural and political traditions. Relations with East Asia at large conditioned developmental patterns from the Heian era onwards (798-1185), inasmuch as orientations to the Sinic world order always structured the organisation of power, changing techniques of statecraft and philosophical and religious doctrine. China's presence in the cultural, religious and economic universes of Japanese civilisation lent the latter a dual character. That Japan's relational orientation is reaffirmed throughout its history is evident in major episodes of engagement with the outside world and reflection on its existing dynamic traditions.

The formative period features in the three major perspectives. The three diverge, however, on how social change is conditioned by relations with the East Asian region. For Eisenstadt, Japan was an unusual de-axialising civilisation (1996). In its digestion and relativisation of the world religions, Japan had a foundational moment in which a pattern of ontological dualism was established. The universalism of philosophy and religions entering from Asia was relativised when resituated in Japanese cultural environments. Native traditions played off against foreign influences during the early era of adaptation of the Chinese model set an ontological blueprint of uchi-soto (inside-outside) orientations for relations with foreign cultures. Uchi-soto demanded highly creative agency on part of the intelligentsia. In that role, intellectuals reinterpreted the polarised dualisms of the doctrines of Buddhism and Confucianism and diminished the polarity of opposites. In doing so, they produced different versions of situational ethics. From the ontological principles of imported relations, they selected only those elements that were given to easy accommodation of varying environments. In rejecting stronger axioms, Japanese civilisation adopted a trajectory of negation of universalist principles. 
Arnason's reconstruction of the historical experiences diverges from Eisenstadt's on key points (1997a). Though there are similarities in how each views the ontological shape of Japanese dualism, Arnason baulks at the linear trajectory implicit in Eisenstadt's application of the theory of Axial civilisations to a comparative sociology of Japan. Arnason views the original Japanese constellation as a mixture of archaic and foreign elements that is too messy to subsume under the categories of Axial civilisations, or to account for as a process of deaxialisation. The originality of historical experiences cannot simply be accounted for by means of a far-reaching qualification of Axial traditions that Eisenstadt strives for. Instead, Arnason perceives greater space for interpretation, reconstruction and reinterpretation of civilisational dynamics in the centres of power. Strategic orientations have a more decisive part and thus Arnason attributes more historical specificity to processes of change, including in modernity. Arnason's rendition of the Japanese trajectory asserts more latitude for transformative processes to be analysed. Furthermore, there is greater room for the ramifications of transformation for the overall pattern of duality to be taken into account.

Like Eisenstadt, Bellah conceives of Japanese civilisation as non-Axial. His early research anticipated Eisenstadt's judgement that Japan de-axialised foreign doctrines and religions (Bellah, 2003: 4). In defining historical periods, cultural elites sought to introduce transcendental doctrines and religious ethics into Japanese society, only to find that 'the moment of transcendence was quickly submerged' (2003: 4). The most important outside influences were religious, for Bellah as a neo-Weberian at least. The submergence of transcendence did not entail its abandonment, however, but an appreciation of foreign cultures contextualised by Japan's own non-Axial premises. The major transcendental movements - the world religions and Marxism - find a place in society, but have negligible impact on the core ethics of Japanese culture. They coexist with native beliefs and have many followers, but do so in a submerged state.

There is a clear resemblance to Eisenstadt's perspective. Bellah diverges on one crucial point: Japanese civilisation is pre-Axial inasmuch as its premises are deep-seated and unmovable. 'They are off the board ... when it comes to serious discussion of fundamental change' (Bellah, 2003: 6). There is an image of cultural segmentation produced in Bellah's description of Japan's engagement with the universalist premises of the world religions. I suggest, instead, that international movements, currents of belief and thought and political models had more subtle and sustained effects on Japanese culture. A highly relational society emerged and not just a segmented social order of coexisting groups. I prosecute an argument along these lines below by exploring the modern intelligentsia of the Meiji era and their struggles and achievements. 
Still, there is more to Bellah's penetrating analysis. China was the luminous centre of the East Asian order with deep influence on other polities in the region and their figurations of power. In Japan, patterns of military rule both emulated and diverged from the Sinic constellation of East Asia. The revolutionary restoration of the Meiji era transformed the state, structures of the public sphere and social relations. The magnitude of change did not fundamentally displace non-Axial principles, according to Bellah, which remained evident in the form of nationalism that emerged. Even in modernity, Japan's non-Axial principles are still primary in rooting the social and political order in the particularism of Japanese civilisation (Bellah, 2003: 39). In this aspect of Bellah's argument, he is closer to Eisenstadt than Arnason in emphasising the enduring longevity of the civilisational premises of this particular East Asian trajectory. Consistent with Weberian principles, universalist cosmologies are central to the problems under consideration and historical questions are posed in frames of long-term history.

No more systematic assessment of the three perspectives will be made here, except to table two points. First, all three accredit high levels of activism to interpretive agents embedded in institutions of power. Second, they position Japan in interactive relationships with regional forces and processes. Taking both points into a discussion of the modern constitution of inter-civilisational engagement, it is proposed that Japan's particularly intense encounters with the West in the nineteenth century included an unusual and distinctive process of creation of a 'discourse of civilisations' (Duara, 2001). A significant confrontation with existing Western concepts of 'civilisations' was not only an encounter with a civilisational other; it was also the culmination of a longer history of engagement, especially in East Asia. Aspects of Japan's historical experience informed the wide-ranging confrontation with the global order and with Western empires in particular. Engagement with the West stimulated Japanese development of its own early discourse of civilisations. The remainder of the chapter elaborates on how this occurred.

The next section explores Japan's discourse of civilisation in depth. Examination of the modern Japanese figuration encompasses several thinkers and a particularly engaging environment of interpretation in Meiji-era Japan (1868-1912). The selection of intellectuals is based on how their key insights are stimulated by inter-civilisational engagement and how they are significant figures in cultural and political interpretations of modernity. In other words, the figures in question made significant contributions to the discourse of civilisations through creative borrowing, synthesis and fresh interpretations. 


\section{The discourse of civilisation in Meiji Japan}

The historical engagement with China ruptured suddenly, with the momentous encounters with the West. The dramatic consequence was a multifaceted transformation of state structures, politics, culture and economy. Worldwide cultural exploration of many other countries, along with an outgrowth of trade, stimulated an overhaul of the conceptual apparatus of Japan's political culture. The transformation involved the trans-cultural comprehension and deep consideration of foreign social, economic and political concepts. Debates about new concepts ensued and in turn problematised widely accepted traditions.

In a short time, the Meiji intelligentsia embarked on the creation of an early discourse of civilisations. Comprehension of foreign ideas about civilisation took place in public debates on the contents of what was believed to be a civilised mode of being. They fuelled a coalescing discourse of civilisations that incorporated impressions of Asian and East Asian civilisations (Duara, 2001; Mazlish, 2004). Western modernity seemed to the Japanese to be the embodiment of 'civilisation' as a mode of being juxtaposed to the moral value attributed to the religious heritage of Asian civilisations (Gluck, 2011). In the early years, 'being civilised' meant superficially following Western etiquette, fashions and speech. Many Japanese came to believe that the deeper attributes of Western modernities could be carefully modified. Encounters with the conceptual apparatus of Western thought encouraged this understanding. As with other concepts that entered East Asia in wider confrontation with Western colonialism (such as 'society', 'liberty', 'people', 'rights' and 'equality'), 'civilisation' was subject to intercultural appropriation and reconstruction during this period.

A particularly interpretive part of the Meiji-era transformation was careful observation of the world. Japan's intelligentsia was well equipped with existing learning processes, as it had for years deliberated on secularised neo-Confucian principles of knowledge (Collins, 2000: 685-6). Universities quickly sprang up with official support and patronage, once the German ideal of university education was discovered. The strong interest in philosophy is likely to have been accentuated by German universities acting as the inspiration (Collins, 2000: 371-2). Building on pre-Meiji traditions of school and academy education, they also had other pedagogical models to work with, which helped contend with new Western philosophies of utilitarianism and materialism. An additional experience of collective learning was the extraordinary Iwakura Mission (1871-73). Much of the intelligentsia learned from the hundreds who toured so many countries of the world in such a short time, learning about numerous national cultures. 
A many-sided inter-civilisational encounter resulted. Nearly four hundred days of travel brought extraordinary cultural learning in the physical and social sciences and humanities. The mode of comprehension of the sciences, economics, philosophies and political theories enabled Japan's leading intellectual-officials to recalibrate how knowledge was acquired and how it should be acquired in future. An accommodating and responsive civilisational pattern was activated to quickly acquire and recompose foreign theories, epistemologies and methodologies.

Knowledge and learning would only reach more deeply into society if a new public could be created. The new regime set about a partial democratisation of the polity and an overhaul of the centuries-old status hierarchy of four estates (known as shi-no-ko-sho). Beginning with the Charter Oath of 1868, levelling reforms flattened out the previous order. The five articles of the Charter Oath were civilisational goals for the restructuring of public life. During the 1870s, the common reading public grew rapidly, especially around newspaper readership.

As part of the urban public, the Meiji Six Society (Meirokusha) formed as an intellectual circle with its own activities and profile. Many of its young members also held government posts. Through its publications and public lectures, the Society acted as an agent of translation and conceptualisation of the Western sciences, as well as a debating society. In doing so the Meirokusha formed a benchmark of debate for a wider spectrum of opinion on Japanese civilisation and modernity. Working at the interstices of Japanese historical experience and Western ideas, members of the Meirokusha engaged in an interpretive role of 'description of a received world and construction of a new one' (Howland, 2002: 5). Many of the essays in its journal, Meiroku Zasshi, were critical of Japanese values, without at the same time being slavishly pro-Western. The Meirokusha were part of a vanguard fostering cultural criticism as part of the cognitive complex. They did not simply receive Western ideas in isolation from the Western origins of those ideas. Instead, the particular conditions of the Meiji upheaval were also a reference point for interpretation of new sociological and philosophical theories by members of the Meiji Six Society, particularly in the works of Kato Hiroyuki (1836-1916), Nakamura Keiu (1832-91), Nishi Amane (1829-97) and Tsuda Mamichi (1829-1903). A heavy emphasis on the properties of civilisation flowed through their writings, speeches, translations and newspaper articles (Braisted, 1976). They and others contributed to a limited, but coalescing, urban public in which the entire mode of public, urban debate was new. Through the medium of deliberative debate, the Meiji Six Society relativised Japanese traditions and Western knowledge both at once. The consequence of the Meirokusha's activities and publications was to promote debate about the direction of Japanese civilisation. Members held differing views about international law, constitutionalism and state formation, civil law and political sovereignty, the matter of 
rights and representation and modern subjectivity. All these were controversies synonymous with 'civilisation' and 'modernity' and part of early attempts to translate and evaluate the conceptual universe of Western knowledge (Mazlish, 2004: 100-3).

The published debates of the Meirokusha affirmed that development of 'civilisation' went beyond the engineering and infrastructural feats of the Meiji regime, beyond its trains, manufactories and street lights. The zeitgeist of the early Meiji years was bunmei kaika or 'civilisation and enlightenment'. Often misunderstood as mere exuberance for Western ways, bunmei kaika signified a larger ideal of modernisation oriented to both national upheaval and to the international environment. For the insiders of early Meiji governments, it looked like a strategy for a state without the capacities of other modernising states at this time. The strategy included restructuring the subjectivity of the Japanese in daily life and in civic obligation (Karlin, 2014). Bunmei kaika in daily life implied a containment and othering of provincial folk knowledge through the introduction of bureaucratic rationalities into the methods of government and propagation of an attitude to the past in popular sentiment. In this sense, bunmei kaika contrasted the existing regional worlds of early Meiji Japan with a modern polity and began the work of fostering a nationalist imaginary by articulating provincial identities with national loyalties in the name of 'civilisation'. At the same time, those regional worlds produced their own varied theories of modernity and democracy in the village-based Popular Rights Movement, which mobilised with considerable force in the 1870 s and the early 1880 s.

Bunmei kaika was also the leitmotif of the Meirokusha. For its members, 'civilisation and enlightenment' accentuated the gap between government ambitions to modernise the economy, rationalise jurisprudence and refine cultural customs and the state of popular consciousness and practice. The raison d'être of the Meiji Six Society therefore became a great deliberation on the character and content of the notion of 'civilisation' and how that gap might be closed. Its members translated and debated the works of the Western sciences for a large literate public with an appetite for foreign ideas and a desire to comprehend enigmatic foreign conceptions. As Fukuzawa noted in his reflections on the Iwakura Mission, even the travelling Japanese leaders on the mission expressed incredulity at the customs and practices of Westerners: 'On our part there were many confusing and embarrassing moments ... for we were quite ignorant of the customs and habits of American life ... Things social, political, and economic proved most inexplicable' (2005: 659).

Much of the scholarship of the Meiji Six Society touches on the perplexity of foreign concepts and how to express them. The idea of civilisation was an object in search of a signifier at this time of doubt. At different times 'civilisation' was 
termed kaikabunmei, keimei and bunka. Translation of the term was foregrounded as a problem in the Society's first issue of Meiroku Zasshi. In his provocative essay on Western languages Nishi Amane proposed shibirizeshon as a foreign loan word for 'civilisation' (Howland, 2002: 46-8). The most drastic pro-Western reform was wholesale adoption of the alphabet, according to Nishi: 'If we adopt their system, all things of Europe will be entirely ours. Since grasping this strong point of theirs while destroying our current writing system is not to be compared with a trivial change in clothing, we can boast to the world that it is the beauty of our people's character thus to follow the good' (Braisted, 1976: 9). Letters themselves in their elegant and tidy simplicity represented a condensation of Western thinking. Therefore, shibirizeshon would stand in well for 'civilisation', so Nishi Amane argued. Debate ensued but the overall proposition was too threatening to a sense of Japanese collectivity. As his propositions received little support, the idea of direct translation was soon abandoned altogether.

Instead, Fukuzawa's work was the means by which bunmei kaika became the most common term. As a linguistic sign, it had hard work to do. Bunmei kaika condensed two conceptions of civilisation into a single phrase (Howland, 2002: 32-43). The two conceptions were the strong noun bunmei for 'civilisation' in the sense of universal civilisation and kaika for the process of cultivating a civilised subjectivity. In this shape bunmei kaika represented a broad-spectrum discourse on the nature of being civilised. In cross-cultural engagement with the West, the outward appearance of 'civilised' behaviour would signal conformity with expectations of behaviour common to Western elites by this time. Members of the Meiji elite understood civility as a gendered exteriorisation of refinement, manners, etiquette and customs (Karlin, 2014). 'Good' comportment reflected well on Japan and the Japanese could impress foreigners with a mannered subjectivity. 'Civilisation' was thus an outward expression of a mode of behaviour.

The phrase was elastic in other ways. The semantics of civilisation could serve a variety of political perspectives on the social order. The Popular Rights Movement imagined a more radical constitutional and societal order and expressed that imagination in a language of democracy. It was an independent movement of forces-from-below with an unprecedented vision of restructuring social life (Bellah, 2003: 167-70). In a backlash against the free thinking of some of the experiments associated with bunmei kaika, Meiji conservatives also spoke a language of civilisations. Moderate conservatives engaged by asserting that the distinctive Japanese character had to be preserved throughout the more general transformation. Traditionalists went further, maintaining an outright xenophobic rejection of foreign influences. Yet even the arguments of the most ardent 
cultural nationalists were enveloped in the new discourse that underlay public debates.

Fukuzawa was a lightning rod for public debate about civilisation. Hundreds of thousands read his major works of public opinion. His interpretation of bunmei kaika in An Encouragement of Learning was a leading opinion read by millions of Japanese. Fukuzawa's opinion was the most especial vision of the civilisational order of this era. China had been the major inspiration to purposeful transformation in the past. Engagement with the West connected Japan to a larger world, however, and China lost its place, according to Fukuzawa. His use of bunmei kaika semantically shifted the term's connotation from the Chinese order and system of moral education familiar to the Japanese to a larger international one (Howland, 2002: 33-8, 50-60). In the process, kaika stood in for cultivation of civilised subjectivity amongst the emperor's subjects, which implied an 'openness' of outlook juxtaposed to the national closure associated with the sakoku policy of the preceding Tokugawa era (Karlin, 2014: 138-9). In Fukuzawa's eyes, all this resulted from the great encounter in which the West's 'unknown culture was to be met and to be closely associated with' (Fukuzawa, 1985: 102), including at the level of the behaviour of the Emperor's officials and subjects. Fukuzawa went further when he fastened Japan's development to the strategy of learning from the West, but then projected it beyond the particular modernity of Western civilisation: 'civilisation is an open-ended process. We cannot be satisfied with the present level of attainment of the West' (2005: 701).

He also spoke of 'civilisation' in the singular as a spirit of independence. Fukuzawa's phrase yo no bunmeikaika can be rendered as 'world civilisation', an expression of the universality that complements the acquisition of 'things Western' (Howland, 2002: 34). In An Encouragement of Learning Fukuzawa depicts his 'spirit' of civilisation as the independent pursuit of knowledge (Fukuzawa, 1985: 93-100). Japan lacked the independence of spirit that Fukuzawa believes to be indispensable for civilised subjectivity. Mere acquisition of technology is insufficient. The value of civilisation lies in a practised inquisitiveness. Progress cannot be indexed by the accumulation of material appurtenances alone, but by the popular exercise of independence of mind. For Fukuzawa, this was a matter of the kind of society that modern Japan would produce. He believed in principles of meritocracy, but articulated these in the context of national integration (Bellah, 2003: 167). At the beginning of Outline of Civilisation, he states that a 'discourse on civilisation is a discourse on the development of the human. It does not deal with the development of the mind of an individual but the minds of people as a group in the whole of society' (Fukuzawa, 1985: 101). Fukuzawa hoped to create coherence around the larger group identity using the language of civilisation, society and nation. Through such a connection the Japanese people 
could identify with an abstract and unfamiliar ideal, while at the same time also identifying with the sovereign body of the Emperor.

Fukuzawa was an exceptional figure in promoting the discourse of civilisations. His published opinions reflected the general debates of the Meirokusha. That the phrase had currency in the Meiji Six Society by early 1875 is confirmed in Nishimura Shigeki's 'An Explanation of Twelve Western Words' . Nishimura presented a lexicology of 'civilisation' in this essay. He found that the term had a double connotation in European languages. On one hand, as a noun it connoted the ensemble of economic and cultural institutions. On the other hand, it signified a tempering subjectivity. The double entendre is captured in a reading of Guizot and Mill that is reminiscent of Fukuzawa:

In the view of these two scholars, civilization's form appears on two paths: one is through group relations and the other is through the conduct of man [sic] as an individual ... We cannot speak of civilization unless there is a parallel advance in the dignity of social intercourse as a whole and man [sic] as an individual. Even though the nation as a whole moves towards prosperity, when the wisdom of the people has not advanced in the least, their prosperity is not to be trusted as its source is extremely unclear. Thus, although civilization applies to social intercourse as a whole, as well as to man $[s i c]$ as an individual, its essence, being the elevation of individual dignity, extends by inference to the whole of social intercourse. (Braisted, 1976: 447)

According to Nishimura, acquisition of the virtues of civilised subjectivity should be pre-eminent, the sine qua non of civilisation if you will. The complexity of civilisation that Fukuzawa constructs is echoed here. Evolutionist tones are unmistakable, though Nishimura also acknowledges that the apex of civilisation has shifted frequently throughout global history: 'the areas that have advanced civilisation after achieving prosperity at a particular time were Africa in ancient times, then Asia, and now similarly Europe' (Braisted, 1976: 449). Civilisation is not always European for all places at all times, a conclusion also reached by Fukuzawa.

The commitment to international knowledge by the Meiji elite had oriented the Japanese to an outside universality and situated their society in an international order that included a normative standard of civilisation (Gong, 1984: 164-200). Suggestions that early Meiji Japan merely mirrored the West in development of imperialist missions are not especially convincing. However, there is little doubt that awareness of the greater outside world increased substantially in the early Meiji years and it could not but incorporate Western exemplars of imperialism. That was part of inter-civilisational engagement. Greater awareness of international relations also increased the anger about the secondary place in the world 
order accorded to Japan by Western powers. Many Japanese believed that their civilisation deserved to be treated as an equal. They saw in the normative principles of the international order a justification for their advancement. But Japan's place did not formally alter until after the reversal of the unequal treaties in 1905. Arguably it did not alter much after 1905 either, even though the standard of civilisation continued to reign in the international arena.

Meanwhile Japan's own reckoning of the world had already been irreversibly enlarged. Other civilisations and cultures came into view. Most importantly, the place of Asia and China in the international arena was re-envisaged in which Western states were increasing in imperial power and influence. Governments in the late Meiji era believed that Japan ought to be treated on a par with Western states. A more assertive outlook translated in part into wars with China and Russia and the early stirrings of Japanese colonialism. In this climate, the term bunka as 'culture' began to acquire prominence alongside bunmei (Howland, 2002: 37-8). Like the German distinction of particularising Kultur juxtaposed to the universalist notion of civilisation promoted by the French, the ascendancy of bunka accorded with Japanese nationalism. Unlike the German notion, the Japanese ideal of bunka came to the fore in an environment in which images of civilisation were derived from an international arena dominated by the Western powers.

\section{Late Meiji: civilisation contested}

New perspectives emerged after linguistic consolidation of a discourse of civilisations and after the heightening of consciousness around the standard of civilisation. In the 1890s, Meiji leaders could point to signs of progress in the foundation of a constitutional polity and the early stages of industrialisation. Japan's impact on the international arena also deepened in the wake of military victories over China and Russia. While the West did not fade from Japan's field of vision, Asia was enlarged in strategic considerations. Four perspectives formulated against the backdrop of the two military adventures cast Japanese modernity in a context of shifting balances of international power. Tokutomi Soho, Okakura Tenshin, the scholars of orientalist toyoshi sciences and the Christian pacifist Uchimura Kanzo all circulated different reactions to the new relationship with the world order and particularly with Asia. Experience of international travel and engagement with foreign currents of thought informed this new intelligentsia, which otherwise disagreed on questions of how Japan as a civilisation should relate to the world.

Tokutomi Soho was a youthful participant in the 1880s Popular Rights Movement who emerged as a widely read and admired intellectual. He had a 
sophisticated grasp of influential Western and Japanese thinkers and blended a classical Japanese education with familiarity with Guizot, Macauley, Mill, Spencer and Tocqueville. After his early involvement with liberalism he quickly found a Spencerian voice. In his account of Japan's state in the mid-1880s (Tokutomi, 1989), he positions Japan's fragile modernity on a civilisational path from militant to commercial-industrial society. Tokutomi iterated a disdain for the feudal burden of the past. Style, appearance and refinement were expressions of society in a modernising phase, as far as he was concerned. The backdrop to his sociology was a gendered performance of civilisation (Karlin, 2014). Older manners, clothes and customs gave way to new etiquette, fashion and popular cultures. The new civilities were contested but still moved as part of the shift from militarism to commerce that Tokutomi advocated and described. The measures implemented in the early Meiji years had to go further and reach more deeply into society, if democratisation were to be realised. In a more contingent vein, Tokutomi imagines Japan's prospects as shaped by colliding social forces (1989: 20-1, 167-82). Several scenarios were possible for Japan as domestic conservatism stood in contradiction with compelling international impulses. Furthermore, within Japan itself military and economic logics competed with each other and the outcome looked unclear. So Tokutomi's sociology was not merely a replica of Spencerian evolutionism, but a more ambivalent account of a developmental pattern contingent on unpredictable contradictions. Optimistic about the future, but alert to its pitfalls, Tokutomi was sincerely hopeful for a commercial-industrial and peaceful democratic country, but uncertain whether it would emerge or not. In this respect, his perspective on the order of civilisations gave him more of a sensibility about Japan's historically specific development than Spencer allowed for. As time went on, however, Tokutomi's vision of civilisation turned to a soft nationalism, which then steadily hardened as militarism arose.

Two Asia-oriented instantiations of the discourse of civilisations are too important to ignore in light of subsequent developments. Okakura Tenshin's Pan-Asian perspective was solidarity-oriented and affirmed nascent nationalisms in Asia that were emerging in reaction to the double standard of the international standard of civilisation. There was another Asia-oriented intervention in the form of toyoshi (Oriental) studies that pictured Japan in the lead. Romanticising a 'lost' ecumenical Asian past, Okakura sees in Japan's modernity an overall negotiation with the West's civilisation on Japan's terms (2006 [1904]). In contrast, other great powers in Asia have either succumbed to Western colonialism or been forcefully subordinated by it. Okakura's catalogue of the contributions of different Asian civilisations to the cultural vitality aggregated in independent modern Japan seems not to have implied a closed Orientalism. If Okakura's 1904 tract, The Awakening of Japan, was easily given to later ultra-nationalist reception, then 
it was also pliable to other points of view. The most remarkable example of his Pan-Asianism was his inter-cultural dialogues with anti-colonialist Rabindranath Tagore. Through his relationship with Tagore, he helped craft a moderate Asiaoriented world view grounded in the agreed common ground of Asian cultures (Bharucha, 2006; Dirlik, 1997: 113-14). By the time he came to consider 'civilisation' in those dialogues, it seemed the discourse of civilisations dealt with a datum of assumed common sense, and not the indefinitely problematised notion that 'civilisation' was for his interlocutor Tagore (Bharucha, 2006: 76-83). As the cries of nationalism increased, Okakura went silent on Asia's relationship with Japan. By way of contrast, Tagore's stance became more significant in India as anti-colonialist nationalism became more compelling. A second Asia-oriented position edged out this first inter-cultural perspective.

The orientalist history that laid quasi-scientific grounds for militarist orientations to Asia was toyoshi studies. A brief summary cannot do justice to the disciplinary breadth of Japanese orientalism, but a few pointers are pertinent. Toyoshi studies coalesced in the 1890 s with abandonment of the Enlightenment enthusiasm of the early Meiji period (Tanaka, 1993). This stridently nationalist school of cultural Asianism evolved alongside Okakura's inter-cultural articulation of Asian solidarities, but was also a rival vision. The past-oriented Romanticism of Okakura had no place in toyoshi histories with its positivist mood. Deterred by the cultural and historical specificity of the Western social sciences, toyoshi turned away from universalism. Toyoshi scholars embraced an Asian particularism in its place, which situated Japan at Asia's head as representative of its treasures. Civilisation was still the premier condition, and Japan represented the apparent ways-of-civilisation for Asia. Carol Gluck's summary (1985: 253-7) of the process of adoption and 'naturalization' of bunmei by the time toyoshi studies started to emerge is apt: " civilisation" appeared as an indigenous fact of social life that possessed the same descriptive transparency as any unmodified common noun' (1985: 254). The theories of civilisation spanning the range of Asianist perspectives may have varied. However, they all built on the apparatus of concepts and sciences constructed in the early Meiji period and thus could take a place in the more fulsome discourse of civilisations that Duara points to.

Concerns over the 'progress' of Japanese civilisation that circulated in the public writings of Tokutomi were shared by the author of the next perspective heterodox Protestant Uchimura Kanzo. Some comparison of the two can help clarify the power of Uchimura's point of view. Both had negative experiences of life in the United States and were focused on trans-Pacific relations. Japan's seizure of Taiwan and Korea and the annexation of Samoa, Guam and the Philippines by the United States enlarged the importance of the Pacific for the Japanese (see Matsuda, 2012: 243-5). But Tokutomi and Uchimura each drew different 
conclusions. Tokutomi steadily became more nationalist, whereas Uchimura steadily became more alarmed about the military consequences of the regime's self-understanding of civilisation. Tokutomi's earlier optimism had given way to bitterness about the deep misunderstandings in relations with the United States. Premonitions of the deterioration in relations during the late Meiji era turned into full-blown warnings in the Taisho years (Tokutomi, 1922). Tokutomi's fear of an extension of the Monroe Doctrine to the Pacific drove him to a more stridently nationalist position. His fear was nourished by the United States' antiJapanese immigration policies. The alarm about the United States rang out differently in Uchimura's projections of Japan's destiny. Uchimura couches his fears in the language of 'civilisations': 'What is Japan's mission, or what can she do for the world? If Egypt and Babylon started civilisation, Phoenicia dispersed it, Judea purified it, Greece polished it, Italy preserved it, Germany reformed it, England tempered it, and America executed it, is nothing more left for Japan to work on?' (cited in Lee, 1981: 89). He is disappointed that history has left nothing for Japan to do. Like Tokutomi, Uchimura also felt disappointment with the United States. He had invested high hopes and saw the United States as an ideal of modernity. His ultra-Protestantism and pacifist ethics set him apart from Tokutomi, however. A well-informed figure on Japan-US relations, he was well placed to compare the styles of life of both societies. His bitter memories of studying in the United States refined his understanding of a Japanese subjectivity. For Uchimura, only an independence of mind would give Japanese Christians the autonomous congregational and social life that he thought they needed. If Japanese Christians could attain a spirit of independence they would exemplify modern civilisation and, incidentally, resist the pressures to conform that mounted in the late 1920s (Bellah, 2003: 44). With his 'non-church movement' (mukyokai), Uchimura organised a non-sectarian home for dissenting Christians, a 'dormitory for those who have no home, the orphanage or foundling home for the spirit' (Uchimura, 1958: 347). His heterodox Protestantism brought him public scandal and marginalised him along with a growing number of socialists and pacifists. While he was ambiguous about socialism, and saw a developmental role for private enterprise in society, his pacifism was unshakable.

He and his associate dissenters in the mukyokai acted as a clearing house of religious, moral, sociological and political ideas taken from an image of US modernity, from developments in unfolding American-Japanese relations and from experiences of life in the United States. With these, Uchimura developed a sui generis pacifist Japanism. His version of 'Japanese Christianity' was a blend of Western influences with the valued moral traditions of Japan (Howes, 2006). From the West he freely took tenets of Christianity, while refusing to be dominated by missionary agencies. With this cross-civilisational fusion, Uchimura 
sought to balance two equations: one of patriotism and an ethic of independence, and the other of Western Christianity and the core moral traditions of Confucianism and Buddhism. Bellah fairly describes this as an 'ethical individualism' (2003: 103-7). With a blended Japanism, he stood with socialists and Okakura in opposition to the nationalist version of civilisation envisaged by the regime. There were a few exceptional socialists who, alongside Okakura and Uchimura, spoke out against Japanese expansion. Their perspectives would be interesting too, but cannot be explored here.

\section{Conclusion}

East Asia's discourse of civilisations had its origins in Japan in the 1870s. The Japanese found themselves reorienting to a largely unfamiliar Western political, cultural, economic and cognitive complex. They grappled with new and unfamiliar ideas, with translation being a point of first deep contact in what would turn out to be a longer cultural and political engagement. The 'Japanisation' of the human sciences and its conceptual apparatus came about via a particular struggle around conceptions of civilisation, society and modernity. Different terms to express new conceptions emerged from this exceptionally intense phase of inter-civilisational engagement, which can be reckoned as encounters. Deliberation over a number of perceived elements of civilisations in the Meirokusha gave way to versions of civilisation oriented to the Asian region and to the United States. The discourse of civilisations obtained an Asian-oriented form in the early twentieth century encompassing four competing perspectives on relations between Japan, Asia and the West in the late-Meiji-Taisho eras. The denial of equal status with the West generated tensions on the international front, which contextualised all four. With the ascendency of militarism, the most contestatory visions of civilisation faded. But the discourse of civilisations posited by Duara as a development of the 1920s and 1930s did not.

Japan embarked on an inter-civilisational encounter on a large scale at the outset of this period. However, the encounter both based itself on historical experiences of engagement with East Asia and broke new ground in engaging a larger international arena of empires and civilisations. Japan's orientation were northern to Russia, western to Europe and Asia, southern to Australia and, most importantly, trans-Pacific. New landscapes of cultural and political engagement emerged, which I have focused on in this chapter. By extending the model of interaction laid down in the major studies of Japan in contemporary civilisational analysis, I have linked inter-civilisational encounters and engagement in a very 
particular context. As well as an enlargement of the range of inter-civilisational engagement in political and cultural perspectives, there was a widening of economic relations and emigration as well. How that transpired is beyond this chapter (but see Smith, 2014c).

This chapter completes the in-depth studies of Part II. I have fathomed particular examples of inter-civilisational engagement. My survey includes oceanic civilisations, the Oceanian civilisation, Latin American movements of political and cultural engagements and, finally, Japan's exceptional encounter with the West and instances of political and cultural engagement that ensued. I have examined, to varying degrees in all cases, the four dimensions of intercivilisational engagement to support my critical synthesis of the illuminating insights of civilisational analysis. I am stressing the relational character of civilisational formations, howsoever they may be construed. Immediately, the question is posed, again, of the conception of civilisation and civilisations at work in the field and, indeed, in the perspective unpacked in these pages. In the Conclusion, I return to conceptual problems and some other important questions of the human condition. 


\section{9 \\ Conclusion}

In the first part, I portray civilisational analysis as a two-sided, multidimensional field of the humanities and social sciences. On one side, contemporary civilisational analysis has a delimited set of major problematics and analytics. On the other side, it formed as a wide-ranging field of debate and has remained one. Paradigmatically speaking, several questions are problematised in contemporary civilisational analysis. Both the questions and the provisional answers given to them shape the three specific images I discern in the field. What defines civilisations? What creates them? Is it their materiality, their art or their religious ethics? Are they old and evolutionary, or constituted anew in modernity? How have moderns judged them, or rather discursively cast them? What ideological uses are made of the idea of civilisation and how should they be disentangled from archaeological, anthropological, sociological and historical investigation and methodology? Each question is a debating point. Images of the character of civilisation and civilisations underpin the diversity of explanations. Are they entities that can be named as groups of kindred societies - the West, Confucian civilisation, Islamic civilisation and so on? Are they processes of the formation of institutions of power, tempering human conduct and consciousness, or are they discourses? Are they orientations that take shape in momentous encounters with another? It has been argued in the preceding pages that the last image, the relational image, is the most productive and holds the best prospects as a direction of further development. In this Conclusion, I summarise the findings of the book in the wake of that argument before posing some questions of the human condition.

\section{The argument in summary}

The problematic of inter-civilisational encounters is a point of reference for the version of civilisational analysis assembled in these pages. Yet the sociology of encounters between civilisations also has its limits. It has yet to extensively unpack colonial modernities, capitalism and new world and oceanic societies 
in the theatres of the Americas and Oceania. The perspectives in post-colonial sociology, Marxism and globalisation analysis examined in Chapter 3 are specialist studies of colonial and post-colonial conditions and capitalism and thus give greater visibility to neglected problematics. Yet they too fall short of considering the specific characteristics of new world societies and oceanic contexts. At the same time, perspectives at the edges of the three paradigms are suggestive of intersections with civilisational analysis - specifically longer historical perspectives on global connectivity, a theory of the imaginary institution of capitalism and its variants, and the illuminating role of connected and relational methodologies in highlighting global patterns of power.

It becomes possible, building on findings in the first part of the book, to take another path: to analytically grasp the connections of different social formations instituted by collective imaginaries. Following Castoriadis's theory of social imaginaries, I have suggested that macro-regional constellations like civilisations are collective creations. Imaginaries institute the development of inclinations and aversions to encounters and engagement in which civilisations are created. Castoriadis's theory of the imaginary institution informs my development of a notion of inter-civilisational engagement in which civilisations acquire meaning at the point of inter-relationship with other social, historical and cultural forms; that is, other civilisational patterns, to use Arnason's phrase. To recount, there are four dimensions to this inter-relationship. Interaction occurs through migration, economic relations, cultural exchange and the extension of models of polity and civilisation. The four dimensions of inter-civilisational engagement featured in Chapters 4 and 5 highlight deep connections, including ones that sit outside of social formations traditionally recognised as high civilisations.

Each of the four dimensions is distinct. Migration as engagement has the strongest sense of motion. People move, but so also do their sentiments of belonging, which are often also collective sentiments. In moving, immigrants create new attachments, often also engendering trans-national links between networks or diasporas of their compatriots (Cohen, 2008). Where migrants move under explicit compulsion, links can be severed or actively blocked. Migrants were economic agents, whether as labourers, consumers or traders. Bearing and exchanging goods, however conceived, involved exchanging values, especially when exchanges have been in inter-cultural contexts. The impact of early modern trade can be no less evident than in the example of intercontinental dispersion and circulation of species of flora and fauna stimulated by colonialism. But, then again the length and strength of the chains of connection that finance lubricated - even before the rise of Italian banking - is surprising. Contracts, insurance, money itself: all these were ancient instruments as well as proto-capitalist instruments of greater magnitude. The extent of trust and 
tightness of consociation in family-based, religious and mercantile networks is impressive. We can observe how inter-civilisational engagement fostered trust over distances and through various cultural environments via these imagined communities' of transport of goods and services, news and information. Do ideas, precepts, doctrines and information travel as easily as goods of trade? Collins's answer is that they do and with greater velocity in and through the centres of culture and knowledge. We can say the results of his historical sociology of the spread of knowledge are replicated in other zones outside the scope of his study - specifically oceanic, coastal and new world connections. My work in Chapters 6, 7 and 8 on the Pacific, Latin America and Japan suggest as much also. In looking at the fourth dimension in Chapter 4, I focus on the differentiation of empire and civilisation in historical processes of communication and transformation of civilisational models. Seen from this angle, the diversification of forms of power is more evident. My three examples of China, the Sanskrit Empire of the first millennium and the Iberian world order of early modernity give a fraction of insight into the diversity of combinations.

Such are the connections of civilisations. Chapters 4 and 5 also pay closer attention to Latin America and begin to touch on Oceania as an islander civilisation. With a focus on inter-civilisational engagement, it becomes easier to see how the societies of the Americas and Oceania are underestimated. The indigenous civilisations subsumed had creative and complex cosmologies and sophisticated orientations towards interaction. They appeared, in European eyes, to lack the institutional complexes, economic forms and material structures of 'civilisation'. Of course, colonisation of the Americas looked very different to the later subjugation of Oceania. Nevertheless, both historical processes had comparable aspects. In the imperial imaginary, the signs of civilisation were instituted originally in the Americas, forming part of western European experiences of power. The image of 'civilisation' construed indigenous civilisations as 'savage'. This barbarisation of Ando-American, North American, Meso-American and Pacific Islander civilisations was an epistemological violence committed by currents of forming societies of colonisers (and, in the Americas, their republican successors). The civilisational relegation of conquered societies was always also contested, however. From Jesuit disputation of the violent upheaval of MesoAmerica and Ando-America to Indian rebellion against colonial authorities to latter-day social movements, there have always been counter-currents affirming the civilisational value of Amerindian worlds. In Chapter 6, I show two sides of the recuperation of the civilisational value of Oceania. First, the colonisation of islander societies expanded ethnological knowledge in such a way that Western understanding of civilisation was both confirmed and put into question. Anthropology was at the forefront of entanglements of Enlightenment and 
Romantic traditions that were capable of critique of evolutionist assumptions as much as defence of them. Second, cultural and political movements in the Pacific since the 1980s have affirmed the civilisational character of Oceania and crucially add that islander societies have a living vitality and are engaged recreations of Oceanian civilisation.

Latin American and Pacific new worlds were invaded and overtaken by historically specific forms of state. Oceanic empires and the oceanic civilisations and imperial imaginaries from which they issued were the wellsprings of conquest. As I demonstrate in Chapter 5, they are distinguished from portal civilisations by this very aspect of conquest. Portal civilisations create institutions and practices of power capable of extensive contacts and relationships without conquest of vast territories. To be sure, they build empires and extend spheres of commerce, culture and travel in which explicit power is created. My synopses of the Venetian Mediterranean (during the era of Venice's naval dominance) and the Omani West Indian Ocean (with its flows of slave trading) are indicative of the balance of engagement and explicit power. Nonetheless, they are distinct from oceanic civilisations that bear capacity for global empires. Also distinct are islander societies, though both oceanic empires and portal civilisations embraced islands also. Islands warrant a great deal more attention (Gillis, 2004, 2013) and lack it in civilisational analysis. I have argued in Part II that the resurgence in thalassology in comparative and world history can be pressed into the service of contemporary civilisational analysis. I would go so far as to suggest that specialists may, heuristically at least, pose questions about the civilisational standing of some islander societies. There is an outstanding example of inter-cultural and intra-civilisational engagement in Oceanian civilisation. Europe's visions and institutional logics of power did much to disorder the Pacific's cultural worlds, as did later Cold War rivalries. Yet, engagement and connectedness are still celebrated in cultural memory and reaffirmed in the social, cultural and economic practices of islanders. Their resilience and the vitality of traditions is reminiscent of the Amerindian ontologies renewed in indigenous communities and movements of the Americas, as I observe in Chapter 7.

I have focused on Latin America and the Pacific in order to address regions and whole collective experiences that are largely missing in civilisational analysis. Taken with the example of Japan, I have sought to analyse inter-civilisational engagement through exposés on specific kinds of engagement in three zones. Discussion around Latin American, Japanese and Oceanic perspectives follows components of Randall Collins's approach to cultural and political engagement, if not his specific prognoses. When it comes to Japan, I delimit a specific period in which different paths of modern development were open and potential for broad international relationships was undecided. The Chinese order in East Asia 
and the intercession of the West in the mid nineteenth century were contexts of encounters and inter-civilisational engagement in which Japanese perspectives on civilisation were generated. Asia and the Pacific were often debatably represented in Japanese perspectives. Solidarity-based versions of relations with Asia competed with expansionist and militarist ones, and ultimately failed to prevail. In the long post-war period, Asia became a problematic part of Japan's regionalised model of capitalism and remains so, suggesting that Japan's intercivilisational relations are still tension-laden. In this scenario, the past is articulated with the present. In fact, civilisations in Latin America, Japan and the Pacific are all instituted at context-dependent intersections of influences of present and past. The last task remaining to us is to indicate global problems of the current human condition that provide a compelling reason to pursue a research agenda in civilisational analysis that will operate more closely at the intersection of past and present.

\section{Intersections of past and present}

Debating Civilisations began with anthropological axioms posited by Ibn Khaldun, Simon Bolivar and George Pachymeres. Each axiom alludes to perceptions of deep connectivity that pre-date processes of modern globalisation. The three extracts in another way are anecdotes of inter-civilisational engagement predating the global age, which is one of the problems I pose and unpack in the book. The argument I have supported, that analytics of inter-civilisational engagement can form a useful way of looking at global history, might seem like an invitation to an Apollonian panorama of human existence. But a historical perspective has much to offer anyone seeking another way to understand contexts of globality, as critics of globalisation theory have pointed out.

At the same time, there is a chance that, in the rush to exercise historical sensibility, contemporary civilisational analysis might neglect the present. Logically, this might reinforce the presupposition of the globalisation paradigm that civilisations no longer matter and have been flattened out by globalising processes. How much neglect of the present is there? Several points based on my survey of the field in Chapters 1 and 2 can be assembled in support of contemporary civilisational analysis. However, on the whole, they amount to an inconsistent picture. When Robertson, Cox and Katzenstein throw into relief civilisational processes and forces in the present they show how relevant the paradigm is to understanding the international arena. Add in Hall and Jackson's collaborations, and it seems that there is strength in the discipline of international relations. In comparative sociology, Eisenstadt's civilisation of modernity was an attempt to 
outline a civilisational framework for study of contemporary trends. It identified important problems for debate. The question of the historical lineages of modern democratic movements is partly framed by the controversy around Axial civilisations. The other side of the theorisation of democracy is oriented to a critique of totalitarianism and fundamentalist modernities. The critique furnishes important insights into the modernity of authoritarian and totalitarian logics and the abiding tensions of democracy. But, more powerfully, the commitment to democratic projects is an orienting position for contemporary civilisational analysis, a place to stand in respect of the global order. Others mentioned in these pages, such as Arjomand, Arnason and Spohn, reveal their currency when they address problematics of modernity in the twentieth and twenty-first centuries. In each of these accounts, contemporary civilisational analysis has shown some relevance to evaluations of the post-Cold War era, but efforts in international relations address the present more decisively than comparative sociology has to date.

Other arguments can be assembled in favour of keeping civilisational patterns on the research agenda for the social sciences. The arguments relate well to my own version of contemporary civilisational analysis but also have a broader relevance. Application of the version I have developed requires two sensibilities, both of which are variably exercised in the field. Contemporary imaginaries, first of all, are frequently manifest as regional patterns. Globalisation analysis, as an alternative, has not done sufficient justice to either regional plurality or the dynamics of regionalisation. Second, analysis of the four dimensions of inter-civilisational engagement presupposes an acute appreciation that social formations are multidimensional and are made up, in other words, of co-determining spheres of social life. While my precise focus is on interactive dimensions of civilisational constellations and patterns, there is a whole other endogenous side to the multidimensional orders instituted by social imaginaries that remains indispensable.

The two sensibilities add up to a commitment to non-reductive social theory and social science. By asserting appreciation of the complexity and multiplicity of large-scale formations, versions of contemporary civilisational analysis that enliven both sensibilities can be alert to the co-determination and multidetermination of social life. They can aim at provisional conclusions and broad understanding and not reductionist explanation. Civilisational analysis has a strong record of investigation of historical civilisations, notwithstanding the shortcomings analysed in this book. Practitioners in the field have more or less applied those sensibilities, and where they haven't their theoretical and empirical findings point to further research into complexity and multiplicity.

Treatment of contemporary problems of modernity is another matter. The record of investigation is inconsistent, as I suggest above. Any perspectives informed by civilisational analysis that aim to combine horizons of past and present 
will require a wider optic of social scientific and theoretical inquiry. Inquiry into present and past should be premised on three requisites. The first is an orientation to social change and not unconditionally any projects of change, but ones that confront problems of the contemporary human condition. Those problems include: wars and the plight of refugees, the related attrition of fragile cosmopolitan and democratic ideals, poverty and access to the essential resources of life (water, energy, breathable air), and the precipitous degeneration of the biosphere in which all exists. The critical impulses of contemporary imaginaries call for radically democratic responses to global, regional and local problems, responses that are amenable to different collective modes of living, belonging, relating, organising, negotiating and solving. Beyond shallow multicultural regimes of management of ethnic coexistence, the transformative responses of democratic projects invoke potential for inter-cultural living in which core problems of social and economic life - especially those noted above - are seriously foregrounded, deliberated, negotiated and confronted. No future of problem-solving can be found in the opposite of this potential, which indeed is a great threat in the early twentyfirst century: the retreat into nationalism, homelands and border closures, which are closures of the mind as well as closures of territory.

The 'mission', if you will, of responding to the problems of the present therefore, as a second requisite, calls for recognition of complexity in collective modes of living and an appreciation for the extent of complexity in so-called traditional societies. Too many instantiations of collective imaginaries throughout world history exhibit multidimensional complexity for any presumption to be rightly made that societies of the global age, and Western societies in particular, are more highly differentiated. An intellectual openness to multiple forms of complexity is an imperative to collective problematising, learning and confronting in the face of contemporary crises.

The third requisite is a deeper understanding of the vitality of traditions in the present - in other words, an awareness of how continuous or discontinuous the past is. That different civilisations and cultures have a variety of historicities is more widely accepted in the social sciences and humanities in the wake of post-colonial critique. Contemporary civilisational analysis is also attuned to the deep appreciation of continuities and discontinuities in historical civilisations. What it has yet to do is systematically apply that appreciation to contexts of the present. An opportunity is there for the field to fully elaborate how this might be undertaken in a manner that takes productive directions out of the analyses of modernity it has already founded.

The contribution of Debating Civilisations is a model of civilisational analysis that elucidates lines of engagement, a model that can be applied to the conjuncture of the present as well as to historical civilisations. Horizons of 
past and present are equally imperatives in a more generalised scholarship of inter-civilisational connectivity that can help make sense of the present conjuncture. That project must also presuppose a conception of civilisation freed from closures of every kind - territorial, cultural, political, communicative and capable of problematising the contemporary conjuncture in such a way that potential transformations with lasting improvements to the human condition can be imagined. But profound understanding of plurality, complexity and diverse historicities should also be central to visions of democratic transformation and imagined paths to fresh institutions of inter-connected collective modes of life. In other words, a consequence of deeper understanding of complexity is that it must always be possible to put transformations and institutions productively into question. This book is a very modest contribution to that end, one that emphasises engagement and connection as forms of social creation. 


\section{References}

Adams, S. and Arnason, J. P. 2016. 'Sociology, Philosophy, History: A Discussion', Social Imaginaries, 2, 1, 151-90.

Adams, S., Blokker, P., Doyle, N. J., Krummel, J. W. M. and Smith, J. C. A. 2015. 'Social Imaginaries in Debate', Social Imaginaries, 1, 1, 15-52.

Aktürk, S. 2009. 'What Is Civilization? From Braudel to Elias - The Various Definitions of "Civilization” in Social Sciences', in S. Unay and M. Senel (eds), Global Orders and Civilizations: Perspectives from History, Philosophy and International Relations (New York: Nova Science Publishers), pp. 49-66.

Albrow, M. 1996. The Global Age: State and Society beyond Modernity (Stanford, CA: Stanford University Press).

Arjomand, S. A. 2004. 'Transformation of the Islamicate Civilization: A Turning Point in the Thirteenth Century?', in J. Arnason and B. Wittrock (eds), Eurasian Transformations, 10th to 13th Centuries: Crystallizations, Divergences, Renaissances (Leiden: Brill), pp. 213-45.

Arjomand, S. A. (ed.). 2014a. Social Theory and Regional Studies in the Global Age (New York: SUNY Press).

Arjomand, S. A. 2014b. 'Three Generations of Comparative Sociologies', in S. A. Arjomand (ed.), Social Theory and Regional Studies in the Global Age (New York: SUNY Press), pp. 23-61.

Arjomand, S. A. and Tiryakian, E. (eds). 2004a. Rethinking Civilizational Analysis (London: Sage).

Arjomand, S. A. and Tiryakian, E. 2004b. 'Introduction', in S. A. Arjomand and E. Tiryakian (eds), Rethinking Civilizational Analysis (London: Sage), pp. 1-20.

Armitage, D. and Bashford, A. (eds). 2014. Pacific Histories: Ocean, Land, People (New York: Palgrave Macmillan).

Arnason, J. P. 1993. The Future That Failed: Origins and Destinies of the Soviet Model (Hoboken, NJ: Routledge).

Arnason, J. P. 1997a. Social Theory and Japanese Experience: The Dual Civilization (London: Kegan Paul International).

Arnason, J. P. 1997b. 'The Southeast Asian Labyrinth: Historical and Comparative Perspectives', Thesis Eleven, 50, 99-122.

Arnason, J. P. 2000. 'Approaching Byzantium: Identity, Predicament and Afterlife', Thesis Eleven, 62, 97-122. 
Arnason, J. P. 2001. 'Civilizational Analysis, History of', in N. Smelser and P. B. Balters (eds), International Encyclopaedia of Social and Behavioural Science (Oxford: Elsevier), pp. 1909-15.

Arnason, J. P. 2002. The Peripheral Centre: Essays on Japanese History and Civilization (Melbourne: TransPacific Press).

Arnason, J. P. 2003. Civilizations in Dispute: Historical Questions and Theoretical Traditions (Leiden: Brill).

Arnason, J. P. 2004. 'Civilizational Patterns and Civilizing Processes', in S. A. Arjomand and E. Tiryakian (eds), Rethinking Civilizational Analysis (London: Sage), pp. 103-18.

Arnason, J. P. 2005. 'The Varieties of Accumulation: Civilisational Perspectives on Capitalism', in C. Joerges, B. Strath and P. Wagner (eds), The Economy as a Polity: The Political Constitution of Contemporary Capitalism (London: UCL Press), pp. 17-36.

Arnason, J. P. 2006. 'Understanding Intercivilizational Encounters', Thesis Eleven, 86, 39-53.

Arnason, J. P. 2007. 'Civilizational Analysis: A Paradigm in the Making in World Civilizations', in R. Holton (ed.), Encyclopedia of Life Support Systems (EOLSS), developed under the auspices of UNESCO (Oxford: EOLSS Publishers, UK [www.eolss.net]).

Arnason, J. P. 2010. 'Domains and Perspectives of Civilizational Analysis', European Journal of Social Theory, 13, 1, 5-13.

Arnason, J. P. (ed.). 2011a. The Roman Empire in Context: Historical and Comparative Perspectives (Oxford: John Wiley \& Sons).

Arnason, J. P. 2011b. 'Response to Comments and Criticisms', European Journal of Social Theory, 14, 1, 435-51.

Arnason, J. P. 2014. 'Historicizing Axial Civilizations', in S. A. Arjomand (ed.), Social Theory and Regional Studies in the Global Age (New York: SUNY Press), pp. 179-201.

Arnason, J. P. 2015. 'Elias and Eisenstadt: The Multiple Meanings of Civilisations', Social Imaginaries, 1, 2, 146-76.

Arnason, J. P., Eisenstadt, S. N. and Wittrock, B. (eds). 2005. Axial Civilizations and World History (Leiden: Brill).

Arnason, J. P. and Murphy, P. (eds). 2001. Agon, Polis, Logos: The Greek Achievement and Its Aftermath (Stuttgart: Franz Steiner Verlag).

Arnason, J. P., Salvatore, A. and Stauth, G. (eds). 2006. Islam in Process: Historical and Civilizational Perspectives (New Brunswick, NJ: Transaction Publishers).

Arnason, J. P. and Wittrock, B. (eds). 2004. Eurasian Transformations, Tenth to Thirteenth Centuries: Crystallizations, Divergences, Renaissances (Leiden: Brill).

Aslanian, S. D. 2011. From the Indian Ocean to the Mediterranean: The Global Trade Networks of Armenian Merchants from New Julfa (Berkeley: University of California Press).

Barlow, T. (ed.) 1997. Formations of Colonial Modernity in East Asia (Durham, NC: Duke University Press).

Bayly, C. A. 2012. 'Introduction: The Connected World of Empires', in L. Fawaz, C. A Bayly and R. Gilbert (eds), Modernity and Culture from the Mediterranean to the Indian Ocean (New York: Colombia University Press), pp. 1-27.

Beilharz, P. 1997. Imagining the Antipodes: Culture, Theory, and the Visual in the Work of Bernard Smith (New York: Cambridge University Press). 
Bellah, R. N. 2003. Imagining Japan: The Japanese Tradition and Its Modern Interpretation (Berkeley: University of California Press).

Bellah, R. N. and Joas, H. (eds). 2012. The Axial Age and Its Consequences (Cambridge, MA: The Belknap Press).

Bentley, J. J., Bridenthal, R. and Wigen, K. (eds). 2007. Seascapes: Maritime Histories, Littoral Cultures, and Transoceanic Exchanges (Honolulu: University of Hawaii Press).

Bhambra, G. 2007. Rethinking Modernity: Postcolonialism and the Sociological Imagination (New York: Palgrave).

Bhambra, G. 2014. Connected Sociologies (London: Bloomsbury).

Bharucha, R. 2006. Another Asia: Rabindranath Tagore and Okakura Tenshin (Oxford: Oxford University Press).

Blokker, P. and Delanty, G. 2011. 'An Interview with Johann P. Arnason: Critical Theory, Modernity, Civilizations and Democracy', European Journal of Social Theory, 14, 1, 435-51.

Boatcă, M. and Costa, S. 2010. 'Postcolonial Sociology: A Research Agenda', in E. R. Gutiérrez, M. Boatcă and S. Costa (eds), Decolonizing European Sociology: Transdisciplinary Approaches (Farnham: Ashgate), pp. 13-31.

Bolivar, S. 2009. 'Angostura Address, 1819', in M. Brown (ed.), The Bolivarian Revolution (London: Verso), pp. 77-107.

Borofsky, R. 2000. Remembrance of Pacific Pasts: An Invitation to Remake History (Honolulu: University of Hawaii Press).

Bowden, B. 2007. 'The River of Inter-Civilisational Relations: The Ebb and Flow of Peoples, Ideas and Innovations', ThirdWorld Quarterly, 28, 7, 1359-74.

Braisted, W. R. (ed.). 1976. Meiroku Zasshi: Journal of the Japanese Enlightenment (Cambridge, MA: Harvard University Press).

Braudel, F. 1985. The Perspective of the World, trans. S. Reynolds (London: Fontana Press).

Braudel, F. 1993. A History of Civilizations, trans. R. Mayne (London: Penguin).

Braudel, F. 2001. Memory and the Mediterranean, trans. S. Reynolds (New York: Alfred A. Knopf).

Castles, S., de Haas, H. and Miller, M. J. (eds). 2014. The Age of Migration: International Population Movements in the ModernWorld (5th edn, London: Palgrave).

Castoriadis, C. 1987 [1975]. The Imaginary Institution of Society (Cambridge: Polity Press).

Castoriadis, C. 1991. 'Power, Politics, Autonomy', in D. E. Curtis (ed.), Philosophy, Politics, Autonomy (Oxford: Oxford University Press), pp. 143-74.

Chakrabarty, D. 2000. Provincializing Europe: Postcolonial Thought and Historical Difference (Princeton, NJ: Princeton University Press).

Chaudhuri, K. N. 1985. Trade and Civilisation in the Indian Ocean: An Economic History from the Rise of Islam to 1750 (Cambridge: Cambridge University Press).

Cohen, R. 2008. Global Diasporas: An Introduction (2nd edn, London: Routledge).

Collins, R. 2000. The Sociology of Philosophies: A Global Theory of Intellectual Change (Cambridge, MA: Harvard University Press).

Collins, R. 2004. 'Civilizations as Zones of Prestige and Social Contact', in S. Arjomand and E. A. Tiryakian (eds), Rethinking Civilizational Analysis (London: Sage), pp. 132-47. 
Comblin, J. 2006. 'Churches and Religious Reconciliation: The Theme of Reconciliation in Theology in Latin America', in I. Maclean (ed.), Reconciliation, Nations and Churches in Latin America (Aldershot: Ashgate), pp. 135-70.

Connell, R. 2007. Southern Theory: The Global Dynamics of Knowledge in Social Science (Crows Nest, NSW: Allen \& Unwin).

Conrad, S. and Sachsenmaier, D. (eds). 2007. Competing Visions of World Order: Global Moments and Movements, 1880s-1930s (New York: Palgrave Macmillan).

Cox, R. W. 2002. The Political Economy of a PluralWorld: Critical Reflections on Power, Morals and Civilization (London: Routledge).

Curtin, P. D. 1984. Cross-Cultural Trade in World History (Cambridge: Cambridge University Press).

Delanty, G. 2003. 'Cultural Translations and European Modernity', in E. Ben-Rafael and Y. Sternberg (eds), Comparing Modernities: Pluralism versus Homogeneity, Essays in Homage to Shmuel N. Eisenstadt (Leiden: Brill), pp. 443-60.

Delanty, G. 2004. 'An Interview with S. N. Eisenstadt: Pluralism and the Multiple Forms of Modernity', European Journal of Social Theory, 7, 3, 391-404.

Dirlik, A. 1997. The Postcolonial Aura: Third World Criticism in the Age of Global Capitalism (Boulder, CO: Westview Press).

Domingues, J. M. 2012. Global Modernity, Development and Contemporary Civilization: Towards a Renewal of Critical Theory (London: Routledge).

Duara, P. 2001. 'The Discourse of Civilization and Pan-Asianism', Journal of World History, $12,1,99-122$.

Duara, P. 2004. 'The Discourse of Civilization and Decolonization', Journal of World History, $15,1,1-5$.

Durkheim, E. 1965. The Elementary Forms of the Religious Life, trans. J. W. Swain (New York: Free Press).

Durkheim, E. and Mauss, M. 1971. 'Note on the Notion of Civilization', Social Research, 38, 4, 808-13.

Dussel, E. 1996. The Underside of Modernity: Apel, Ricoeur, Rorty, Taylor, and the Philosophy of Liberation, ed. and trans. E. Mendieta (Amherst, NY: Humanity Books).

Eisenstadt, S. N. 1986. The Origins and Diversity of Axial Age Civilizations (Albany, NY: SUNY Press).

Eisenstadt, S. N. 1996. Japanese Civilization: A Comparative View (Chicago: University of Chicago Press).

Eisenstadt, S. N. 1999a. Fundamentalism, Sectarianism and Revolution: The Jacobin Dimension of Modernity (Cambridge: Cambridge University Press).

Eisenstadt, S. N. 1999b. Paradoxes of Democracy: Fragility, Continuity and Change (Baltimore and London: Johns Hopkins University Press).

Eisenstadt, S. N. 2000a. 'Multiple Modernities', Daedalus, 129, 1-30.

Eisenstadt, S. N. 2000b. 'The Civilizational Dimension in Sociological Analysis', Thesis Eleven, $62,1-21$.

Eisenstadt, S. N. 2001. 'Civilizations', in N. Smelser and P. B. Balters (eds), International Encyclopaedia of Social and Behavioural Science (Oxford: Elsevier), pp. 1915-21.

Eisenstadt, S. N. 2002a. Comparative Civilizations and Multiple Modernities, 2 vols (Leiden: Brill). 
Eisenstadt, S. N. 2002b. 'The Civilizations of the Americas: The Crystallization of Distinct Modernities', Comparative Sociology, 1, 1, 43-61.

Eisenstadt, S. N. 2004. 'The Civilizational Dimension of Modernity', in S. A. Arjomand and E. Tiryakian (eds), Rethinking Civilizational Analysis (London: Sage), pp. 48-66.

Eisenstadt, S. N. 2005. 'Axial Civilizations and the Axial Age Reconsidered', in J. P. Arnason, S. N. Eisenstadt and B. Wittrock (eds), Axial Civilizations and World History (Leiden: Brill), pp. 531-64.

Eisenstadt, S. N. and Schlucter, W. 1998. 'Introduction: Paths to Early Modernities A Comparative View', Daedalus, 127, 3, 1-18.

Elias, N. 1978. The History of Manners (Oxford: Oxford University Press).

Elias, N. 1982. State Formation and Civilization (Oxford: Basil Blackwell).

Febvre, L. 1973. 'Civilisation: Evolution of a Word and a Group of Ideas', in P. Burke (ed.), A New Kind of History: From theWritings of Febvre (London: Routledge), pp. 219-57.

Fernández-Armesto, F. 2000. 'The Indian Ocean in World History', in A. Disney and E. Booth (eds), Vasco da Gama and the Linking of Europe and Asia (New Delhi: Oxford University Press), pp. 11-29.

Fernández-Armesto, F. 2001. Civilizations: Culture, Ambition and the Transformation of Nature (New York: The Free Press).

Franco, A. P. and Sánchez Prado, I. M. (eds). 2004. Alfonso Reyes y los estudios latinoamericanos (Pittsburgh: University of Pittsburgh).

Fukuzawa, Y. 1985. Fukuzawa Yukichi on Education: Selected Works, trans. Eiichi Kiyooka (Tokyo: University of Tokyo Press).

Fukuzawa, Y. 2005. 'An Outline of a Theory of Civilization', in W. T. de Bary, C. Gluck and A. E. Tiedemann (eds), Sources of Japanese Tradition, Vol. II: 1600 to 2000 (New York: Colombia University Press), pp. 696-707.

Gaonkar, D. P. (ed.). 1999. 'On Alternative Modernities', Public Culture, 11, 1, 1-18.

Gillis, J. 2004. Islands of the Mind: How the Human Imagination Created the Atlantic World (London: Palgrave).

Gillis, J. 2013. The Human Shore: Seacoasts in History (Chicago: University of Chicago Press).

Gluck, C. 1985. Japan's Modern Myths: Ideology in the Late Meiji Period (Princeton, NJ: Princeton University Press).

Gluck, C. 2011. 'The End of Elsewhere: Writing Modernity Now', American Historical Review, 116, 3, 676-87.

Go, J. 2013. 'Introduction: Entangling Postcoloniality and Sociological Thought', in J. Go (ed.), Postcolonial Sociology (Bradford: Emerald Group Publishing), pp. 3-31.

Goldin, I., Cameron, G. and Balarajan, M. 2011. Exceptional People: How Migration Shaped Our World andWill Define Our Future (Princeton, NJ: Princeton University Press).

Gong, G. W. 1984. The Standard of 'Civilization' in International Society (Oxford: Oxford University Press).

Gramsci, A. 1971. Selections from the Prison Notebooks of Antonio Gramsci, ed. and trans. Q. Hoare and G. N. Smith (London: Lawrence \& Wishart).

Gutierrez, G. 1973. A Theology of Liberation: History, Politics and Salvation, trans. Str. C. Inda and J. Eagleson (Maryknoll, NY: Orbis Books). 
Hall, M. and Jackson, P.T. 2007. 'Introduction: Civilizations and International RelationsTheory', in M. Hall and P. T. Jackson (eds), Civilizational Identity: The Production and Reproduction of ‘Civilizations' in International Relations (New York: Palgrave Macmillan), pp. 1-12.

Hanchard, M. 1999. 'Afro-Modernity: Temporality, Politics, and the African Diaspora', Public Culture, 11, 1, 245-68.

Hau'ofa, E. 2008. We Are the Ocean: SelectedWorks (Honolulu: University of Hawaii Press).

Hodgson, M. 1974. The Venture of Islam, Vol. III: The Gunpowder Empires and Modern Times (Chicago: University of Chicago Press).

Hodgson, M. 1993. Rethinking World History: Essays on Europe, Islam and World History (Cambridge: Cambridge University Press).

Hoerder, D. 2002. Cultures in Contact: World Migrations in the Second Millennium (Durham, NC and London: Duke University Press).

Howe, K. R., Kiste, R. C. and Lal, B. V. (eds). 1994. Tides of History: The Pacific Islands in the Twentieth Century (St Leonards, NSW: Allen \& Unwin).

Howes, J. F. 2006. Japan's Modern Prophet: Uchimura Kanzo, 1861-1930 (Washington: University of Washington Press).

Howland, D. R. 2002. Translating the West: Language and Political Reason in Nineteenth Century Japan (Honolulu: University of Hawaii Press).

Howland, D. R. 2007. Personal Liberty and Public Good: The Introduction of John Stuart Mill to Japan and China (Toronto: University of Toronto Press).

Huntington, S. 1996. The Clash of Civilizations and the Remaking of the World Order (New York: Simon \& Schuster).

Inglis, D. 2010. 'Civilizations or Globalization(s)? Intellectual Rapprochements and Historical World Vision', European Journal of Social Theory, 13, 1, 135-52.

Jackson, P. T. 2010. 'How to Think about Civilizations', in P. Katzenstein (ed.), Civilizations in World Politics, Plural and Pluralist Perspectives (London and New York: Routledge), pp. 176-200.

Jolly, M. 2007. 'Imagining Oceania: Indigenous and Foreign Representations of a Sea of Islands', The Comparative Pacific, 19, 2, 508-45.

Kapustin, B. 2009. 'Some Political Meanings of “Civilization”', Diogenes, 222 \& 223, 151-69.

Karlin, J. G. 2014. Gender and Nation in Meiji Japan: Modernity, Loss, and the Doing of History (Honolulu: University of Hawaii Press).

Katzenstein, P. J. (ed.). 2010a. Civilizations in World Politics: Plural and Pluralist Perspectives (London and New York: Routledge).

Katzenstein, P. J. 2010b. 'A World of Plural and Pluralist Civilizations: Multiple Actors, Traditions, and Practices', in P. J. Katzenstein (ed.), Civilizations inWorld Politics: Plural and Pluralist Perspectives (London: Routledge), pp. 1-40.

Katzenstein, P. J. (ed.). 2012a. Anglo-America and Its Discontents: Civilizational Identities beyond West and East (London: Routledge).

Katzenstein, P. J. 2012b. 'Many Wests and Polymorphic Globalism', in P. J. Katzenstein (ed.), Anglo-America and Its Discontents: Civilizational Identities beyond West and East (London: Routledge), pp. 207-47.

Kavolis, V. 1995. Civilization Analysis as a Sociology of Culture (Lewiston: E. Mellen Press). 
Klein, B. and MacKenthun, G. (eds). 2004. Sea Changes: Historicizing the Ocean (London: Routledge).

Knöbl, W. 2006a. 'Multiple Modernities and Political Sociology', in S. Costa, J. M. Domingues, W. Knöbl and J. P. da Silva (eds), The Plurality of Modernity: Decentring Sociology (Mering: Rainer Hampp Verlag), pp. 215-27.

Knöbl, W. 2006b. 'Of Contingencies and Breaks: The US American South as an Anomaly in the Debate on Multiple Modernities', Archives Européennes des Sociologie, 47, 125-57.

Knöbl, W. 2011. 'Contingency and Modernity in the Thought of J. P. Arnason', European Journal of Sociology, 14, 1, 9-22.

Kroeber, A. L. 1948. Anthropology (London: George G. Harrap \& Co).

Lee, R. 1981. 'Uchimura's Search for Meaning', in R. A. Moore (ed.), Culture and Religion in Japanese-American Relations: Essays on Uchimura Kanzō, 1861-1930 (Ann Arbor: Center for Japanese Studies, University of Michigan), pp. 71-96.

Lowy, M. 1996. TheWar of Gods: Religion and Politics in Latin America (London: Verso).

Lowy, M. 2014. 'Ecosocial Struggles of Indigenous Peoples', Capitalism Nature Socialism, 25, 2, $14-24$.

Lowy, M. and Duggan, P. 1998. 'Marxism and Romanticism in the Work of José Carlos Mariátegui', Latin American Perspectives, 25, 76-88.

McNeill, W. H. 1991. The Rise of theWest: A History of Human Community (Chicago: University of Chicago Press).

McNeill, W. H. and McNeill, J. R. 2003. The Human Web: A Bird's Eye View of World History (London: W. W. Norton).

Mancke, E. 1999. 'Early Modern Expansion and the Politicization of Oceanic Space', Geographical Review, 89, 2, 225-37.

Manning, P. 2013. Migration in World History (New York: Routledge).

Mariátegui, J. 2007. Siete ensayos de interpretation de la realidad peruano (Caracas: Fundacion Biblioteca Ayacucho).

Marx, K. 1973. Grundrisse: Foundations of the Critique of Political Economy (Rough Draft), trans. M Nicolaus (Harmondsworth: Penguin).

Matsuda, M. K. 2012. Pacific Worlds: A History of Seas, Peoples, and Cultures (Cambridge: Cambridge University Press).

Mauss, M. 1969. The Gift: Forms and Functions of Exchanges in Archaic Societies (London: Cohen and West Ltd).

Mauss, M. 2004. 'Civilizational Forms', in S. A. Arjomand and E. A. Tiryakian (eds), Rethinking Civilizational Analysis (London: Sage), pp. 21-9.

Mazlish, B. 2004. Civilization and Its Contents (Stanford, CA: Stanford University Press).

Melko, M. and Scott, L. R. 1987. The Boundaries of Civilizations in Space and Time (Lanham, MD: University Press of America).

Miller, N. 2008. Reinventing Modernity in Latin America: Intellectuals Imagine the Future 19001930 (London: Palgrave).

Mills, A. 2005. Mythology: Myths, Legends and Fantasies (Sydney: Hodder).

Moreno, M., Dussel, E. and Jáuregui, C. A. 2008. Coloniality at Large: Latin America and the Postcolonial Debate (Durham, NC: Duke University Press). 
Morris-Suzuki, T. 1993. 'Rewriting History: Civilization Theory in Contemporary Japan', Positions, 1, 2, 526-49.

Murphy, P. 2001. 'Marine Reason', Thesis Eleven, 67, 11-37.

Nassaney, M. N. and Sassaman, K. E. 1995. Native American Interactions: Multiscalar Analyses and Interpretations in the Eastern Woodlands (Knoxville: University of Tennessee Press).

Nelson, B. 2012. On the Roads to Modernity: Conscience, Science and Civilizations - Selected Writings by Benjamin Nelson, ed. T. Huff (Plymouth: Lexington Books).

Nicolini, B. 2004. Makran, Oman and Zanzibar: Three-Terminal Cultural Corridor in the Western Indian Ocean 1799-1856 (Leiden: Brill).

Okakura, T. 2006. The Awakening of Japan (New York: The Century Company, 1904).

Paine, L. 2013. The Sea and Civilization: A Maritime History of the World (New York: Alfred A. Knopf).

Patel, S. 2013. 'Are the Theories of Multiple Modernities Eurocentric? The Problem of Colonialism and Its Knowledge(s)', in S. Arjomand and E. Reis (eds), Worlds of Difference (London: Sage), pp. 28-45.

Pieterse, J. N. 2010. 'New Modernities: What's New?', in E. R. Gutiérrez, M. Boatcă, and S. Costa (eds), Decolonizing European Sociology: Transdisciplinary Approaches (Farnham: Ashgate), pp. 85-102.

Pieterse, J. N. 2012. 'Global Rebalancing: Crisis and the East-South Turn', in J. Kim and J. N. Pieterse (eds), Globalization and Development in East Asia (Hoboken, NJ: Taylor \& Francis), pp. 36-60.

Pollock, S. 1998. 'The Cosmopolitan Vernacular', Journal of Asian Studies, 57, 1, 6-37.

Pollock, S. 2004. 'The Transformation of Culture-Power in Indo-Europe, 1000-1300', in J. P. Arnason, and B. Wittrock (eds), Eurasian Transformations, Tenth to Thirteenth Centuries: Crystallizations, Divergences, Renaissances (Leiden: Brill), pp. 247-78.

Pomeranz, K. and Topik, S. 1999. The World That Trade Created: Society, Culture and the World Economy 1400 to the Present (Armonk, NY: M. E. Sharpe, Inc).

Quigley, C. 1979. The Evolution of Civilizations: An Introduction to Historical Analysis (Indianapolis: Liberty Press).

Randeria, S. 2002. 'Entangled Histories of Uneven Modernities', in Y. Elkana, I. Krastev, E. Macamo and S. Randeria (eds), Unraveling Ties: From Social Cohesion to New Practices of Connectedness (Frankfurt and New York: Campus), pp. 284-312.

Reyes, A. 1950. The Position of America and Other Essays, trans. H. de Onís (New York: Knopf).

Robertson, R. 1992. Globalization: Social Theory and Global Culture (London: Sage).

Robertson, R. 2011. 'S. N. Eisenstadt: A Sociological Giant', Journal of Classical Sociology, 11, 303-11.

Rodó, J. E. 1988. Ariel, trans. M. Peden (Austin: University of Texas Press).

Rowland, C. 1988. Radical Christianity: A Reading of Recovery (New York: Orbis Books).

Rundell, J. F. 1987. Origins of Modernity: The Origins of Modern Social Theory from Kant to Hegel to Marx (Cambridge: Polity Press).

Rundell, J. F. 2004. 'From Indigenous Civilization to Indigenous Modernities', in S. A. Arjomand and E. A. Tiryakian (eds), Rethinking Civilizational Analysis (London: Sage). 
Rundell, J. F. 2014. 'Autonomy, Oligarchy, Statesman: Weber, Castoriadis and the Fragility of Politics', in V. Karalis (ed.), Cornelius Castoriadis and Radical Democracy (Leiden: Brill), pp. 235-62.

Rundell, J. F. 2015. 'Intersections and Tensions between Civilizations and Modernities: The Case of Oman', Arena Journal, 43, 55-79.

Rundell, J. F. and Mennell, S. (eds). 1998. Classical Readings in Culture and Civilization (London: Routledge).

Russell-Wood, A. J. R. 1998. The Portuguese Empire, 1415-1808 (Baltimore, MD: Johns Hopkins University Press).

Sabloff, J. A. and Lamberg-Karlovsky, C. C. (eds). 1975. Ancient Civilization and Trade (Albuquerque: University of New Mexico Press).

Sachsenmaier, D. and Riedel, J. (eds). 2002. Reflections on Multiple Modernities: European, Chinese and Other Interpretation (Leiden: Brill).

Sahlins, M. 1989. 'Cosmologies of Capitalism: The Trans-Pacific Sector of "The World System"', The Radcliffe-Brown Lecture in Social Anthropology 1988, Proceedings of the British Academy, 74, 1-51.

Salvatore, A. 2006. 'Reflexivity, Praxis, and "Spirituality": Western Islam and Beyond', in J. P. Arnason, A. Salvatore and G. Stauth (eds), Islam in Process: Historical and Civilizational Perspectives (New Brunswick, NJ: Transaction Publisher), pp. 279-305.

Salvatore, A. 2007. 'Review of Johann P. Arnason, Civilizations in Dispute: Historical Questions and Theoretical Traditions', European Journal of Social Theory, 10, 2, 327-31.

Scarr, D. 2001. A History of the Pacific Islands: Passages through Tropical Time (Richmond: Curzon). Schelling, V. 2000. Through the Kaleidoscope: The Experience of Modernity in Latin America (London: Verso).

Schutte, O. 1993. Cultural Identity and Social Liberation in Latin American Thought (Albany, NY: SUNY Press).

Segundo, J. L. 1976. The Liberation of Theology, trans. J. Drury (Dublin: Gill and Macmillan). Sentürk, R. and Nizamuddin, A. M. 2009. 'The Sociology of Civilizations: Ibn Khaldun and a Multi-Civilizational World Order', in S. Unay and M. Senel (eds), Global Orders and Civilizations: Perspectives from History, Philosophy and International Relations (New York: Nova Science Publishers), pp. 67-90.

Shilliam, R. 2015. The Black Pacific: Anti-Colonial Struggles and Oceanic Connections (London: Bloomsbury).

Simmel, G. 2004. The Philosophy of Money (London: Routledge).

Smith, J. 2006. Europe and the Americas: State Formation, Capitalism and Civilizations in Atlantic Modernity (Leiden: Brill).

Smith, J. 2014a. ““...Diversity within Unity”: Sovereignty, Recognition and Ecology in Indigenous Interpretations of Modernity', Asian Journal of Latin American Studies, 27, $1,65-87$.

Smith, J. 2014b. 'Atlantic Capitalism, American Economic Cultures', in S. A. Arjomand (ed.), Social Theory and Regional Studies in the Global Age (New York: SUNY Press), pp. 339-59. 
Smith, J. 2014c. 'Contexts of Capitalism: From the Unlimited Extension of "Rational Mastery" to Civilizational Varieties of Accumulation and Economic Imagination', in V. Karalis (ed.), Cornelius Castoriadis and Radical Democracy (Leiden: Brill), pp. 158-76. Spengler, O. 1966. The Decline of theWest (New York: Random House).

Spohn, W. 2003. 'Multiple Modernity, Nationalism and Religion: A Global Perspective', Current Sociology, 51, 3, 265-86.

Spohn, W. 2006. 'Multiple, Entangled, Fragmented and Other Modernities', in S. Costa, J. M. Domingues, W. Knöbl and J. P. da Silva (eds), The Plurality of Modernity: Decentring Sociology (Mering: Rainer Hampp Verlag), pp. 11-22.

Spohn, W. 2010. 'Political Sociology: Between Civilizations and Modernities - A Multiple Modernities Perspective', European Journal of Sociology, 13, 1, 49-66.

Spohn, W. 2011. 'World History, Civilizational Analysis and Historical Sociology: Interpretations of Non-Western Civilizations in the Work of Johann Arnason', European Journal of Sociology, 14, 1, 23-39.

Spohn, W. 2014. 'Power: Nation-States, Civilizations, and Globalization - A Multiple Modernities Perspective', in S. A. Arjomand (ed.), Social Theory and Regional Studies in the Global Age (New York: SUNY Press), pp. 113-43.

Steinberg, P. E. 2013. 'Of Other Seas: Metaphors and Materialities in Maritime Regions', Atlantic Studies, 10, 2, 156-69.

Subrahmanyam, S. 1997. 'Connected Histories: Notes towards a Reconfiguration of Early Modern Eurasia', Modern Asian Studies, 31, 3, 735-62.

Subrahmanyam, S. 2005a. 'On World Historians in the Sixteenth Century', Representations, 91, 26-56.

Subrahmanyam, S. 2005b. Explorations in Connected History: From the Tagus to the Ganges (Oxford: Oxford University Press).

Subrahmanyam, S. 2007. 'Holding the World in Balance: The Connected Histories of the Iberian Overseas Empires 1500-1640’, American Historical Review, 112, 5, 1359-85.

Swedberg, R. 2010. 'A Note on Civilizations and Economies', European Journal of Social Theory, 13, 1, 15-30.

Tanaka, S. 1993. Japan's Orient: Rendering Pasts into History (Berkeley: University of California Press).

Therborn, G. 2003. 'Entangled Modernities', European Journal of Social Theory, 6, 3, 293-305.

Therborn, G. 2011. TheWorld: A Beginner's Guide (Cambridge: Polity Press).

Tiryakian, E. 2004. 'Civilizational Analysis', in S. A. Arjomand and E. A. Tiryakian (eds), Rethinking Civilizational Analysis (London: Sage), pp. 30-47.

Tiryakian, E. 2014. 'Civilization in the Global Era: One, Many ... or None?', in S. A. Arjomand (ed.), Social Theory and Regional Studies in the Global Age (New York: SUNY Press), pp. 91-112.

Tokutomi, S. 1989. The Future Japan, trans. V. Singh (Edmonton: University of Alberta Press).

Tokutomi, S. 1922. Japanese-American Relations, trans. S. Yanagiwara (New York: The Macmillan Company).

Toynbee, A. 1972. A Study of History (London: Oxford University Press and Thames \& Hudson). 
Trombold, C. D. (ed.). 1991. Ancient Road Networks and Settlement Hierarchies in the New World (Cambridge: Cambridge University Press).

Uchimura, K. 1958. 'The Non-Church Movement', in R. Tsunoda, W. T. de Bary and D. Keene (eds), Sources of Japanese Tradition,Vol. II (New York: Colombia University Press), pp. 347-8.

Unay, S. and Senel, M. (eds). 2009. Global Orders and Civilizations: Perspectives from History, Philosophy and International Relations (New York: Nova Science Publishers).

Waddell, E., Naidu, V. and Hau'ofa, E. (eds). 1993. A New Oceania: Rediscovering Our Sea of Islands (Suva, Fiji: The University of the South Pacific).

Wagner, P. 1994. A Sociology of Modernity: Liberty and Discipline (London: Routledge).

Wagner, P. 2012. Modernity: Understanding the Present (Cambridge: Polity Press).

Wagner, P. 2014. 'World Sociology beyond the Fragments: Oblivion and Advance in the Comparative Analysis of Modernities', in S. A. Arjomand (ed.), Social Theory and Regional Studies in the Global Age (New York: SUNY Press), pp. 293-311.

Weber, M. 1951. The Religion of China (New York: Free Press).

Weber, M. 1958. The Religion of India (New York: Free Press).

Wittrock, B. 2000. 'Modernity: One, None, or Many? European Origins and Modernity as a Global Condition', Daedalus, 129, 1, 31-60.

Wittrock, B. 2014. 'History, Sociology and the Reconfiguration of Civilizations', in S. A. Arjomand (ed.), Social Theory and Regional Studies in the Global Age (New York: SUNY Press), pp. 63-90.

Wright, R. 1992. Stolen Continents: The Americas through Indian Eyes since 1492 (Boston: Houghton Mifflin).

Young, M. W. (ed.). 1979. The Ethnography of Malinowski: The Trobriand Islands 1915-18 (London: Routledge \& Kegan Paul). 


\section{Index}

Africa 8, 51, 71, 72, 73, 83, 84, 85-6, 87, 89, $91,93,106,107,116,117,120,125-7$ passim, 151, 155, 167

Americas, the 8, 33, 50, 71, 80, 83, 84, 86, 93-4, 116-17, 118, 150

see also Latin America

ancient and archaic civilisations 18-19, 35, 46, 58, 83-4, 88-9, 122, 134-5

see also Axial age civilisations

Arjomand, S. A. 14, 27, 28, 190

Arnason, J. P. 5, 15-17, 18, 25, 28, 29, 34, $38-52,60,70,73,75,81,98,99$, $169-72$

Arts, the 9, 82, 89, 100, 133, 145, 147, 152, $153,156,173$

Australia 87, 133, 134, 137, 139, 141, 142, 147-50, 183

Axial Age civilisations 29-30, 31, 33-4, 35, $42-3,44,58,73,170-2$

Braudel, F. 23, 42, 100, 102, 128, 129

Byzantium 43, 44, 93, 94, 109-10, 122-3

capitalism 13, 21-2, 42, 45, 52, 54, 55, 61-8 passim, 71, 78, 82, 84, 94-100, 116, 123, $134,137-8,157,160,186$

see also money

Castoriadis, C. 17-20, 37, 65, 186 see also imaginaries

China 8, 12, 23, 44, 45, 47, 77, 83, 84, 85, $89,90,91,92,94,97,99,104-5,108$, 120, 170-9 passim

climate change 6, 35, 130, 145, 150, 166 see also environment

Cold War 5, 6, 25-6, 58, 146-7, 188

Collins, R. 100-2, 153-4, 187, 188 colonialism 7-9, 26, 27, 32, 38, 60, 106-15, 116, 118-19, 120, 130, 132-3, 137-43, 148-9

see also empires

Cox, R. W. 21-2, 28, 61, 62, 64, 66-8, 78, 99, 189

Durkheim, E. 4, 8, 9, 11, 13, 39, 41, 51, 132 see also Mauss, M.

early modernities 28, 35, 48, 49, 56, 75-6, 77, 78,116

Eisenstadt, S. N. E. 5, 15, 17, 25, 28, 29-36, 42, $45,50,59,72,73,151,169-72$

Elias, N. 13, 15, 25, 28, 29, 36-9, 56, $59,190-1$

Empires 4, 9-10, 18, 23, 26, 27, 30, 38, 44, 55-6, 58, 60, 67, 69-70, 76, 78, 103, 114-127 passim, 133, 138-41, 170, 172, 187-9

British 46, 86-7, 94, 108, 117-120, 126-7, 139-43, 148-9

Chinese 89-91, 104-5, 108

Dutch 108, 118-120

French 85, 107, 117, 139-43

Roman 58, 83, 89-91

Russian 44-5, 139, 179

Spanish 76-7, 115, 117

see also colonialism

environment 4, 35, 64, 67, 128, 129, 130, 141, $144,149,150,164,167$

see also climate change

eurocentrism 4, 31, 32, 51, 54, 69, 76

globalization 31-3 passim, 52, 54, 55-61, 79-80, 99, 110 
Gramsci, A. 54, 61, 64-6, 78

Hau' ofa, E. 23, 133, 145-7

Huntington, S. 6, 7, 69

imaginaries 12, 17-21, 32, 34, 35, 42, 44, 47, 54, 59-60, 61-4, 68, 78, 79, 81, 82, 96, $98,105,110,114-15,116,121,122,124$, $135,137,138,141,144-7,150,161,163$, 170,175

see also Castoriadis, C.

India 8, 12, 46-7, 48, 51, 84-5, 86, 90, 91, 92, 94, 95, 101, 103, 104, 105, 107, 120, 129, $132,151,181$

indigenous civilisations $11,17,18,23,50-1$, $71-2,73,82,127,133,145-5,147-8$, $149,156-7,161-3$ passim, 164-7, 187

Indonesia 8, 41, 86, 119-20, 128, 134

Islam 8, 27, 35, 41, 46, 48, 83, 91, 94, 185

Japan 8, 30, 38, 41, 43 , 44-5, 46-7, 57-8, 77, $80,87,99,101,102,104,108,131,168$, 169-84, 188-9

Katzenstein, P. J. 14-15, 28, 33-4, 67, 70, 189

Latin America 23, 71, 131, 151-68 passim, 187 see also Americas, the

liberation theology 71, 74, 152, 160-6

Marx, K. 21, 61-4, 67, 68, 78, 95-6

Marxism 20, 21-2, 44, 51, 52, 54, 61-8, 78, $80,98,152,156-7,159-60,163,171$

Mauss, M. 4, 9, 11, 13, 39, 41, 50, 132, 136-7, 140

see also Durkheim, E.

Mediterranean, the 35, 83, 95, 102, 122-3, 128,188

Melanesia 127, 129, 131, 134, 136, 144

Micronesia 134, 135, 136, 141-2, 144

migration $6,26,52,59,80,81,82-8,103,128$, 134-6, 145, 148, 154, 182, 184, 186

modernisation 25-7, 29, 44, 55-6, 61, 109, 151-4 passim, 159, 175

money $21,36,52,54,61-4,68,78,88,94-6$, $98,147,186$

see also capitalism multiple modernities 9, 28-35 passim, 42-3, 54, $55,68,72-3,77,78,151$

see also Eisenstadt, S. N.

New Zealand 71, 73, 74, 83, 134, 135, 137, $139,141,142,147,148$

oceans $23,50,51,82,84,89,90,102,113-31$ passim, 133-4, 135, 144-5, 146, 150, 184,188

see also Pacific Ocean

Oman, civilisation 122, 125-8, 188

Ottoman civilisation 86, 87, 97, 110, $119,123-4$

Pacific Ocean 71, 83, 114, 116, 128-31 passim, 132-50, passim, 184, 188

politics $6-7,14,52,57,59,64,65,67,69-72$, 103-10, 121, 124, 131, 133, 152-3, 154, $157,163,173$

Polynesia $83,129,131,134-6$ passim, 137-41 passim, 144, 147-8

post-colonialism 9, 52, 54, 55, 68-72, 80, 191

religion 10, 12-13, 30-1, 34-5, 58, 82, 84, 85-6, 91-2, 100, 101, 102, 104, 105, 117-18, 127, 139-40, 159-64, 170-1, $173,181-3$

Romanticism 7-8, 64, 124, 141, 143, 148, 154, $156-9,180-1,188$

Russia 41, 44, 84, 92-3, 139, 179, 180

slavery 58, 71, 72, 77, 82, 84, 86, 87, 94, 103, $116,125,126,167$

South-east Asia 8, 43, 84-5, 87, 92, 95, 101, $105-6,120,128,134$

standard of civilisation $8,10,36,178-9$

United States 38, 57, 65, 71, 73, 85, 109, $139,141-2,148,149,154,155,159$, 181-2, 183

Venice 122-4, 129, 188

Vikings 93-4, 115

Weber, M. 4, 9, 12-13, 34, 36, 39, 40, 52, 64, $65,66,76,98,122,162$ 
Jeremy C.A. Smith - 9781526105318 Downloaded from manchesterhive.com at 04/26/2023 01:55:36PM via free access 
Jeremy C.A. Smith - 9781526105318 Downloaded from manchesterhive.com at 04/26/2023 01:55:36PM via free access 
Jeremy C.A. Smith - 9781526105318 Downloaded from manchesterhive.com at 04/26/2023 01:55:36PM via free access 